

\section{Propositions}

1) In live-bearing fish, the locomotor costs of pregnancy are an important evolutionary driver.

(this thesis)

2) The Poeciliidae placenta is a suitable model system to study the evolution of complex organs.

(this thesis)

3) Nothing in ecology makes sense except in the light of performance.

4) The biggest challenge of multi-disciplinary research is mutual understanding.

5) Programming skills should become part of the learning outcomes of the Biology curriculum of Wageningen University.

6) As mobile augmented-reality games like Pokémon GO change the world around you into fantasy, every workplace can become a place to relax.

7) To increase the societal impact of propositions, they should be restricted to 140 characters and posted on a dedicated Twitter account.

Propositions belonging to the thesis, entitled:

'Reproductive adaptations to reduce locomotor costs in viviparous fish (Poeciliidae)'

Mike Fleuren

Wageningen, 19 December 2017 
Reproductive adaptations to reduce locomotor costs in viviparous fish (Poeciliidae)

Mike Fleuren 


\section{Thesis committee}

\section{Promotor}

Prof. Dr J.L. van Leeuwen

Professor of Experimental Zoology

Wageningen University \& Research

\section{Co-promotor}

Dr B.J.A. Pollux

Assistant professor, Experimental Zoology Group

Wageningen University \& Research

\section{Other members}

Prof. Dr M. Naguib, Wageningen University \& Research Prof. (Em.) Dr E.J. Stamhuis, University of Groningen

Prof. Dr R. van Damme, University of Antwerp, Belgium

Dr M.E. Maan, University of Groningen

This research was conducted under the auspices of the Graduate School of the Wageningen Institute of Animal Sciences (WIAS) 


\title{
Reproductive adaptations to reduce locomotor costs in viviparous fish (Poeciliidae)
}

\author{
Mike Fleuren
}

Thesis

submitted in fulfilment of the requirements for the degree of doctor at Wageningen University

by the authority of the Rector Magnificus,

Prof. Dr A.P.J. Mol, in the presence of the

Thesis Committee appointed by the Academic Board to be defended in public

on Tuesday 19 December 2017

at 4 p.m. in the Aula. 
Mike Fleuren

Reproductive adaptations to reduce locomotor costs in viviparous fish (Poeciliidae), 204 pages.

$\mathrm{PhD}$ thesis, Wageningen University, Wageningen, the Netherlands (2017) With references, with summaries in English and Dutch

ISBN 978-94-6343-802-5

DOI $10.18174 / 424276$ 




\section{Table of Contents}

Chapter 1 General Introduction 9

Chapter 2 The burden of viviparity: the locomotor costs of live-bearing and the adaptations to reduce them

Chapter 3 Why do placentas evolve? First evidence for a morphological advantage during pregnancy in live-bearing fish

Chapter 4 Three-dimensional analysis of the fast-start escape response of the least killifish, Heterandria formosa

Chapter 5 How pregnancy affects body shape and 3D fast-start performance in live-bearing fish (Poeciliidae)

Chapter 6 General Discussion

Summaries

Summary (English)

Samenvatting (Nederlands) 190

About the author

List of Publications 196

Overview of completed training activities 197

Curriculum vitae 199

Acknowledgements 200 


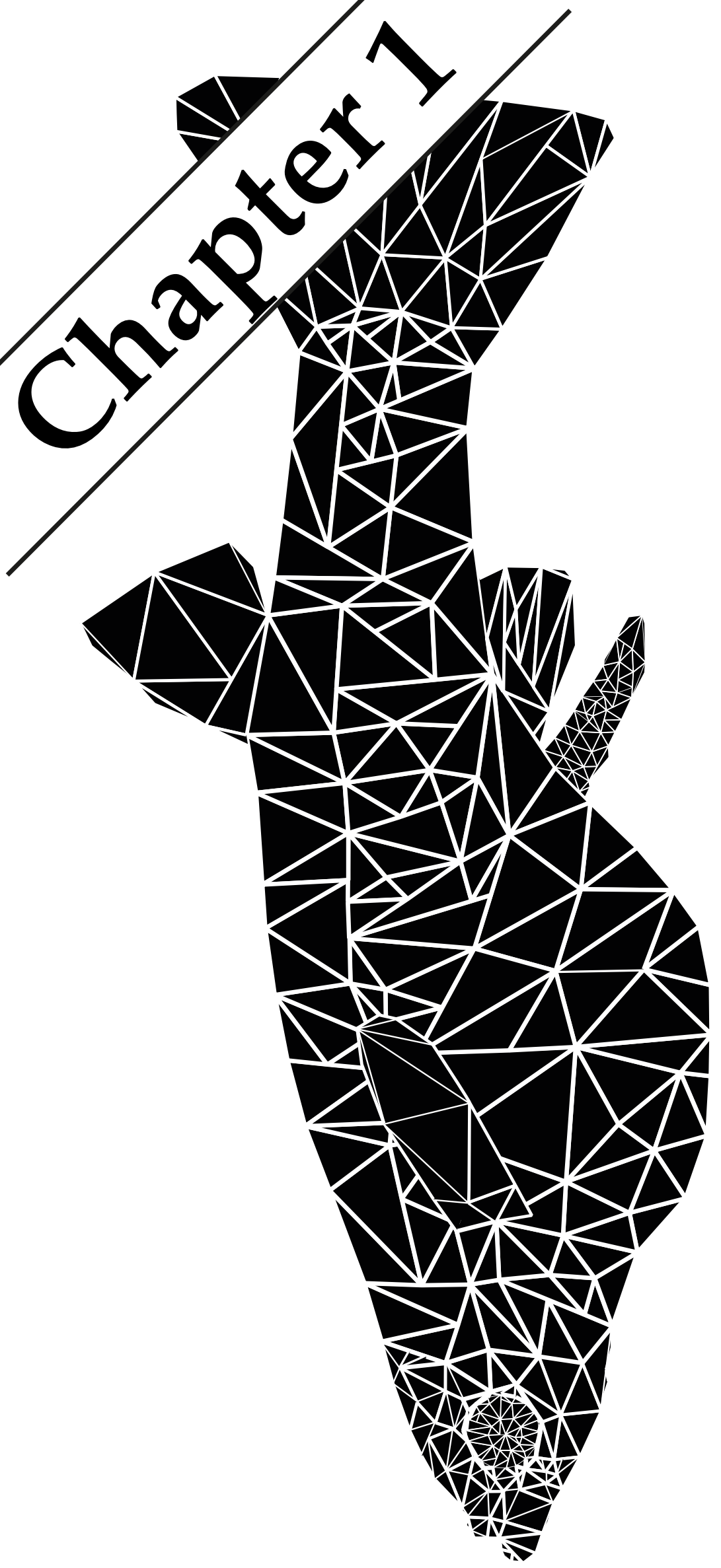




\section{Chapter 1}

General Introduction 
Viviparity, a live-bearing mode of reproduction, has evolved independently over 200 times in the animal kingdom [1,2]. However, giving birth to live young confers a large burden to carrying mothers: during the internal development of the offspring, the female's ability to run, jump, fly or swim fast is often impaired [e.g. 3-7]. As a consequence, pregnant animals might be less adept in catching food, in migrating through harsh environments or in escaping predators [8]. To reduce these disadvantageous effects of pregnancy on locomotion, reproductive adaptations could have evolved, independently, in separate lineages of viviparous animals.

In this thesis, I combine the field of evolutionary biology with a biomechanics approach. Currently, the field of biomechanics is rapidly changing. Highspeed videos are now able to record at high frame rates and in high resolution while being relatively affordable. Automated tracking allows for the analysis of large databases of high-speed video sequences [9]. Furthermore, the field is rapidly moving forward into the world of three-dimensional motion [9-11]; something that was not possible previously due to difficulties with measurement and analysis. With these methodological advances in biomechanics, I want to answer an evolutionary question. I aim to show how pregnancy affects morphology and three-dimensional swimming performance in the live-bearing fish family Poeciliidae, and how this relates to two hypothesised reproductive adaptations: matrotrophy (provisioning of nutrients to the embryo post-fertilization) and superfetation (the simultaneous presence of multiple broods of different developmental stages).

\section{Viviparity: a reproductive mode not exclusive to mammals}

Reproductive modes are classified using a dichotomous system, with viviparity on one side and oviparity, egg-laying, on the other. In the oviparous reproductive pattern, females deposit fertilized or unfertilized eggs with intact egg shells or jelly coats, while viviparous animals retain developing eggs inside their reproductive tract, giving birth to fully-developed or pre-metamorphic young that are able to behaviourally interact with their environment [12]. The classification of reproductive modes is, however, not as dichotomous as described by these definitions due to prolonged egg retention in, for instance, reptiles and fishes [13-16].

Historically, research on non-mammalian viviparity has suffered from anthropocentric views on reproduction, considering human (and mammalian) reproduction to be unique: live-bearing reproduction in non-mammalian species was considered a 'simple pattern' in which fertilized eggs developed and hatched inside the female $[17,18]$. Animals that lack 'true placentas', 
like those of mammals, were classified 'ovoviviparous' [1,12], and therefore unlikely to provide any insights relevant for the evolution of viviparity in (Eutherian) mammals. This view gradually changed in the 1970's and 1980's following influential work on the reproductive modes of fishes $[19,20]$, amphibians [21,22], reptiles [23,24], and marsupials [25,26], as well as the emergence and application of novel life-history theories [23,27]. Currently, the convergent evolution of physiological and developmental similarities in reproductive modes among a wide range of vertebrate and invertebrate clades is widely acknowledged, providing insights into the processes that drive the evolution and establishment of a live-bearing mode of reproduction and into the reproductive adaptations that have evolved in these clades $[2,28]$.

Oviparity is generally considered to be the ancestral mode of reproduction from which viviparity evolved. Most research on the transition from oviparity to viviparity has been done in squamate reptiles (lizards and snakes). The frequent independent evolution of viviparity in this group, at least 115 times [1,12,29], often at sub-generic level [30], make this an excellent model system for this transition [31]. Reversals from viviparity to oviparity are rare, but have occurred [32-36]. The major driving force for the evolution of viviparity in squamate reptiles is likely maternal thermoregulatory behaviour, which allows retained embryos to develop under high and/or stable temperatures at the cost of a bigger and/or longer physical burden to the female and (often) a reduced fecundity [37-39].

The evolution of viviparity has recurrently been followed by a rapid speciation event $[32,36,40,41]$. With the evolution of a viviparous mode of reproduction, animals were able to colonize novel geographical ranges or ecological niches that were previously unsuitable for colonization [23,42]. Viviparity might simplify range expansion: only one pregnant female is needed to start a small novel population. Furthermore, it is not necessary to migrate to nesting grounds that provide the proper environmental conditions to develop and hatch eggs. As a consequence, the evolution of viviparity is often assumed to precede the colonization of marine habitats by extinct reptiles and extant sea snakes [40,43-45].

\section{Poeciliidae: a model family of live-bearing fishes}

The Poeciliidae family consists of 220 species in 28 genera [46, Figure 1-1]. The original geographic range of this family spans parts of the Americas and Africa, but due to aquarium trade and introductions to prevent the dispersal of malaria-mosquitos, populations of certain species have established themselves throughout the world [47-50]. The Poeciliidae family represents 
one of twelve evolutionary origins of live-bearing in ray-finned fishes (Actinopterygii) [1]. Viviparous animals form a minority in this class, with only about $2.5 \%$ of all documented species of ray-finned fishes giving birth to live-young. This is especially little compared to the other major clade of fishes, cartilaginous fishes, as over half of the recorded species of rays and sharks are viviparous [1]. Despite the low number of live-bearing species, the origins of viviparity are widely distributed between the major taxonomic clades of ray-finned fishes, with no to only a few documented reversals from viviparity to oviparity including one possible reversal in the Poeciliidae [51-54].

Poeciliid fishes have grown as a model system in ecology and evolutionary biology. This family includes established study systems like the Trinidadian guppy (Poecilia reticulata), mosquitofish (Gambusia spp.), mollies (Mollieniesa spp.) and swordtails (Xiphophorus spp.). One particular feature of their reproductive biology makes this family very persistent: female Poeciliidae have the possibility to store sperm, and, once fertilized, do not require the presence of males to produce new offspring [55,56]. As a consequence, female livebearers are almost always pregnant, although the number and size of the offspring can vary throughout the year $[57,58]$, while males can conceive females up to at least ten months after their death [56]. But the most appealing characteristics of the Poeciliidae are their relative ease to keep and reproduce in laboratory or common-garden settings, their short generation times (it typically takes \pm 3 months for a female to reach reproductive age), and the staggering range of reproductive adaptations they possess [59].

The Trinidadian guppy is used in a wide range of natural- and transplantation experiments in which the evolutionary response to high- and low-predation levels are studied [3,60,61]. Populations of guppies are separated by waterfalls, acting as natural occurring barriers that are impenetrable to (piscine) predators: downstream populations co-occur with several piscivorous species (e.g. the pike-cichlid, Crenicichla alta, and predatory gobies Eleotris spp. and Gobiomorus spp.), while upstream populations generally co-occur just with only other guppies and the killifish Rivulus hartii (which only predates on juvenile guppies) [3]. As a result, these populations show persistent

Figure 1-1. (next page) Phylogeny of the Poeciliidae indicating the level of matrotrophy and the presence of superfetation. Names depicted in bold indicate species used in this thesis. Boxes at the terminal ends indicate the presence (grey) or absence (white) of superfetation. Branch colour indicates a maximum likelihood reconstruction of maternal provisioning for natural log-transformed matrotrophy indices (MI), InMI. Arrow indicates an MI of 1. The single egg-layer in the Poeciliidae family, Tomeurus gracilis, was excluded from this analysis. Adapted with permission from [67]. 


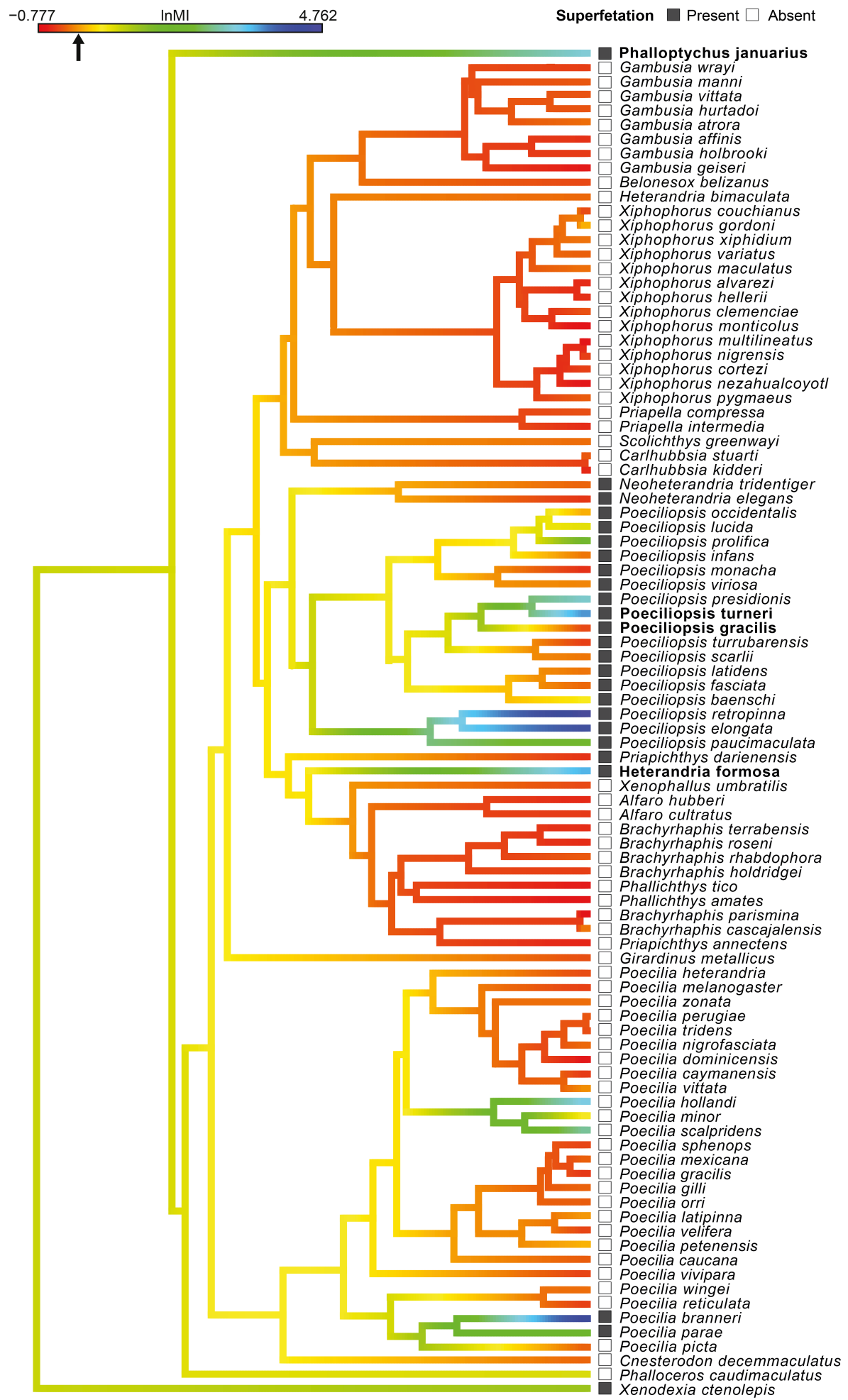


differences in individual and group behaviour, colour patterns and life history that can all be contributed to the presence or absence of predators $[7,62-$ 64]. Natural selection experiments in the field and in the laboratory, as well as human selection experiments, repeatedly showed that guppy populations that suffered high mortality rapidly evolved earlier maturity, increased fecundity, increased reproductive allocation and shorter interbrood intervals than communities that experienced less predation $[60,61,65]$.

The (increased) presence of predators makes natural selection act in two different directions: 1), selection acts on females to produce more offspring quickly (the life history traits mentioned above), a life history generally referred to as the 'live fast - die young'-pattern [66]; while 2), selection acts on survival of predatory strikes. These two selection forces seem to be a functional trade-off: selection for more offspring causes larger abdominal distention, which should result in reduced swimming performance and reduced odds of surviving a predatory strike. However, they might not be: Ghalambor and colleagues [3] found that, at the beginning of the pregnancy, female guppies from high-predation populations attain higher accelerations, velocities and a larger distance travelled during fast-start swimming trials than females from low-predation localities. As pregnancy progressed, the swimming performance declined more rapidly in females from high-predation populations. These findings indicate the high level of integration of different aspects of the phenotype (swimming performance, life history), and highlight the complexity of adaptation at the whole-organism level.

The complex trade-off between reproduction and survival can be dealt with in several ways. Ideally, both fecundity and survival rate would be high to maximize fitness. However, it would already be beneficial to improve the performance in one without affecting the other. This is the hypothesised effect of two (linked) reproductive adaptations: matrotrophy and superfetation.

\section{Matrotrophy: post-fertilization nutrient provisioning}

Developing embryos of oviparous animals feed on yolk that is supplied by the mother before fertilization of the oocyte. With egg-laying being the ancestral condition viviparity has evolved from, yolk-feeding (lecithotrophy) is arguably the ancestral mode of nutrient provisioning in live-bearing animals. In the derived state, substantial amounts of nutrients are supplied by the mother during development of the embryo, i.e. after fertilization of the oocyte. This mode is called matrotrophy, feeding from the mother. 
Six different categories of matrotrophic nutrient provisioning are recognized, which differ in the way the nutrients are provisioned by the mother and how these are taken up by the embryos [1]. Four of these categories include the oral ingestion of nutrients by the embryo: 'oophagy' in which the embryo ingests sibling (unfertilized) oocytes, 'embryophagy' in which the embryo ingests developing sibling embryos, 'histophagy' in which the embryos ingest maternal secretions (often liquid nutrients), and 'matrophagy' in which the embryo ingests maternal tissues. The other two categories include absorption of nutrients through absorptive sites on the embryo: 'histotrophy' in which nutrients diffuse across tissues and/or space to absorptive sites on the embryo, for instance gill epithelium or the skin, and 'placentotrophy', in which nutrients are provided through a placenta.

Placentas are generally defined following the definition of Mossman [68] as an "intimate apposition or fusion of the foetal organs to the maternal (or paternal) tissues for physiological exchange". With this definition, the close association between embryonic tissues (in Poeciliidae often a large expansion of the pericardial sac) and the ovarian lining fits the definition for placentotrophy $[14,69]$. Matrotrophy in Poeciliid fishes also coincides with increased blood flow to the ovarian vesicle and extensive folding of the follicular epithelium [70, Figure 1-2A].

Lecithotrophy and matrotrophy form two ends of a continuum: at one end, the only nutrients the embryos consume is the yolk supplied pre-fertilization of the oocyte while at the other (theoretical) end, no yolk is present at fertilization of the oocyte and all nutrients are supplied during development. The level of matrotrophy is indicated by the matrotrophy index (MI), the ratio between the dry mass of the neonate at birth and the dry mass of the unfertilized egg [14,71,72]. In Poeciliidae, this continuum also exists [28, Figure 1-2B]: species with an MI of $<1$ are classified as lecithotrophic [67, Figure $1-1]$, although some others use a threshold of MI $<0.7$ as embryos lose dry weight during development due to metabolism $[14,28,73]$. Species that have some matrotrophic provisioning are classified as "incipient" or "limited" matrotrophs, while species that have an MI $\gg 1$ are classified as "extensive" matrotrophs. Because it's a truely continuous scale, objective borders that define modes of nutrient provisioning do not exist.

Hypotheses that explain the frequent evolution of matrotrophy in Poeciliidae (at least 7 times independently [67, Figure 1-1]) can be divided into two categories. The first category only contains one hypothesis: the viviparity driven-conflict hypothesis [74-76]. As both mother and offspring influence the amount of nutrients that are provisioned, the evolution of matrotrophy 

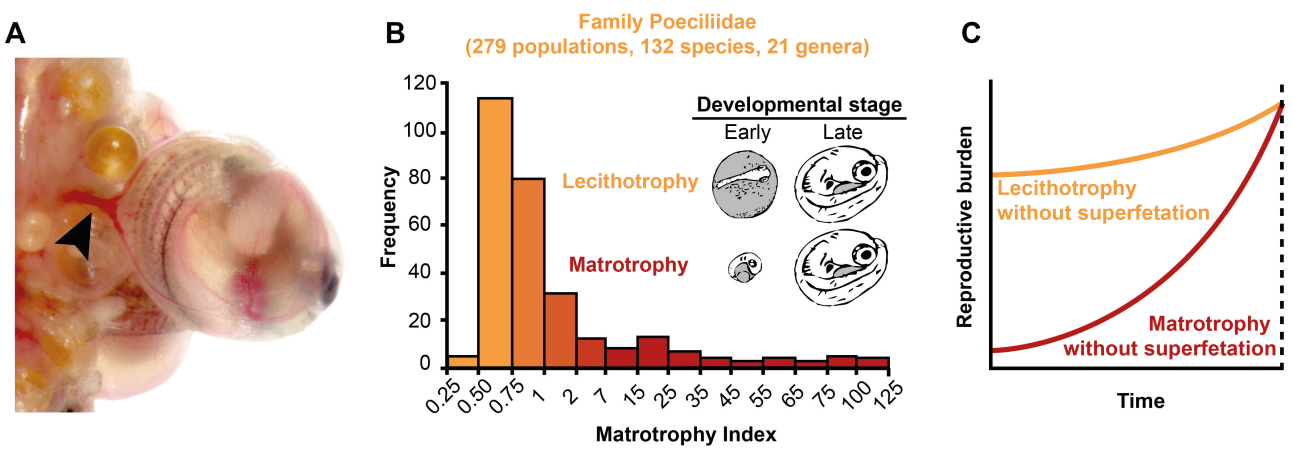

Figure 1-2. Overview of matrotrophy. A: Detail of an ovary of Phalloptychus januarius displaying matrotrophy. Arrowhead: maternal blood supply to a late-stage embryo. B: Frequency distribution of different levels of matrotrophy in Poeciliidae. Adapted from [28]. Inset: schematic overview of early- and late-stage embryos in lecithotrophic and matrotrophic species. C: The locomotor costs hypothesis predicts that the smaller oocytes at fertilization in matrotrophic fishes (B, inset) lead to a lower reproductive burden throughout pregnancy; the difference between the lecithotrophic and matrotrophic mode diminishes as pregnancy progresses.

could give rise to prenatal parent-offspring conflicts [77,78]: an overall high fitness for the whole brood is best from a maternal perspective, an advantage over their siblings (especially in broods with multiple paternity) is best from the perspective of individual offspring. This conflict is thought to accelerate the evolution of post-zygotic reproductive isolation in matrotrophic Poeciliidae [76].

The second category contains three hypotheses that infer an adaptive benefit to the placenta: the resource availability hypothesis, the life history facilitation hypothesis, and the locomotor costs hypothesis. The resource availability hypothesis suggests that matrotrophy offers the ability to increase the fecundity when resources availability is high [72,79]. Matrotrophic females could fertilize more ova, as the costs of provisioning these with yolk is lower than in lecithotrophic fishes that supply more yolk per egg. If food availability is low, the resources could be restricted to only the number of embryos that could be sustained to full development, leading to abortion and/or resorption of the others. However, recent work on several species of Poeciliidae has shown that mothers are not able to abort offspring, meaning that this hypothesis only holds when food abundance is high and stable [80-83]. The life history facilitation hypothesis states that matrotrophy facilitates the evolution of other life history traits, most notably the ability of fish to mature at an earlier age, and the ability to produce more and/or larger offspring $[42,72,84,85]$. Correlation studies within live-bearing fishes, mostly within the Poeciliid genus Poeciliopsis, have revealed no consistent relationship between life history traits and the evolution of matrotrophy, however, indicat- 
A

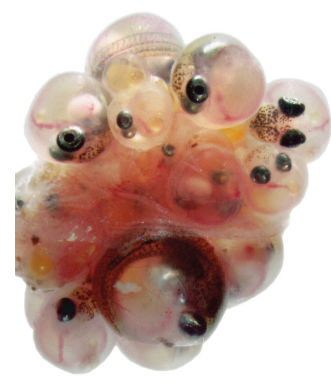

B

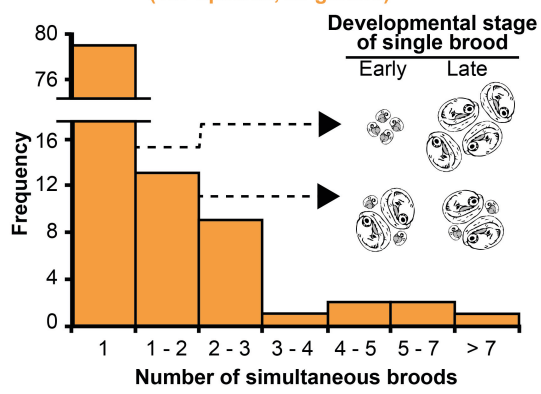

C

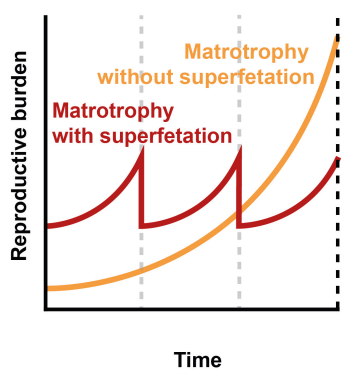

Figure 1-3. Overview of superfetation. A: Image of an ovary of Phalloptychus januarius that clearly displays superfetation: embryos of multiple developmental stages can be discriminated. B: Frequency distribution of different levels of superfetation in Poeciliidae. Inset: schematic overview of the effect of superfetation at different developmental stages of a single brood. Data from [28,67,82,87,103-108]. C: The locomotor costs hypothesis predicts that superfetation leads to a reduction in the amplitude of the changes in reproductive burden (number of simultaneous broods, orange: 1 ; red: 3 ).

ing that the evolution of matrotrophy does not lead to directed changes in life history traits [86-88].

The third adaptive hypothesis, the locomotor costs hypothesis, states that matrotrophy might have evolved to reduce the locomotor costs associated with pregnancy [28]. Selection could act on swimming performance through the ability to acquire food sources or survival of predatory strikes. However, pregnancy progressively increases wet reproductive allotment, with embryos increasing in wet mass and volume over time: this lowers the swimming performance over the course of gestation [3,89]. Swimming performance and the odds of surviving a predatory strike are correlated, suggesting that pregnant females become more vulnerable to predation [8]. The adaptive benefit of matrotrophy could lie in the lower volume of (un)fertilized eggs and early-stage embryos: due to the lower amount of yolk, the total volume and mass of a litter should be smaller than in lecithotrophic fishes (Figure 1-2C). This hypothesis has one important assumption: the fecundity (offspring number and size at birth) should be equal between reproductive modes. In support of the locomotor cost hypothesis, it has recently been found that the matrotrophy index of high-predation populations of Phalloceros harpagos is higher than that of low-predation populations [90], but experimental evidence that matrotrophy indeed provides an adaptive benefit to morphology and swimming performance during pregnancy is currently still lacking. 


\section{Superfetation: an optimal packing strategy?}

The second hypothesised reproductive adaptation to live-bearing in Poeciliid fishes is superfetation: the simultaneous presence of broods of embryos at different developmental stages [55,91, Figure 1-3A]. This reproductive trait is especially common in the live-bearing fish families Poeciliidae, Clinidae and Zenarchopteridae (halfbeaks), but it is also found in a couple of mammalian species [92,93]. In Poeciliidae, the evolution of superfetation is closely correlated with the evolution of matrotrophy [67]: species with matrotrophy are very likely to have some degree of superfetation. Similar to matrotrophy, superfetation occurs at different levels: from no superfetation (i.e. offspring of only one stage of development), to more than seven different developmental stages (Figure 1-3B). Over the past decades, five different hypotheses have been developed that could explain the frequent evolution of superfetation in Poeciliid fishes [94]. These hypotheses can be classified into a facilitative hypothesis, demographic hypotheses and adaptive hypotheses.

The facilitative hypothesis argues that superfetation improves female mate choice, increasing the female's control over paternity of the offspring [95], sprouting from pre-existing ideas about sexual conflicts in Poeciliid fishes (see the viviparity-driven conflict hypothesis for matrotrophy). Increased levels of matrotrophy are associated with reduced coloration in males and an increase in sneak copulation or coercive mating, reducing the potential for female pre-copulatory sexual selection [67]. Superfetation is thought to increase the levels of polyandry through the formation of smaller, temporally overlapping litters increasing the chances of offspring from high-quality males. However, it has not yet been shown whether superfetation indeed facilitates polyandry.

The two demographic hypotheses state that superfetation either is beneficial for offspring survival, or could increase the rate of offspring production. In situations where offspring mortality is unpredictable in space or time, superfetation could provide a bet-hedging strategy [96]. By spreading the litters over time, the risk of losing all offspring at once is reduced: this should result in higher juvenile survival and a selective advantage over single large broods [97]. To my knowledge, no empirical studies (e.g. mark-recapture studies in populations with stochastically varying juvenile survival rates) have been performed to test this prediction. The second demographic hypothesis links superfetation to an increase in offspring production. Using clutch overlap, it could for instance be possible to produce two litters of two offspring, while there might be insufficient energy or time, due to seasonality of reproduction or due to adult mortality, to produce multiple larger litters (of three 
offspring) [98]. In such a scenario, superfetation would be beneficial in environments with high food abundance. Work by Travis and colleagues [99] provides some evidence for this hypothesis, finding that superfetation level in Heterandria formosa increases with higher food availability.

Finally, the adaptive hypotheses state that superfetation could reduce the costs of reproduction, either energetically, morphologically, and/or with regard to adult survival. The common ground between these hypotheses is the difference in size of embryos of different developmental stages. Smaller embryos are thought to have lower energetic demands than embryos close to parturition. One single brood would thus cause large fluctuations in reproductive investments over the cycle of pregnancy, while these investments are spread out over time with multiple broods [100]. This would mean that superfetation could provide an adaptive benefit in environments with low and/or unpredictable environments: with superfetation the chances that females are able to allocate sufficient amounts of energy to their broods are larger. However, experiments with $H$. formosa on different levels of food availability show the opposite: superfetation level was increased with higher levels of food availability [100].

The final hypothesis overlaps with the locomotor costs hypothesis for matrotrophy [28,71]: superfetation could reduce the morphological changes during pregnancy, leading to a more slender body shape, better locomotor performance and higher adult survival. At equal levels of fecundity (i.e. similar number of offspring on the long-term and similar offspring size at birth), the difference in volume between recently fertilized and full-term embryos should lead to a smaller total volume of embryo mass in species with superfetation. Superfetation should thus result in a reduced amplitude of morphological changes during pregnancy, and lead to a body shape that is more slender than that of near-parturition females without superfetation (Figure 1-3C). Slender body shapes are advantageous in environments with high-predation pressures or in fast-flowing rivers [3,101,102], indicating that in such environments superfetation could provide an adaptive advantage.

The effect of different levels of superfetation on body shape changes and swimming performance have not yet been measured directly. There is however, a small body of work that provides circumstantial evidence through the comparison of superfetation levels of populations that differed in water flow velocity and predation pressure. First, Zúñiga-Vega and colleagues [103] showed that superfetation level is higher in Poeciliopsis turrubarensis from the fast-flowing inland streams in Costa Rica, and that these fish have a more fusiform body shape (defined as less deep bodies with shorter caudal 
peduncles) than populations that inhabit the lower-gradient rivers near the coast. However, in a follow-up study, Frías-Alvares and Zuñíga-Vega [104] found no correlation between water flow, the level of superfetation and body shape in two other species of Poeciliid fishes, Poeciliopsis gracilis and Poeciliopsis infans. Lastly, superfetation level was indeed higher in populations of Phalloceros harpagos that co-occured with piscine predators [90]. Although they did not measure body shape to provide a mechanistic link, their finding does provide circumstantial evidence for the locomotor costs hypothesis.

The inconclusiveness of these studies, and the large number of hypotheses that aim to explain the evolution of superfetation, highlight the complexity of explaining (adaptive) evolution. To examine whether superfetation has beneficial effects on morphology and swimming performance, an experimental approach is necessary. However, even if the outcome would be positive, this does not yet explain the adaptive benefit of superfetation for all evolutionary origins.

\section{Swimming performance: a selective agent}

It has long been known that locomotor performance influences the fitness of an individual. One important determinant of performance is the morphology of an animal: different morphologies are suited better or worse for certain tasks. This paradigm is captured in Arnold's morphology $\rightarrow$ performance $\rightarrow$ fitness framework [109]. Ideally, to understand why one individual or population has a higher fitness than another, the complete relationship between morphology, performance and fitness needs to be understood. However, with knowing one or two of these three, predictions about the other(s) can be made.

As mentioned in the above paragraphs: swimming performance can be a selective agent. This goes as far as evolving different body shapes, but could also affect different aspects of an animal's biology: the locomotor costs hypothesis predicts that matrotrophy and superfetation each lead to a body shape that enhances swimming performance in live-bearing fishes [28].

Focussing on swimming, there are generally two types of locomotion that each have their own morphological and physiological demands: continuous swimming (here assumed to include cyclic and burst and coast-swimming styles) and fast-start swimming. The former mode is mainly of importance for long migrations, long chases (e.g. how tuna hunt) and swimming in fast-flowing streams. Fish that predominantly exhibit this type of swimming have a high proportion of aerobic (red) muscle to supply force for a long 
period of time, and have a fusiform body shape that minimizes the friction drag of the water [110]. In live-bearing fishes, effects of fast-flowing rivers on body shape and superfetation are seen in Poeciliopsis turrubarensis [103], but not in Poeciliopsis gracilis nor Poeciliopsis infans [104].

For the second mode of swimming, fast-start swimming, the morphological and physiological demands are different for those required for continuous swimming: these two modes present a trade-off to some extent. Fast-start swimming requires only shorts bouts of energy, which are supplied by the strong anaerobic muscles [111]. Furthermore, for fast acceleration, it is beneficial to have a high caudal peduncle with a large tail blade [112]. Indeed, in Gambusia affinis, populations that co-occur with piscine predators have evolved relatively smaller heads and larger caudal regions [102].

Fast-start swimming is mainly executed to escape predatory strikes and involves rapid propulsion and, often, a large reorientation of the body [112115]. The behaviour is initiated by the Mauthner-neurons, a pair of giant interneurons that are located in the hindbrain with axons running through the spinal cord [115,116]. Following stimulation (either tactile, vibrational or visual) one of the pair of Mauthner-neurons fires and causes a lateral contraction of the muscle on one side of the body. As a result, the fish bends into a C-shape. This is followed by contraction of the contralateral muscles, driving the fish forwards in a direction often different from its initial orientation $[117,118]$. Another type of fast-start, the 'S-start' in which the fish curves in an S-shape, is mainly exhibited by predatory fish to perform a strike [119].

Fast-start manoeuvres have traditionally been described as manoeuvres strictly in a 2D (horizontal) plane [113]. However, recent technological advances, mainly high-resolution 3D high-speed video and automated analysis software [e.g. 9], have revealed that, at least in larval zebrafish (Danio rerio), these manoeuvres can contain significant vertical components that can be related to the direction of predator approach $[11,120]$.

\section{Aim and outline of the thesis}

With this project, I attempt a cross-pollination between two different field of biology, which together, are well suited in finding answers to evolutionary questions [121]. The specific aim of this thesis is to determine if, and to what extent, matrotrophy and superfetation function as reproductive adaptations to reduce the locomotor costs associated with viviparity in the live-bearing fish family Poeciliidae. 
The relationship between morphological traits and fitness is often described through Arnold's morphology-performance-fitness-diagram [109]. In this thesis, I try to unravel parts of the relationship between pregnancy and its adaptations, morphology, performance and fitness [Figure 1-4].

In Chapter 2, we provide an overview of literature on the effects of pregnancy on morphology, performance and fitness. The biomechanics of locomotion differs between swimming, walking and flying; so how pregnancy affects these different types of locomotor arguably differs. We aim to identify how pregnancy affects the biomechanics of locomotion for each type of locomotion. A second aim of this chapter is to document the possible adaptations to viviparity and determine which part of the morphology-performance-fitness-diagram they affect. Overall, we aim to find and explain patterns in the evolution of viviparity and adaptations to this reproductive mode.

In Chapter 3, we zoom in on one of the hypothesised reproductive adaptations in Poeciliidae: matrotrophy. This reproductive adaptation is expected to lead to a more slender body shape during the early stages of pregnancy, but evidence for this hypothesis is lacking. By comparing the morphological changes between a lecithotrophic livebearer, Poeciliopsis gracilis, and a matrotrophic sister species, Poeciliopsis turneri, we aim to provide the first

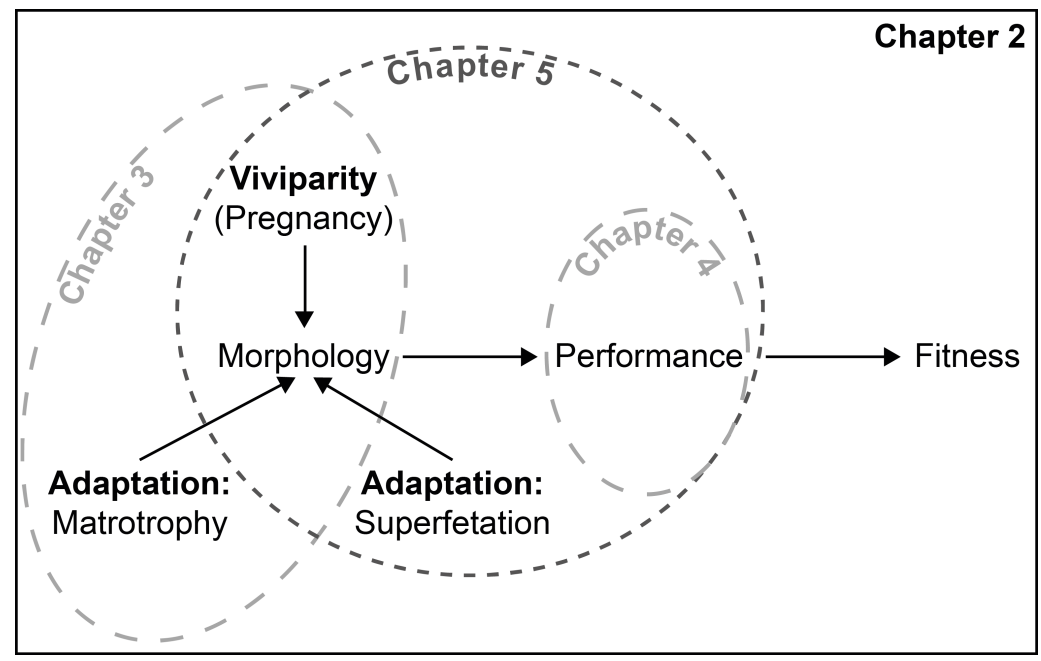

Figure 1-4. Schematic overview of the thesis chapters. Chapter 2 reviews how pregnancy and reproductive adaptations affect morphology, performance and fitness throughout the animal kingdom. Chapter 3 describes the effect of matrotrophy on the morphological changes during pregnancy. In chapter 4, the three-dimensional nature of fast-start performance manoeuvres is examined. Chapter 5 describes how the morphological changes during pregnancy affect fast-start performance and how superfetation affects morphology. Lastly, in chapter 6 (not depicted in this picture), the results of the previous chapters will be placed into a wider context with a perspective for future work. 
empirical test of this hypothesis. We examined these changes with a novel non-invasive method, that provides accurate measurements on three-dimensional body shape.

Fast-start performance is important in determining the odds of survival in predator attacks. In Chapter 4, we took a step back from the reproductive adaptations to analyse how fast-start manoeuvres are performed in three-dimensional space in adult fish (Heterandria formosa). Fast starts have mostly been reduced to a two-dimensional manoeuvre, and here we aim to show that there is a three-dimensional component to this behaviour. Variation in escape angle, not only in the horizontal plane but also in the vertical direction, could increase the unpredictability of prey.

The results of Chapter 4 are elaborated in Chapter 5, in which we describe how pregnancy affects morphology and three-dimensional fast-start performance in three species of Poeciliidae that differ in their level of superfetation: Poeciliopsis turneri, Heterandria formosa and Phalloptychus januarius. We aim to show that superfetation is a reproductive adaptation as it leads to a reduction in morphological changes during pregnancy. Furthermore, we aim to show to what extent changes in body shape, particularly a thickening abdomen full of offspring, negatively affects the three-dimensional fast-start manoeuvre.

In the last chapter, Chapter 6, I discuss and integrate the results of the previous chapters. The results are placed in perspective of life history evolution and in the light of the other hypotheses regarding the evolution of matrotrophy and superfetation. Furthermore, I elaborate on the methodological difficulties we experienced gathering enormous datasets of high-speed video movies and how to improve this in future work. This work could contribute to the understanding of the evolution of viviparity and associated reproductive adaptations also in other groups of animals. 


\section{References}

1. Blackburn DG. Evolution of vertebrate viviparity and specializations for fetal nutrition: A quantitative and qualitative analysis. J Morphol. 2015;276: 961-990. doi:10.1002/jmor.20272

2. Ostrovsky AN, Lidgard S, Gordon DP, Schwaha T, Genikhovich G, Ereskovsky A V. Matrotrophy and placentation in invertebrates: a new paradigm. Biol Rev. 2016;91: 673-711. doi:10.1111/brv.12189

3. Ghalambor CK, Reznick DN, Walker JA. Constraints on adaptive evolution: the functional trade-off between reproduction and fast-start swimming performance in the Trinidadian guppy (Poecilia reticulata). Am Nat. 2004;164: 38-50. doi:10.1086/421412

4. Van Damme R, Bauwens D, Verheyen R. Effect of relative clutch mass on sprint speed in the lizard Lacerta vivipara. J Herpetol. 1989;23: 459-461. Available: http://www.jstor.org/stable/10.2307/1564069

5. Noren SR, Redfern J V, Edwards EF. Pregnancy is a drag: hydrodynamics, kinematics and performance in pre- and post-parturition bottlenose dolphins (Tursiops truncatus). J Exp Biol. 2011;214: 4151-9. doi:10.1242/ jeb.059121

6. Shine R. “Costs" of reproduction in reptiles. Oecologia. 1980;46: 92-100. Available: http://link.springer.com/article/10.1007/BF00346972

7. Banet AI, Svendsen JC, Eng KJ, Reznick DN. Linking reproduction, locomotion, and habitat use in the Trinidadian guppy (Poecilia reticulata). Oecologia. 2016;181: 87-96.

8. Walker JA, Ghalambor CK, Griset OL, McKenney D, Reznick DN. Do faster starts increase the probability of evading predators? Funct Ecol. 2005;19: 808-815. doi:DOI 10.1111/j.1365-2435.2005.01033.x

9. Voesenek CJ, Pieters RPM, Van Leeuwen JL. Automated reconstruction of three-dimensional fish motion, forces, and torques. PLoS One. 2016;11: e0146682. doi:10.1371/journal.pone.0146682

10. Butail S, Paley D a. Three-dimensional reconstruction of the fast-start swimming kinematics of densely schooling fish. J R Soc Interface. 2011;9: 77-88. doi:10.1098/rsif.2011.0113

11. Nair A, Azatian G, McHenry MJ. The kinematics of directional control in the fast start of zebrafish larvae. J Exp Biol. 2015; 3996-4004. doi:10.1242/ jeb.126292

12. Blackburn DG. Classification of the Reproductive Patterns of Amniotes. Herpetol Monogr. 2000;14: 371-377.

13. Blackburn DG. Convergent evolution of viviparity, matrotrophy, and specializations for fetal nutrition in reptiles and other vertebrates. Am Zool. 1992;32: 313-321. Available: http://icb.oxfordjournals.org/content/32/2/313.short 
14. Wourms JP, Grove BD, Lombardi J. The maternal-embryonic relationship in viviparous fishes. In: Hoar WS, Randal DJ, editors. Fish Physiology. New York: Academic Press; 1988. pp. 1-134.

15. Furness AI, Morrison KR, Orr TJ, Arendt JD, Reznick DN. Reproductive mode and the shifting arenas of evolutionary conflict. Ann N Y Acad Sci. 2015;1360: 75-100. doi:10.1111/nyas.12835

16. Lodé T. Oviparity or viviparity? That is the question... Reprod Biol. 2012;12: 259-264. doi:10.1016/j.repbio.2012.09.001

17. Lamarck J-B. Histoire naturelle des animaux sans vertebres. 2nd ed. Balliere JB, editor. Paris; 1835.

18. Rothchild I. The yolkless egg and the evolution of eutherian viviparity. Biol Reprod. 2003;68: 337-357. doi:10.1095/biolreprod.102.004531

19. Wourms JP. Viviparity: the maternal-fetal relationships in fishes. Am Zool. 1981;21: 473-515.

20. Wourms JP. Reproduction and development in Chondrichthyan fishes. Am Zool. 1977;17: 379-410. doi:10.1093/icb/17.2.379

21. Wake MH. Oviduct structure and function in non-mammalian vertebrates. Fortschr Zool. 1985;30: 427-435.

22. Wake MH. The Reproductive Biology of Caecilians: An Evolutionary Perspective. In: Taylor DH, Guttman SI, editors. The Reproductive Biology of Amphibians. Springer US; 1977. pp. 73-101.

23. Tinkle DW, Gibbons JW. The distribution and evolution of viviparity in reptiles. Misc Publ Museum Zool Univ Michigan. 1977; 1-55.

24. Shine R, Bull JJ. The evolution of live-bearing in lizards and snakes. Am Nat. 1979;113: 905-923.

25. Sharman GB. Reproductive physiology of marsupials. Science. 1970;167: 1221-1228.

26. Renfree MB. Marsupials: alternative mammals. Nature. 1981;293: 100101.

27. Tinkle DW, Willbur HM, Tilley SG. Evolutionary Strategies in Lizard Reproduction. Evolution (NY). 1970;24: 55-74.

28. Pollux BJA, Pires MN, Banet AI, Reznick DN. Evolution of Placentas in the Fish Family Poeciliidae: An Empirical Study of Macroevolution. Annu Rev Ecol Evol Syst. 2009;40: 271-289. doi:DOI 10.1146/annurev. ecolsys.110308.120209

29. Stewart JR, Blackburn DG. Viviparity and Placentation in Lizards. In: Rheubert JL, Siegel DS, Trauth SE, editors. Reproductive Biology and Phylogeny of Lizards and Tuatara. CRC Press; 2014. pp. 448-563.

30. Shine R. The evolution of viviparity in reptiles: an ecological analysis. In: Gans C, Billet F, editors. Biology of the Reptilia. New York: Wiley; 1985. pp. 605-694. 
31. Blackburn DG. Squamate reptiles as model organisms for the evolution of viviparity. Herpetol Monogr. 2006;20: 131-146. Available: http:// www.hljournals.org/doi/abs/10.1655/0733-1347(2007)20\%5B131\%3ASRAMOF\%5D2.0.CO;2

32. Pyron RA, Burbrink FT. Early origin of viviparity and multiple reversions to oviparity in squamate reptiles. Ecol Lett. 2014;17: 13-21. doi:10.1111/ele.12168

33. Blackburn DG. Evolution of viviparity in squamate reptiles: Reversibility reconsidered. J Exp Zool Part B Mol Dev Evol. 2015;324: 473-486. doi:10.1002/jez.b.22625

34. Shine R. The evolution of oviparity in squamate reptiles: An adaptationist perspective. J Exp Zool Part B Mol Dev Evol. 2015;324: 487-492. doi:10.1002/jez.b.22622

35. Shine R, Lee MSY. A Reanalysis of the Evolution of Viviparity and Egg-Guarding in Squamate Reptiles. Herpetologica. 1999;55: 538-549.

36. Pincheira-Donoso D, Tregenza T, Witt MJ, Hodgson DJ. The evolution of viviparity opens opportunities for lizard radiation but drives it into a climatic cul-de-sac. Glob Ecol Biogeogr. 2013;22: 857-867. doi:10.1111/ geb.12052

37. Shine R. A New Hypothesis for the Evolution of Viviparity in Reptiles. Am Nat. 1995;145: 809-823.

38. Lorioux S, DeNardo DF, Gorelick R, Lourdais O. Maternal influences on early development: preferred temperature prior to oviposition hastens embryogenesis and enhances offspring traits in the Children's python, Antaresia childreni. J Exp Biol. 2012;215: 1346-1353. doi:10.1242/ jeb.059113

39. Lourdais O, Heulin B, Denardo DF. Thermoregulation during gravidity in the children's python (Antaresia childreni): A test of the preadaptation hypothesis for maternal thermophily in snakes. Biol J Linn Soc. 2008;93: 499-508. doi:10.1111/j.1095-8312.2007.00925.x

40. Sanders KL, Lee MS, Leys R, Foster R, Keogh JS. Molecular phylogeny and divergence dates for Australasian elapids and sea snakes (hydrophiinae): evidence from seven genes for rapid evolutionary radiations. J Evol Biol. 2008;21: 682-695. doi:10.1111/j.1420-9101.2008.01525.x

41. Helmstetter AJ, Papadopulos AST, Igea J, Van Dooren TJM, Leroi AM, Savolainen V. Viviparity stimulates diversification in an order of fish. Nat Commun. Nature Publishing Group; 2016;7: 11271. doi:10.1038/ ncomms11271

42. Wourms JP, Lombardi J. Reflections on the evolution of piscine viviparity. Am Zool. 1992;32: 276-293. Available: http://icb.oxfordjournals.org/ content/32/2/276.short

43. Neill WT. Viviparity in Snakes: Some Ecological and Zoogeographical Considerations. Am Nat. 1964;98: 35-55. doi:10.1086/282299 
44. Motani R. The Evolution of Marine Reptiles. Evol Educ Outreach. 2009;2: 224-235. doi:10.1007/s12052-009-0139-y

45. Motani R, Jiang D-Y, Tintori A, Rieppel O, Chen G-B. Terrestrial origin of viviparity in mesozoic marine reptiles indicated by early triassic embryonic fossils. PLoS One. 2014;9: e88640. doi:10.1371/journal.pone.0088640

46. Lucinda PHF, Reis RE. Systematics of the subfamily Poeciliinae Bonaparte (Cyprinodontiformes: Poeciliidae), with an emphasis on the tribe Cnesterodontini Hubbs. Neotrop Ichthyol. 2005;3: 1-60. doi:10.1590/ S1679-62252005000100001

47. Cech Jr J, Massingill M, Vondracek B, Linden A. Respiratory metabolism of mosquitofish, Gambusia affinis: effects of temperature, dissolved oxygen, and sex difference. Environ Biol Fishes. 1985;13: 297-307. Available: http://link.springer.com/article/10.1007/BF00002914

48. Wischnath L. Atlas of livebearers of the world. Hants, United Kingdom: TFH Publications; 1993.

49. Rosen DE, Bailey RM. The poeciliid fishes (Cyprinodontiformes), their structure, zoogeography and systematics. Bull Am Museum Nat Hist. 1963;126: 1-176.

50. Reznick DN, Furness AI, Meredith RW, Springer MS. The origin and biogeographic diversification of fishes in the family Poeciliidae. PLoS One. 2017;12: 1-20. doi:10.1371/journal.pone.0172546

51. Goodwin NB, Dulvy NK, Reynolds JD. Life-history correlates of the evolution of live bearing in fishes. Philos Trans R Soc B-Biological Sci. 2002;357: 259-267. doi:DOI 10.1098/rstb.2001.0958

52. Mank JE, Promislow DEL, Avise JC. Phylogenetic Perspectives in the Evolution of Parental Care in Ray-Finned Fishes. Evolution (N Y). 2005;59: 1570-1578.

53. Hrbek T, Seckinger J, Meyer A. A phylogenetic and biogeographic perspective on the evolution of poeciliid fishes. Mol Phylogenet Evol. 2007;43: 986-998.

54. Parenti LR, Lonostro FL, Grier HJ. Reproductive histology of Tomeurus gracilis Eigenmann, 1909 (Teleostei: Atherinomorpha: Poeciliidae) with comments on evolution of viviparity in atherinomorph fishes. J Morphol. 2010;271: 1399-1406. doi:10.1002/jmor.10886

55. Turner CL. Superfetation in Viviparous Cyprinodont Fishes. Copeia. 1940; 88-91.

56. Lopez-Sepulcre A, Gordon SP, Paterson IG, Bentzen P, Reznick DN. Beyond lifetime reproductive success: the posthumous reproductive dynamics of male Trinidadian guppies. Proc R Soc B Biol Sci. 2013;280: 20131116-20131116. doi:10.1098/rspb.2013.1116

57. De Vlaming VL. Environmental control of teleost reproductive cycles: a brief review. J Fish Biol. 1972;4: 131-140. doi:10.1111/j.1095-8649.1972. tb05661.x 
58. Frías-Alvarez P, Macías Garcia C, Vázquez-Vega L, Zúñiga-Vega J. Spatial and temporal variation in superfoetation and related life history traits of two viviparous fishes: Poeciliopsis gracilis and P. infans. Naturwissenschaften. 2014;101: 1085-1098. doi:10.1007/s00114-014-1247-2

59. Meffe GK, Snelson FF. Ecology \& evolution of livebearing fishes (Poeciliidae). Upper Saddle River, NJ: Prentice Hall; 1989.

60. Reznick DN, Endler JA. The Impact of Predation on Life History Evolution in Trinidadian Guppies (Poecilia reticulata). Evolution (NY). 1982;36: 160-177.

61. Reznick DN, Bryga H, Endler JA. Experimentally induced life-history evolution in a natural population. Nature. 1990;346: 183-187. doi:10.1038/346183a0

62. Endler JA. Multiple-trait evolution and environmental gradients in guppies. Trends Ecol Evol. 1995;10: 22-29.

63. Ioannou CC, Ramnarine IW, Torney CJ. High-predation habitats affect the social dynamics of collective exploration in a shoaling fish. Sci Adv. 2017;3: 1-8. doi:10.1126/sciadv.1602682

64. Godin JGJ, McDonough HE. Predator preference for brightly colored males in the guppy: A viability cost for a sexually selected trait. Behav Ecol. 2003;14: 194-200. doi:10.1093/beheco/14.2.194

65. Reznick DN, Shaw FH, Rodd FH, Shaw RG. Evaluation of the Rate of Evolution in Natural Populations of Guppies (Poecilia reticulata). Science. 1997;275: 1934-1937.

66. Charlesworth B. Evolution in Age-Structured Populations. Cambridge University Press.; 1994.

67. Pollux BJA, Meredith RW, Springer MS, Garland T, Reznick DN. The evolution of the placenta drives a shift in sexual selection in livebearing fish. Nature. 2014;513: 233-236. doi:10.1038/nature13451

68. Mossman HW. Comparative morphogenesis of the fetal membranes and accessory uterine structures. Carnegie Inst Contr Embryol. 1937;26: 129-246.

69. Grove B, Wourms J. The follicular placenta of the viviparous fish, Heterandria formosa. I. Ultrastructure and development of the embryonic absorptive surface. J Morphol. 1991;209: 265-284. Available: http://onlinelibrary.wiley.com/doi/10.1002/jmor.1052090304/abstract

70. Kwan L, Fris M, Rodd FH, Rowe L, Tuhela L, Panhuis TM. An examination of the variation in maternal placentae across the genus Poeciliopsis (Poeciliidae). J Morphol. 2015;276: 707-720. doi:10.1002/jmor.20381

71. Thibault RE, Schultz RJ. Reproductive adaptations among viviparous fishes (Cyprinodontiformes: Poeciliidae). Evolution (NY). 1978;32: 320333. Available: http://www.jstor.org/stable/10.2307/2407600 
72. Trexler JC. Resource Availability and Plasticity in Offspring Provisioning: Embryo Nourishment in Sailfin Mollies. Ecology. 1997;78: 13701381.

73. Reznick DN, Mateos M, Springer MS. Independent origins and rapid evolution of the placenta in the fish genus Poeciliopsis. Science. 2002;298: 1018-1020. doi:10.1126/science.1076018

74. Zeh DW, Zeh JA. Reproductive mode and speciation: the viviparity-drive conflict hypothesis. Bioessays. 2000;22: 938-946.

75. Zeh JA, Zeh DW. Viviparity-driven conflict: More to speciation than meets the fly. Ann N Y Acad Sci. 2008;1133: 126-148. doi:10.1196/annals.1438.006

76. Schrader M, Travis J. Testing the viviparity-driven-conflict hypothesis: parent-offspring conflict and the evolution of reproductive isolation in a poeciliid fish. Am Nat. 2008;172: 806-817. doi:10.1086/592999

77. Crespi B, Semeniuk C. Parent-offspring conflict in the evolution of vertebrate reproductive mode. Am Nat. 2004;163: 635-653. doi:10.1086/382734

78. Trivers RL. Parent-Offspring Conflict. Am Zool. 1974;14: 249-264.

79. Trexler JC, DeAngelis DL. Resource allocation in offspring provisioning: An evaluation of the conditions favoring the evolution of matrotrophy. Am Nat. 2003;162: 574-585. doi:10.1086/378822

80. Reznick DN, Yang AP. The influence of fluctuating resources on life history: patterns of allocation and plasticity in female guppies. Ecology. 1993;74: 2011-2019.

81. Banet AI, Au AG, Reznick DN. Is mom in charge? Implications of resource provisioning on the evolution of the placenta. Evolution (NY). 2010;64: 3172-3182. doi:10.1111/j.1558-5646.2010.01059.x

82. Banet AI, Reznick DN. Do placental species abort offspring? Testing an assumption of the Trexler-DeAngelis model. Funct Ecol. 2008;22: 323331. doi:10.1111/j.1365-2435.2007.01367.x

83. Pollux BJA, Reznick DN. Matrotrophy limits a female's ability to adaptively adjust offspring size and fecundity in fluctuating environments. Funct Ecol. 2011;25: 747-756. doi:10.1111/j.1365-2435.2011.01831.x

84. Blackburn DG, Vitt LJ, Beuchat CA. Eutherian-like reproductive specializations in a viviparous reptile. Proc Natl Acad Sci. 1984;81: 4860-4863. doi:10.1073/pnas.81.15.4860

85. Schrader M, Travis J. Population Differences in Pre- and Post-Fertilization Offspring Provisioning in the Least Killifish, Heterandria formosa. Copeia. 2005;2005: 649-656.

86. Reznick DN, Meredith R, Collette BB. Independent Evolution of Complex Life History Adaptations in Two Families of Fishes, Live-bearing Halfbeaks (Zenarchopteridae, Beloniformes) and Poeciliidae (Cyprinodontiformes). Evolution (NY). 2007;61: 2570-2583. 
87. Pires MN, Bassar RD, McBride KE, Regus JU, Garland T, Reznick DN. Why do placentas evolve? An evaluation of the life-history facilitation hypothesis in the fish genus Poeciliopsis. Funct Ecol. 2011;25: 757-768. doi:10.1111/j.1365-2435.2011.01842.x

88. Bassar RD, Auer SK, Reznick DN. Why do placentas evolve? A test of the life-history facilitation hypothesis in two clades in the genus Poeciliopsis representing two independent origins of placentas. Funct Ecol. 2014;28: 999-1010. doi:10.1111/1365-2435.12233

89. Plaut I. Does pregnancy affect swimming performance of female Mosquitofish, Gambusia affinis? Funct Ecol. 2002;16: 290-295. doi:DOI 10.1046/j.1365-2435.2002.00638.x

90. Gorini-Pacheco B, Zandonà E, Mazzoni R. Predation effects on matrotrophy, superfetation and other life history traits in Phalloceros harpagos. Ecol Freshw Fish. 2017; doi:10.1111/eff.12359

91. Turner CL. Reproductive Cycles and Superfetation in Pœciliïd Fishes. Biol Bull. 1937;72: 145-164.

92. Roellig K, Menzies BR, Hildebrandt TB, Goeritz F. The concept of superfetation: a critical review on a "myth" in mammalian reproduction. Biol Rev. 2011;86: 77-95. doi:10.1111/j.1469-185X.2010.00135.x

93. Gunn JS, Thresher RE. Viviparity and the reproductive ecology of clinid fishes (Clinidae) from temperate Australian waters. Environ Biol Fishes. 1991;31: 323-344. doi:10.1007/BF00002357

94. Zúñiga-Vega JJ, Macías-Garcia C, Johnson JB. Hypotheses to explain the evolution of superfetation in viviparous fishes. In: Uribe $\mathrm{M}$, Grier $\mathrm{H}$, editors. Viviparous fishes II. New Life Publications, Homestead, Florida; 2010. pp. 241-253.

95. Macías-García C, González-Zuarth CA. Reproductive behaviour in viviparous fish and intersexual conflict. In: Uribe MC, Grier HJ, editors. Viviparous fishes. Homestead: New Life Publications; 2005. pp. 289302.

96. Thibault RE. Genetics of cannibalism in a viviparous fish and its relationship to population density. Nature. 1974;251: 138-140. doi:10.1038/251138a0

97. Slatkin M. Hedging one's evolutionary bets. Nature. 1974;250: 81-82. doi:10.1038/252497a0

98. Burley N. Clutch Overlap and Clutch Size: Alternative and Complementary Reproductive Tactics. Am Nat. 1980;115: 223-246. doi:Doi $10.1086 / 283556$

99. Travis J, Farr JA, Henrich S, Cheong RT. Testing Theories of Clutch Overlap with the Reproductive Ecology of Heterandria Formosa. Ecology. 1987;68: 611-623.

100. Downhower JF, Brown LP. Superfoetation in fishes and the cost of reproduction. Nature. 1975;256: 345-345. doi:10.1038/256345b0 
101. Langerhans RB, Gifford ME, Joseph EO. Ecological speciation in Gambusia fishes. Evolution (NY). 2007;61: 2056-2074. doi:10.1111/j.15585646.2007.00171.x

102. Langerhans RB. Trade-off between steady and unsteady swimming underlies predator-driven divergence in Gambusia affinis. J Evol Biol. 2009;22: 1057-1075. doi:10.1111/j.1420-9101.2009.01716.x

103. Zúñiga-Vega JJ, Reznick DN, Johnson JB. Habitat predicts reproductive superfetation and body shape in the livebearing fish Poeciliopsis turrubarensis. Oikos. 2007;116: 995-1005. doi:10.1111/j.2007.0030-1299.15763.x

104. Frías-Alvarez P, Zúniga-Vega JJ. Superfetation in live-bearing fishes is not always the result of a morphological constraint. Oecologia. 2016;181: 645-658. doi:10.1007/s00442-015-3477-1

105. Meredith RW, Pires MN, Reznick DN, Springer MS. Molecular phylogenetic relationships and the coevolution of placentotrophy and superfetation in Poecilia (Poeciliidae: Cyprinodontiformes). Mol Phylogenet Evol. 2011;59: 148-57. doi:10.1016/j.ympev.2011.01.014

106. Reznick DN, Miles DB. Review of life history patterns in Poeciliid fishes. In: Meffe GK, Snelson FF, editors. Ecology and Evolution of Livebearing Fishes (Poeciliidae). Prentice Hall, Englewood Cliffs, NJ; 1989. pp. $125-148$.

107. Scrimshaw N. Superfetation in Poeciliid Fishes. Copeia. 1944;3: 180-183.

108. Meyer MK. Lebendgebärende Zierfische Band 1: Poeciliidae. Eigenverlag; 2015.

109. Arnold SJ. Morphology, performance and fitness. Am Zool. 1983;23: 347-361.

110. Webb PW. Form and Function in Fish Swimming. Sci Am. 1984;251: 72 82. doi:10.1038/scientificamerican0784-72

111. Wakeling JM, Johnston IA. Muscle power output limits fast-start performance in fish. J Exp Biol. 1998;201: 1505-1526.

112. Weihs D. The mechanism of rapid starting of slender fish. Biorheology. 1973;10: 343-350.

113. Domenici P, Blake RW. The kinematics and performance of fish faststart swimming. J Exp Biol. 1997;200: 1165-1178. Available: http://jeb. biologists.org/content/200/8/1165.short

114. Domenici P, Blagburn JM, Bacon JP. Animal escapology II: escape trajectory case studies. J Exp Biol. 2011;214: 2474-2494. doi:10.1242/jeb.053801

115. Eaton RC, Bombardieri RA, Meyer DL. The Mauthner-initiated startle response in teleost fish. J Exp Biol. 1977;66: 65-81.

116. Canfield JG. Functional evidence for visuospatial coding in the Mauthner neuron. Brain Behav Evol. 2006;67: 188-202. doi:10.1159/000091652 
117. Spierts ILY, Van Leeuwen JL. Kinematics and muscle dynamics of Cand S-starts of carp (Cyprinus carpio L.). J Exp Biol. 1999;202: 393-406. Available: http://www.ncbi.nlm.nih.gov/pubmed/9914147\%5Cnhttp:// jeb.biologists.org/content/202/4/393.short\%0Ahttp://www.ncbi.nlm. nih.gov/pubmed/9914147

118. Müller UK, Van Leeuwen JL. Swimming of larval zebrafish: ontogeny of body waves and implications for locomotory development. J Exp Biol. 2004;207: 853-868. doi:10.1242/jeb.00821

119. Johnston IA, Van Leeuwen JL, Davies MLF, Beddow T. How fish power predation fast-starts. J Exp Biol. 1995;198: 1851-1861. Available: http:// www.biologists.com/JEB/198/09/jeb9901.html

120. Stewart WJ, Cardenas GS, McHenry MJ. Zebrafish larvae evade predators by sensing water flow. J Exp Biol. 2013;216: 388-398. doi:10.1242/ jeb.072751

121. Higham TM, Rogers SM, Langerhans RB, Jamniczky HA, Lauder G V, Stewart WJ, et al. Speciation through the lens of biomechanics: locomotion, prey capture and reproductive isolation. Proc R Soc London B Biol Sci. 2016;283: 20161294. doi:10.1098/rspb.2016.1294 


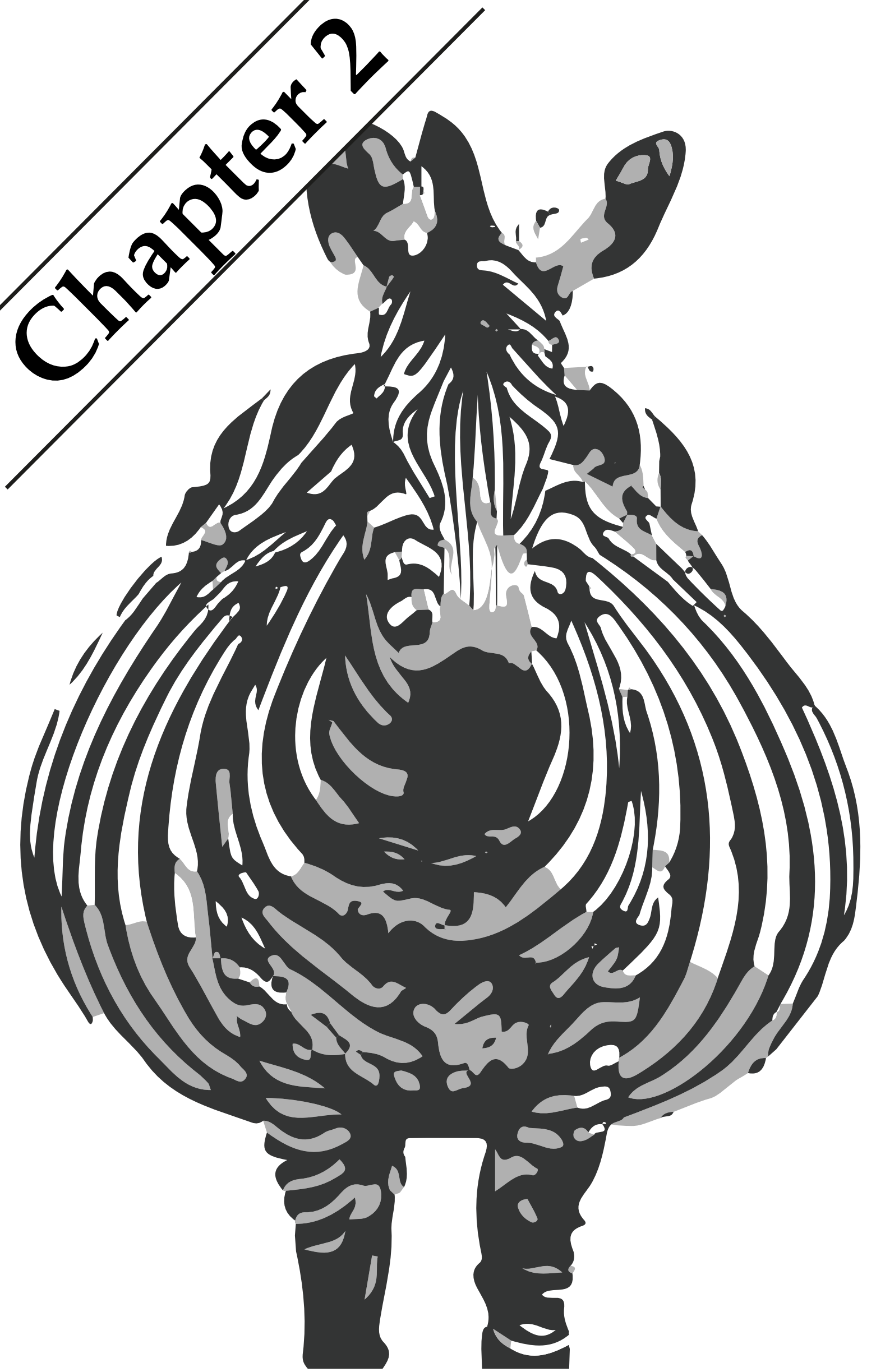




\section{Chapter 2}

The burden of viviparity:

The locomotor costs of livebearing and the adaptations to reduce them

Mike Fleuren ${ }^{1}$,

Johan L. van Leeuwen ${ }^{1}$,

David N. Reznick²,

Bart J.A. Pollux ${ }^{1}$

${ }^{1}$ Experimental Zoology Group, Department of Animal Sciences, Wageningen University, 6708 WD Wageningen, The Netherlands;

${ }^{2}$ Department of Biology, University of California, Riverside, California 92521, USA. 
Chapter 2 I Locomotor costs of live-bearing and adaptations to reduce them

\begin{abstract}
Viviparity (live-bearing) evolved over a hundred times in the animal kingdom, and is found in a wide range of taxa and ecologies. For this trait to evolve or persist, the advantages of viviparity should outweigh the disadvantages, all compared to an ancestral oviparous (egg-laying) mode of reproduction. As viviparity could decrease locomotor performance during pregnancy, it is expected that animals evolved adaptations to alleviate the locomotor costs during gestation. Here, we present an overview of the effects of pregnancy on locomotor performance for the three main modes of locomotion (aquatic, terrestrial and aerial) and explain differences between them from a biomechanical point of view. Furthermore, we identify three broad types of adaptations to live-bearing: (i) anatomical adaptations that reduce the morphological effects of pregnancy, (ii) behavioural adaptations that reduce the dependency on (maximum) locomotor performance and (iii) life history adaptations. We found that pregnancy tends to have negative consequences for locomotor performance in all three locomotor modes, but there is still insufficient basis to verify biomechanical hypotheses regarding the differences between the three modes, nor to extrapolate expected locomotor declines to other evolutionary origins of viviparity. With the available data, phylogenetic comparisons of the performance effects of pregnancy between taxa are hampered by differences in experimental setup and quantified performance parameters, lack of reliable controls, large variation in the number and timing of measurements, and the often undocumented presence of adaptations to live-bearing among studies. To overcome these problems, we propose a standardized experimental approach to facilitate comparisons among future studies and highlight areas for future research. Studying the effects of pregnancy on the biomechanics of locomotion is crucial for acquiring an understanding of the causes of the expected and often measured declines, and if and how adaptations could reduce these locomotor costs. Despite an observed trend towards a performance decline during pregnancy in several lineages, quantitative data are still lacking for most evolutionary origins of viviparity. This inhibits a direct comparison of reproductive modes and/or adaptations in a broad general framework.
\end{abstract}




\section{Introduction}

Reproduction is one of the most impactful activities in an animal's life. It is the time when animals pass on their genes to future generations, but it is also a time that may be particularly demanding on the parent(s), because of high investments into the offspring. These demands are likely to be more pronounced in viviparous (live-bearing) than oviparous (egg-laying) animals because of the longer period of internal development.

\section{(1) Definitions}

The literature contains various definitions for oviparity and viviparity. Here, we employ the dichotomous definitions proposed by Blackburn [1-3]. Oviparity refers to females that deposit (un)fertilized ova covered by an eggshell or jelly coat into the external environment, while viviparity refers to females that retain their young and give birth to offspring that are able to interact with their environment. These definitions uncouple the location of development from the method and timing (pre- or post-fertilization) of nutrient allocation to the embryos, eliminating potentially confusing terms like 'ovoviviparity' [3].

\section{(2) Evolutionary origins of viviparity}

Viviparity is found in over 300 families of invertebrate animals, covering 20 of the 34 invertebrate phyla (e.g. Arthropoda, Cnidaria, Echinodermata, Mollusca, Nematoda, Platyhelminthes and Porifera), many of which represent independent evolutionary origins [4]. In vertebrates, viviparity evolved in more than 150 lineages, including Placoderm fishes (1), cartilaginous fishes (9), bony fishes (13), amphibians (8), extinct prehistoric reptiles (6), squamate reptiles (115) and mammals (1) [3].

\section{(3) Advantages of viviparity}

The repeated evolution of viviparity throughout the animal kingdom points to an adaptive advantage of this reproductive mode, but the selective forces that drive its evolution are not fully understood. Three adaptive hypotheses have been proposed for the evolution of viviparity in squamate reptiles, but to what extent these are applicable to the evolution of viviparity in other taxa is currently unclear.

The "safe harbour hypothesis" [5] predicts that natural selection should maximize the duration developing organisms spend in the safest stages of development and minimize time spent in those stages where instantaneous 
rate of mortality is highest. In this case, higher mortality rate of eggs and small larvae compared to those of internally developing embryos and large neonates drives the evolution of prolonged intra-uterine development and, ultimately, viviparity [5-10].

The "cold-climate hypothesis" [11-13] states that prolonged uterine retention of eggs evolved in ectothermic animals that live in cold climates, because eggs develop more rapidly at maternal body temperatures than at lower soil temperatures, allowing for faster development and increased offspring fitness $[14,15]$. The "maternal manipulation hypothesis" [16] instead predicts that it is the more constant, not necessarily higher, temperatures provided in utero that conveys an adaptive advantage to the offspring. This hypothesis includes an adaptive advantage for the evolutionary benefit of viviparity in warmer environments [17-19]. The latter two hypotheses specifically pertain to squamate reptiles [11-15,17,19-26]; similar patterns have not (yet) been found for other ectotherm animal lineages (e.g. in fishes, [27]).

Finally, studies show that the evolution of viviparity is often followed by accelerated speciation rates [22,28-30], suggesting that viviparity, once acquired, could facilitate radiation into novel geographical areas or even ecological niches [14,31]. For example, viviparous snakes colonized marine habitats following the evolution of a live-bearing mode of reproduction in terrestrial ancestors $[29,32,33]$.

\section{(4) Disadvantages of viviparity}

Viviparity is hypothesized to have three main disadvantages, which could differ between taxa in presence and/or magnitude. Thus far, the presence and the extent of these disadvantages, and whether they differ among taxa or ecology, have received little attention.

First, a live-bearing mode of reproduction is often correlated with the production of fewer offspring per litter [34,35], and the longer retention of embryos may cause the period between successive broods to become longer [34]. A shift towards fewer high quality offspring, however, might result in a higher probability of offspring survival, hence favouring the evolution of livebearing.

Second, viviparity increases metabolic costs for the mother both in duration and magnitude compared to oviparous mothers, as developing offspring need to be provisioned with water, oxygen, and in some species nutrients; 
and waste products need to be disposed of [36-40]. These metabolic costs must be covered by reserves, (somatic) tissue degeneration or an increase in uptake.

Lastly, viviparity can be detrimental to the locomotor performance of the mother during the period of internal development: the developing offspring increases load in the abdomen, reducing the mothers ability to swim, walk or fly [41]. This locomotor performance decline may affect a female's ability to gather food or evade predators, potentially leading to a reduced maternal survival rate [42].

\section{(5) Adaptations to viviparity}

For viviparity to evolve, the advantages of viviparity should outweigh the costs. Compensation for these costs could have come in part from adaptations that preceded the evolution of viviparity (exaptation; [43]) or from adaptations that co-evolved with viviparity. The importance of distinguishing between exaptation and adaptation is that the former suggests that the evolution of livebearing may be facilitated in some lineages by pre-existing traits. The latter represents traits that evolve with livebearing, perhaps to directly enable livebearing or perhaps to indirectly facilitate the evolution of livebearing by alleviating some of the costs associated with this mode of reproduction. It is currently not well-documented which traits may act as adaptations to live-bearing, or to what extent these may compensate for the disadvantages associated with viviparity (e.g. how a trait compensates for

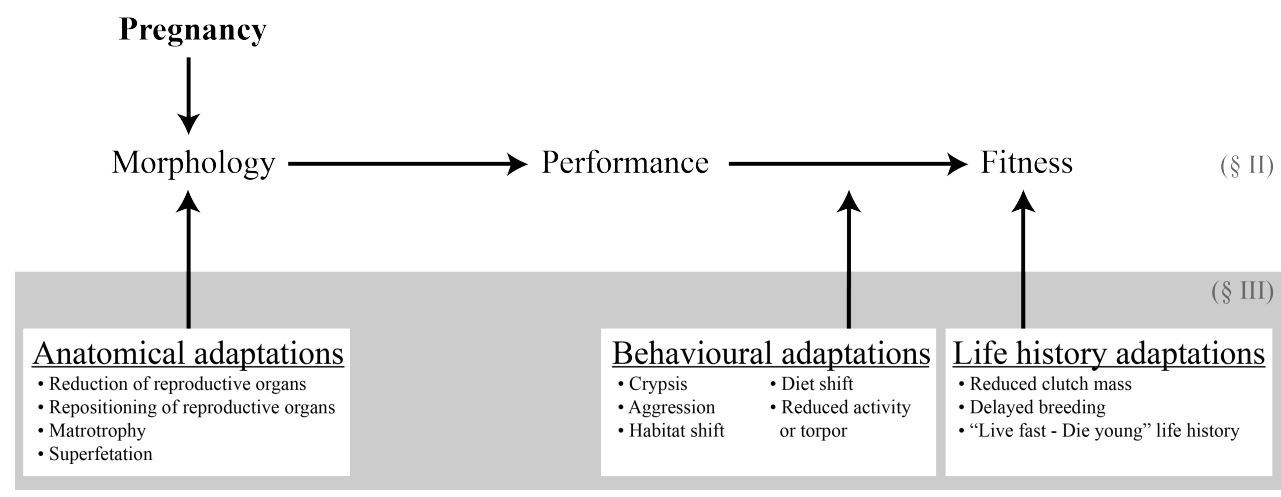

Figure 2-1. Schematic overview of how pregnancy and adaptations to live-bearing influence Arnold's morphology $\rightarrow$ performance $\rightarrow$ fitness framework [44]. The effect of pregnancy on morphology, performance and fitness are discussed in Section II. Adaptations to pregnancy are discussed in Section III, and are subdivided into three classes: adaptations that reduce the performance costs by affecting the morphology of the animal, adaptations that avoid the performance cost by changing the performance $\rightarrow$ fitness-link and adaptations to life-history that directly influence fitness. 
Chapter 2 I Locomotor costs of live-bearing and adaptations to reduce them

the added costs of locomotion during pregnancy). The reason is that organisms are 'package deals', meaning that viviparity and presumed adaptations that compensate for the costs of viviparity are inherently confounded with one another. We must find a way of separating them to perceive their adaptive significance, either via experiments or comparative studies of intra- and interspecific variation in reproduction.

\section{(6) The scope of this review}

In this review, we discuss the effects of a live-bearing mode of reproduction, following Arnolds's "morphology $\rightarrow$ performance $\rightarrow$ fitness framework" [44] (Figure 2-1). In Section II, we review the effects of pregnancy on morphology, locomotor performance and survival. Here we discriminate between aquatic, terrestrial and aerial locomotion, as pregnancy has distinctly different biomechanical consequences for each of these locomotor modes. Prerequisite for inclusion in Section II (and the overview in Table 2-1) is the documentation of the effects of pregnancy on performance variable(s) or survival rate. In Section III, we list and discuss potential adaptations to reduce or avoid the locomotor costs during pregnancy. We divided the adaptations in three classes, as they each work on a different part of the morphology $\rightarrow$ performance $\rightarrow$ fitness framework (Figure 2-1). In Section IV we discuss the aforementioned paragraphs and suggest improvements for future comparative work on the locomotor costs of viviparity.

\section{The effect of viviparity on locomotor performance}

Animals move through the environment to collect food, migrate to other areas, find a mate or avoid predation. The medium against which they exert the forces to propel themselves forward largely determines the biomechanical stressors that act on the animal's locomotor performance. Therefore, to understand the effects of pregnancy on locomotion, it is necessary to consider the animal's environment. We reviewed the available literature that compared performance during pregnancy with that of unburdened animals, and reported the relative performance change ('costs') in Table 2-1. In the upcoming paragraphs, we explain measured and hypothesized effects of pregnancy on locomotion using biomechanical principles, in a way that is understandable to a broad readership. 


\section{(1) Aquatic locomotion}

Two main types of aquatic locomotion exist within vertebrates: (1) undulation of the axial skeleton or (2) delivering thrust by moving the appendages. The species listed in Table 2-1 either exclusively use the first mode during locomotion, or use a combination of the two modes.

In aquatic and semi-aquatic animals, pregnancy is correlated with an increase in body mass (Table 2-1), ranging from $26 \%$ in the lizard Oligosoma smithi Gray (1845) [45] to 47-82\% in three species of semi-aquatic snake [46-48]. The acceleration $(a)$ of a body is directly proportional to the magnitude of the net forward force $(F)$ and inversely proportional to body mass $(m)$. Thus, an increase in female body mass during gestation should, if the net forward force remains unchanged, result in a proportional decline in maximal acceleration performance $(a=F / m)$. Reductions in escape or sprint performance and endurance over the course of a pregnancy have been observed in most live-bearing fishes [49-51], snakes [48,52] and dolphins [53], with reductions ranging between 30-59\%. Winne and Hopkins [48] report a trade-off between mass increase and locomotor impairment in the semi-aquatic snake Seminatrix pygaea Cope (1871), with individuals that had a larger reproductive allotment showing a greater reduction in swimming performance.

Pregnancy can also lead to an increase in body volume and frontal surface area (i.e. the area of the animal projected into the plane perpendicular to the direction of motion) (Table 2-1). The live-bearing fish species Gambusia affinis Baird \& Girard (1853) and the common bottlenose dolphin Tursiops truncatus Montagu (1821) show a $>50 \%$ increase in frontal surface area during pregnancy [53,54]. An increase in frontal surface area $(A)$ increases the drag $\left(F_{\mathrm{D}}\right)$ on the fema le, which acts opposite to the swimming direction and further depends on fluid properties $(\rho)$, shape $\left(C_{D}\right)$ and speed $(u)$ of the female $\left(F_{\mathrm{D}}=1 / 2 \cdot \rho \cdot u^{2} \cdot C_{\mathrm{D}} \cdot A\right)$. When frontal surface area and all other determinants of drag force are known, one can in principle derive the effect of pregnancy on the drag coefficient (e.g. dolphins, [53]). However, because undulatory swimming causes the body to deform continuously, the pressure and shear stress applied to the body change constantly, making the relationship between surface area, body shape and drag during undulatory swimming complex $[55,56]$. The formula for drag force thus is only truly valid when the moving body is straight and stiff (for instance during gliding), but at least gives a comparable indication of the effect of shape. Drag enlargement increases the metabolic cost of sustained locomotion. Pregnancy-related de- 
Chapter 2 I Locomotor costs of live-bearing and adaptations to reduce them

clines in sustained swimming performance have been reported in livebearing fishes (in [54,57] but not in [58]), semi-aquatic lizards [59] and dolphins [53], with declines ranging from 20 to $62 \%$ (Table 2-1).

The additional embryonic mass in the abdomen and associated stretching of the locomotor muscles in this region could prevent the vertebral column to bend normally. It could either require more force to make the same motion (increasing the metabolic costs of swimming), or reduce maximal bending, limiting the envelope of possible swimming gaits. An increase in flexural stiffness could be the cause of the measured decline in tail beat amplitude in pregnant dolphins [53], but experimental evidence for this mechanism is still lacking.

Another way in which pregnancy could influence aquatic locomotion is through effects on body density. Due to the presence of lipid-rich eggs or developing embryos, these changes could occur specifically in the abdominal region [60], but could also be distributed along the body, for example due to changes in blubber composition (e.g. in the common bottlenose dolphin, T. truncatus; [61]) or increased lipid stores during the pregnancy (e.g. in the live-bearing fish Phalloptychus januarius Hensel (1868); [62]). Variation in density changes the lift force acting on the body: when a female becomes less dense than water she will have a greater tendency to float, whereas if she becomes denser than water she will tend to sink [63,64]. Animals with a buoyancy organ may counterbalance these lift forces (e.g. bony fishes that have a gas-filled swim bladder; [64]). Animals that lack a buoyancy organ may compensate for the lift forces in other ways, such as by: (i) tilting the body slightly in the direction opposite of the lift force, (ii) supplying thrust in the opposite direction, or (iii) altering the position of the (pectoral) fins to supply extra lift force [64]. Notably, options (i) and (iii) will result in a decrease in the amount of force available for forward motion and increase the drag acting on the body $[63,64]$. To date, no study has examined the effects of pregnancy-related changes in body density on the swimming performance of aquatic live-bearing animals.

In live-bearing fish, a decrease in locomotor performance is known to adversely affect female survival $[65,66]$ (Table 2-1). Gambusia affinis experience a reduction in swimming ability during pregnancy, resulting in an increased mortality when exposed to a predatory fish: i.e. late-stage pregnant females had a $70 \%$ higher mortality rate compared to early-stage females [67]. Pregnant G. affinis females represent a far more profitable prey to predators compared to males, because they are larger (having a $5-25$ times higher energy content than males) while having a reduced locomotor performance. 
Avian predators, such as herons, are found to prey almost exclusively on females, rather than males [68]. Pregnant Atlantic mollies (Poecilia mexicana Steindachner, 1863) are more vulnerable to predation by giant water bugs (Belostoma sp. Latreille, 1807) in hypoxic environments than non-pregnant conspecifics, probably due to higher incidence of aquatic surface respiration (greater oxygen demands) and reduced flight ability [69].

\section{(2) Terrestrial locomotion}

Terrestrial locomotion can be roughly subdivided into four different types: (i) walking or crawling, i.e. forward motion in the same plane as the ground surface while being continuously supported by a part of the body; (ii) running, trotting, galloping or hopping, i.e. natural extension of walking that is characterized by higher velocities and recurrent aerial phases during which the entire body (including all limbs or appendages) is lifted off the ground; (iii) burrowing, digging or 'sand-swimming', i.e. underground (fossorial) locomotion and (iv) climbing, i.e. mountainous or arboreal locomotion, typically with traverses over narrow ridges or branches and with a high proportion of vertical movement.

The effect of pregnancy on terrestrial locomotion has only been measured in walking, crawling and running animals, with a strong focus on lizards and snakes (Table 2-1). An increase in female body mass during pregnancy is reported in all of these studies, ranging from approximately $25 \%$ in humans [70] and the scincid lizard Niveoscincus ocellatus Gray (1845) [71] to $82 \%$ in the semi-aquatic colubrid snake Seminatrix pygaea [48]. An increase in mass should reduce acceleration of the body, leading to lower expected sprint performance (see Section II.1). Such declines have been reported in a number of studies (Table 2-1); e.g. the increase in body mass of $27 \%$ and $82 \%$ in N. ocellatus and S. pygaea, respectively, correspond with declines in sprint performance of $20 \%$ and $73 \%$ [48,71]. Nevertheless, the link between clutch mass and locomotor performance is not always found (Table 2-1), highlighting the need for continued investigations into the causal basis for locomotor impairment during gestation.

The internal development and growth of embryos causes an increase in body volume during pregnancy, particularly in the abdominal region [35]. In vertebrates, this could reduce the flexibility of the vertebral column and lower manoeuvrability, and/or decrease the maximally possible leg amplitude. Moreover, changes in abdominal shape may cause a shift in the position of the centre of mass causing instability [72]. In humans, women opt for a more stable gait to compensate for this loss of stability, at the cost of speed $[73,74]$. 
Chapter 2 I Locomotor costs of live-bearing and adaptations to reduce them

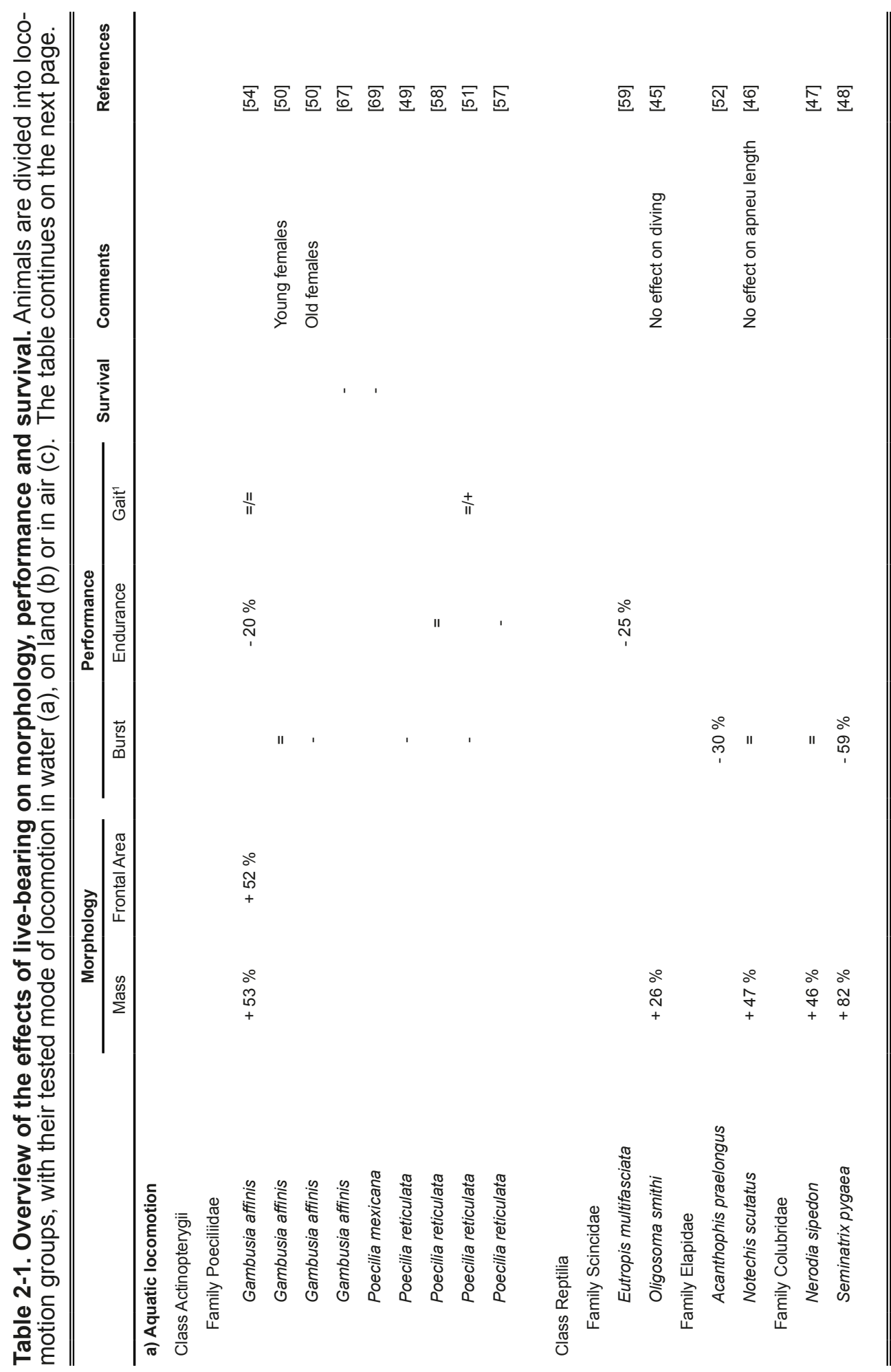




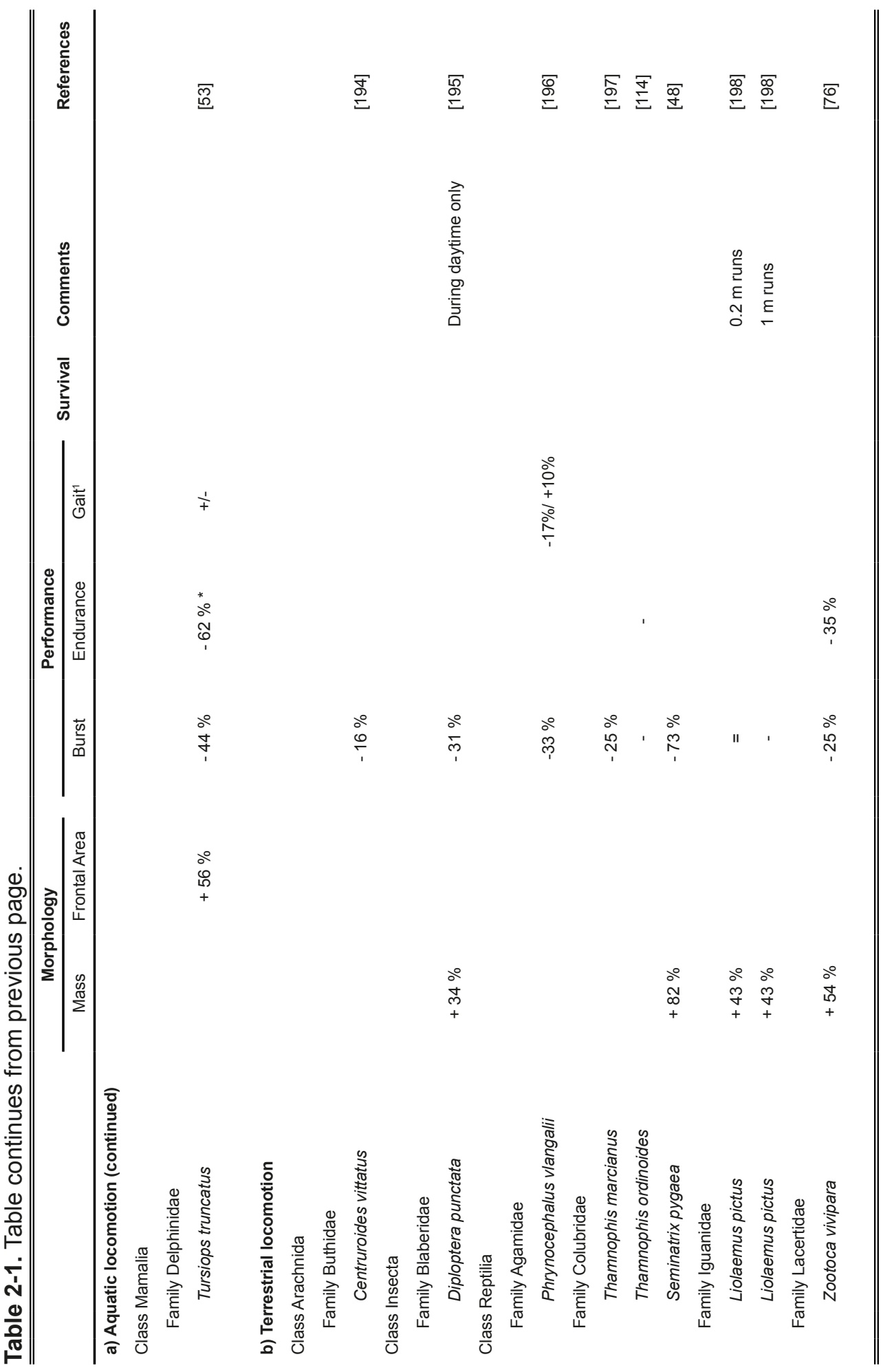


Chapter 2 I Locomotor costs of live-bearing and adaptations to reduce them

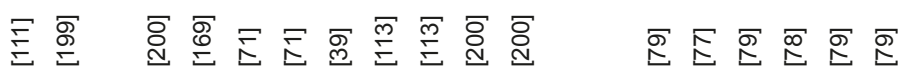

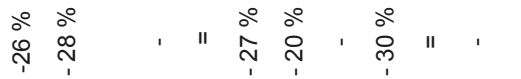

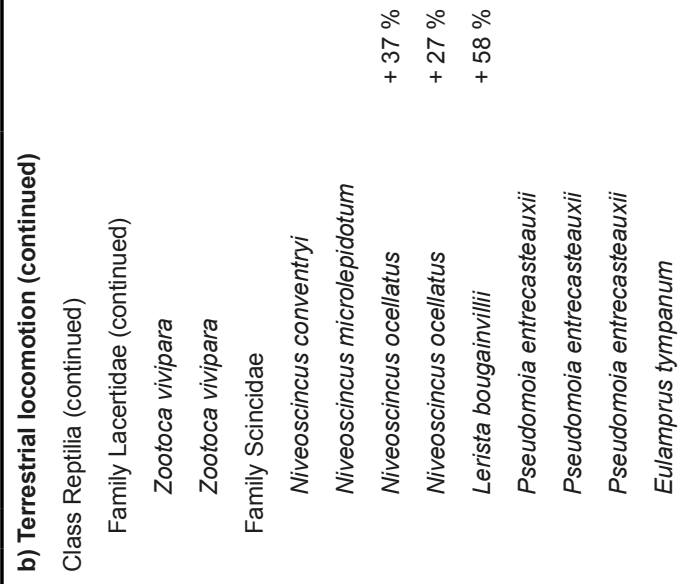

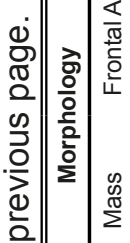

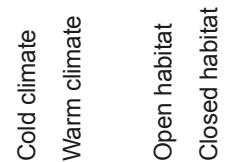
I
离

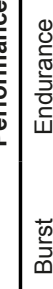

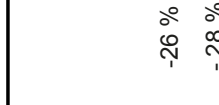

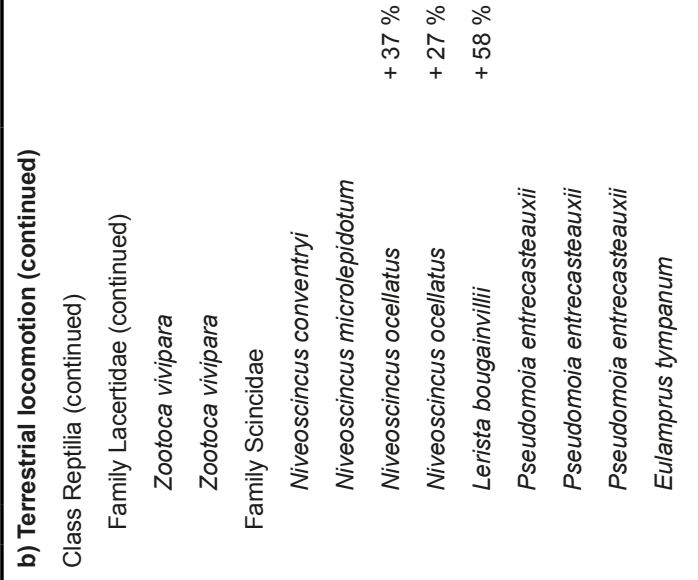

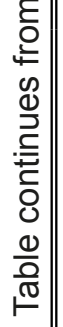

돈

W

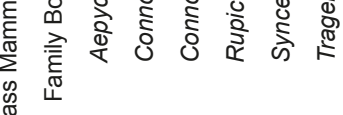




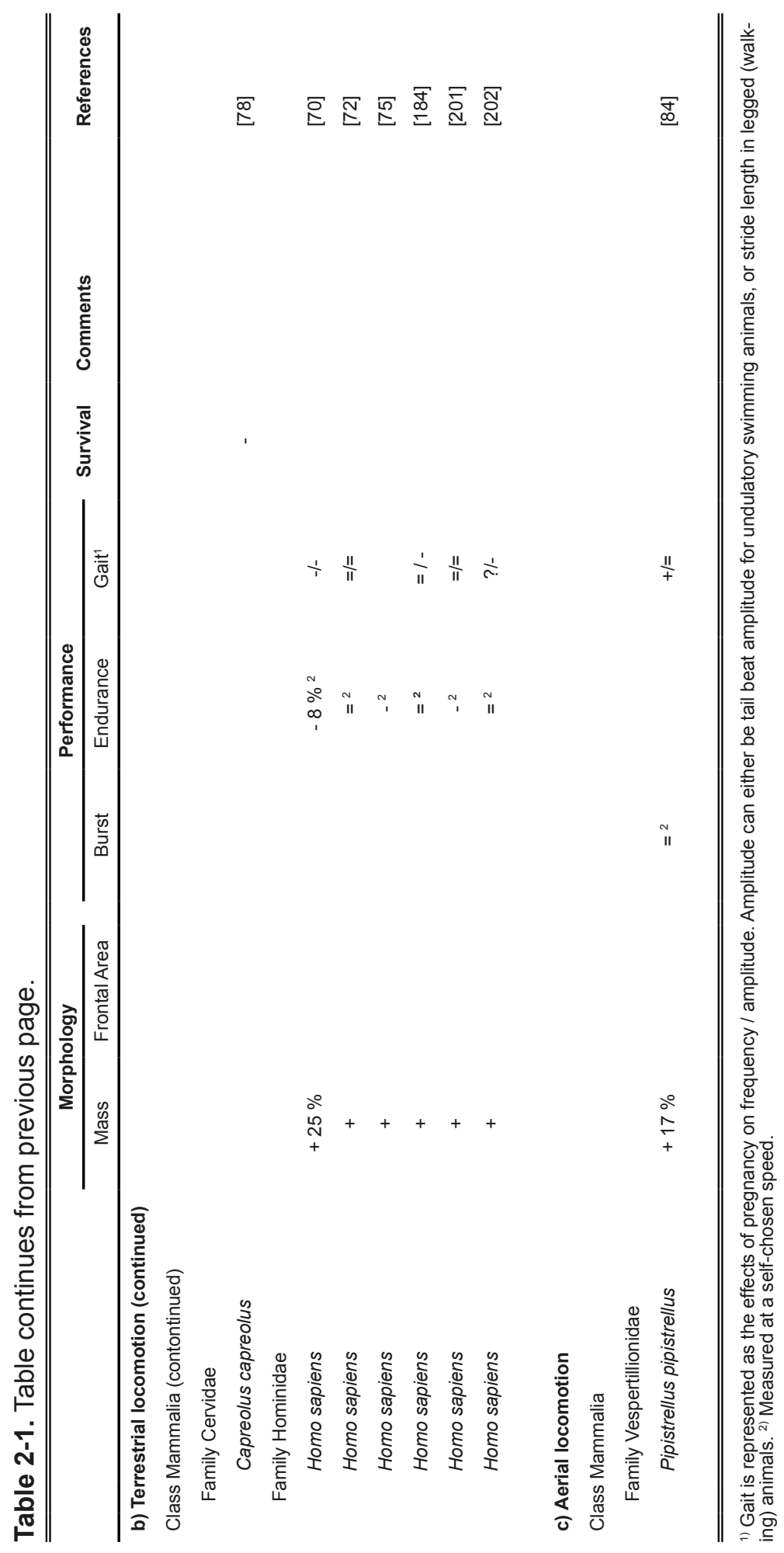

2 
Chapter 2 I Locomotor costs of live-bearing and adaptations to reduce them

Sustained locomotor performance is also often found to decline during pregnancy (Table 2-1), though it is difficult to attribute the declines in endurance to a single causal factor (increased body mass, shape change and associated shifts in the centre of mass, decreased amount of energy and oxygen; [75,76]).

Pregnant terrestrial animals are known to suffer an increased vulnerability to predation and reduced survival $[77,78]$. Female roe deer (Capreolus capreolus Linnaeus, 1758) and chamois (Rupicapra rupicapra Linnaeus, 1758), for example, have a higher chance of being killed by Eurasian lynx during their gestational period [78], while in South Africa's Kruger National Park females of several ungulate species are more likely to be killed by lions during late gestation [79]. In the viviparous fossorial lizard Concinnia brachyosoma Lönnberg \& Andersson (1915), which relies heavily on crevices and other narrow hiding spaces, the increased girth of pregnancy severely limits the number of available retreats. This adversely affects survival probability, because the remaining crevices are more easily accessible to predators [80].

\section{(3) Aerial locomotion}

Aerial locomotion can be subdivided in two different types: (i) gliding or soaring, i.e. unpowered locomotion, and (ii) powered flight. There are species of livebearers exhibiting both types of locomotion.

Flight is a rare trait in viviparous animals - or vice versa, viviparity is a rare reproductive mode in flying animals. It has been argued that the low incidence of viviparity in aerial animals is associated with the increased wing loading during gestation, which makes flight exceedingly difficult [81]. Because wing area generally does not change during gestation, wing load (mass divided by the area of the wing) increases proportionally with the increase in mass during pregnancy [82]. Consequently, the minimum power needed to get and stay airborne increases, making flight a very costly mode of transport during pregnancy. Furthermore, an increase in body mass decreases manoeuvrability and results in an increase in minimum required flight speed and cost of transportation [83]: i.e. not only is it more difficult for heavier animals to fly, they also have to fly faster in order to optimize flight efficiency. Despite these apparent difficulties, aerial locomotion did evolve in a number of viviparous animal lineages (e.g. bats, flying squirrels, insects) but unfortunately direct experimental research on the effect of pregnancy in flying or gliding performance is extremely scarce (Table 2-1). 
In theory, flying animals can (partly) compensate for the effects of pregnancy by increasing wing beat amplitude and/or frequency to supply more power, increasing metabolic costs. Pregnant bats are found to increase wing beat frequency, but not amplitude, to provide the additionally required power [84].

Finally, increases in abdominal volume or changes in body shape are likely to occur during pregnancy in flying animals, but have not yet been studied in relation to performance. The morphological alterations that occur during pregnancy would probably result in a 'less aerodynamic' shape, an increase in drag and, without compensatory kinematics, a lower locomotor performance.

\section{Adaptations to viviparity}

The locomotor costs of pregnancy, and their effects on fitness, may be compensated for by a diverse array of adaptations. These can be categorized into three broad categories (Table 2-2, see also Figure 2-1): 1) adaptations that reduce the reproductive burden during pregnancy (Section III.1), 2) behavioural or physiological modifications that circumvent performance-demanding situations (Section III.2), and 3) the co-evolution of other components of the life-history (Section III.3).

\section{(1) Adaptations to reduce the locomotor costs during gestation}

One way to reduce locomotor costs during gestation is to reduce reproductive allocation. Three different adaptations can be discriminated within this category: 1) reduction or repositioning of reproductive organs, 2) matrotrophy, and 3) superfetation.

\section{a. Reduction or repositioning of reproductive organs}

Reproductive organs of Squamate reptiles are often paired, but many species display a distinct asymmetry with the right ovary and oviduct extending anteriorly from the left [85]. In extreme cases, the left oviduct is reduced completely. This reduction has occurred independently at least 10 times [85,86], in a group of (predominantly viviparous) scincid lizards, occupying a wide range of habitats, and in fossorial squamate reptiles that have burrowing or digging lifestyles.

Asymmetry or loss of one of the reproductive organs reduces extension of the abdomen (girth) in the lateral direction. This reduces the frictional surface that comes into contact with the surrounding substrate, allowing for (easier) access to previously dug burrows and underground passageways 
Chapter 2 I Locomotor costs of live-bearing and adaptations to reduce them

[86]. Furthermore, it allows positioning of the ova or developing embryos closer to the body axis, which helps minimize the adverse effects on leg motion and flexibility. Changes to the reproductive organ could be regarded as a partial exaptation to viviparity, as some of these changes also seem to be present in oviparous ancestors [85].

Ovarian asymmetry further arose during the evolutionary transition from a terrestrial to an arboreal life style in pythonid and boid snakes [87]. The reduced body distention during pregnancy (but also during vitellogenesis or retention of eggs) allowed these snakes to maintain a more laterally compressed body shape during pregnancy, which is beneficial for their climbing performance and/or camouflage $[87,88]$.

The transition from terrestrial to aquatic habitats in (viviparous) snakes is also associated with an anterior-directed repositioning of the reproductive organs, together with a reduction in clutch mass [89]. In aquatic snakes, the posterior part of the body is most important for propulsion through water. This form of locomotion is most efficient with a laterally compressed body shape, which would be impaired by a posterior-placed clutch.

Finally, repositioning of reproductive organs often leads to a reduction in fecundity. However this is not always the case, as shown in a variety of lizard taxa, where it could also come at the cost of reduced space for other abdominal organs [90]. This could place an additional trade-off on the animal, because such a reduction in abdominal space could for instance lead to inability to eat adequate amounts of food or to a reduced maximal rate of respiration.

\section{b. Matrotrophy}

The ancestral mode of nutrient provisioning in live-bearing lineages is lecithotrophy, in which yolk-reserves are the sole nutrient source for the embryos. These nutrients are supplied to the ova pre-fertilization, i.e. the eggs are packaged with yolk (vitellogenesis) before they are fertilized. Alternatively, resources can also be supplied by the mother after fertilization, a derived mode of nutrient provisioning called matrotrophy [36,91]. Matrotrophy has evolved at least 140 times in invertebrates [4] and 36 times in vertebrates $[3,92,93]$. Matrotrophy is thought to reduce the mother's reproductive burden during the early stages of pregnancy, because the eggs are initially very small (they carry only minimal amounts of yolk). Instead, nutrients are transferred to the mother post-fertilization, i.e. during the pregnancy $[3,94,95]$ 
Matrotrophy can potentially enhance a female's locomotor performance during pregnancy by reducing the average burden during the full term of pregnancy since offspring are smaller and lighter early in development. However, matrotrophy requires a continuously supply of nutrients to the embryo during development, increasing the need of the mother to feed, possibly exposing herself to predation. Furthermore, investments are required for the generation of placental structures, and for modifications to physiological, endocrine and immunological systems that allow closer contact between maternal and embryonic tissues [96,97].

\section{c. Superfetation}

Embryos increase in (wet) mass and volume during development due to the uptake of water and/or nutrients, causing late-stage embryos to be significantly larger than recently fertilized ova. In the lecithotrophic Trinidadian guppy Poecilia reticulata Peters (1859) for instance, embryos experience a threefold increase in wet mass due to the uptake of water [49]. The size difference between early- and late-stage embryos could be averaged out by carrying multiple (smaller) overlapping broods of different developmental stages. This interesting reproductive phenomenon, called superfetation, has evolved in a number of viviparous fish lineages (e.g. Poeciliidae, Clinidae and Zenarchopteridae; [36,91,94,95,98-101]) and in a few mammals [102].

Superfetation results in an increased frequency of litter production and a reduction of maternal wet mass fluctuation during the pregnancy, while maintaining equal levels of fecundity [94,100]. The level of superfetation varies between species; some carry only two litters at a time, while others can carry up to eight simultaneously developing broods [62]. Notably, the predicted effect of superfetation on mass, volume and performance should be larger in animals with matrotrophic nutrient provisioning, because the difference in wet mass between early- and late-stage embryos are larger [94].

Direct experimental studies on the effect of superfetation on locomotor performance are still lacking. Field studies have revealed intra-specific variation in the level of superfetation in Poeciliid species [103-105]; this might (in part) reflect an adaptation to performance-demanding environments (i.e. higher flow velocities demand more 'streamlined' bodies, and thus higher levels of superfetation), but could also be related to other environmental pressures [106-109]. 
Chapter 2 I Locomotor costs of live-bearing and adaptations to reduce them

(2) Adaptations to avoid high-performance demanding situations

A second way to cope with the locomotor costs of pregnancy is by avoiding situations in which maximum performance is demanded. Contrary to the previously mentioned adaptations, these reduce the dependency on (maximum) locomotor performance instead of their decline. We identified five adaptations that could circumvent the need for maximum locomotor performance in viviparous animals: 1) crypsis, 2) aggressive behaviour, 3) habitat shift, 4) diet shift, and 5) reduced activity and torpor.

\section{a. Crypsis}

During a predator encounter, prey species can elicit three types of responses: flight, fight or freeze [reviewed in 110]. If flight ability is impaired due to pregnancy, fight or freeze may be better options. Animals can try to avoid detection by a predator by staying motionless (freezing) and by relying on camouflage, a strategy called crypsis. In several species of squamate reptiles, for example, a reduced flight performance is behaviourally compensated for by such a shift [111-114].

The positive effect of crypsis on survival rate during pregnancy is confirmed in field studies. Increased levels of crypsis, staying motionless in hiding for longer, make pregnant Zootoca vivipara Lichtenstein (1823) lizards less conspicuous to human observers, resulting in reduced capture rates [111]. Furthermore, despite a reduced maximum locomotor performance, pregnant Eulamprus tympanum Lönnberg and Andersson (1915) skinks have similar survival rates as non-pregnant females or males when exposed to natural predators, due to a change to increased cryptic behaviour [112]. A potential disadvantage of cryptic behaviour is that it could conflict with other (necessary) activities, e.g. feeding or basking.

\section{b. Aggression}

Some animals switch to a "fight" response, rather than switching to a "freeze" response, during pregnancy. An increase in aggressive behaviour during pregnancy is seen in ground squirrels. The animals establish maternal territories during gestation, which females vigorously defend by showing intensified aggressive behaviour towards predators and conspecifics during pregnancy and lactation periods [115]. 


\section{c. Habitat shift}

Rather than changing behaviour when detecting a predator, females can display adaptive anti-predator behaviour $[116,117]$ and try to avoid predators during periods in which reduced flight capability increases vulnerability. Pregnant bighorn sheep (Ovis canadensis Shaw, 1804) migrate from low-elevation feeding grounds to less-accessible higher elevations [116]. A comparable habitat shift occurs in Trinidadian guppies ( $P$. reticulata): pregnant females from 'high-predation' populations were restricted to shallow pools and slow-flowing margins that were inaccessible to piscivorous predators [51]. In another species of live-bearing fish (Gambusia affinis), however, no evidence has been found for a habitat shift (i.e. increased use of refuges) during pregnancy [67]. Females may face a feeding/predation-risk trade-off when undertaking these habitat shifts, because areas with low predation pressure sometimes correlate with low food quality or abundance $[67,116,117]$.

\section{d. Diet shift}

A reduced locomotor performance might also make it harder, or even impossible, to acquire certain resources. Consequently, in some animals a shift to more easily obtainable food sources is observed during pregnancy. Pregnant wolverines (Gulo gulo Linnaeus, 1758) for instance, switch from preying on moose to easier to catch prey in Canada [118], and from consumption of self-captured prey to carrion in Finland [119].

Similar examples can be found in aquatic and flying animals. Dolphins switch from a diet of fast-swimming pelagic fish to a diet of squid and slower benthic fish [120,121]. In bats, the increase in body mass during pregnancy decreases flight manoeuvrability, reducing their ability to capture highly manoeuvrable nutrient-rich prey insects [83]. As a consequence, a more opportunistic foraging strategy is often observed, in which pregnant bats instead feed on the most abundant and readily available prey [122].

\section{e. Reduced activity and torpor}

Pregnancy is an energetically demanding period and conservation of energy can be important. One way to achieve this is by reducing locomotor activity, a strategy observed throughout many major lineages of viviparous animals and all locomotor modes, including insects [123-128], snakes [129,130], bats [131,132] and primates [133-135]. A reduction in activity is also reflected in smaller home ranges, e.g. in sex-role-reversed seahorses [136] and in wolverines (G. gulo) [119]. In contrast, total active (foraging) time was found to 
Chapter 2 I Locomotor costs of live-bearing and adaptations to reduce them

be increased in pregnant bats (Myotis daubentoni Kuhl, 1817) compared to males, probably to accommodate the increased metabolic demand of pregnancy [137].

In situations where resources are scarce, or when environmental conditions are demanding, the increased locomotor cost of pregnancy could result in a net energy loss during food collection. To circumvent this, some mammals can delay parturition until more favourable conditions occur by lowering physiological activity, metabolic rate and body temperature: a state called torpor $[138,139]$. A strategy of deep torpor during pregnancy has been observed in a number of marsupial and bat species [138,140-142], implying an adaptive advantage of this physiological state. However, less frequent and/ or shorter periods of torpor during pregnancy have been observed in related species, indicating that a reduced or delayed foetal development may also pose a risk to reproductive success [143-148].

\section{(3) Life history adaptations}

A third type of adaptations consists of changes in life history strategy (Table 2-2, Figure 2-1). These strategies could also have a secondary effect in a change in morphology (reducing fecundity), or in a change in behaviour (delayed breeding).

\section{a. Reduced clutch mass}

An intuitive way to reduce the morphological changes during pregnancy is by directly lowering the mass and volume of the brood. This can be achieved by reducing the number of offspring in a brood and/or the mass of individual offspring. This could be a relevant adaptation for all locomotor modes, but especially for flying animals as they suffer the largest increase in locomotor costs due to added mass.

Indeed, compared to terrestrial ( $25-82 \%)$ and aquatic (26- $82 \%)$ animals, flying animals seem to experience the least body mass increase during pregnancy, ranging from only $13 \%$ in Myotis daubentoni [137] and 17\% in Pipistrellus pipistrellus Schreber (1774) [84] to $30 \%$ in Myotis yumanenesis Allen (1864) [83]. Gliding squirrels, however, are found to have a relatively large relative clutch mass compared to non-gliding (terrestrial) relatives [82]. Interestingly, females with higher non-reproductive wing loading were found to have a higher litter mass [149], indicating offspring weight might also be influenced by other ecological factors. 


\section{b. Delayed breeding}

Under temporally varying predation intensity, females are hypothesized to adjust their reproductive behaviour to optimize reproductive fitness. Under short periods of high predation risk, the trade-off between female survival and reproduction might favour delayed breeding (predator-induced breeding suppression), given that the breeding season is long enough to accommodate the delay [150]. Field experiments on house mice indeed show that females exposed to predators delay breeding [151]. When small mustelid predator occurrence was reduced for two species of vole, the proportion of pregnant females in the population increased; but whether this reflects a true adaptive strategy, or that the predators had a preference for preying upon pregnant females, is not known [152].

$$
\text { c. "Live fast-die young"-life history }
$$

In the face of an unyielding risk of predation and associated high mortality rates, species are predicted to evolve a set of life history traits that are characterized by early maturity and reproduction and increased reproductive investment [153]. As pregnancy reduces locomotor performance and maternal survival more than oviparous reproduction, viviparous animals could have evolved a "live fast - die young"-life history faster or to a more extreme extent.

"Live fast - die young"-life histories are extensively characterized in comparative studies of interspecific life history patterns in diverse organisms $[154,155]$ and particularly well described in a few focal species. For example, natural populations of Trinidadian guppies (Poecilia reticulata) from the Northern Range Mountains of Trinidad co-occur with a diversity of fish predators in downstream localities, but progressively fewer predators upstream because natural barriers exclude predators but not guppies [156,157]. Mark-recapture studies have shown that guppy populations that co-occur with predators have higher mortality rates than those found further upstream without predators [158]. Female guppies from 'high-predation' populations mature earlier and begin to reproduce when they are younger, devote more resources to each litter of babies and produce litters more often [158-161].

Devoting more resources to each litter, and hence increasing the reproductive burden during gestation, may seem a counter-productive strategy since it will further increase the locomotor costs during pregnancy. However, 'high-predation' guppies partly compensate for this by evolving faster escape responses and higher accelerations, albeit the exact mechanism how they attain this performance increase is unknown [49]. Their better perfor- 
Chapter 2 I Locomotor costs of live-bearing and adaptations to reduce them

mance is sufficient to significantly increase their odds of survival in encounters with predators during early pregnancy [66]. These studies thus show that the evolution of increased locomotor performance (through unknown processes) can partly compensate the higher cost associated with the evolution of increased reproductive investment.

Direct comparisons of life history strategies between oviparous and viviparous species or populations are rare, but these reproductive modes are generally characterized by distinct life history patterns. Oviparous squamate lizards mature early and produce frequent clutches, while viviparous lizards mature late and produce larger clutches [20]. In snakes, three main reproductive modes were characterized: single-brood oviparous species, and annual and biennial-breeding viviparous species [162], albeit these life history characteristics are also strongly correlated with body size and phylogenetic relationship [163-165]. The tendency for viviparity to be associated with larger clutches is surprising as it significantly increases locomotor costs. Furthermore, comparison of demography and survival rate of oviparous and viviparous populations in the bimodal lizard species Zootoca vivipara did not reveal any clear-cut differences related to reproductive mode other than a lower number of annual clutches in the viviparous populations [166]. More comparative work on the link between reproductive mode and life history is necessary to show if, and how, species (further) adapt their life history to the evolution of viviparity.

\section{Discussion}

\section{(1) Trends in locomotor decline during pregnancy}

Our literature review shows that the locomotor performance of females tends to decline during pregnancy (Table 2-1). This trend occurs is all three modes of locomotion (aquatic, terrestrial or aerial locomotion). However, it remains difficult to infer reliable relationships between morphology, performance and fitness for the three different locomotor modes separately, for a number of reasons:

\section{a. Taxonomic bias}

There is a strong taxonomic bias in the literature. First, most studies are done on terrestrial animals. Within this group there is a very strong focus on squamate reptiles. Within the aquatic animals there is an overrepresentation of fishes. In both of these groups, it is remarkable that there are hardly any 


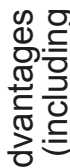

용

둥

क ำ

$\Phi_{0}$

ฐ্ণ

든

ชั

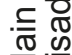

$\sum \frac{\infty}{0}$

অ

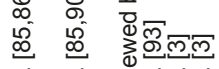

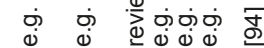

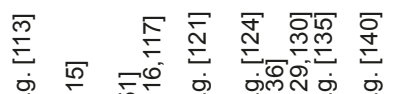

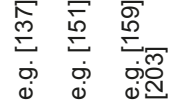

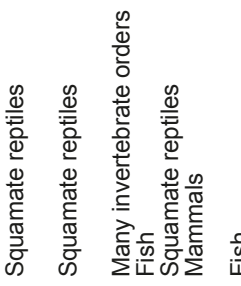

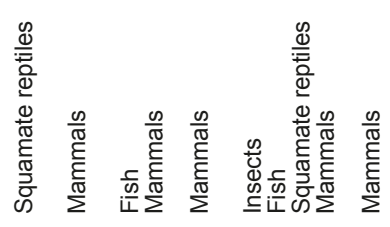

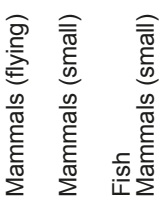

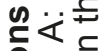
훙

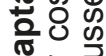
卷 흥

t。

उ잉

응

궝웡

ठ뮹

งั่ับข

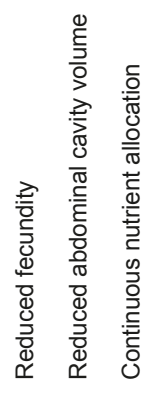

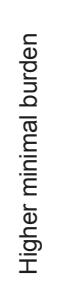

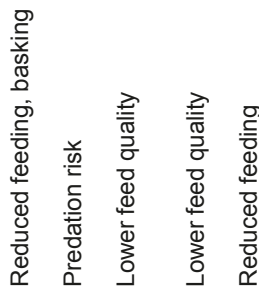

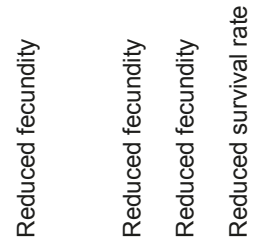

๖ํํํำ

는.

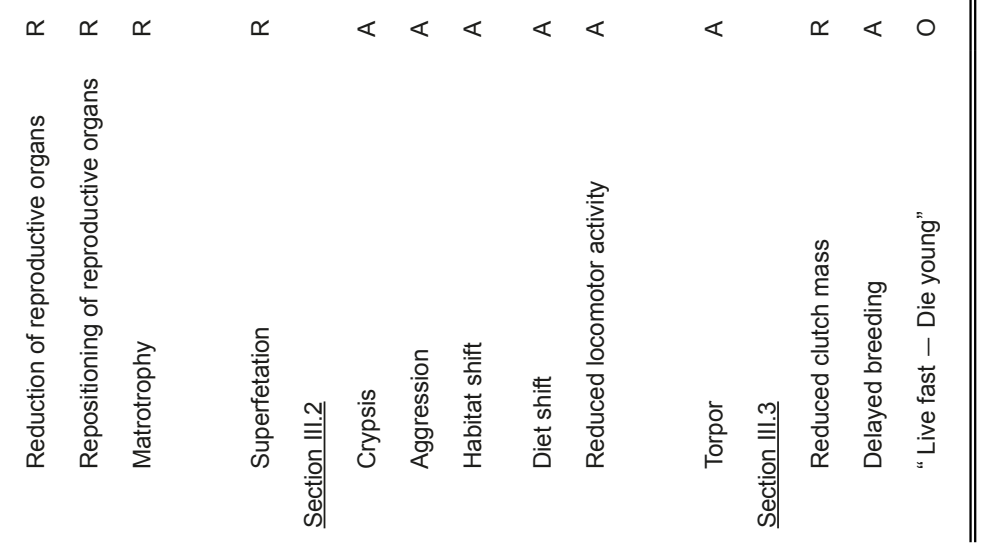


Chapter 2 I Locomotor costs of live-bearing and adaptations to reduce them

comparative performance studies on pregnant vs. non-pregnant mammals, perhaps due to the lack of an oviparous close relative. Only a few quantitative performance studies exist for flying animals, limited to bats.

Secondly, invertebrates are severely underrepresented, despite having the largest number of viviparous lineages [4], being found in all environments and displaying all locomotor modes (flying, swimming, running). This group thus offers interesting opportunities to study the effects of live-bearing on locomotion as all locomotor modes are present, in addition to a broad range of different ecologies and life histories.

\section{b. Methodological differences}

It is difficult to compare the effect of pregnancy on locomotor performance between independent studies (Table 2-1) because of differences among studies in the performance parameters quantified and in how they are quantified. In fish, anaerobic (burst) performance is often measured as velocity or acceleration during the fast start escape response, a stereotypical behaviour used to escape predators $[167,168]$, while critical swimming speed is used as a measure of aerobic performance. The studies on swimming reptiles and mammals used different measures of performance, more alike those used for terrestrial animals. Here, animals are often chased through a race track and the fastest (sub)section is taken as a measure of anaerobic (sprint) performance. A similar design was used to test flight speed in bats [84]. Longer race tracks are used for endurance measurements, while other studies use 'self-chosen locomotor speed': two parameters that represent ecologically relevant but incomparable aspects of aerobic locomotion.

\section{c. The use of control groups}

Some studies performed repeated measurements, while others did not. If repeated measures are employed, then there must also be a control group to enable the investigator to correct for habituation. This also means multiple stimuli, sometimes in fairly short succession, which could elicit habituation to the stimulus and thus a measured decline in performance unrelated to pregnancy. Comparing the performance decline between studies of repeated measured is difficult, however, as the used control groups often differ. Virgin females (preferably siblings of the pregnant females) would be the best possible control to monitor the effects of pregnancy as they most closely resemble the pregnant animals in genetics, age, size, morphology and physiology. Furthermore, they are expected to be morphologically and physiologically stable over time. 


\section{d. Timing of measurements}

Studies differ in the timing of measurements. Most studies try to capture the moment of the biggest expected effect, i.e. close to parturition, using repeated measures of the same individual over time. Possible performance effects at the beginning of pregnancy, often assumed to be small(er), could then be overlooked. However, a number of studies on fish [e.g. 49,51,58], only take one measurement per female and extrapolate the effects of pregnancy from staging the developing embryos and calculating the relative reproductive mass. Such an approach requires larger sample sizes than a repeated measures-approach. Although there is inherently nothing wrong with this study design, it is difficult to compare studies employing this method, because there is no species-specific baseline offered by non-pregnant controls. The magnitude of measured performance might be due to unstandardized differences between the compared species or populations. Postpartum females are not a desirable control, due to possible long-term physiological effects of pregnancy [169].

\section{e. Presence or absence of adaptations}

Despite the fact that all species listed in Table 2-1 are live-bearing, they generally do not share the same adaptations to viviparity and/or authors did not evaluate the same spectrum of adaptations. While some studies documented animal behaviour during performance trials, most do not mention possible anatomical or behavioural changes. This severely complicates a comparison between studies and quantification of the 'raw' locomotor costs of pregnancy per locomotor mode.

\section{(2) Recommendations for future research}

To improve comparison between studies, we propose a number of recommendations to arrive at a more standardized approach to study the effect of pregnancy on locomotor performance in future studies (Figure 2-2).

\section{a. Standardized study design}

To measure the effects of viviparity or specific adaptations on locomotor performance, a comparative approach between species that differ in their reproductive mode is preferred (Figure 2-2). The compared species should differ in the trait of interest but should otherwise be as similar to the target species as possible, plus share a recent common ancestor with the target species. Closely shared ancestry will minimize the risk of interspecific differences being the product of variation other than the reproductive mode or adaptation 
of interest. It follows that a well-resolved phylogeny is essential if one is to minimize confounding in paired comparisons among taxa. Furthermore, it becomes possible to formally incorporate phylogeny into analyses if studies include multiple species from within a clade $[170,171]$. One must also include performance measures on control animals in all species to account for between-species differences in performance unrelated to pregnancy [172]. Measures on kinematics can help standardizing the results for differences in motivation [173].

Level 1: between-species or between-populations comparison

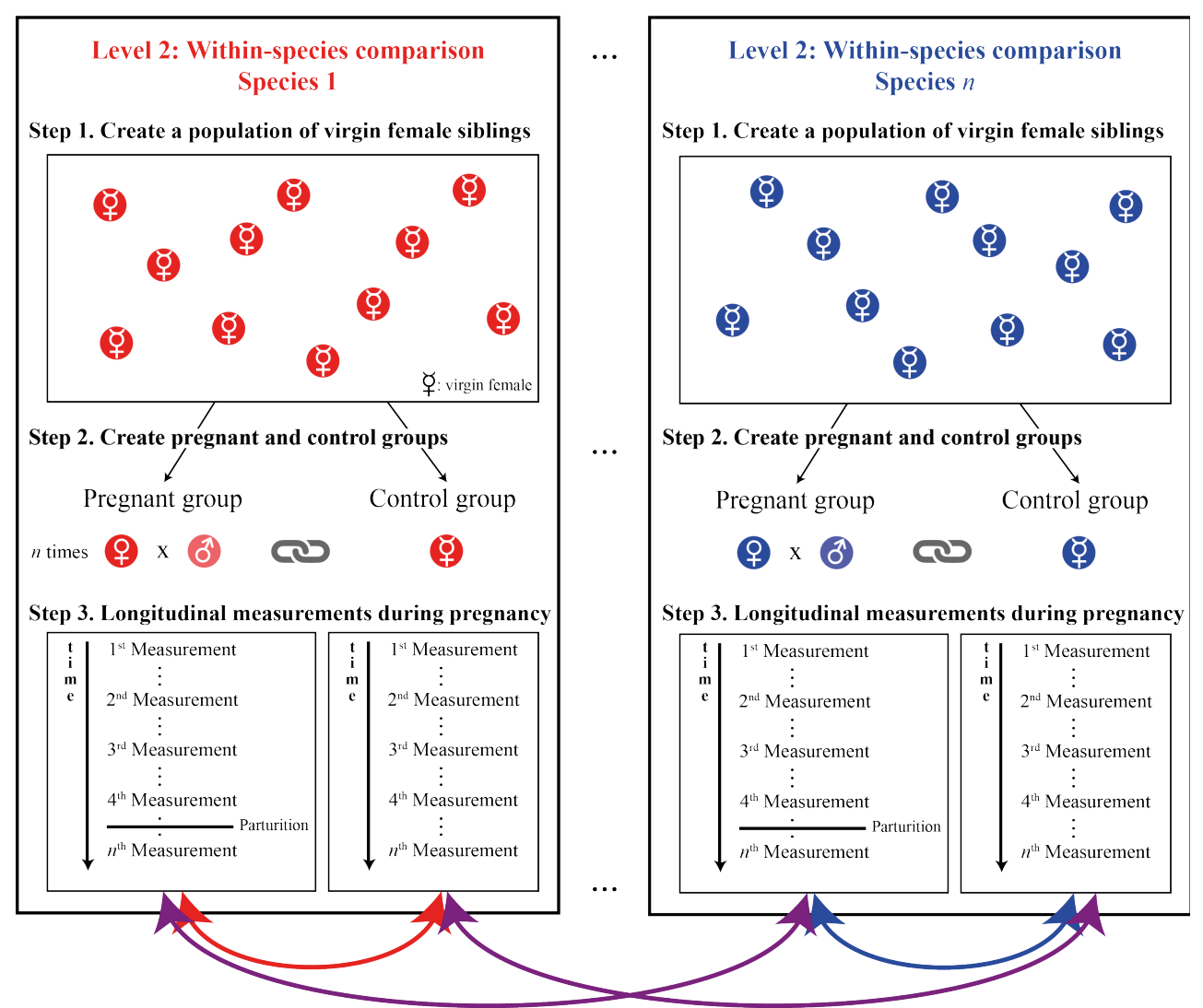

Figure 2-2. Suggested multi-level experimental approach for between-species comparison of performance. A population of virgin animals, preferably siblings, are split into a virgin control group and a pregnant group. When pregnancy progresses, multiple performance measurements are taken from pairs of control and pregnant animals, until after parturition. Every pregnant female is paired (linked) with a control female, as to have equal numbers of equally-spaced measurements under equal environmental conditions. The effects of pregnancy within one species can be determined from the pregnant versus control comparison, while differences between species can be determined from the pregnant versus pregnant comparison. An interspecies comparison of control versus control allows one to standardize for adaptations. 


\section{b. Providing biomechanical explanations}

To understand how viviparity affects locomotor performance, and how adaptations can reduce these effects, reporting differences in performance is not enough. We must also study the affected morphological and kinematic parameters if we are to understand the mechanisms that determine the costs of viviparity and hence improve our understanding on why this reproductive mode evolved. Current literature largely lacks this biomechanical substantiation of the measured performance declines: most studies link a performance decline with increase in female or clutch mass, or with developmental stage of embryos, but do not consider other parameters. Depending on the mode of locomotion, surface area, volume and changes in shape and tissue density all could play a role in determining locomotor performance, while effects of pregnancy on kinematics could limit the range of motions an animal is able to exhibit.

Over the past decades, novel techniques have been developed that not only make it possible to execute large-scale performance and biomechanics research, but also simplify the acquisition of large datasets. Morphological changes can be recorded using minimally invasive modelling approaches [174]. Automated tracking software significantly shortens analysis times for high-speed video recordings, allowing 3D characterization of both performance and kinematics [175-178]. Lastly, position trackers have become increasingly less invasive and more accurate [179-181] and could provide additional insights in behavioural adaptations to viviparity, for instance activity and motion patterns [181,182].

\section{c. Stability and manoeuvrability}

The effect of pregnancy on two other performance parameters has been left virtually untouched. Stability and manoeuvrability are linked parameters: stability is important in keeping position, orientation and torque control, while manoeuvrability represents a form of controlled instability in a dynamic context [183].

Stability is considered in a number of studies on the effect of pregnancy on locomotion in humans: the walking gait of pregnant women shifts towards a more stable pattern to reduce the chance of falling [70,184]. But pregnancy is expected to change stability in other animals as well: in aquatic organisms for instance, differences in the position of the centre of mass and centre of buoyancy could result in rolling or pitching torques when the centre of buoyancy and centre of mass are not aligned [185]. As the reproductive mass is often located in the ventral region and due to differences in density 
Chapter 2 I Locomotor costs of live-bearing and adaptations to reduce them

between maternal and embryonic tissue, it is likely that pregnancy affects stability if animals do not compensate for these changes regardless of mode of locomotion.

Manoeuvrability is important in both prey capture and predator escape $[66,186,187]$, but also to correct for sudden disturbances in air or water flow and to quickly navigate through an obstacle-ridden terrain. Manoeuvrability can be tested by measuring the ability of an animal to turn during free movement [e.g. 188], by measuring the ability to make obligatory turns while running [e.g. 186], or by measuring performance in an obstacle course [e.g. 189]. Manoeuvrability could be reduced during pregnancy due to changes in flexural stiffness (it could locally cost more force to move the extra abdominal mass), or, in undulating aquatic animals like fish, by an increase in the inertial resistance to yawing motions when the centre of mass is shifted to a more anterior position [190].

\section{(3) The broader picture}

With this review, we tried to answer a small part of a large evolutionary question: how does the evolution of viviparity affect locomotor performance, and how have species adapted to these costs. Understanding the evolution of viviparity requires knowledge on all possible advantages and disadvantages of this reproductive mode and of the ancestral state of oviparity. These (dis)advantages, as well as the listed adaptations to live-bearing (Section III), span a wide range of scientific fields including, but not limited to, physiology, morphology, biomechanics, ecology and evolutionary biology: interdisciplinary cooperative work is needed to tackle such broad problems [191-193]. Our understanding of how and why viviparity, along with adaptations to this reproductive mode, has evolved will be facilitated by the use of a standardized comparative approach, embedded in biomechanical theory, for the quantification of the locomotor costs of pregnancy for each locomotor mode.

\section{Conclusions}

1) For viviparity to evolve, its advantages for mother and future offspring should outweigh its disadvantages. One of the most important disadvantages of viviparity, the prolonged locomotor performance decline, is often assumed but rarely quantified. 
2) The locomotor performance decline likely varies between locomotor modes, as the biomechanics of locomotion for aquatic, terrestrial and aerial modes of locomotion are affected differently. The existing literature does not reveal a clear relationship between locomotor mode and performance, largely due to lack of comparable data.

3) Animals have evolved a diverse array of adaptations to reduce or avoid the locomotor costs of pregnancy. Mechanisms of cost reduction include morphological or physiological changes, e.g. changes to the reproductive organs, or adaptations to the reproductive biology like matrotrophy or superfetation. Mechanisms of cost avoidance also include diverse behavioural adaptations, such as shifts in habitat or diet, or a change in escape behaviour from flight to crypsis. A live-bearing mode of reproduction might lead to further life history changes, for instance the earlier adoption of a 'life fast - die young"-strategy. This large range of adaptations severely reduces our ability to compare the locomotor costs of pregnancy between studies/species.

4) Currently, quantifying the existing literature on the locomotor performance decline during pregnancy is difficult due to taxonomic bias, differences in timing of measurements and methodology, the use of different (or no) control groups, and differences in the presence of adaptations and poor documentation of these traits.

5) We propose a standardized repeated-measures design using virgin females as a control for habituation and species-specific differences in performance, with a strong emphasis on the biomechanics of locomotion to explain any measured differences between pregnant and virgin females and between species. Such an approach eases future comparison between studies, but also provides scientific arguments for hypotheses regarding other species and suspected adaptations to viviparity.

6) To answer the question why viviparity evolved (so often), an interdisciplinary approach is necessary. That approach must contain a balanced assessment of the costs and benefits of livebearing. Large-scale comparative studies are necessary to characterize the correlated costs (e.g. reduced fecundity, locomotor costs and increased adult mortality) and benefits (e.g. increased juvenile survivorship). 
Chapter 2 I Locomotor costs of live-bearing and adaptations to reduce them

\section{Author contributions}

M.F. and B.J.A.P. came up with the idea for this literature review. M.F. gathered literature and wrote the first draft of the manuscript, with input on specific parts from D.N.R., J.L.V.L. and B.J.A.P. Following comments from D.N.R., J.L.V.L. an B.J.A.P., M.F. wrote the final draft. 


\section{References}

1. Blackburn DG. Standardized Criteria for the Recognition of Reproductive Modes in Squamate Reptiles. Herpetologica. 1993;49: 118-132.

2. Blackburn DG. Classification of the Reproductive Patterns of Amniotes. Herpetol Monogr. 2000;14: 371-377.

3. Blackburn DG. Evolution of vertebrate viviparity and specializations for fetal nutrition: A quantitative and qualitative analysis. J Morphol. 2015;276: 961-990. doi:10.1002/jmor.20272

4. Ostrovsky AN, Lidgard S, Gordon DP, Schwaha T, Genikhovich G, Ereskovsky A V. Matrotrophy and placentation in invertebrates: a new paradigm. Biol Rev. 2016;91: 673-711. doi:10.1111/brv.12189

5. Shine R. Propagule size and parental care: The "safe harbor" hypothesis. J Theor Biol. 1978;75: 417-424. doi:10.1016/0022-5193(78)90353-3

6. Shine R. Alternative models for the evolution of offspring size. Am Nat. 1989;134: 311-317.

7. Nussbaum RA. Parental care and egg size in salamanders: An examination of the safe harbor hypothesis. Res Popul Ecol (Kyoto). 1987;29: 27-44. doi:10.1007/BF02515423

8. Nussbaum RA, Schultz DL. Coevolution of Parental Care and Egg Size. Am Nat. 1989;133: 591-603.

9. Sargent RC, Taylor PD, Gross MR. Parental Care and the evolution of egg size in fishes. Am Nat. 1987;129: 32-46.

10. Williams GC. Adaptation and Natural Selection. Princeton: Princeton University Press; 1966.

11. Mell R. Grundzüge einer Ökologie der chinesischen Reptilien und einer herpetologischen Tiergeographie Chinas. de Gruyter W, editor. Berlin; 1929.

12. Weekes HC. A review of placentation among reptiles with particular regard to the function and evolution of the placenta. Proc R Linn Soc NSW. 1935;59: 380-391.

13. Sergeev AM. Researches on the viviparity of reptiles. Moscow Soc Nat. 1940; 1-34.

14. Tinkle DW, Gibbons JW. The distribution and evolution of viviparity in reptiles. Misc Publ Museum Zool Univ Michigan. 1977; 1-55.

15. Shine R. The evolution of viviparity in reptiles: an ecological analysis. In: Gans C, Billet F, editors. Biology of the Reptilia. New York: Wiley; 1985. pp. 605-694.

16. Shine R. A New Hypothesis for the Evolution of Viviparity in Reptiles. Am Nat. 1995;145: 809-823. 
Chapter 2 I Locomotor costs of live-bearing and adaptations to reduce them

17. Shine R. Does Viviparity Evolve in Cold Climate Reptiles Because Pregnant Females Maintain Stable (Not High) Body Temperatures? Evolution (N Y). 2004;58: 1809-1818.

18. Webb JK, Shine R, Christian KA. the Adaptive Significance of Reptilian Viviparity in the Tropics : Testing the Maternal Manipulation Hypothesis. Evolution (N Y). 2006;60: 115-122.

19. Lambert SM, Wiens JJ. Evolution of Viviparity: a Phylogenetic Test of the Cold-Climate Hypothesis in Phrynosomatid Lizards. Evolution (N Y). 2013;67: 2614-2630. doi:10.1111/evo.12130

20. Tinkle DW, Willbur HM, Tilley SG. Evolutionary Strategies in Lizard Reproduction. Evolution (N Y). 1970;24: 55-74.

21. Shine R. Life-History Evolution in Reptiles. Annu Rev Ecol Evol Syst. 2005;36: 23-46. doi:10.1146/annurev.ecolsys.36.102003.152631

22. Pincheira-Donoso D, Tregenza T, Witt MJ, Hodgson DJ. The evolution of viviparity opens opportunities for lizard radiation but drives it into a climatic cul-de-sac. Glob Ecol Biogeogr. 2013;22: 857-867. doi:10.1111/ geb.12052

23. Shine R. Evolution of an Evolutionary Hypothesis: A History of Changing Ideas about the Adaptive Significance of Viviparity in Reptiles. J Herpetol. 2014;48: 147-161. doi:10.1670/13-075

24. Stewart JR, Blackburn DG. Viviparity and Placentation in Lizards. In: Rheubert JL, Siegel DS, Trauth SE, editors. Reproductive Biology and Phylogeny of Lizards and Tuatara. CRC Press; 2014. pp. 448-563.

25. Watson CM, Makowsky R, Bagley JC. Reproductive mode evolution in lizards revisited: Updated analyses examining geographic, climatic and phylogenetic effects support the cold-climate hypothesis. J Evol Biol. 2014;27: 2767-2780. doi:10.1111/jeb.12536

26. Mesquita DO, Costa GC, Colli GR, Costa TB, Shepard DB, Vitt LJ, et al. Life-History Patterns of Lizards of the World. Am Nat. 2016;187: 679705. doi:10.1086/686055

27. Goodwin NB, Dulvy NK, Reynolds JD. Macroecology of Live-Bearing in Fishes : Latitudinal and Depth Range Comparisons with Egg-Laying Relatives. Oikos. 2005;110: 209-218.

28. Helmstetter AJ, Papadopulos AST, Igea J, Van Dooren TJM, Leroi AM, Savolainen V. Viviparity stimulates diversification in an order of fish. Nat Commun. Nature Publishing Group; 2016;7: 11271. doi:10.1038/ ncomms11271

29. Sanders KL, Lee MS, Leys R, Foster R, Keogh JS. Molecular phylogeny and divergence dates for Australasian elapids and sea snakes (hydrophiinae): evidence from seven genes for rapid evolutionary radiations. J Evol Biol. 2008;21: 682-695. doi:10.1111/j.1420-9101.2008.01525.x 
30. Pyron RA, Burbrink FT. Early origin of viviparity and multiple reversions to oviparity in squamate reptiles. Ecol Lett. 2014;17: 13-21. doi:10.1111/ele.12168

31. Wourms JP, Lombardi J. Reflections on the evolution of piscine viviparity. Am Zool. 1992;32: 276-293. Available: http://icb.oxfordjournals.org/ content/32/2/276.short

32. Neill WT. Viviparity in Snakes: Some Ecological and Zoogeographical Considerations. Am Nat. 1964;98: 35-55. doi:10.1086/282299

33. Motani R. The Evolution of Marine Reptiles. Evol Educ Outreach. 2009;2: 224-235. doi:10.1007/s12052-009-0139-y

34. Goodwin NB, Dulvy NK, Reynolds JD. Life-history correlates of the evolution of live bearing in fishes. Philos Trans R Soc B-Biological Sci. 2002;357: 259-267. doi:DOI 10.1098/rstb.2001.0958

35. Qualls CP, Shine R. Maternal Body-Volume As a Constraint on Reproductive Output in Lizards: Evidence From the Evolution of Viviparity. Oecologia. 1995;103: 73-78. doi:Doi 10.1007/Bf00328427

36. Wourms JP. Viviparity: the maternal-fetal relationships in fishes. Am Zool. 1981;21: 473-515.

37. Boehlert G, Kusakari M, Yamada J. Oxygen-consumption of gestating female Sebastes schlegeli - Estimating the reproductive costs of livebearing. Environ Biol Fishes. 1991;30: 81-89. doi:Doi 10.1007/Bf02296879

38. Dulvy NK, Reynolds JD. Evolutionary transitions among egg-laying, live-bearing and maternal inputs in sharks and rays. Proc R Soc B Biol Sci. 1997;264: 1309-1315. doi:10.1098/rspb.1997.0181

39. Qualls C, Shine R. Costs of reproduction in conspecific oviparous and viviparous lizards, Lerista bougainvillii. Oikos. 1998;82: 539-551. Available: http://www.jstor.org/stable/10.2307/3546374

40. Foucart T, Lourdais O, DeNardo DF, Heulin B. Influence of reproductive mode on metabolic costs of reproduction: insight from the bimodal lizard Zootoca vivipara. J Exp Biol. 2014;217: 4049-56. doi:10.1242/ jeb.104315

41. Thibault RE, Schultz RJ. Reproductive adaptations among viviparous fishes (Cyprinodontiformes: Poeciliidae). Evolution (NY). 1978;32: 320333. Available: http://www.jstor.org/stable/10.2307/2407600

42. Magnhagen C. Predation Risk as a Cost of Reproduction. Trends Ecol Evol. 1991;6: 183-185. doi:Doi 10.1016/0169-5347(91)90210-O

43. Gould SJ, Vrba ES. Exaptation-A Missing Term in the Science of Form. Paleobiology. 1982;8: 4-15.

44. Arnold SJ. Morphology, performance and fitness. Am Zool. 1983;23: 347-361. 
Chapter 2 I Locomotor costs of live-bearing and adaptations to reduce them

45. Hare KM, Miller KA. What Dives Beneath: Diving as a Measure of Performance in Lizards. Herpetologica. 2009;65: 227-236. doi:10.1655/08032R2.1

46. Aubret F, Bonnet X, Shine R, Maumelat S. Swimming and pregnancy in Tiger snakes, Notechis scutatus. Amphib Reptil. 2005;26: 396-400. Available: http://www.bio.usyd.edu.au/shine/publications/reprints_legal/445swimming.pdf

47. Brown G, Weatherhead P. Effects of reproduction on survival and growth of female northern water snakes, Nerodia sipedon. Can J Zool Can Zool. 1997;75: 424-432. doi:Doi 10.1139/Z97-052

48. Winne CT, Hopkins WA. Influence of sex and reproductive condition on terrestrial and aquatic locomotor performance in the semi-aquatic snake Seminatrix pygaea. Funct Ecol. 2006;20: 1054-1061.

49. Ghalambor CK, Reznick DN, Walker JA. Constraints on adaptive evolution: the functional trade-off between reproduction and fast-start swimming performance in the Trinidadian guppy (Poecilia reticulata). Am Nat. 2004;164: 38-50. doi:10.1086/421412

50. Belk MC, Tuckfield RC. Changing costs of reproduction: age-based differences in reproductive allocation and escape performance in a livebearing fish. Oikos. 2010;119: 163-169. doi:10.1111/j.1600-0706.2009.17742.x

51. Banet AI, Svendsen JC, Eng KJ, Reznick DN. Linking reproduction, locomotion, and habitat use in the Trinidadian guppy (Poecilia reticulata). Oecologia. 2016;181: 87-96.

52. Webb JK. Pregnancy decreases swimming performance of female northern death adders (Acanthophis praelongus). Copeia. 2004;2: 357-363.

53. Noren SR, Redfern J V, Edwards EF. Pregnancy is a drag: hydrodynamics, kinematics and performance in pre- and post-parturition bottlenose dolphins (Tursiops truncatus). J Exp Biol. 2011;214: 4151-9. doi:10.1242/ jeb.059121

54. Plaut I. Does pregnancy affect swimming performance of female Mosquitofish, Gambusia affinis? Funct Ecol. 2002;16: 290-295. doi:DOI 10.1046/j.1365-2435.2002.00638.x

55. Tytell ED, Borazjani I, Sotiropoulos F, Baker TV, Anderson EJ, Lauder G V. Disentangling the functional roles of morphology and motion in the swimming of fish. Integr Comp Biol. 2010;50: 1140-1154. doi:10.1093/ icb/icq057

56. Tokic G, Yue DKP. Optimal shape and motion of undulatory swimming organisms. Proc R Soc B Biol Sci. 2012;279: 3065-3074. doi:10.1098/ rspb.2012.0057

57. Gordon SP, Chen YY, Yamashita K, Bejar C, Wilshire A, Cheung V. Sex-specific genetic differences in endurance swimming of Trinidadian guppies. Ecol Evol. 2015;5: 5318-5328. doi:10.1002/ece3.1789 
58. Svendsen JC, Banet AI, Christensen RHB, Steffensen JF, Aarestrup K. Effects of intraspecific variation in reproductive traits, pectoral fin use and burst swimming on metabolic rates and swimming performance in the Trinidadian guppy (Poecilia reticulata). J Exp Biol. 2013;216: 3564-74. doi:10.1242/jeb.083089

59. Lin C, Zhang L, Ji X. Influence of pregnancy on locomotor and feeding performances of the skink, Mabuya multifasciata: Why do females shift thermal preferences when pregnant? Zoology. 2008;111: 188-195. doi:DOI 10.1016/j.zool.2007.06.005

60. Reznick DN, Yang AP. The influence of fluctuating resources on life history: patterns of allocation and plasticity in female guppies. Ecology. 1993;74: 2011-2019.

61. Dunkin RC, McLellan WA, Blum JE, Pabst DA. The buoyancy of the integument of Atlantic bottlenose dolphins (Tursiops truncatus): Effects of growth, reproduction, and nutritional state. Mar Mammal Sci. 2010;26: 573-587. doi:10.1111/j.1748-7692.2009.00353.x

62. Pollux BJA, Reznick DN. Matrotrophy limits a female's ability to adaptively adjust offspring size and fecundity in fluctuating environments. Funct Ecol. 2011;25: 747-756. doi:10.1111/j.1365-2435.2011.01831.x

63. Videler JJ. Fish Swimming. 1st ed. Videler JJ, editor. London: Chapman \& Hall; 1993.

64. McNeill Alexander R. Principles of Animal Locomotion. Princeton, NJ: Princeton University Press; 2003.

65. Katzir G, Camhi JM. Escape Response of Black Mollies (Poecilia sphenops) to Predatory Dives of a Pied Kingfisher (Ceryle rudis). Copeia. 1993;1993: 549-553.

66. Walker JA, Ghalambor CK, Griset OL, McKenney D, Reznick DN. Do faster starts increase the probability of evading predators? Funct Ecol. 2005;19: 808-815. doi:DOI 10.1111/j.1365-2435.2005.01033.x

67. Laidlaw CT, Condon JM, Belk MC. Viability Costs of Reproduction and Behavioral Compensation in Western Mosquitofish (Gambusia). PLoS One. 2014;9: e110524. doi:10.1371/journal.pone.0110524

68. Britton R, Moser M. Size specific predation by herons and its effect on the sex-ratio of natural populations of the mosquito fish Gambusia affinis Baird and Girard. Oecologia. 1982;53: 146-151. Available: http://link. springer.com/article/10.1007/BF00545657

69. Plath M, Riesch R, Culumber Z, Streit B, Tobler M. Giant water bug (Belostoma sp.) predation on a cave fish (Poecilia mexicana): effects of female body size and gestational state. Evol Ecol Res. 2011;13: 133-144.

70. Forczek W, Staszkiewicz R. Changes of kinematic gait parameters due to pregnancy. Acta Bioeng Biomech. 2012;14. doi:10.5277/abb120413 
Chapter 2 I Locomotor costs of live-bearing and adaptations to reduce them

71. Wapstra E, O'Reilly JM. Potential "costs of reproduction" in a skink: Inter- and intrapopulational variation. Austral Ecol. 2001;26: 179-186. doi:10.1046/j.1442-9993.2001.01104.x

72. Foti T, Davids J, Bagley A. A Biomechanical Analysis of Gait During Pregnancy. J Bone Jt Surg. 2000;82-A: 625-632. Available: http://jbjs.org/ article. aspx?articleid $=24588$

73. Lymbery JK, Gilleard W. The stance phase of walking during late pregnancy. J Am Podiatr Med Assoc. 2005;95: 247-253.

74. McCrory JL, Chambers AJ, Daftary A, Redfern MS. Ground reaction forces during gait in pregnant fallers and non-fallers. Gait Posture. 2011;34: 524-528.

75. Nagy LE, King JC. Energy expenditure of pregnant walking self-paced. Am J Clin Nutr. 1983;38: 369-376.

76. Le Galliard J, Bris M Le, Clobert J. Timing of locomotor impairment and shift in thermal preferences during gravidity in a viviparous lizard. Funct Ecol. 2003;17: 877-885. Available: http://onlinelibrary.wiley.com/ doi/10.1046/j.0269-8463.2003.00800.x/full

77. Kruuk H. The spotted hyena. Chicago, IL: University of Chicago Press.; 1972.

78. Molinari-Jobin A, Molinari P, Loison A, Gaillard J, Breitenmoser U. Life cycle period and activity of prey influence their susceptibility to predators. Ecography (Cop). 2004;27: 323-329.

79. Owen-Smith N. Changing vulnerability to predation related to season and sex in an African ungulate assemblage. Oikos. 2008;117: 602-610. doi:10.1111/j.2007.0030-1299.16309.x

80. Schwarzkopf L, Barnes M, Goodman B. Belly up: Reduced crevice accessibility as a cost of reproduction caused by increased girth in a rock-using lizard. Austral Ecol. 2010;35: 82-86. doi:DOI 10.1111/j.14429993.2009.02015.x

81. Blackburn DG, Evans HE. Why are there no Viviparous Birds ? Am Nat. 1986;128: 165-190.

82. Fokidis HB, Risch TS. Does gliding when pregnant select for larger females? J Zool. 2008;275: 237-244. doi:10.1111/j.1469-7998.2008.00433.x

83. Aldridge HDJN, Brigham RM. Load Carrying and Maneuverability in an Insectivorous Bat: A Test of The 5\% "Rule" of Radio-Telemetry. J Mammal. 1988;69: 379-382. doi:10.2307/1381393

84. Hughes P, Rayner JM V. The flight of pipistrelle bats Pipistrellus pipistrellus during pregnancy and lactation. J Zool. 1993;230: 541-555. doi:10.1111/j.1469-7998.1993.tb02705.x 
85. Blackburn DG. Structure, function, and evolution of the oviducts of squamate reptiles, with special reference to viviparity and placentation. J Exp Zool. 1998;282: 560-617. doi:Doi 10.1002/(Sici)1097010x(199811/12)282:4/5<560::Aid-Jez10>3.3.Co;2-A

86. Greer A. On the adaptive significance of the loss of an oviduct in reptiles. Proc Linn Soc New South Wales. 1976;101: 242-249. Available: http:// scholar.google.com/scholar?hl=en\&btnG=Search\&q=intitle:On+the+adaptive+significance+of+the+loss+of + an+oviduct+in+reptiles $\# 0$

87. Pizzatto L, Almeida-Santos SM, Shine R. Life-history adaptations to arboreality in snakes. Ecology. 2007;88: 359-366. doi:Doi 10.1890/0012-9658(2007)88[359:Latais]2.0.Co;2

88. Lillywhite HB, Henderson RW. Behavioral and functional ecology of arboreal snakes. In: Seigel RA, Collings JT, editors. Snakes: ecology and behavior. New York: McGraw-Hill; 1993. pp. 1-48.

89. Shine R. Constraints on Reproductive Investment : A Comparison between Aquatic and Terrestrial Snakes. Soc Study Evol. 1988;42: 17-27. Available: http://www.jstor.org/stable/2409112

90. Goodman BA, Hudson SC, Isaac JL, Schwarzkopf L. The evolution of body shape in response to habitat: Is reproductive output reduced in flat lizards? Evolution (NY). 2009;63: 1279-1291. doi:10.1111/j.15585646.2009.00621.x

91. Wourms JP, Grove BD, Lombardi J. The maternal-embryonic relationship in viviparous fishes. In: Hoar WS, Randal DJ, editors. Fish Physiology. New York: Academic Press; 1988. pp. 1-134.

92. Thompson MB, Speake BK. A review of the evolution of viviparity in lizards: structure, function and physiology of the placenta. J Comp Physiol B. 2006;176: 179-189. doi:10.1007/s00360-005-0048-5

93. Pollux BJA, Meredith RW, Springer MS, Garland T, Reznick DN. The evolution of the placenta drives a shift in sexual selection in livebearing fish. Nature. 2014;513: 233-236. doi:10.1038/nature13451

94. Pollux BJA, Pires MN, Banet AI, Reznick DN. Evolution of Placentas in the Fish Family Poeciliidae: An Empirical Study of Macroevolution. Annu Rev Ecol Evol Syst. 2009;40: 271-289. doi:DOI 10.1146/annurev. ecolsys.110308.120209

95. Reznick DN, Meredith R, Collette BB. Independent Evolution of Complex Life History Adaptations in Two Families of Fishes, Live-bearing Halfbeaks (Zenarchopteridae, Beloniformes) and Poeciliidae (Cyprinodontiformes). Evolution (NY). 2007;61: 2570-2583.

96. Stewart JR, Thompson MB. Placental structure of the Australian lizard, Niveoscincus metallicus. J Morphol. 1994;220: 223-236. 
Chapter 2 I Locomotor costs of live-bearing and adaptations to reduce them

97. Lourdais O, Brischoux F, DeNardo DF, Shine R. Protein catabolism in pregnant snakes (Epicrates cenchria maurus Boidae) compromises musculature and performance after reproduction. J Comp Physiol B-Biochemical Syst Environ Physiol. 2004;174: 383-391. doi:10.1007/s00360004-0424-6

98. Turner CL. Reproductive Cycles and Superfetation in Pœciliïd Fishes. Biol Bull. 1937;72: 145-164.

99. Scrimshaw N. Superfetation in Poeciliid Fishes. Copeia. 1944;3: 180-183.

100. Reznick DN, Miles DB. Review of life history patterns in Poeciliid fishes. In: Meffe GK, Snelson FF, editors. Ecology and Evolution of Livebearing Fishes (Poeciliidae). Prentice Hall, Englewood Cliffs, NJ; 1989. pp. 125-148.

101. Gunn JS, Thresher RE. Viviparity and the reproductive ecology of clinid fishes (Clinidae) from temperate Australian waters. Environ Biol Fishes. 1991;31: 323-344. doi:10.1007/BF00002357

102. Roellig K, Menzies BR, Hildebrandt TB, Goeritz F. The concept of superfetation: a critical review on a "myth" in mammalian reproduction. Biol Rev. 2011;86: 77-95. doi:10.1111/j.1469-185X.2010.00135.x

103. Frías-Alvarez P, Zúñiga-Vega JJ. Superfetation in live-bearing fishes is not always the result of a morphological constraint. Oecologia. 2016;181: 645-658. doi:10.1007/s00442-015-3477-1

104. Zúñiga-Vega JJ, Reznick DN, Johnson JB. Habitat predicts reproductive superfetation and body shape in the livebearing fish Poeciliopsis turrubarensis. Oikos. 2007; 995-1005. doi:10.1111/j.2007.0030-1299.15763.x

105. Frías-Alvarez P, Macías Garcia C, Vázquez-Vega L, Zúñiga-Vega J. Spatial and temporal variation in superfoetation and related life history traits of two viviparous fishes: Poeciliopsis gracilis and P. infans. Naturwissenschaften. 2014;101: 1085-1098. doi:10.1007/s00114-014-1247-2

106. Downhower JF, Brown LP, Matsui ML. Litter overlap in Gambusia hubbsi: superfetation revisited. Environ Biol Fishes. 2002;65: 423-430. doi:10.1023/A:1021151428795

107. Downhower JF, Brown LP. Superfoetation in fishes and the cost of reproduction. Nature. 1978;256: 345.

108. Travis J, Farr JA, Henrich S, Cheong RT. Testing Theories of Clutch Overlap with the Reproductive Ecology of Heterandria Formosa. Ecology. 1987;68: 611-623.

109. Zúñiga-Vega JJ, Macías-Garcia C, Johnson JB. Hypotheses to explain the evolution of superfetation in viviparous fishes. In: Uribe $\mathrm{M}$, Grier $\mathrm{H}$, editors. Viviparous fishes II. New Life Publications, Homestead, Florida; 2010. pp. 241-253.

110. Roelofs K. Freeze for action: neurobiological mechanisms in animal and human freezing. Philos Trans R Soc B Biol Sci. 2017;372: 20160206. doi:10.1098/rstb.2016.0206 
111. Bauwens D, Thoen C. Escape tactics and vulnerability to predation associated with reproduction in the lizard Lacerta vivipara. J Anim Ecol. 1981;50: 733-743. doi:Doi 10.2307/4133

112. Schwarzkopf L, Shine R. Costs of reproduction in lizards: escape tactics and susceptibility to predation. Behav Ecol Sociobiol. 1992;31: 17-25. doi:10.1007/BF00167812

113. Itonaga K, Edwards A, Wapstra E, Jones SM. Interpopulational variation in costs of reproduction related to pregnancy in a viviparous lizard. Ethology, Ecol Evol. 2012;24: 367-376. doi:10.1080/03949370.2012.702686

114. Brodie III E. Behavioral modification as a means of reducing the cost of reproduction. Am Nat. 1989;134: 225-238. Available: http://www.jstor. org/stable/10.2307/2462100

115. Nunes S. Maternal experience and territorial behavior in ground squirrels. J Mammal. 2014;95: 491-502. doi:10.1644/13-MAMM-A-284

116. Festa-Bianchet M. Seasonal range selection in bighorn sheep: conflicts between forage quality, forage quantity, and predator avoidance. Oecologia. 1988;75: 580-586. doi:10.1007/BF00776423

117. Berger J. Pregnancy incentives, predation constraints and habitat shifts: experimental and field evidence for wild bighorn sheep. Anim Behav. 1991;41: 61-77. doi:10.1016/S0003-3472(05)80503-2

118. Lofroth EC, Krebs JA, Harrower WL, Lewis D. Food habits of wolverine Gulo gulo in montane ecosystems of British Columbia, Canada. Wildlife Biol. 2007;13: 31-37. doi:10.2981/0909-6396(2007)13[31:FHOWGG]2.0. $\mathrm{CO} ; 2$

119. Koskela A, Kojola L, Aspi J, Hyvärinen M. Effect of Reproductive Status on the Diet Composition of Wolverines (Gulo gulo) in Boreal Forests of Eastern Finland. Ann Zool Fennici. 2013;50: 100-106. doi:10.5735/086.050.0109

120. Bernard HJ, Hohn AA. Differences in Feeding Habits between Pregnant and Lactating Spotted Dolphins (Stenella attenuata). J Mammal. 1989;70: 211-215.

121. Malinowski CR, Herzing DL. Prey use and nutritional differences between reproductive states and age classes in Atlantic spotted dolphins (Stenella frontalis) in the Bahamas. Mar Mammal Sci. 2015;31: 1471-1493. doi:10.1111/mms.12238

122. Anthony EPL, Kunz TH. Feeding Strategies of the Little Brown Bat, Myotis Lucifugus, in Southern New Hampshire. Ecology. 1977;58: 775-786.

123. Brady J, Gibson G. Activity patterns in pregnant tsetse flies, Glossina morsitans. Physiol Entomol. 1983;8: 359-369.

124. Lee $\mathrm{HJ}, \mathrm{Wu}$ YL. Mating effects on the feeding and locomotion of the German cockroach, Blattella germanica. Physiol Entomol. 1994;19: 39-45. 
Chapter 2 I Locomotor costs of live-bearing and adaptations to reduce them

125. Tsai C-W, Lee H-J. Circadian locomotor rhythm masked by the female reproduction cycle in cockroaches. Physiol Entomol. 2000;25: 63-73. doi:10.1046/j.1365-3032.2000.00165.x

126. Schultze-Motel P, Greven H. Metabolic heat flux in pregnant females of the viviparous cockroach Nauphoeta cinerea (Blaberoidea: Blaberidae). Entomol Gen. Schweizerbart; 1998;22: 199-204. Available: http://cat. inist.fr/?aModele=afficheN\&cpsidt=2209252

127. Rowclife C, Finlayson LH. Active and resting behaviour of virgin and pregnant females of Glossina morsitans morsitans Westwood (Diptera: Glossinidae) in the laboratory. Bull Entomol Res. 1982;72: 271-288. doi:10.1017/S0007485300010579

128. Abdelkarim EI, Brady J. Changing visual responsiveness in pregnant and larvipositing tsetse flies, Glossina morsitans. Physiol Entomol. 1984;9: 125-131. doi:10.1111/j.1365-3032.1984.tb00690.x

129. Lourdais O, Bonnet X, Doughty P. Costs of anorexia during pregnancy in a viviparous snake (Vipera aspis). J Exp Zool. 2002;292: 487-493. doi:10.1002/jez.10065

130. Lee H-J, Lee J-H, Park D. Habitat use and movement patterns of the viviparous aquatic snake, Oocatochus rufodorsatus, from northeast Asia. Zoolog Sci. 2011;28: 593-599. doi:10.2108/zsj.28.593

131. Rydell J. Variation in Foraging Activity of an Aerial Insectivorous Bat during Reproduction. J Mammal. 1993;74: 503-509.

132. Voigt CC. Reproductive energetics of the nectar-feeding bat Glossophaga soricina (Phyllostomidae). J Comp Physiol B. 2003;173: 79-85. doi:10.1007/s00360-002-0316-6

133. Price EC. Changes in the activity of captive cotton-top tamarins (Saguinus oedipus) over the breeding cycle. Primates. 1992;33: 99-106. doi:10.1007/ BF02382765

134. Vasey N. Activity budgets and activity rhythms in red ruffed lemurs (Varecia rubra) on the Masoala Peninsula, Madagascar: Seasonality and reproductive energetics. Am J Primatol. 2005;66: 23-44. doi:10.1002/ ajp.20126

135. Murray CM, Lonsdorf E V, Eberly LE, Pusey AE. Reproductive energetics in free-living female chimpanzees (Pan troglodytes schweinfurthii). Behav Ecol. 2009;20: 1211-1216. doi:10.1093/beheco/arp114

136. Kvarnemo C, Moore GI, Jones AG. Sexually selected females in the monogamous Western Australian seahorse. Proc R Soc B Biol Sci. 2007;274: 521-525. doi:10.1098/rspb.2006.3753

137. Dietz M, Kalko EKV. Reproduction affects flight activity in female and male Daubenton's bats, Myotis daubentoni. Can J Zool. 2007;85: 653-664. doi:10.1139/Z07-045 
138. Willis CKR, Brigham RM, Geiser F. Deep, prolonged torpor by pregnant, free-ranging bats. Naturwissenschaften. 2006;93: 80-83. doi:10.1007/ s00114-005-0063-0

139. Geiser F, Brigham RMM. The other functions of torpor. In: Ruf T, Bieber C, Arnold W, Millesi E, editors. Living in a Seasonal World: Thermoregulatory and Metabolic Adaptations. Springer-Verlag Berlin Heidelberg; 2012. pp. 109-121. doi:10.1007/978-3-642-28678-0

140. Daniel S, Korine C, Pinshow B. The use of torpor in reproductive female Hemprich's long-eared bats (Otonycteris hemprichii). Physiol Biochem Zool. 2010;83: 142-148. doi:10.1086/647926

141. Geiser F, Masters P. Torpor in relation to reproduction in the mulgara, Dasycercus cristicauda (Dasyuridae: Marsupialia). J Therm Biol. 1994;19: 33-40. doi:10.1016/0306-4565(94)90007-8

142. Chruszcz BJ, Barclay RMR. Thermoregulatory ecology of a solitary bat, Myotis evotis, roosting in rock crevices. Funct Ecol. 2002;16: 18-26. doi:10.1046/j.0269-8463.2001.00602.x

143. Audet D, Fentron MB. Heterothermy and the Use of Torpor by the Bat Eptesicus fuscus (Chiroptera: Vespertilionidae): A Field Study. Physiological Zool. 1988;61: 197-204.

144. Geiser F, McAllan BM, Brigham RM. Daily torpor in a pregnant dunnart (Sminthopsis macroura Dasyuridae: Marsupialia). Mamm Biol Zeitschrift für Säugetierkunder. 2005;70: 117-121. doi:10.1016/j.mambio.2004.06.003

145. Solick DI, Barclay RMR. Thermoregulation and roosting behaviour of reproductive and nonreproductive female western long-eared bats (Myotis evotis) in the Rocky Mountains of Alberta. Can J Zool. 2006;84: 589-599. doi:10.1139/z06-028

146. Turbill C, Geiser F. Thermal physiology of pregnant and lactating female and male long-eared bats, Nyctophilus geoffroyi and N. gouldi. J Comp Physiol B Biochem Syst Environ Physiol. 2006;176: 165-172. doi:10.1007/ s00360-005-0038-7

147. Stawski C, Geiser F. Fat and fed: Frequent use of summer torpor in a subtropical bat. Naturwissenschaften. 2010;97: 29-35. doi:10.1007/ s00114-009-0606-x

148. Dzal YA, Brigham RM. The tradeoff between torpor use and reproduction in little brown bats (Myotis lucifugus). J Comp Physiol B Biochem Syst Environ Physiol. 2013;183: 279-288. doi:10.1007/s00360-012-0705-4

149. Fokidis HB, Risch TS. The burden of motherhood: gliding locomotion in mammals influences maternal reproductive investment. J Mammal. 2008;89: 617-625. doi:10.1644/07-MAMM-A-116R1.1

150. Trebatická L, Suortti P, Sundell J, Ylönen H. Predation risk and reproduction in the bank vole. Wildl Res. 2012;39: 463-468. doi:10.1071/ WR12012 
Chapter 2 I Locomotor costs of live-bearing and adaptations to reduce them

151. Arthur AD, Pech RP, Dickman CR. Habitat structure mediates the non lethal effects of predation on enclosed populations of house mice. J Anim Ecol. 2004;73: 867-877. doi:10.1111/j.0021-8790.2004.00864.x

152. Klemola T, Koivula M, Korpimaki E, Norrdahl K. Small Mustelid Predation Slows Population Growth of Microtus Voles: A Predator Reduction Experiment. J Anim Ecol. 1997;66: 607-614.

153. Charlesworth B. Evolution in Age-Structured Populations. Cambridge University Press.; 1994.

154. Roff DA. The evolution of life histories: theories and analysis. London: Chapman \& Hall; 1992.

155. Stearns SC. The evolution of life histories. Oxford: Oxford University Press, Inc.; 1992.

156. Haskins CP, Haskins EF, McLaughlin JJA, Hewitt RE. Polymorphism and population structure in Lebistes reticulatus, an ecological study. In: Blair WF, editor. Vertebrate speciation. Austin: Univ. Texas Press; 1961. pp. 320-395.

157. Endler JA. A Predator's View of Animal Color Patterns. In: Hecht MK, Steere WC, Wallace B, editors. Evolutionary Biology. Boston, MA: Springer US; 1978. pp. 319-364. doi:10.1007/978-1-4615-6956-5_5

158. Reznick DN, Butler IV MJ, Rodd FH, Ross P. Life-History evolution in Guppies (Poecilia reticulata) VI. differential mortality as a mechanism for natural selection. Evolution (NY). 1996;50: 1651-1660.

159. Reznick DN, Endler JA. The Impact of Predation on Life History Evolution in Trinidadian Guppies (Poecilia reticulata). Evolution (NY). 1982;36: 160-177.

160. Reznick DN, Bryga HA. Life-history evolution in Guppies (Poecilia reticulata: Poeciliidae). V . Genetic basis of parallelism in life histories. Am Nat. 1996;147: 339-359.

161. Evans JP, Gasparini C, Pilastro A. Female guppies shorten brood retention in response to predator cues. Behav Ecol Sociobiol. 2007;61: 719727. doi:10.1007/s00265-006-0302-1

162. Dunham AE, Miles DB, Reznick DN. Life history patterns in squamate reptiles. In: Gans C, Huey RB, editors. Biology of the Reptilia. New York: Alan R. Liss; 1988. pp. 441-522.

163. Stearns SC. The Effects of Size and Phylogeny on Patterns of Covariation in the Life History Traits of Lizards and Snakes. Am Nat. 1984;123: $56-72$.

164. Dunham AE, Miles DB. Patterns of Covariation in Life History Traits of Squamate Reptiles: The Effects of Size and Phylogeny Reconsidered. Am Nat. 1985;126: 231-257. 
165. Hallmann K, Griebeler EM. Eggshell types and their evolutionary correlation with life-history strategies in squamates. PLoS One. 2015;10: 1-20. doi:10.1371/journal.pone.0138785

166. Heulin B, Osenegg-Leconte K, Michel D. Demography of a Bimodal Reproductive Species of Lizard (Lacerta vivipara): Survival and Density Characteristics of Oviparous Populations. Herpetologica. 1997;53: 432444.

167. Domenici P, Blake RW. The kinematics and performance of fish faststart swimming. J Exp Biol. 1997;200: 1165-1178. Available: http://jeb. biologists.org/content/200/8/1165.short

168. Domenici P, Kapoor B. Fish locomotion: An eco-ethological perspective. Enfield: Science Publishers; 2010.

169. Olsson M, Shine R, Bak-Olsson E. Locomotor impairment of gravid lizards: is the burden physical or physiological? J Evol Biol. 2000;13: 263-268. Available: http://onlinelibrary.wiley.com/doi/10.1046/j.14209101.2000.00162.x/full

170. Nunn CL. The comparative approach in evolutionary anthropology and biology. Chicago, IL: University of Chicago Press; 2011.

171. Garamszegi LZ. Modern Phylogenetic Comparative Methods and their Application in Evolutionary Biology. Berlin, Germany: Springer; 2014.

172. Oufiero CE, Garland T. Evaluating performance costs of sexually selected traits. Funct Ecol. 2007;21: 676-689. doi:10.1111/j.1365-2435.2007.01259.x

173. Losos J, Creer D, Schulte J. Cautionary comments on the measurement of maximum locomotor capabilities. J Zool. 2002;258: 57-61. doi:Doi 10.1017/S0952836902001206

174. Fleuren M, Quicazan-Rubio EM, Voesenek CJ, Van Leeuwen JL, Pollux BJA. Reconstructing changes in $3 \mathrm{D}$ body shape during the pregnancy of three species of viviparous fish (Poeciliidae): effects of placentation and superfetation. SICB 2014 Annu Meet Abstr. 2014;

175. Dunn TW, Gebhardt C, Naumann EA, Riegler C, Ahrens MB, Engert F, et al. Neural Circuits Underlying Visually Evoked Escapes in Larval Zebrafish. Neuron. Elsevier Inc.; 2016;89: 613-628. doi:10.1016/j.neuron.2015.12.021

176. Voesenek CJ, Pieters RPM, Van Leeuwen JL. Automated reconstruction of three-dimensional fish motion, forces, and torques. PLoS One. 2016;11: e0146682. doi:10.1371/journal.pone.0146682

177. Ristroph L, Berman GJ, Bergou AJ, Wang ZJ, Cohen I. Automated hull reconstruction motion tracking (HRMT) applied to sideways maneuvers of free-flying insects. J Exp Biol. 2009;212: 1324-1335. doi:10.1242/ jeb.025502

178. Fontaine EI, Zabala F, Dickinson MH, Burdick JW. Wing and body motion during flight initiation in Drosophila revealed by automated visual tracking. J Exp Biol. 2009;212: 1307-23. doi:10.1242/jeb.025379 
Chapter 2 I Locomotor costs of live-bearing and adaptations to reduce them

179. Bridge ES, Kelly JF, Contina A, Gabrielson RM, MacCurdy RB, Winkler DW. Advances in tracking small migratory birds: A technical review of light-level geolocation. J F Ornithol. 2013;84: 121-137. doi:10.1111/ jofo.12011

180. Hussey NE, Kessel ST, Aarestrup K, Cooke SJ, Cowley PD, Fisk AT, et al. Aquatic animal telemetry: A panoramic window into the underwater world. Science. 2015;348: aaa2478. doi:10.1126/science.1255642

181. Kays R, Crofoot MC, Jetz W, Wikelski M. Terrestrial animal tracking as an eye on life and planet. Science. 2015;348: 1255642. doi:10.1126/science.aaa2478

182. Breed GA, Costa DP, Goebel ME, Robinson PW. Electronic tracking tag programming is critical to data collection for behavioral time-series analysis. Ecosphere. 2011;2: Article 10. doi:10.1890/ES10-00021.1

183. Fish FE. Balancing requirements for stability and maneuverability in cetaceans. Integr Comp Biol. 2002;42: 85-93. doi:10.1093/icb/42.1.85

184. Branco M, Santos-Rocha R, Aguiar L, Vieira F, Veloso A. Kinematic analysis of gait in the second and third trimesters of pregnancy. J Pregnancy. 2013;2013: 718095. doi:10.1155/2013/718095

185. Aleyev YR. Nekton. The Hague, The Netherlands: Dr. W. Junk b.v. Publishers; 1977.

186. Wynn ML, Clemente C, Nasir AFAA, Wilson RS. Running faster causes disaster: trade-offs between speed, manoeuvrability and motor control when running around corners in northern quolls (Dasyurus hallucatus). J Exp Biol. 2015;218: 433-439. doi:10.1242/jeb.111682

187. Clemente CJ, Wilson RS. Speed and maneuverability jointly determine escape success: Exploring the functional bases of escape performance using simulated games. Behav Ecol. 2016;27: 45-54. doi:10.1093/beheco/ arv080

188. Porter ME, Roque CM, Long JH. Swimming fundamentals: Turning performance of leopard sharks (Triakis semifasciata) is predicted by body shape and postural reconfiguration. Zoology. 2011;114: 348-359. doi:10.1016/j.zool.2011.06.001

189. Witter MS, Cuthill IC, Bonser RHC. Experimental investigations of mass-dependent predation risk in the European starling, Sturnus vulgaris. Anim Behav. 1994;48: 201-222. doi:10.1006/anbe.1994.1227

190. Webb PW, Weihs D. Stability versus maneuvering: Challenges for stability during swimming by fishes. Integr Comp Biol. 2015;55: 753-764. doi:10.1093/icb/icv053

191. Langerhans RB, Reznick DN. Ecology and Evolution of Swimming Performance in Fishes: Predicting Evolution with Biomechanics. In: Domenici P, Kapoor BG, editors. Fish Locomotion. Science Publishers; 2010. pp. 200-248. doi:10.1201/b10190-8 
192. Lailvaux SP, Husak JF. The life history of whole-organism performance. Q Rev Biol. 2014;89: 285-318. doi:10.1086/669266

193. Higham TM, Rogers SM, Langerhans RB, Jamniczky HA, Lauder GV, Stewart WJ, et al. Speciation through the lens of biomechanics: locomotion, prey capture and reproductive isolation. Proc R Soc London B Biol Sci. 2016;283: 20161294. doi:10.1098/rspb.2016.1294

194. Shaffer LR, Formanowicz DR. A cost of viviparity and parental care in scorpions: Reduced sprint speed and behavioural compensation. Anim Behav. 1996;51: 1017-1023. doi:DOI 10.1006/anbe.1996.0104

195. Greven H, Flossdorf D, Köthe J, List F, Zwanzig N. Running speed and food intake of the matrotrophic viviparous cockroach Diploptera punctata (Blattodea : Blaberidae) during gestation. Entomol heute. 2014;26: $53-72$.

196. Lu H, Jiang C, Ji X. Locomotor costs of pregnancy in a viviparous toad-headed lizard, Phrynocephalus vlangalii (Agamidae). Herpetol J. 2015;25: 149-154.

197. Seigel R, Huggins M, Ford N. Reduction in locomotor ability as a cost of reproduction in gravid snakes. Oecologia. 1987;73: 481-485. Available: http://link.springer.com/article/10.1007/BF00379404

198. Kubisch EL, Fernández JB, Ibargüengoytía NR. Is locomotor performance optimised at preferred body temperature? A study of Liolaemus pictus argentinus from northern Patagonia, Argentina. J Therm Biol. 2011;36: 328-333. doi:10.1016/j.jtherbio.2011.06.006

199. Van Damme R, Bauwens D, Verheyen RF. Effect of relative clutch mass on sprint speed in the lizard Lacerta vivipara. J Herpetol. 1989;23: 459461. Available: http://www.jstor.org/stable/10.2307/1564069

200. Shine R. “Costs” of reproduction in reptiles. Oecologia. 1980;46: 92-100. Available: http://link.springer.com/article/10.1007/BF00346972

201. Wu W, Meijer OG, Lamoth CJC, Uegaki K, Van Dieën JH, Wuisman PIJM, et al. Gait coordination in pregnancy: transverse pelvic and thoracic rotations and their relative phase. Clin Biomech. 2004;19: 480-8. doi:10.1016/j.clinbiomech.2004.02.003

202. Gilleard WL. Trunk motion and gait characteristics of pregnant women when walking: report of a longitudinal study with a control group. BMC Pregnancy Childbirth. 2013;13: 71. doi:10.1186/1471-2393-13-71

203. Mappes T, Ylönen H. Reproductive effort of female bank voles in a risky environment. Evol Ecol. 1997;11: 591-598. doi:10.1007/s10682-997-15141 


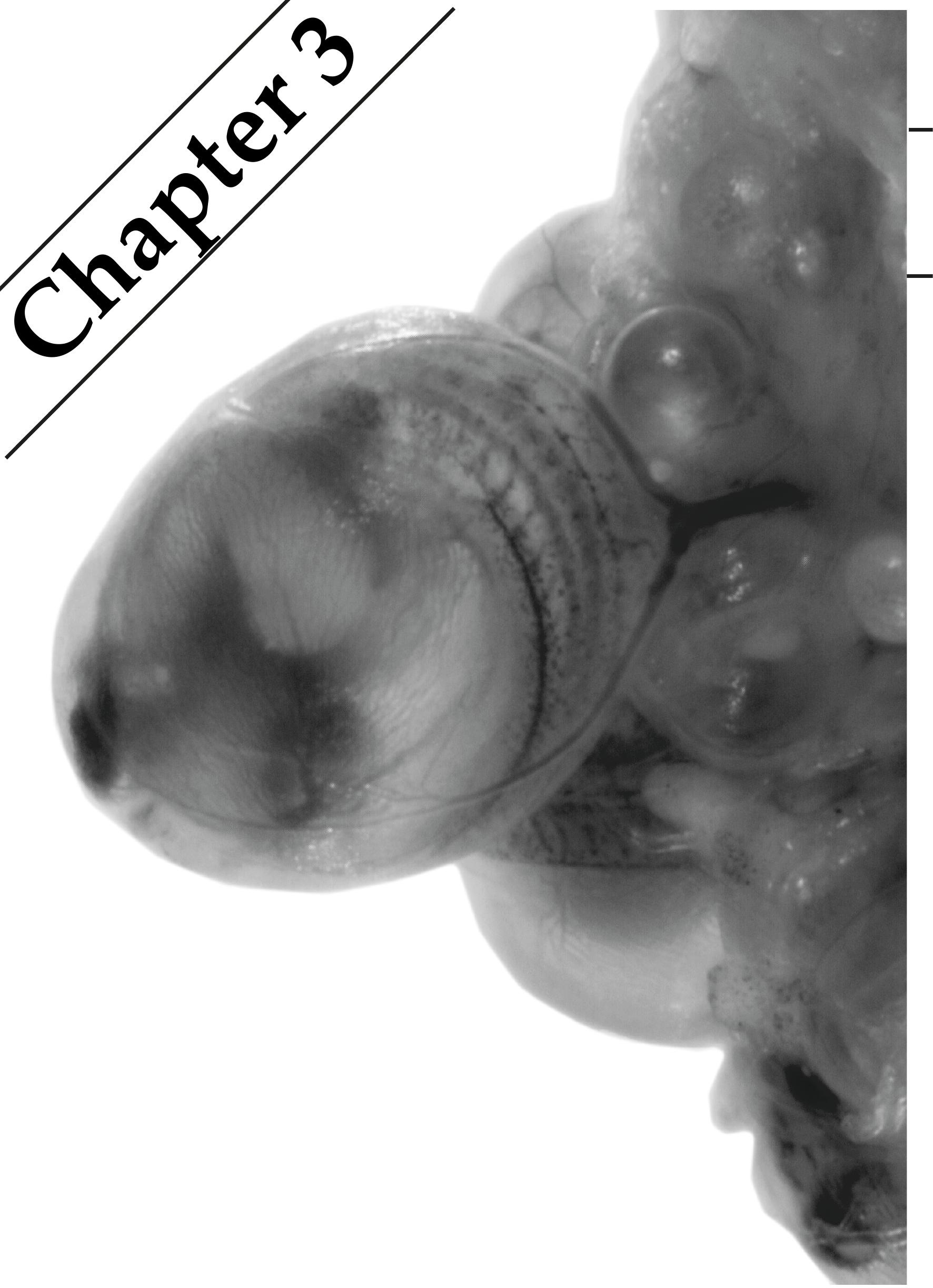




\section{Chapter 3}

\section{Why do placentas evolve?}

First evidence for a morphological advantage during pregnancy in live-bearing fish

Mike Fleuren,

Elsa M. Quicazan-Rubio, Johan L. van Leeuwen, Bart J.A. Pollux

Experimental Zoology Group, Department of Animal Sciences, Wageningen University, 6708 WD Wageningen, The Netherlands. 
Chapter 3 I First evidence for the morphological advantage of matrotrophy

\section{Abstract}

Live-bearing is a reproductive strategy that can confer large morphological changes to the mother. The evolution of the placenta in swimming animals is hypothesized to be an adaptation that reduces body volume early during pregnancy, because it involves a shift of reproductive allocation from pre- to post-fertilization. We tested this hypothesis by quantifying three-dimensional shape and volume changes during pregnancy and in full-grown virgin controls of two species within the live-bearing fish family Poeciliidae: Poeciliopsis gracilis (non-placental) and Poeciliopsis turneri (placental). We show that $P$. turneri is more slender than $P$. gracilis at the beginning of the interbrood interval and in virgins, and that these differences diminish towards the end of pregnancy. This study provides the first evidence for an adaptive morphological advantage of the placenta in live-bearing fish. A similar morphological benefit could drive the evolution of placentas in other live-bearing (swimming) animal lineages. 


\section{Introduction}

The placenta, defined as an intimate apposition or fusion of maternal and foetal tissues for physiological exchange [1], evolved many times independently throughout the animal kingdom (e.g. in invertebrates, fish, amphibians, reptiles and mammals; [2-6]), including at least eight times within the live-bearing fish family Poeciliidae [7-10]. Despite the repeated emergence of placentas among widely diverged animal lineages, it is still unclear what selective forces drive their evolution. Three non-mutually exclusive adaptive hypotheses have been proposed to explain why the placenta may have evolved in Poeciliid fish: the resource availability hypothesis, the life history facilitation hypothesis and the locomotor cost hypothesis.

The resource availability hypothesis suggests that the evolution of the placenta and associated reduction in egg size at fertilization might allow females to attain a higher fitness through increased litter sizes. A critical assumption of this hypothesis is that females must be able to abort embryos when facing adverse food conditions [11]. Recent empirical studies in Poeciliidae, however, show that they are not able to do this, suggesting that the conditions under which the placenta might be favoured by natural selection are, at least in this taxonomic group, restricted to environments characterized by high and stable resource conditions [12-15].

The life history facilitation hypothesis states that the placenta might evolve to facilitate the evolution of other life history traits, for example to enable organisms to mature at an earlier age or to produce more or larger offspring that have a higher early-life survivorship [16-21]. However, recent studies in Poeciliidae show that there are no consistent associations between placentation and life history traits, arguing against this hypothesis as a likely explanation for the evolution of the placenta in this taxonomic group [22-24].

Finally, the locomotor cost hypothesis argues that the placenta might evolve to offset some of the locomotor cost associated with a live-bearing mode of reproduction. The physical and physiological burden of a pregnancy negatively affects a female's locomotor performance in a broad range of live-bearing animals (e.g. scorpions, [25]; fishes, [26-29]; reptiles, [30,31]; and mammals, $[32,33])$. In aquatic animals an increase in abdominal volume may locally limit axial bending and, furthermore, enlarge frontal surface area thereby increasing the drag forces on the body [26,33-35]. An increase in body mass during pregnancy could reduce the ability to rapidly accelerate [27]. The locomotor cost hypothesis proposes that the evolution of a placenta reduces a female's reproductive allocation (the proportion of female wet mass allocat- 
- - - Lecithotrophy $\Delta-$ - Placentotrophy

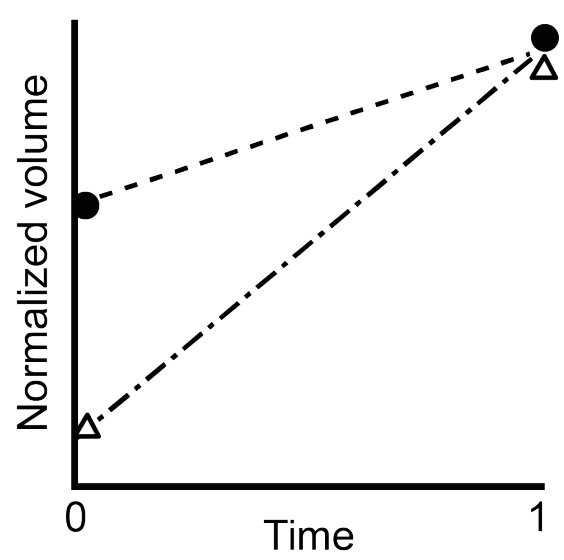

Figure 3-1.Predicted change in female body volume during pregnancy in lecithotrophic and placental live-bearing fish species. (1) the placental species (dash-dot line) will have a smaller volume during its entire pregnancy than the lecithotrophic species (dashed line) and (2) the relationship for the placental species will show a steeper slope than for the lecithotrophic species, indicating that the difference in body volume will be greatest at the beginning of the pregnancy and gradually diminish towards zero at end of the interbrood interval (redrawn after [9]). Similar plots could be constructed for frontal or wetted surface area. For heuristic purposes the temporal patterns are assumed linear, because the exact shape of the relationship between female volume and time is currently unknown [20].

totrophic; $[7,10])$. Specifically, we test whether, compared to $P$. gracilis, the placental species $P$. turneri has (1) a lower body volume and frontal surface area at the beginning of the interbrood interval and in virgin controls, and (2) a stronger increase in volume and frontal surface area (i.e. have a steeper slope) when pregnancy progresses, indicating that the potentially beneficial reduction in body volume associated with placentation will be greatest at the beginning of the pregnancy and will gradually diminish towards the end of the interbrood interval (Figure 3-1). 


\section{Material \& Methods}

A detailed description of the species, fish rearing protocols and (pre-)experimental husbandry is provided in the Supporting Information S1. All procedures were approved by the Animal Ethics Committee of Wageningen University \& Research (permit number 2013103). All efforts were made to minimize suffering.

\section{Time schedule and sample size.}

We studied changes in body shape during the pregnancy of Poeciliopsis gracilis (lecithotrophic) and Poeciliopsis turneri (placentotrophic) by creating a series of 3D body reconstructions. For each female, these models were created at evenly spaced time points (every second and every fourth day for P. turneri and $P$. gracilis respectively) during one interbrood interval (IB), defined as the period between two parturitions starting the day after a female gave birth (hereafter referred to as IB $=0$ ) and lasting until the next parturition (IB $=1$ ). To avoid an effect of feeding on body shape (i.e. abdominal extension), the feeding schedules of both species included a 16-24 h food deprivation period prior to the measurements (see S1 for further information regarding feeding). Our final dataset comprised 246 three-dimensional body models for 10 pregnant (plus 10 virgin control) $P$. gracilis and 14 pregnant (plus 14 virgin control) $P$. turneri. Of these 246 body models, six $P$. turneri models were omitted preceding analysis because these females were fed shortly before imaging.

\section{Creation of three-dimensional body models.}

To create a single body model, a fish was first transferred to a small tank $(8 \times$ $8 \times 8 \mathrm{~cm}$ ) with scale bars for image calibration on all walls. Orientation of the female was limited by a separate movable divider. Three photos were taken simultaneously with three Nikon D3200 DSLR cameras (Nikon, Tokyo, Japan; sensor resolution 24 Mpix, equipped with Micro-Nikkor $\mathrm{f}=55 \mathrm{~mm}$ lenses), synchronized with a remote trigger (JinJiaCheng Photography Equipment Co., Ltd., Shenzhen, China) and with LED lights behind glass fibre cloths opposite to the cameras providing diffuse back lighting. The three orthogonally placed cameras yielded a lateral, ventral and rostral/caudal view of the fish. Multiple sets of photos were taken during one measurement session, for further analysis a set of three synchronized pictures was selected in which the fish was in a straight and minimally rotated position. 
Chapter 3 I First evidence for the morphological advantage of matrotrophy

A
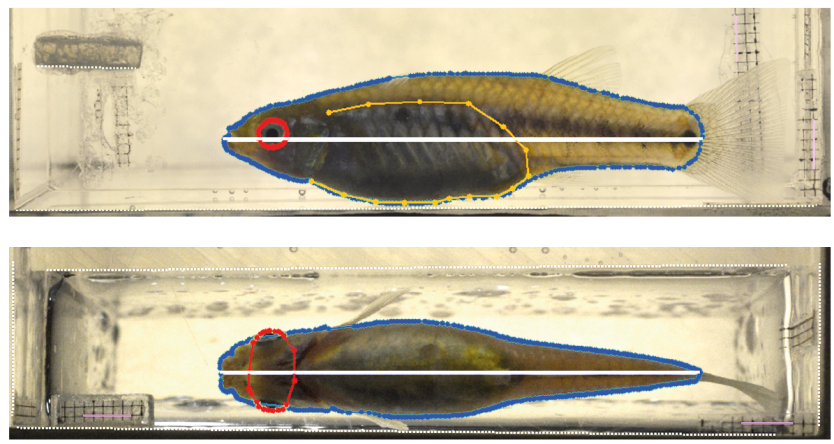

B
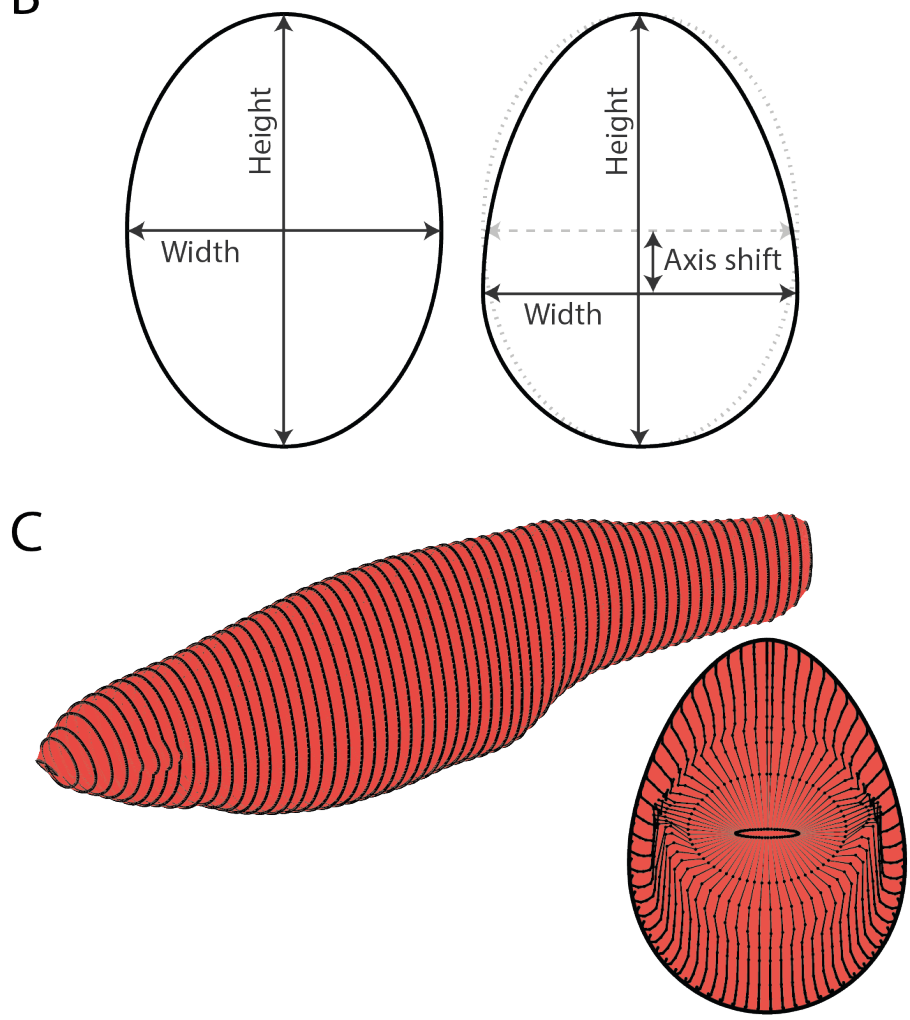

Figure 3-2. Morphological measurement and 3D model construction. A. Lateral and ventral photographs in which the trunk (green), abdomen (orange) and eyes (red) are outlined by manually indicated polygons. The longitudinal axis is depicted by white lines. B. At 251 equidistant points along the longitudinal axis, the width and height of the polygons are converted into ellipse-like cross-sections; in the abdominal area, the vertical position of the horizontal axis is shifted. C. Stitching the cross-sections of trunk and eyes results in a 3D model from which volume, wetted surface area and frontal surface area (projection at the right) can be calculated. For illustrative purposes these examples only consist of one-fourth of the number of cross-sections. 
These photos were subsequently processed with an in-house developed program in MATLAB 2013a (MathWorks, Natick, MA, United States), adapted from a program previously described by [39]. The longitudinal axis of the fish was defined by a straight line between the most anterior point of the snout and the most posterior part of the caudal peduncle (Standard Length, $L_{\mathrm{SL}}$; white lines in Figure 3-2A). The longitudinal axis of the fish consisted of on average $3122(\mathrm{SE} \pm 14)$ pixels and $3193( \pm 15)$ pixels in the lateral and ventral views respectively. Outlines of trunk and eyes were manually digitized (Figure 3-2A, blue and red lines respectively) as was the position of the abdomen of the fish (lateral view only; delimited by the dorsal edge of the vertebral column, swim bladder and the bottom of the abdomen; Figure 3-2A, orange line). After cubic spline interpolation of the outlines, the position of the outlines with respect to the longitudinal axis was measured at 251 equidistant points along the longitudinal axis. Using cubic spline interpolation, these points were subsequently converted into ellipse-like cross-sections, that differed in shape depending on whether the section was located in the abdominal region (Figure 3-2B). In the abdominal region, the minor axis is shifted to half-way the abdominal polygon at that section (default at centre of major axis). Cubic spline interpolations were also used to create a 3D-model of the eyes (with a cubic spline resembling a super-ellipse), which was then stitched to the trunk to create a full 3D-model (Figure 3-2C).

From these 3D models maximum height, maximum width, frontal surface area (area of frontal view projection, Figure 3-2C), wetted surface area (total body surface area), and volume were calculated. Maximum height was determined for the whole body, while maximum width was determined for the abdominal region only as the level of opercular distention (the moment in the breathing cycle) caused the position of the widest point to fluctuate in the slender-most fish. These fluctuations only had a minimal effect on the measured total body volume (on average $0.53 \%$ with respect to the instance with the least distention). To correct for the effect of intra- and interspecies differences in body size, maximum values of all one-dimensional parameters were normalized by dividing the values by $L_{\mathrm{SL}}$, surface areas by dividing by $L_{\mathrm{SL}}{ }^{2}$ and volume was normalized by dividing by $L_{\mathrm{SL}}{ }^{3}$.

\section{Litter wet mass.}

To get an estimate of the partial reproductive allotment at IB $=1$, all newborns from the litter were caught on the day of delivery and euthanized with a lethal dose of MS-222 (Tricaine-S; Western Chemical Inc., Ferndale, WA, United States). Total litter wet mass was measured after carefully removing excess liquid with a paper towel on a Mettler AE200 analytic balance (scale 
accuracy 0.0001 g; Mettler-Toledo B.V., Tiel, The Netherlands). Litter wet mass provides a better approximation of reproductive burden than litter dry mass, because the water content of the embryos contributes to the total volume of the brood. Not all $P$. gracilis litters could be weighed; however, since offspring size did not differ between females (Mixed model, $F_{9,19}=1.31, p=$ 0.2953 ) total litter wet mass was instead estimated using a linear fit between offspring number and measured litter wet mass (wet mass $(\mathrm{g})=0.0078 \cdot N_{\text {new- }}$ $\left.{ }_{\text {borns }} ; R^{2}=0.9469\right)$.

\section{Statistical analysis}

The change in morphological parameters was modelled as a two-level longitudinal growth model [40], using the Mixed procedure (proc mixed) in SAS version 9.3 (SAS Institute, Cary, NC, United States) under restricted maximum likelihood (REML). This multi-level modelling (MLM) method compares individual growth trajectories between species, allows time to be processed as a continuous variable and is able to handle unbalanced and missing data $[40,41]$. The model exists of two levels, the level-one model (Equation 3-1) that represents individual change trajectories, and the level-two model (Equation 3-2, 3-3) that provides intercept and slope term for the sample average. For each individual $\left({ }_{i}\right)$ and time point $\left({ }_{j}\right)$, the measured parameter is a function of the individual intercept $\left(\alpha_{i}\right)$, the individual growth trajectory $\left(\beta_{i} \cdot T_{j}\right)$ and a random error term for that specific individual and time point $\left(\varepsilon_{\mathrm{ij}}\right)$. Litter wet mass $\left(w_{\mathrm{i}}\right)$ at IB $=1$ was added as a covariate in the level-two model for slope (Equation 3-3), as arguably larger broods result in increasingly larger morphological parameters due to a higher growth rate. This also allows comparison of the morphologies without the effect of offspring wet mass. The common intercept $\left(\gamma_{11}\right)$, linear slope $\left(\gamma_{21}\right)$ an covariate $\left(\gamma_{23}\right)$ terms in equations 2 and 3 represent the values for $P$. gracilis while the $\gamma_{12} \gamma_{22}$ and $\gamma_{24}$ terms represent the added difference for $P$. turneri for intercept, linear slope and covariate values respectively; $\zeta_{1 \mathrm{i}}$ and $\zeta_{2 \mathrm{i}}$ factor individual random error terms. 'Variance components' was used as covariance structure (default in SAS proc mixed), denominator degrees of freedom were calculated with Kenward-Roger and significance level alpha was set to 0.05 (default in SAS proc mixed). To compare model parameter estimates, post-hoc tests were performed using contrast and lsmeans statements. Virgin data was analysed using a similar MLM method, albeit with a simpler model. Because we did not expect any time-dependent effects, and the virgin controls did not have litter wet mass to use as a covariate, the model consisted solely of an effect of species. 
Transformation of the data occasionally resulted in slightly better fits as indicated by marginally higher $R^{2}$-values from linear fits (using Proc GLM in SAS version 9.3), but using transformed data did not change the outcomes of the previously mentioned statistical models. Furthermore, we did not have any a priori expectations for the curve of the line. Therefore, we opted to use the original untransformed data and a linear depiction of change.

$$
\begin{aligned}
& Y_{\mathrm{ij}}=\alpha_{\mathrm{i}}+\beta_{\mathrm{i}} \cdot T_{\mathrm{j}}+\varepsilon_{\mathrm{ij}} \\
& \alpha_{\mathrm{i}}=\gamma_{11}+\gamma_{12} \cdot S_{\mathrm{i}}+\zeta_{1 \mathrm{i}} \\
& \beta_{\mathrm{i}}=\left(\gamma_{21}+\gamma_{22} \cdot S_{\mathrm{i}}\right)+\left(\gamma_{23}+\gamma_{24} \cdot S_{\mathrm{i}}\right) \cdot w_{\mathrm{i}}+\zeta_{2 \mathrm{i}}
\end{aligned}
$$

\section{Results}

Type 3 tests for Fixed Effects for both the pregnant and the virgin MLM model can be found in Table 3-S3. All fixed effects in the model were significant, for all measured morphological parameters.

\section{Morphological changes during pregnancy}

At the beginning of the interbrood interval $(\mathrm{IB}=0)$, Poeciliopsis gracilis females have an overall larger normalized body size than females of Poeciliopsis turneri. Except for maximum width (MLM contrast of intercepts: $F_{1,21.2}=2.52, p$ $=0.1275$; Figure 3-3A), females of $P$. gracilis have a higher maximum height $\left(F_{1,21.4}=15.46, p=0.0007\right.$; Figure 3-3B $)$, frontal surface area $\left(F_{1,21.6}=12.49, p=\right.$ 0.0019; Figure 3-3C), wetted surface area $\left(F_{1,24.8}=18.17, p=0.0003\right.$; Figure 3-3D) and volume $\left(F_{1,24.3}=12.10, p=0.0019\right.$; Figure 3-3E) than females of $P$. turneri.

We found that $P$. turneri increases in body size faster than females of $P$. gracilis, as indicated by the steeper slopes of the former species in maximum width (MLM contrast of slopes: $F_{1,23}=11.42, p=0.0026$; Figure 3-3A), maximum height $\left(F_{1,17.9}=13.01, p=0.0020\right.$; Figure 3-3B $)$, frontal surface area $\left(F_{1,21.6}\right.$ $=11.84, p=0.0024$; Figure 3-3C), wetted surface area $\left(F_{1,21.1}=6.76, p=0.0167\right.$; Figure 3-3D) and volume $\left(F_{1,22.2}=5.92, p=0.0235\right.$; Figure 3-3E). As a consequence, the measured differences at IB $=0$ diminished towards the end of pregnancy $(\mathrm{IB}=1)$ (post hoc comparison, maximum height: $p=0.6531$; frontal surface area: $p=0.0866$; wetted surface area: $p=0.9541$; volume: $p=0.4696$; Figure 3-3 B - E respectively), while at this point in time females of $P$. turneri have a larger maximum width ( $p=0.0127$; Figure $3-3 \mathrm{~A})$. 

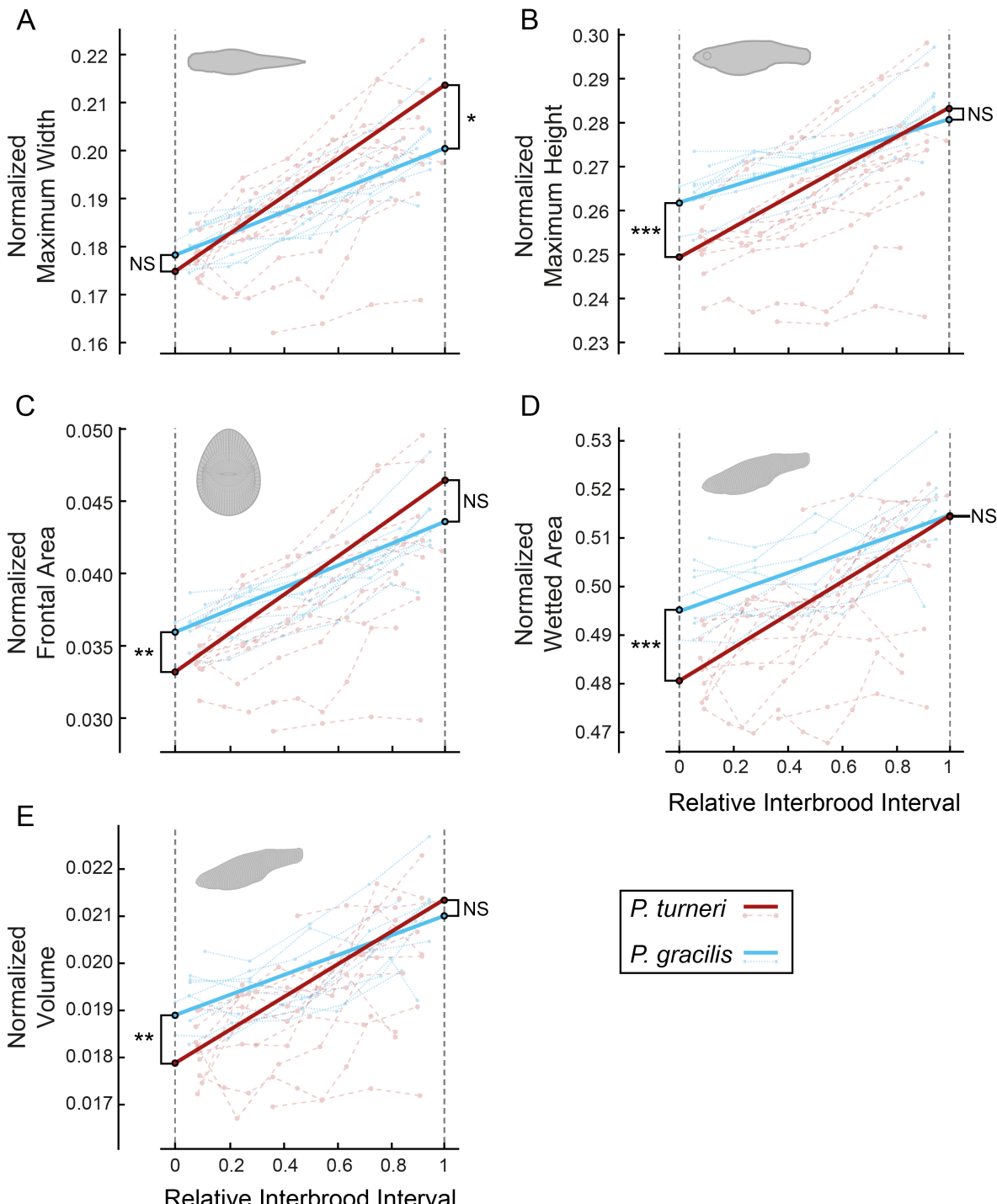

Relative Interbrood Interval

Relative Interbrood Interval

Figure 3-3. Shape parameters of pregnant $P$. turneri (with placenta) and P. gracilis (without placenta) from $N=122$ three-dimensional models. The multi-level longitudinal growth models (MLM) indicate changes in normalized maximum width (A), maximum height (B), frontal surface area (C), wetted surface area (D) and volume $($ E) during one interbrood interval for pregnant $P$. turneri (red, $N=14$ ) and $P$. gracilis (blue, $N=10$ ). To account for individual variation in body size, one-dimensional parameters ( $A$ and $B$ ) were normalized by dividing the values by standard length $\left(L_{S L}\right)$, the surface areas (C and D) by dividing by $L_{S L}{ }^{2}$ and volume (E) by dividing by $L_{\mathrm{sL}}{ }^{3}$. Connected circles represent individual female growth trajectories, solid lines are plotted from the MLM estimates for intercept and slope with equal litter wet $\operatorname{mass}\left(\mathrm{NS}=p>0.05,{ }^{*}=0.01<p<0.05,{ }^{* *}=0.001<p<0.01,{ }^{* * *}=p<0.001\right)$. Projections show examples of the respective model projections $(A-C)$ or the complete model $(D, E)$. 


\section{Morphological differences between virgins}

In line with the measured differences at $\mathrm{IB}=0$ for their pregnant conspecifics, virgin fish of $P$. gracilis (P.g.) have a larger overall normalized body size than virgins of $P$. turneri (P.t.). We found significant effects of species on maximum width (MLM contrast: $F_{1,20.9}=39.62, p<0.0001$; MLM estimate \pm SE: P.g. $0.1800 \pm 0.0021$, P.t. $0.1624 \pm 0.0018)$, maximum height $\left(F_{1,21.2}=84.02, p<\right.$ 0.0001 ; P.g. $0.2652 \pm 0.0025$, P.t. $0.2354 \pm 0.0021)$, frontal surface area $\left(F_{1,20.6}=\right.$ $77.98, p<0.0001$; P.g. $0.0367 \pm 0.0006$, P.t. $0.0298 \pm 0.0005)$, wetted surface area $\left(F_{1,19.5}=35.28, p<0.0001\right.$; P.g. $0.4972 \pm 0.0032$, P.t. $\left.0.4726 \pm 0.0027\right)$, and volume $\left(F_{1,19.3}=32.62, p<0.0001\right.$; P.g. $0.0191 \pm 0.0003$, P.t. $\left.0.0171 \pm 0.0002\right)$.

\section{Discussion}

A key aspect of this study is that we compare two different reproductive states (pregnant and virgin fish) in two closely related 'sister' species that differ in the way that they provision their embryos [7]: Poeciliopsis gracilis is a lecithotrophic species that lacks a placenta, while Poeciliopsis turneri represents one of three independent origins of extensive placentation in the genus Poeciliopsis $[7,10]$. Poeciliopsis gracilis and P. turneri have moderate levels of a second reproductive adaptation called superfetation, which is the ability of a female to carry simultaneous litters that are each at a different stage of development $[23,36]$. Due to smaller litters per parturition, higher levels of superfetation could result in reduced litter wet mass (Table 3-S4). Since the level of superfetation also affects the length of the interbrood interval $[9,23,42]$, time was normalized in our MLM models to account for variation in interbrood interval both within and between species. In absolute terms, the difference in growth rate between the two species would be even more pronounced than is currently shown by our results. Finally, we measured the morphology of virgin controls, because they offer a morphological 'baseline' similar to the start of the first pregnancy: all virgin females carried unfertilized, fully yolk-provisioned eggs but were not yet affected by having to carry overlapping broods (superfetation). We showed that virgins of $P$. turneri have a more slender body shape than those of $P$. gracilis, in line with the observed differences at the beginning of the interbrood interval of pregnant females. Together these findings provide the first evidence in support of two key predictions of the locomotor cost hypothesis that the evolution of post-fertilization maternal provisioning by means of a placenta leads to a more slender body shape at the beginning of the pregnancy, and that this 'morphological benefit' diminishes over the course of the pregnancy (Figure $3-1 ;[9,36,37])$. Our results further show that maximum width is higher in fe- 
Chapter 3 I First evidence for the morphological advantage of matrotrophy

males of $P$. turneri during late pregnancy which could lead to a reduction in abdominal flexibility during this period, more than experienced by $P$. gracilis.

Whether, and to what extent, the measured morphological differences translate directly into differences in swimming performance requires further investigation, as other parameters that determine performance (e.g. physiology, flexural stiffness) could also be affected by pregnancy. Body shape, however, is known to affect the drag forces a fish experiences during swimming, such that more slender animals have a better continuous swimming performance and lower metabolic costs of swimming (e.g. [43-47]). There are two main types of drag that act on swimming fish of this size: pressure drag and friction drag; the former is related to the frontal surface area and the latter to the wetted surface area $[48,49]$. In P. turneri, both surface areas are lower at the beginning of pregnancy, and increase more rapidly over time than in $P$. gracilis (Figure 3-3 C-D), implying an absolute benefit during the early stages and a mean benefit over the whole interbrood interval. During undulatory swimming, the experienced drag is highly complex due to the changing pressure and shear stress distribution on the deforming body [50]. It is, however, apparent that the survival value of optimizing swimming speed and cost of transport (and thus reducing drag forces on the body) could be a driving force behind the evolution of fish morphology [51].

To study female morphology in three dimensions, we used a novel method for collecting longitudinal data, adapted from an in-house developed program originally designed to create 3D-models for zebrafish (Danio rerio) larvae [39]. Our method offers two advantages over conventional two-dimensional geometric morphometric approaches. First, we took pictures while the female is in the water, thereby avoiding the need to kill, anesthetize and/or handle the fish with a paintbrush or tweezers [26,52-56]. Minimizing stress, potential physical damage and risk of death is particularly important in longitudinal studies where a single individual is measured repeatedly over a period of time. Second, we use information from 251 equidistant cross-sections and two orthogonal planes to reconstruct 3D body models. Even in a single 2D-plane (e.g. lateral view), our method produces a more accurate approximation of female body shape than landmark-based geometric morphometric approaches, which are often based on a limited number of (semi-) landmarks (typically between 12 to 17) and are hampered by a lack of clear landmarks in the abdominal region of pregnant females [52-56]. Perhaps more importantly, we show that different planes can yield different patterns of shape change through time (e.g. compare the effects in maximum width 
and height; Figure 3-3 A, B), suggesting that information from one plane cannot be readily used to make inferences about temporal changes during the pregnancy in the other planes nor overall streamlining (e.g. volume or frontal surface area).

We studied only one of eight independent origins of the evolution of the placenta in the family Poeciliidae $[8,10]$. To test the generality of our results, a wider comparative survey is required that includes other independent evolutionary origins of the placenta. Recent studies in the family Poeciliidae have revealed three independent origins of placentation in the genus Poeciliopsis (of which this study examined one; [7]) and two independent origins of placentation in the genus Poecilia (in the subgenera Micropoecilia and Pamphorichthys, respectively; [57,58]). These (sub)genera contain closely related species that differ in whether they have a placenta and are eminently suitable for further comparative experimental studies $[13,14,23,24,37]$ to test whether the morphological benefits we found in this study are repeated in other placental lineages.

Moreover, it is possible that drag reduction is one of the driving forces behind the evolution of a placenta in other families of live-bearing bony fish (e.g. Goodeidae) [59-61] and of a placenta or other ways of post-fertilization nutrient allocation (matrotrophy) in live-bearing cartilaginous fishes $[5,62,63]$. Furthermore, it could be worthwhile to study the effects of a placenta on morphology and relevant performance parameters in animals that otherwise try to maximize slenderness, for instance live-bearing Squamate reptiles with a predominantly burrowing or 'sand-swimming' mode of locomotion (e.g. viviparous skinks) [64] or animals that are girth-restricted, for instance by the crevices they inhabit [65].

To conclude, in this study we compared changes in volume and frontal surface area during gestation between a lecithotrophic and a placental fish species using a new 3D-modelling approach. Consistent with the locomotor cost hypothesis, our results provide first evidence that the evolution of a placenta can lead to a more slender body shape at the start of the pregnancy and that this effect disappears towards the end of the pregnancy (Figure 3-1, Figure 3-3). To test the generality of our findings, future research should focus on additional independent placental lineages. The biomechanical importance of drag reduction for locomotion, however, suggests that the locomotor cost hypothesis could potentially be applicable to the evolution of placentas in other swimming live-bearing lineages. 
Chapter 3 I First evidence for the morphological advantage of matrotrophy

\section{Author contributions}

M.F. and B.J.A.P. came up with the idea for this study, M.F., E.M.Q. J.L.V.L. and B.J.A.P. designed the experiment, M.F. and E.M.Q. build the experimental set up, performed the experiments and created the 3D models, M.F. analysed the data and wrote the first draft, M.F. and B.J.A.P. wrote the final draft with input from J.L.V.L.

\section{Acknowledgements}

We thank David Reznick (UC Riverside) for supplying the stocks for our study species and Cees J. Voesenek for his help with the custom-made MATLAB program. We further thank David Reznick, Andrew Furness (UC Irvine) and the Experimental Zoology Journal Club for commenting on an earlier version of the manuscript. 


\section{References}

1. Mossman HW. Comparative morphogenesis of the fetal membranes and accessory uterine structures. Contrib Embryol. 1937;26: 129-246.

2. Wourms JP. Viviparity: the maternal-fetal relationships in fishes. Am Zool. 1981;21: 473-515.

3. Wourms JP, Grove BD, Lombardi J. The maternal-embryonic relationship in viviparous fishes. In: Hoar WS, Randal DJ, editors. Fish Physiology. New York: Academic Press; 1988. pp. 1-134.

4. Wake MH. Evolutionary Scenarios, Homology and Convergence of Structural Specializations for Vertebrate Viviparity. Am Zool. 1992;32: 256-263.

5. Blackburn DG. Evolution of vertebrate viviparity and specializations for fetal nutrition: A quantitative and qualitative analysis. J Morphol. 2015;276: 961-990. doi:10.1002/jmor.20272

6. Ostrovsky AN, Lidgard S, Gordon DP, Schwaha T, Genikhovich G, Ereskovsky A V. Matrotrophy and placentation in invertebrates: a new paradigm. Biol Rev. 2016;91: 673-711. doi:10.1111/brv.12189

7. Reznick DN, Mateos M, Springer MS. Independent origins and rapid evolution of the placenta in the fish genus Poeciliopsis. Science 2002;298: 1018-1020. doi:10.1126/science.1076018

8. Hrbek T, Seckinger J, Meyer A. A phylogenetic and biogeographic perspective on the evolution of poeciliid fishes. Mol Phylogenet Evol. 2007;43: 986-998.

9. Pollux BJA, Pires MN, Banet AI, Reznick DN. Evolution of Placentas in the Fish Family Poeciliidae: An Empirical Study of Macroevolution. Annu Rev Ecol Evol Syst. 2009;40: 271-289. doi:DOI 10.1146/annurev. ecolsys.110308.120209

10. Pollux BJA, Meredith RW, Springer MS, Garland T, Reznick DN. The evolution of the placenta drives a shift in sexual selection in livebearing fish. Nature. 2014;513: 233-236. doi:10.1038/nature13451

11. Trexler JC, DeAngelis DL. Resource allocation in offspring provisioning: An evaluation of the conditions favoring the evolution of matrotrophy. Am Nat. 2003;162: 574-585. doi:10.1086/378822

12. Reznick DN, Yang AP. The influence of fluctuating resources on life history: patterns of allocation and plasticity in female guppies. Ecology. 1993;74: 2011-2019.

13. Banet AI, Reznick DN. Do placental species abort offspring? Testing an assumption of the Trexler-DeAngelis model. Funct Ecol. 2008;22: 323331. doi:10.1111/j.1365-2435.2007.01367.x

14. Banet AI, Au AG, Reznick DN. Is mom in charge? Implications of resource provisioning on the evolution of the placenta. Evolution (N Y). 2010;64: 3172-3182. doi:10.1111/j.1558-5646.2010.01059.x 
Chapter 3 I First evidence for the morphological advantage of matrotrophy

15. Pollux BJA, Reznick DN. Matrotrophy limits a female's ability to adaptively adjust offspring size and fecundity in fluctuating environments. Funct Ecol. 2011;25: 747-756. doi:10.1111/j.1365-2435.2011.01831.x

16. Blackburn DG, Vitt LJ, Beuchat CA. Eutherian-like reproductive specializations in a viviparous reptile. Proc Natl Acad Sci. 1984;81: 4860-4863. doi:10.1073/pnas.81.15.4860

17. Wourms JP, Lombardi J. Reflections on the evolution of piscine viviparity. Am Zool. 1992;32: 276-293. Available: http://icb.oxfordjournals.org/ content $/ 32 / 2 / 276$.short

18. Trexler JC. Resource Availability and Plasticity in Offspring Provisioning: Embryo Nourishment in Sailfin Mollies. Ecology. 1997;78: 13701381.

19. Holbrook GL, Schal C. Maternal investment affects offspring phenotypic plasticity in a viviparous cockroach. Proc Natl Acad Sci U S A. 2004;101: 5595-5597. doi:10.1073/pnas.0400209101

20. Schrader M, Travis J. Population Differences in Pre- and Post-Fertilization Offspring Provisioning in the Least Killifish, Heterandria formosa. Copeia. 2005;2005: 649-656.

21. Wildman DE, Chen C, Erez O, Grossman LI, Goodman M, Romero R. Evolution of the mammalian placenta revealed by phylogenetic analysis. Proc Natl Acad Sci. 2006;103: 3203-3208. doi:10.1073/pnas.0511344103

22. Reznick DN, Meredith R, Collette BB. Independent Evolution of Complex Life History Adaptations in Two Families of Fishes, Live-bearing Halfbeaks (Zenarchopteridae, Beloniformes) and Poeciliidae (Cyprinodontiformes). Evolution (NY). 2007;61: 2570-2583.

23. Pires MN, Bassar RD, McBride KE, Regus JU, Garland T, Reznick DN. Why do placentas evolve? An evaluation of the life-history facilitation hypothesis in the fish genus Poeciliopsis. Funct Ecol. 2011;25: 757-768. doi:10.1111/j.1365-2435.2011.01842.x

24. Bassar RD, Auer SK, Reznick DN. Why do placentas evolve? A test of the life-history facilitation hypothesis in two clades in the genus Poeciliopsis representing two independent origins of placentas. Funct Ecol. 2014;28: 999-1010. doi:10.1111/1365-2435.12233

25. Shaffer LR, Formanowicz DR. A cost of viviparity and parental care in scorpions: Reduced sprint speed and behavioural compensation. Anim Behav. 1996;51: 1017-1023. doi:DOI 10.1006/anbe.1996.0104

26. Plaut I. Does pregnancy affect swimming performance of female Mosquitofish, Gambusia affinis? Funct Ecol. 2002;16: 290-295. doi:DOI 10.1046/j.1365-2435.2002.00638.x

27. Ghalambor CK, Reznick DN, Walker JA. Constraints on adaptive evolution: the functional trade-off between reproduction and fast-start swimming performance in the Trinidadian guppy (Poecilia reticulata). Am Nat. 2004;164: 38-50. doi:10.1086/421412 
28. Belk MC, Tuckfield RC. Changing costs of reproduction: age-based differences in reproductive allocation and escape performance in a livebearing fish. Oikos. 2010;119: 163-169. doi:10.1111/j.1600-0706.2009.17742.x

29. Banet AI, Svendsen JC, Eng KJ, Reznick DN. Linking reproduction, locomotion, and habitat use in the Trinidadian guppy (Poecilia reticulata). Oecologia. 2016;181: 87-96.

30. Shine R. "Costs" of reproduction in reptiles. Oecologia. 1980;46: 92-100. Available: http://link.springer.com/article/10.1007/BF00346972

31. Winne CT, Hopkins WA. Influence of sex and reproductive condition on terrestrial and aquatic locomotor performance in the semi-aquatic snake Seminatrix pygaea. Funct Ecol. 2006;20: 1054-1061.

32. Wu W, Meijer OG, Lamoth CJC, Uegaki K, Van Dieën JH, Wuisman PIJM, et al. Gait coordination in pregnancy: transverse pelvic and thoracic rotations and their relative phase. Clin Biomech (Bristol, Avon). 2004;19: 480-488. doi:10.1016/j.clinbiomech.2004.02.003

33. Noren SR, Redfern JV, Edwards EF. Pregnancy is a drag: hydrodynamics, kinematics and performance in pre- and post-parturition bottlenose dolphins (Tursiops truncatus). J Exp Biol. 2011;214: 4151-9. doi:10.1242/ jeb.059121

34. Langerhans RB, Reznick DN. Ecology and Evolution of Swimming Performance in Fishes: Predicting Evolution with Biomechanics. In: Domenici P, Kapoor BG, editors. Fish Locomotion. Science Publishers; 2010. pp. 200-248. doi:10.1201/b10190-8

35. James R, Johnston I. Influence of spawning on swimming performance and muscle contractile properties in the short-horn sculpin. J Fish Biol. 1998;53: 485-501. doi:10.1006/jfbi.1998.0722

36. Thibault RE, Schultz RJ. Reproductive adaptations among viviparous fishes (Cyprinodontiformes: Poeciliidae). Evolution (NY). 1978;32: 320333. Available: http://www.jstor.org/stable/10.2307/2407600

37. Pires MN, Arendt J, Reznick DN. The evolution of placentas and superfetation in the fish genus Poecilia (Cyprinodontiformes: Poeciliidae: subgenera Micropoecilia and Acanthophacelus). Biol J Linn Soc. 2010;99: 784-796. doi:10.1111/j.1095-8312.2010.01391.x

38. Walker JA, Ghalambor CK, Griset OL, McKenney D, Reznick DN. Do faster starts increase the probability of evading predators? Funct Ecol. 2005;19: 808-815. doi:DOI 10.1111/j.1365-2435.2005.01033.x

39. Voesenek CJ, Pieters RPM, Van Leeuwen JL. Automated reconstruction of three-dimensional fish motion, forces, and torques. PLoS One. 2016;11: e0146682. doi:10.1371/journal.pone.0146682

40. Singer JD. Using SAS PROC MIXED to fit multilevel models, hierarchical models, and individual growth models. J Educ Behav Stat. 1998;23: 323-355. doi:10.3102/10769986023004323 
Chapter 3 I First evidence for the morphological advantage of matrotrophy

41. Singer JD, Willett JB. Applied longitudinal data analysis: Modeling change and event occurrence. New York: Oxford University Press, Inc.; 2003.

42. Reznick DN, Miles DB. Review of life history patterns in Poeciliid fishes. In: Meffe GK, Snelson FF, editors. Ecology and Evolution of Livebearing Fishes (Poeciliidae). Prentice Hall, Englewood Cliffs, NJ; 1989. pp. $125-148$.

43. Pettersson LB, Hedenström A. Energetics, Cost Reduction and Functional Consequences of Fish Morphology. Proc R Soc B. 2000;267: 759-764.

44. Weihs D. Stability Versus Maneuverability in Aquatic Locomotion 1. Integr Comp Biol. 2002;42: 127-134.

45. Law TC, Blake RW. Comparison of the Fast-Start Performances of Closely Related, Morphologically Distinct Threespine Sticklebacks (Gasterosteus spp.). J Fish Biol. 2005;67: 834-848. doi:10.1111/j.1095-8649.2005.00788.x

46. Langerhans RB. Morphology, performance, fitness: functional insight into a post-Pleistocene radiation of mosquitofish. Biol Lett. 2009;5: 488491. doi:10.1098/rsbl.2009.0179

47. Van Wassenbergh S, Potes NZ, Adriaens D. Hydrodynamic drag constrains head enlargement for mouthbrooding in cichlids. J R Soc Interface. 2015;12: 20150461. doi:10.1098/rsif.2015.0461

48. Sfakiotakis M, Lane DM, Davies JBC. Review of fish swimming modes for aquatic locomotion. IEEE J Ocean Eng. 1999;24: 237-252. doi:10.1109/48.757275

49. Videler JJ. Fish Swimming. 1st ed. Videler JJ, editor. London: Chapman \& Hall; 1993.

50. Tytell ED, Borazjani I, Sotiropoulos F, Baker TV, Anderson EJ, Lauder G V. Disentangling the functional roles of morphology and motion in the swimming of fish. Integr Comp Biol. 2010;50: 1140-1154. doi:10.1093/ icb/icq057

51. Tokic G, Yue DKP. Optimal shape and motion of undulatory swimming organisms. Proc R Soc B Biol Sci. 2012;279: 3065-3074. doi:10.1098/ rspb.2012.0057

52. Zúñiga-Vega JJ, Reznick DN, Johnson JB. Habitat predicts reproductive superfetation and body shape in the livebearing fish Poeciliopsis turrubarensis. Oikos. 2007; 995-1005. doi:10.1111/j.2007.0030-1299.15763.x

53. Zúñiga-Vega JJ, Suárez-Rodríguez M, Espinosa-Pérez H, Johnson JB. Morphological and reproductive variation among populations of the Pacific molly Poecilia butleri. J Fish Biol. 2011;79: 1029-1046. doi:10.1111/ j.1095-8649.2011.03081.x

54. Wesner JS, Billman EJ, Meier A, Belk MC. Morphological convergence during pregnancy among predator and nonpredator populations of the livebearing fish Brachyrhaphis rhabdophora (Teleostei: Poeciliidae). Biol J Linn Soc. 2011;104: 386-392. doi:10.1111/j.1095-8312.2011.01715.x 
55. Ingley SJ, Billman EJ, Belk MC, Johnson JB. Morphological divergence driven by predation environment within and between species of brachyrhaphis fishes. PLoS One. 2014;9: 31-36. doi:10.1371/journal. pone.0090274

56. Frías-Alvarez P, Zúñiga-Vega JJ. Superfetation in live-bearing fishes is not always the result of a morphological constraint. Oecologia. 2016;181: 645-658. doi:10.1007/s00442-015-3477-1

57. Meredith RW, Pires MN, Reznick DN, Springer MS. Molecular phylogenetic relationships and the coevolution of placentotrophy and superfetation in Poecilia (Poeciliidae: Cyprinodontiformes). Mol Phylogenet Evol. 2011;59: 148-57. doi:10.1016/j.ympev.2011.01.014

58. Meredith RW, Pires MN, Reznick DN, Springer MS. Molecular phylogenetic relationships and the evolution of the placenta in Poecilia (Micropoecilia) (Poeciliidae: Cyprinodontiformes). Mol Phylogenet Evol. 2010;55: 631-639. doi:10.1016/j.ympev.2009.11.006

59. Uribe MC, Aguilar-Morales M, De la Rosa-Cruz G, García-Alarcón A, Campuzano-Caballero JC, Guerrero-Estévez SM. Ovarian Structure and Embryonic Traits Associated with Viviparity in Poeciliids and Goodeids. In: Uribe MC, Grier HJ, editors. Viviparous fishes II. New Life Publications, Homestead, Florida; 2010. pp. 211-229.

60. Uribe MC, De la Rosa-Cruz G, García-Alarcón A. Branchial placenta in the viviparous teleost Ilyodon whitei (Goodeidae). J Morphol. 2014;275: 1406-1417. doi:10.1002/jmor.20315

61. Schindler JF. Structure and function of placental exchange surfaces in goodeid fishes (Teleostei: Atheriniformes). J Morphol. 2015;276: 9911003. doi:10.1002/jmor.20292

62. Dulvy NK, Reynolds JD. Evolutionary transitions among egg-laying, live-bearing and maternal inputs in sharks and rays. Proc R Soc B Biol Sci. 1997;264: 1309-1315. doi:10.1098/rspb.1997.0181

63. Hamlett WC, Kormanik G, Storrie M, Stevens BS, Walker TI. Chondrichthyan Parity, Lecithotrophy and Matrotrophy. In: Hamlett WC, editor. Reproductive Biology and Phylogeny of Chondrichthyes. CRC Press; 2005. pp. 395-434.

64. Stewart JR, Blackburn DG. Viviparity and Placentation in Lizards. In: Rheubert JL, Siegel DS, Trauth SE, editors. Reproductive Biology and Phylogeny of Lizards and Tuatara. CRC Press; 2014. pp. 448-563.

65. Schwarzkopf L, Barnes M, Goodman B. Belly up: Reduced crevice accessibility as a cost of reproduction caused by increased girth in a rock-using lizard. Austral Ecol. 2010;35: 82-86. doi:DOI 10.1111/j.14429993.2009.02015.x 
Chapter 3 I First evidence for the morphological advantage of matrotrophy

\section{Supporting Material S1. Fish rearing, feeding and husbandry}

\section{Study species}

Poeciliopsis gracilis originated from a small tributary of Rio Motagua, near the village Jones in Zacapa (Guatemala), and Poeciliopsis turneri were collected in Rio Purificacion, near Casimiro Castillo, Jalisco (Mexico). These fish stocks were originally housed at the Reznick lab (University of California Riverside, USA). The fish used in the experiments were bred from laboratory stocks that originate from the Reznick lab and are currently held at the CARUS Aquatic Research Facilities at Wageningen University \& Research (the Netherlands).

Poeciliopsis gracilis and P. turneri are closely-related 'sister'-species that differ markedly in when and how they provision their developing embryos [7]. The matrotrophy index (MI), a dimensionless number defined as the dry mass of the neonate at birth divided by the dry mass of the egg at fertilization, can be used as a proxy for the level of post-fertilization maternal provisioning: P. gracilis has an MI of 0.69 (lecithotrophic) and P. turneri an MI of 41.4 (placentotrophic, [7]). Both exhibit a moderate degree of superfetation, the presence of multiple broods that differ in the developmental stage of the embryos [24,42], the differences in degree of superfetation are reflected in interbrood interval (mean $( \pm$ SE) P. gracilis $18.3( \pm 0.26)$ days vs. P. turneri 11.9 $( \pm 0.90)$ days; Table 3-S4).

\section{Fish rearing \& pre-experimental husbandry}

Breeding stocks were kept in $40 \mathrm{~L}$ tanks. From these tanks, new-born juveniles were moved to other stock tanks based on age cohort (age differences within cohorts spanning $2-4$ weeks). Sexual maturity was monitored daily and males were removed when sexual characteristics started to develop. Female fish were allowed to grow to a length of approximately $4 \mathrm{~cm}( \pm 4-6$ months after parturition), after which they were isolated in $9 \mathrm{~L}$ isolation tanks (Tecniplast, Bugugiatte, Italy) enriched with gravel and a plastic plant. The water in the isolation tanks was maintained at $24-25^{\circ} \mathrm{C}$ and refreshed $(\sim 18 \mathrm{l} \cdot \mathrm{h}-1)$. To ensure homogenisation of water quality among the isolation tanks, all tanks were supplied with water coming from the same biological filtering system. A juvenile conspecific was added to the tanks with virgin $P$. gracilis to reduce potential stress of isolation. The fish were randomly assigned to either a pregnant- or a virgin-treatment group, with one individual of each combined into a 'measurement block'. One to three males were added to tanks of the pregnant group, and switched around regularly. All 
companion fish were removed before the start of the experiments. Before the experiments started, the pregnant fish were allowed to go through at least three parturition events, as the first pregnancies are often smaller in brood size and number (Pollux \& Reznick, unpublished data). Tanks were checked for new-borns at least once a day and parturition history was meticulously documented. Because of an initial high mortality in the isolated P. turneri, 7 additional pregnant females were randomly taken from the stock tanks and included in our study.

\section{Fish feeding protocol}

Stock fish were fed recently hatched brine shrimp (Artemia nauplii) in the morning (around $8 \mathrm{AM}$ ), and either flake paste (TetraMin; Tetra $\mathrm{GmbH}$, Melle, Germany; on Tuesday, Thursday, Saturday and Sunday) or liver paste (Monday, Wednesday and Friday) in the afternoon (around 4 PM). The diet of isolated females consisted of flake- and liver paste during both the mornings and afternoons (days similar to stock), except during the weekend when the females received Artemia nauplii. In addition, at the end of each day each isolated female was fed adult brine shrimp. Sixteen to 24 hours prior to the measurements, females were deprived of food to avoid an effect of feeding on body shape (i.e. abdominal extension). 
Chapter 3 I First evidence for the morphological advantage of matrotrophy

Table 3-S3. Multi-level Modelling output for fixed effects in the pregnant and virgin control models, for all measured morphological parameters. LWM: Litter wet mass

\begin{tabular}{|c|c|c|c|c|}
\hline $\begin{array}{l}\text { Type } 3 \text { Test } \\
\text { of Fixed Effects }\end{array}$ & Species & Species $\times$ Time & Species $\times$ Tim & $\times$ LWM \\
\hline \multicolumn{5}{|l|}{ Pregnant model } \\
\hline Maximum width & $F_{2,21.3}=11879.6, \quad p<0.0001$ & $F_{2,23.3}=94.60, p<0.0001$ & $F_{2,19.5}=10.11$ & $p=0.0010$ \\
\hline Maximum height & $F_{2,21.5}=12600.0, p<0.0001$ & $F_{2,18.0}=95.08, p<0.0001$ & $F_{2,17.5}=9.95$ & $p=0.001$ \\
\hline Frontal surface area & $F_{2,21.7}=3978.58, p<0.0001$ & $F_{2,21.9}=99.70, p<0.0001$ & $F_{2,19.7}=12.44$ & $p=0.0003$ \\
\hline Wetted surface area & $F_{2,25.0}=44623.4, p<0.0001$ & $F_{2,21.4}=59.97, p<0.0001$ & $F_{2,18.3}=6.45$ & $p=0.0076$ \\
\hline Volume & $F_{2,24.5}=8327.83, p<0.0001$ & $F_{2,22.5}=60.12, p<0.0001$ & $F_{2,18.3}=7.76$ & $p=0.0036$ \\
\hline \multicolumn{5}{|l|}{ Virgin model } \\
\hline Maximum width & $F_{2,20.9}=7554.59, p<0.0001$ & & & \\
\hline Maximum height & $F_{2,21.3}=11952.4, p<0.0001$ & & & \\
\hline Frontal surface area & $F_{2,20.6}=3620.88, p<0.0001$ & & & \\
\hline Wetted surface area & $F_{2,19.5}=28014.9, p<0.0001$ & & & \\
\hline Volume & $F_{2,19.3}=5224.14, p<0.0001$ & & & \\
\hline
\end{tabular}

Table 3-S4. General and reproductive parameters of the experimental fish used in this study.

\begin{tabular}{|c|c|c|c|c|c|c|}
\hline \multirow[b]{2}{*}{ Species } & \multirow[b]{2}{*}{ Treatment } & \multirow[b]{2}{*}{$N_{\text {female }}$} & \multicolumn{4}{|c|}{ Mean ( \pm SE) } \\
\hline & & & $L_{\mathrm{SL}}(\mathrm{m})$ & IB Interval (days) & $N_{\text {models per individual }}$ & Litter Wet Mass (g) \\
\hline \multirow[t]{2}{*}{$P$ gracilis } & Pregnant & 10 & $0.047(0.001)$ & $18.3(0.03)$ & $4.9(0.2)$ & $0.1794(0.0143)$ \\
\hline & Virgin & 10 & $0.048(0.001)$ & & & \\
\hline \multirow[t]{2}{*}{ P. turneri } & Pregnant & 14 & $0.047(0.001)$ & $11.9(0.9)$ & $5.6(0.4)$ & $0.1073(0.0090)$ \\
\hline & Virgin & 14 & $0.048(0.001)$ & & & \\
\hline
\end{tabular}




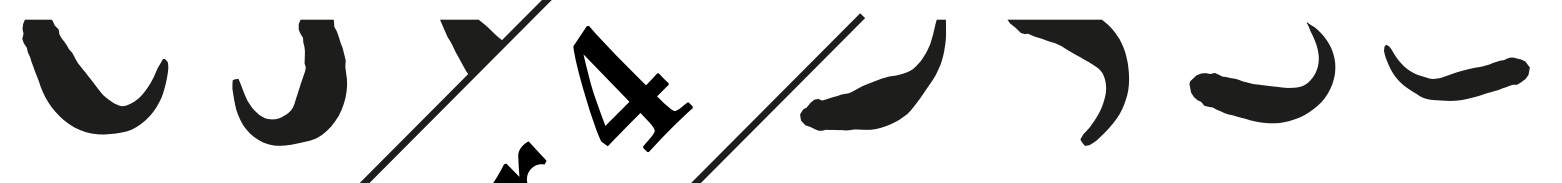

$\checkmark v$
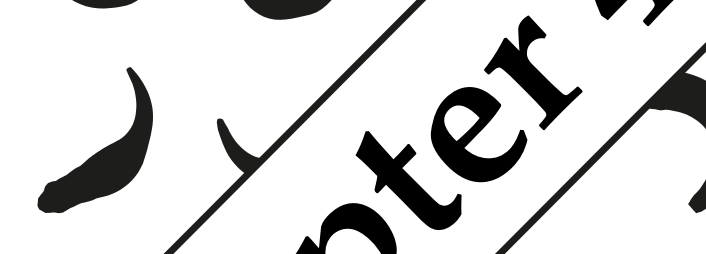

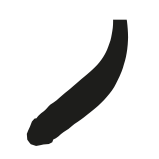

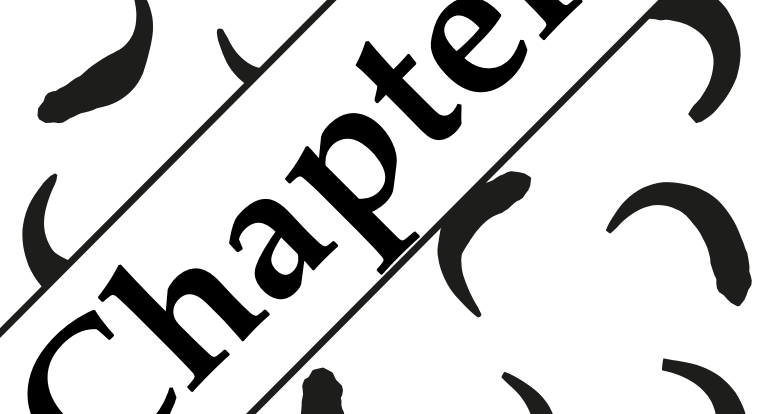
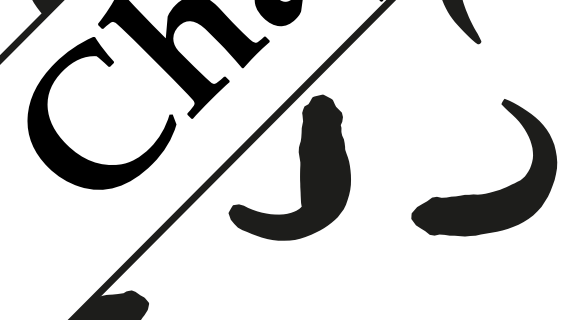

$\checkmark v$

)

n

4

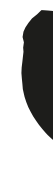
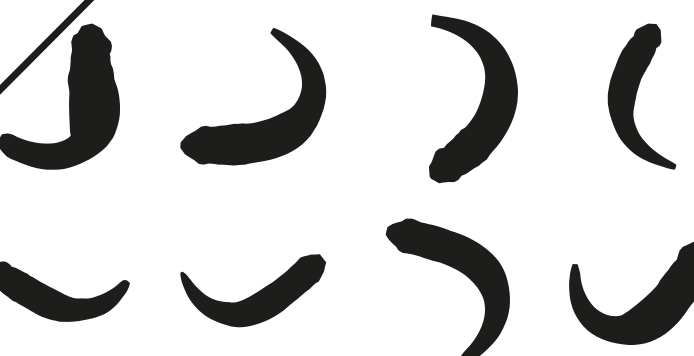

010

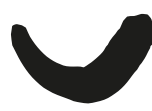

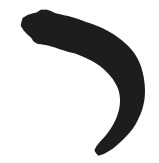

$\checkmark$

-
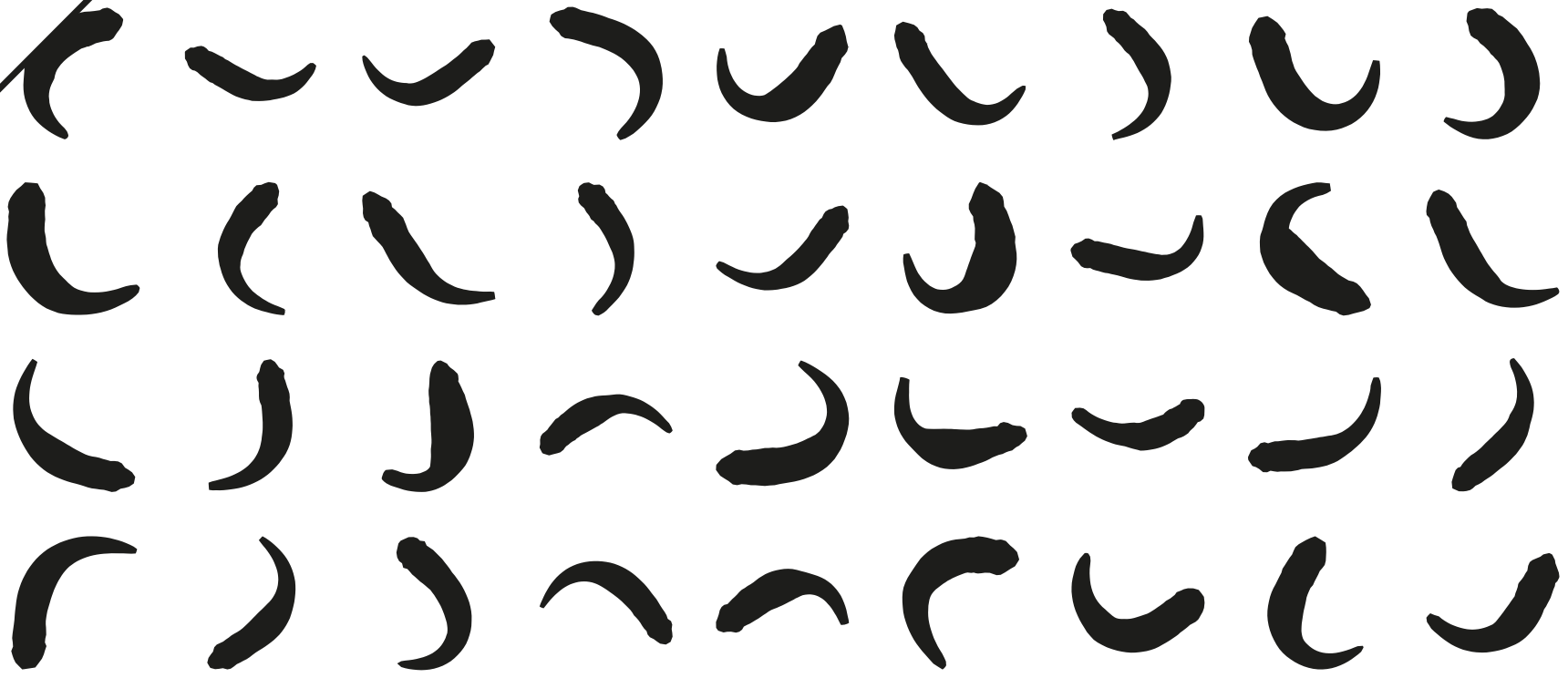

$\checkmark$
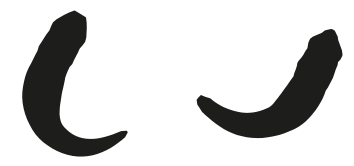

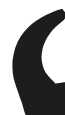
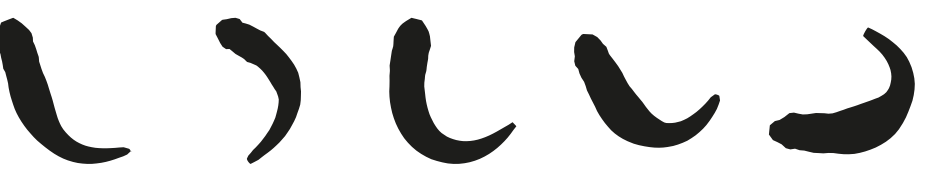

n
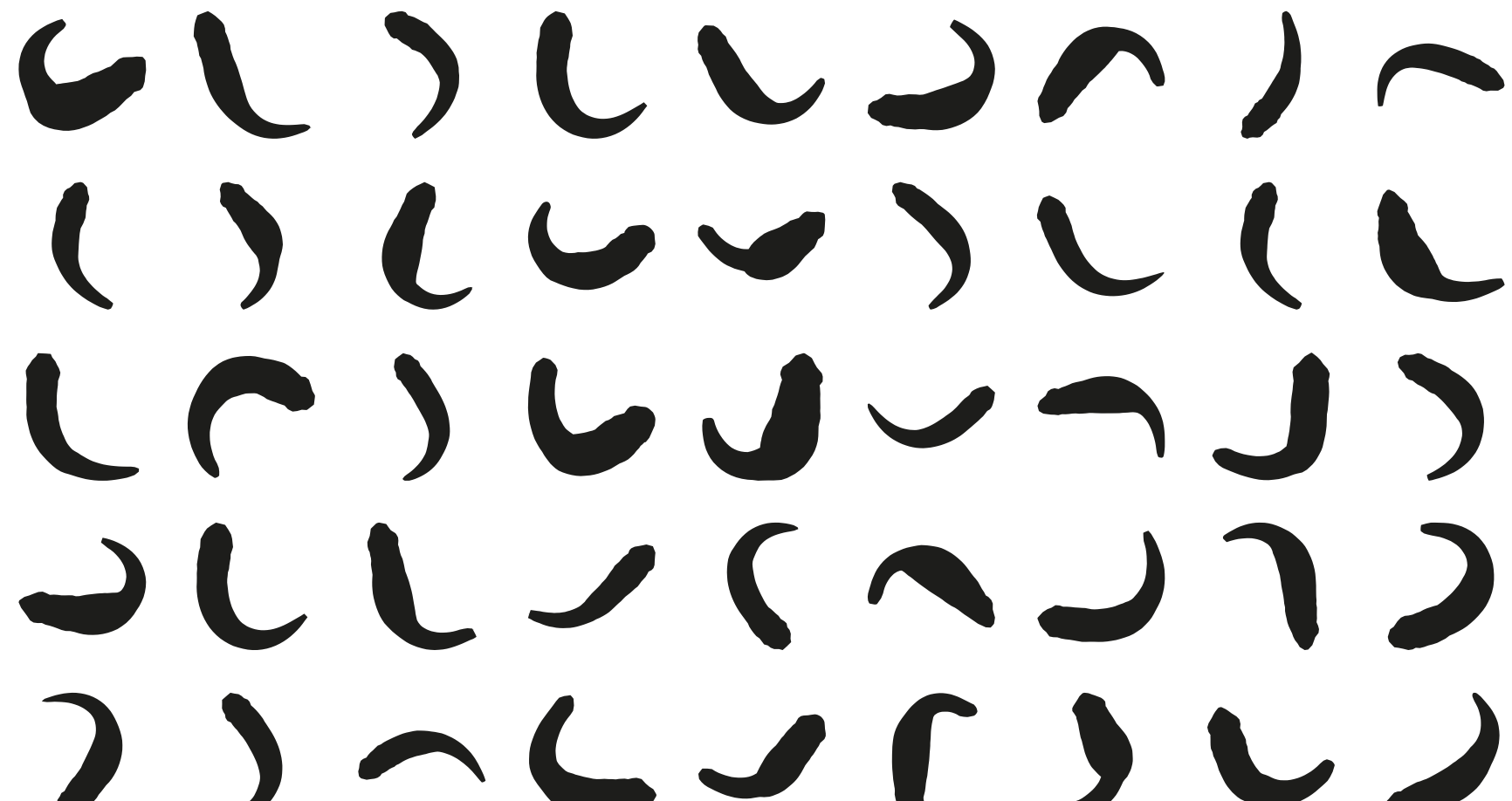


\section{Chapter 4}

\section{Three-dimensional analysis of the fast-start escape response of the least killifish, Heterandria formosa}

Mike Fleuren,

Johan L. van Leeuwen,

Elsa M. Quicazan-Rubio,

Remco P.M. Pieters,

Bart J.A. Pollux,

Cees J. Voesenek

Experimental Zoology Group, Department of Animal Sciences, Wageningen University \& Research, Wageningen, The Netherlands 
Chapter 4 I 3D analysis of the fast-start escape response of the least killifish

\section{Abstract}

Fish make C-starts to evade predator strikes. This manoeuvre consists of three stages: stage 1 , in which the fish rapidly bends into a C-shape; stage 2 , in which the fish bends in the opposite direction; and a variable stage 3 in which the fish either continues swimming, coasts or brakes. Despite fish moving in 3D space, fast-start responses of adult fish have mainly been studied in a horizontal plane. Using automated 3D tracking of multi-camera high-speed video sequences, we show that fast-starts of adult female least killifish (Heterandria formosa) contain a significant vertical velocity component, as well as large changes in pitch (up to $43^{\circ}$ ) and roll (up to $77^{\circ}$ ) angles. Upwards and downwards elevation changes are correlated with changes in pitch angle of the head, motion direction in the horizontal plane is correlated with changes in yaw angle of the head. With respect to the stimulus, escape heading correlates with the elevation of the fish at the onset of motion. Irrespective of the initial orientation, fish can escape in any horizontal direction. In a large number of fast-starts, the mean effective acceleration of the centre of mass is significant during stage 1 , showing that propulsion can already occur in this phase. This suggests that the often used term 'preparatory phase' for stage 1 has to be reconsidered. Our findings highlight the importance of 3D analyses of fast-start manoeuvres of adult fish in uncovering the versatility of fish escape repertoire. 


\section{Introduction}

Fast-start responses are a pivotal manoeuvre in predator-prey interactions of fish: prey exhibit this behaviour to propel themselves away from danger, while predators use it to lunge themselves towards prey [1]. Similar kinematic patterns have also been observed during other behaviours, including social interactions [2], following food capture [3-6] and following air-surface interactions [7].

Fast-start responses can be divided in two types based on their muscle activation and contraction pattern: location-shifted bilateral contraction of the axial muscles results in 'S-starts', named after the S-shaped body bend [810], and 'C-starts' that initially follow unilateral muscle contraction, named after the C-shaped body bend $[1,11,12]$. C-starts are typically described following three distinct stages [13]. During 'stage 1' the fish bends into the characteristic C-shape, while during 'stage 2 ' a contralateral movement of the tail propels the fish away from its original position. The last 'stage 3 ' is highly variable and can consist of a wide range of motions from continued swimming to gliding or braking with the pectoral fins. Hereafter, we will use the term fast-start as a synonym for C-starts.

Over the past decade, the hypothesized roles of the different stages have gradually been changing. Traditionally, stage 1 and stage 2 of the fast-start have been described as the 'preparatory phase' and 'propulsive phase', respectively [13]. Indicative of the presumed preparatory nature of the first stage, is that the reorientation of the head during stage 1 is an important determinant for heading of the escape during subsequent stages [14], while forward motion of the head is limited. However, during the C-bend one of the jets propelling the fish in the subsequent stage is formed, but not yet contributing to propulsion [15], and some studies describe significant movement and acceleration of the centre of mass (CoM) during this stage [13,16]. Arguably, the term 'preparatory phase' is too narrow and both stages of the fast-start could contribute to forward propulsion.

Multiple methods have been developed to determine the end of stage 1 and the beginning of stage 2. Physiologically, it can be determined from the onset of the contralateral electromyography (EMG) signal [e.g. 17,18], but EMG signals during free-swimming are generally not available in kinematics studies. From a biomechanical and/or kinematics perspective, different parameters have been used to describe the transition from stage 1 to stage 2: the onset of forward propulsion [e.g. 19], the change in turning direction of the head or anterior body midline [e.g. 9,11,20-22], or the onset of the return 
tailbeat [e.g. 23]. Although the differences between these methods seem trivial, these definitions will result in observed differences in the timing of the several stages and, because of this, in differences in measured parameters at stage-related time points.

Although fish swim in a three-dimensional space and use the water column as such, fast-starts are often simplified as a two-dimensional manoeuvre with motions parallel to the horizontal plane [1]. Recently, it was shown that escape responses of larval zebrafish (Danio rerio) contain a considerable three-dimensional component: pitch angle changes of the head correlates with changes in elevation $[24,25]$. In two instances, three-dimensional faststart manoeuvres were reported for adult fish, namely in knifefish (Pterophyllum eimekei) and hatchetfish (Carnegiella strigata) [12,21], but fast-starts of adult fish are generally reduced to two-dimensional manoeuvres in the literature [1].

The increasing knowledge of the three-dimensional components of fast-start responses follows from recent methodological developments. Within the field of fish swimming biomechanics, high-speed video imaging is shifting from two-dimensional to three-dimensional recording with multiple synchronized cameras, and simultaneous advances in automated image analysis allow for processing of large sets of movies [e.g. 26]. Most previous work on fast-start responses records movement solely in the horizontal plane, with a setup in which vertical displacement is restricted, and/or discarding movies in which the fish swims out of focus [e.g. 20,23,27], while three-dimensional descriptions remained anecdotal [12,21]. Currently, three-dimensional imaging and analysis is becoming the standard to study swimming kinematics $[25,26,28]$.

A second methodological development is the switch from the usage of a fixed point on the body as an estimate for CoM [e.g. 9,25,29], to a dynamic CoM that shifts position relative to the body during swimming (2D approach: [16,30] , 3D approach [26]). This actual position of the CoM is calculated from the mass distribution along the body, and can lie outside of the fish's body for large body curvatures.

Combining these recent advances from the fields of swimming kinematics and biomechanics, we explore in this study the three-dimensional kinematics of the fast-start escape response of adult least killifish, Heterandria formosa. We hypothesize that, similar to the three-dimensional kinematics of the C-start of the larval zebrafish [25], yawing and pitching motions of the head 
are associated with changes in azimuth and elevation, respectively. In addition, we revisit the function of stage 1 in the fast-start, and analyse the $3 \mathrm{D}$ escape trajectory relative to the direction of the stimulus source.

\section{Material and methods}

\section{Experimental animals}

Experiments were performed with adult females of least killifish (Heterandria formosa Girard [1859]), a species of the live-bearing fish family Poeciliidae that naturally populates a diversity of habitats in south-eastern United States, including small freshwater lakes, streams, and marshes [31]. New born fish from the same age cohort ( $2-3$ weeks) were raised together. Males were removed from these cohorts as soon as secondary sex characteristics started to develop, resulting in all-virgin laboratory populations. Average standard length $\left(L_{\mathrm{SL}}\right)$ of the experimental animals $(N=14)$ was: $27.57 \pm 0.35$ $\mathrm{mm}$ [mean $\pm \mathrm{SE}$ ]. Starting one to two months preceding the experiments, the fish were housed individually at $24{ }^{\circ} \mathrm{C}$ in $9 \mathrm{~L}$ tanks (Tecniplast, Bugugiatte, Italy), enriched with a plastic plant, and fed fixed quantities of flake paste and liver paste $(0.05 \mathrm{ml})$ and approximately 5 adult brine shrimp in the afternoon after experiments. The experimental subjects were subjected to escape response measurements daily: on average, females were subjected to 8.5 measurement days (range: $5-12$ days). All procedures described were approved by the Animal Ethics Committee of Wageningen University \& Research (permit number 2013103).

\section{Escape response measurements}

Escape responses were recorded in a $0.23 \times 0.23 \times 0.30 \mathrm{~m}(1 \times \mathrm{w} \times \mathrm{h})$ aquarium with the water level at $0.23 \mathrm{~m}$ (Figure 4-1A). Water $\left(23.8 \pm 0.3^{\circ} \mathrm{C}\right.$; Mean $\left.\pm \mathrm{SD}\right)$ was refreshed before introduction of each individual. The central area of the aquarium (field of view approximately $0.10 \times 0.10 \times 0.10 \mathrm{~m}$ ) was filmed using Mikroton EoSens CL MC1362 high-speed video cameras (Mikrotron GmbH, Unterschleissheim, Germany; resolution $1040 \times 1020$ pixels; 1/1000 s shutter speed) equipped with Voigtländer Ultron $\mathrm{f}=40 \mathrm{~mm}$ 1:2 Aspherical compact pancake lenses (RINGFOTO GmbH, Fürth, Germany) and Epix PIXCI E8 frame grabbers (EPIX Inc., Buffalo Grove, IL, United States). A Quantum Composers 9214 digital delay pulse generator (Quantum Composers Inc., Bozeman, MT, United States) was used to synchronise the three cameras. Fast-start responses that were in the field of view of the three cameras were recorded with 470 frames per second. The used field of view resulted in a virtually unrestricted environment for the fish to move in, as the closest wall 
was at least $2 L_{\mathrm{SL}}$ away. Cameras were calibrated with direct linear transformation (DLT, method by [32]) by indicating the position of 72 points on a custom-designed 3D-printed frame (printed by Shapeways BV, Eindhoven, The Netherlands) for all cameras.

To elicit an escape response, a $103 \mathrm{~g}$ weight was dropped from the top of the aquarium using a manual electric switch when the fish was in the field of view, preferably in a still, steady and straight position. The stimulus was located in a fixed corner of the aquarium, $1 \mathrm{~cm}$ from the walls. The swimming arena was lit uniformly from the top using a LED panel. Similar panels on the side switched on when the stimulus was dropped, with a delay of a few milliseconds.

Before the first test, fish were allowed to acclimatise ten minutes in the dark and five minutes with the top light turned on. Between stimuli, the fish were allowed a rest-period of at least 5 minutes. A maximum of 5 escape responses were recorded per individual per day.

A

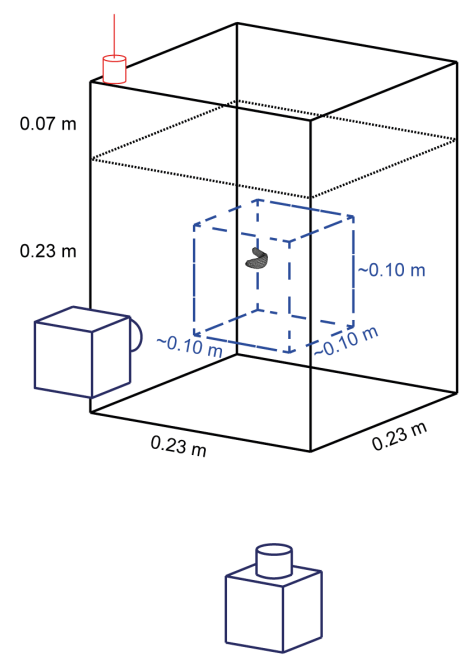

B
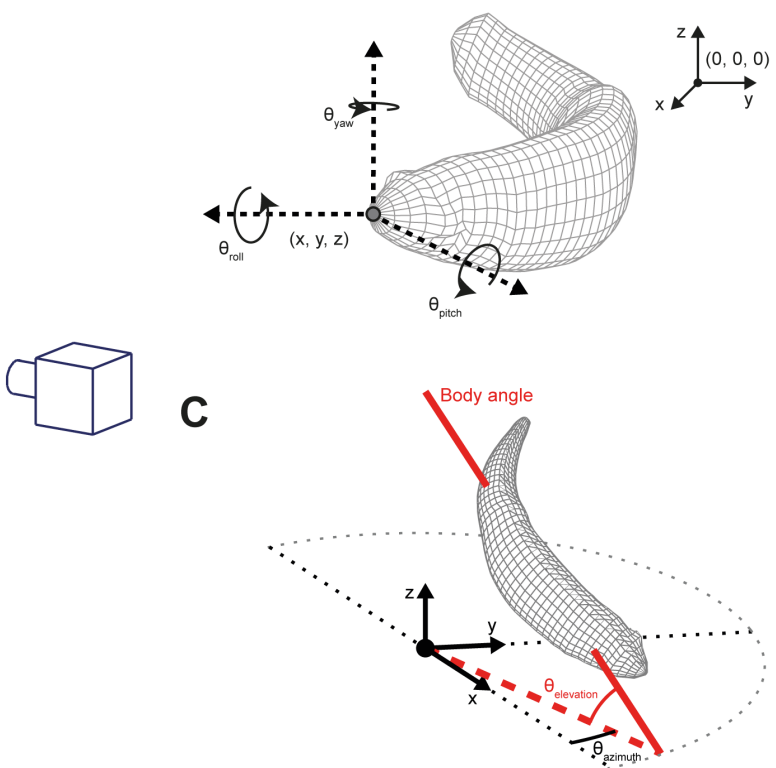

Figure 4-1. Overview of the measurement setup, 3D angles and orientations. A: The swimming arena allowed free swimming in all directions. The field of view (blue dashes) was located in the centre of the arena, and recorded with three orthogonal cameras. The stimulus was given by dropping a weighted in at a fixed location in the corner of the tank. B: Definition of the Tait-Bryan angles (pitch, yaw, and roll) of the head. C: Azimuth and elevation angles of the body angle. 


\section{Tracking and initial analysis}

A total of 437 escape response sequences were recorded. Following tracking and initial analysis (see below), six movies were discarded due to inadequate tracking (bad model fit). We omitted 25 movies because the fish was not still at the detected onset of motion, 54 movies were excluded because no onset of motion was detected and 29 movies were removed from further analysis as the fish did not exhibit a stage 1 bend according to our criteria (see below).

For each movie, fish position, orientation, and curvature were tracked in 3D and analysed using a branch of the Fishtracker program [26] for MATLAB 2013a (MathWorks, Natick, MA, United States). To allow accurate tracking, individual- and day-specific three-dimensional models were created of the fish excluding the fins, as by Voesenek et al. [26], from ventral and lateral pictures created with Nikon D3200 DSLR cameras (Nikon, Tokyo, Japan; sensor resolution 24 Mpix, equipped with Micro-Nikkor $\mathrm{f}=55 \mathrm{~mm}$ lenses), synchronized with a remote trigger (JinJiaCheng Photography Equipment Co., Ltd., Shenzhen, China).

The raw tracked positions of the fish were smoothened by a Whittaker smoothing (settings: $\lambda=4$, order $=0$; [33]). The use of a three-dimensional body model allows calculation of moments of inertia $(I)$ and the actual position of the centre of mass of the fish, under the assumption of a uniform tissue density of $1 \mathrm{~g} \mathrm{~cm}^{-3}$.

Curvature at the posterior end of the body was hard-coded to return to 0 . Because our body model does not include the caudal fin, this assumption might not hold. Therefore, we greyed out the posterior $5 \%$ of all curvature plots.

\section{Onset of motion \& stage transitions}

The transition between the different stages of the fast-start was determined from the moment of inertia in the yaw-plane $\left(I_{\text {yaw }}\right)$, as this accurately represents the effect of whole-body curvature. Intermediate values of $I_{\text {yaw }}$ were approximated by cubic spline interpolation, allowing sub-framerate estimation of starting point of each stage. The transition moments between subsequent stages $(1 \rightarrow 2$, and $2 \rightarrow 3$, respectively) were determined by locating the minima of $I_{\text {yaw }}$ using the findpeaks function from the MATLAB Signal Processing Toolbox version 2013a ( $-I_{\text {yaw }}$ for the negative peaks), using thresholds to filter out noise and starts that do not contain certain stages; threshold stage 1: $0.97 \cdot \max \left(I_{\text {yaw }}\right)$; first peak stage 2: $1.1 \cdot I_{\text {yaw, stage } 1} ;$ second (end) stage 2 peak: $0.99 \cdot I_{\text {yaw, first peak stage } 2}$. As $I_{\text {yaw }}$ is insensitive to the initial head motion, we 
determined the beginning of stage 1 of the fast-start manoeuvre from the change in yaw angle of the head; i.e. the last change of sign of the derivative of the yaw angle preceding the end of stage 1 .

\section{Head and body angles, orientation changes}

The head orientation was defined as the Tait-Bryan angles pitch, yaw and roll (Figure 4-1B), calculated from the angle between the first two centreline segments of the head (see [26] for a more detailed description). Yaw-angles were recalculated from the tracked rotation matrix, to prevent artefacts when these angles surpass $90^{\circ}$. The body angle in the yaw-plane was derived from the yaw-angle of each individual model segment, weighted by the contribution of each segment to the moment of inertia, and subsequently converted to world coordinates comparable to the head angle using the rotation matrix. Orientation of the fish was expressed in azimuth and elevation of the body angle axis (Figure 4-1C).

\section{Mean effective acceleration}

To determine whether the CoM contributes to propulsion, specifically in the direction of the final escape, we calculated the mean effective acceleration of the CoM. This was calculated by taking the dot-product of the mean acceleration of each stage and the velocity unit vector of the CoM at the end of stage 2 .

\section{Statistics}

Linear mixed models were used to determine relationships between angles and orientations using proc mixed for SAS 9.3 (SAS Institute, Cary, NC, United States). This statistical method accounts for repeated measures within individuals [34]. Differences between effective acceleration of stage 1 and 2 were determined using proc univariate for SAS 9.3. Correlations between orientation of the fish and heading were calculated with the circular correlation function from the circular macro [35] in SAS 9.3. Differences were considered significant if $p<0.05$. All the above analyses are performed on events with both stage 1 and stage 2 defined. 
Table 4-1. Mixed model outputs for correlations between Tait-Bryan angles pitch, yaw and roll of the head and position changes of the centre of mass (CoM) in the world coordinate system (azimuth [Azi] and elevation [Elev]) as plotted in Figures 6, 7.

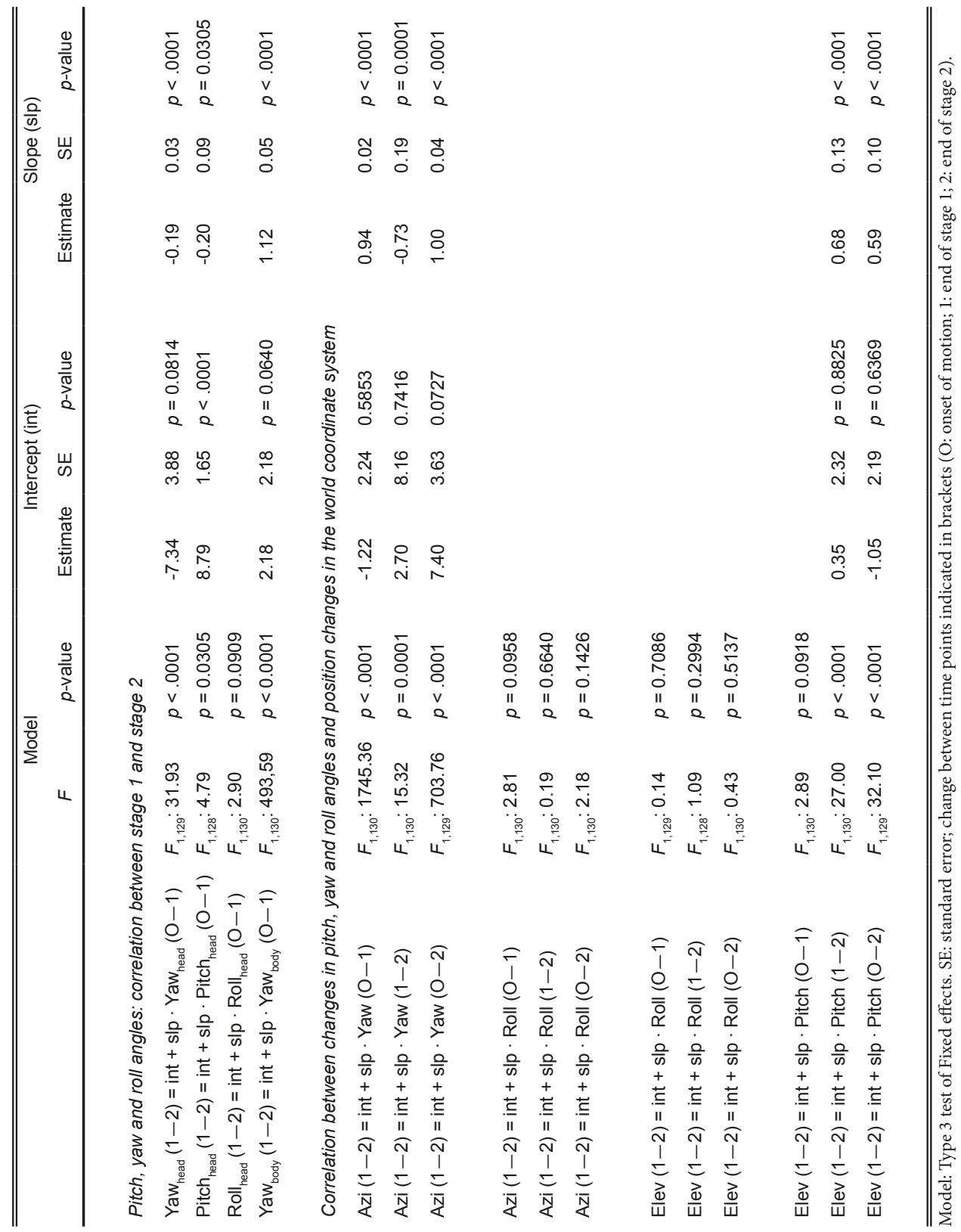


Chapter 4 I 3D analysis of the fast-start escape response of the least killifish

\section{Results}

\section{Example of a 3D fast-start}

The analysed fast-start manoeuvres of Heterandria formosa are characterized by a 'C-bend' in stage 1, followed by forward propulsion in stage 2 and a variable third stage (example in Figure 4-2): changes in three-dimensional orientation can occur during all three stages. The end of stage 1 and stage 2 is determined from minima in the moment of inertia in the yaw-plane $\left(I_{\text {yaw }}\right)$ (Figure 4-3A). $I_{\text {yaw }}$ is insensitive to the motion of the head that indicates onset of motion, therefore the beginning of the manoeuvre is determined from the yaw angle of the head (Figure 4-3B). The body angle is phase shifted with respect to the angle of the head, and has a smaller amplitude: overall body orientation is changing less rapidly than the orientation of the head (Figure 4-3B). Changing pitch and roll angles of the head reflect the three-dimensional nature of the fast-start manoeuvre (Figure 4-3C). The pitch angle of the head increases during both stage 1 and 2, while in this example the roll angle remains almost constant during stage 1 but increases in stage 2 to $35^{\circ}$ (Figure 4-3C).

The speed of the snout increases rapidly after the onset of motion (Figure 4-3D), linked to the rotation and displacement of the head. The speed of the centre of mass (CoM) lags, but is already considerable at the end of stage 1 (Figure 4-3D). The pattern of the speed-curves differs between head and CoM-based systems: the absolute speed of the snout shows two characteristic peaks in both stage 1 and stage 2 that reflect the lateral velocity (Figure 4-3E), while the speed of the CoM increases almost steadily and reaches its peak $4.5 \mathrm{~ms}$ before the end of stage 2 (Figure 4-3D). The speed drops after stage 2; in other cases stage 2 can be followed by further tail beats in stage 3 and a concomitant rise in velocity. The vertical velocity of the snout increases during stage 1 and levels off during stage 2 during this particular manoeuvre (Figure 4-3E). The CoM displaces very little in the vertical direction during stage one, but vertical velocity increases steadily during stage 2 (Figure 4-3E). The body curves heavily in different directions during stage 1 and stage 2, with curvature traveling along the body as a wave (Figure 4-3F), similar to previous observations [e.g. 16,25,27].

\section{Single-bend and double-bend fast-starts}

The recorded fast-start sequences could be divided into two groups: starts in which the fish did not exhibit the contralateral tailbeat characteristic of stage 2 (single-bend fast starts (SB), [20]), and events in which the fish made 
double-bend (DB) fast-starts (example: Figure 4-2, Figure 4-3). In 196 out of 329 analysed manoeuvres, we did not detect a second minimum in $I_{\text {yaw }^{\prime}}$ indicating a lack of the contralateral bend (Figure 4-4A). In these starts, the fish slowly straightens its tail after the initial C-bend. This difference in kinematics is also reflected in the plots of body curvature (Figure 4-4B), where the SB start is characterized by one large curvature wave, whereas the DB start shows two traveling curvature waves along the body during the first two stages of the fast-start. For the subsequent results, we only analysed DB starts.

\section{Variation in fast-start kinematics}

During the first two stages of the fast-start, the snout and the CoM exhibit different patterns in angles and speeds. The snout undergoes large displacements during both stage 1 and stage 2, while the displacement of the CoM is much larger in stage 2 than in stage 1 (Figure 4-5A). These differences are reflected in the horizontal speed during the different stages: the horizontal speed of the snout is mostly larger in stage 1 than in stage 2, as indicated by their position below the isoline, while the CoM attains higher velocities during stage 2 (Figure 4-5B). A similar pattern is visible for the vertical velocity: the snout attains larger vertical velocities than the CoM during stage 1 (Figure 4-5C), but overall the magnitude is lower than for horizontal speed.

The CoM accelerates during both stage 1 and stage 2 (Figure 4-5D). However, this acceleration is not always in the direction of the final escape, as determined from the velocity vector of the CoM at the end of stage 2: in a large fraction of the manoeuvres, the CoM had a negative mean effective acceleration during stage 1 (Figure 4-5E). During stage 2, the CoM generally has a positive mean effective acceleration. On average, the mean effective acceleration of the CoM is larger than 0 during both stage 1 (mean \pm SE: $3.47 \pm 0.61$ $\mathrm{m} \mathrm{s}^{-2}, t$-test: $p<0.001, N=133$ ) and stage 2 (mean \pm SE: $15.86 \pm 1.10 \mathrm{~m} \mathrm{~s}^{-2}, t$-test: $p<0.001, N=133)$, but stage 2 has a larger mean effective acceleration than stage 1 (difference of means: $12.39 \mathrm{~m} \mathrm{~s}^{-2}$; Wilcoxon signed-rank test: $p<0.001$, $N=133$; Figure 4-5F).

The snout moves laterally in stage 1 , followed by a contralateral motion in stage 2 . This is reflected by the observed pattern in yaw angle of the head: the yaw angle of stage 2 generally has the inverse sign of the yaw angle of stage 1 (Table 4-1, Figure 4-6A; range of yaw angle change stage 1: $-178^{\circ}-169^{\circ}$; stage 2: $-110^{\circ}-115^{\circ}$ ). The yaw angle of the body however, has the same sign at the end of stage 1 and stage 2, as the orientation of the body changes more slowly and eventually converges with the head angle at the end of stage 2 
(see for example Figure 4-3B). There is a negative correlation between the change in pitch angle in stage 1 and stage 2 (range of pitch angle change stage 1: $-43^{\circ}-37^{\circ}$; stage $2:-25^{\circ}-43^{\circ}$ ), but the change in roll angle of the head during the two stages of the fast-start are uncorrelated (Table 4-1, Figure $4-6 \mathrm{~B}, \mathrm{C}$; range of roll angle change stage $1:-52^{\circ}-45^{\circ}$; stage 2 : $-78^{\circ}-58^{\circ}$ ).

\section{Changes in 3D Orientation and heading}

Yaw, pitch and roll of the head during the different stages of the fast-start, correlate differently with the attained escape directions. The azimuth change during the fast-start manoeuvre correlates positively with the change in yaw angle of the head during stage 1 and the change in yaw angle of stage 1 and 2 combined, but negatively with the change in yaw angle during stage 2 alone (Table 4-1, Figure 4-7). During stage 2, the head moves in the opposite (yaw)

A
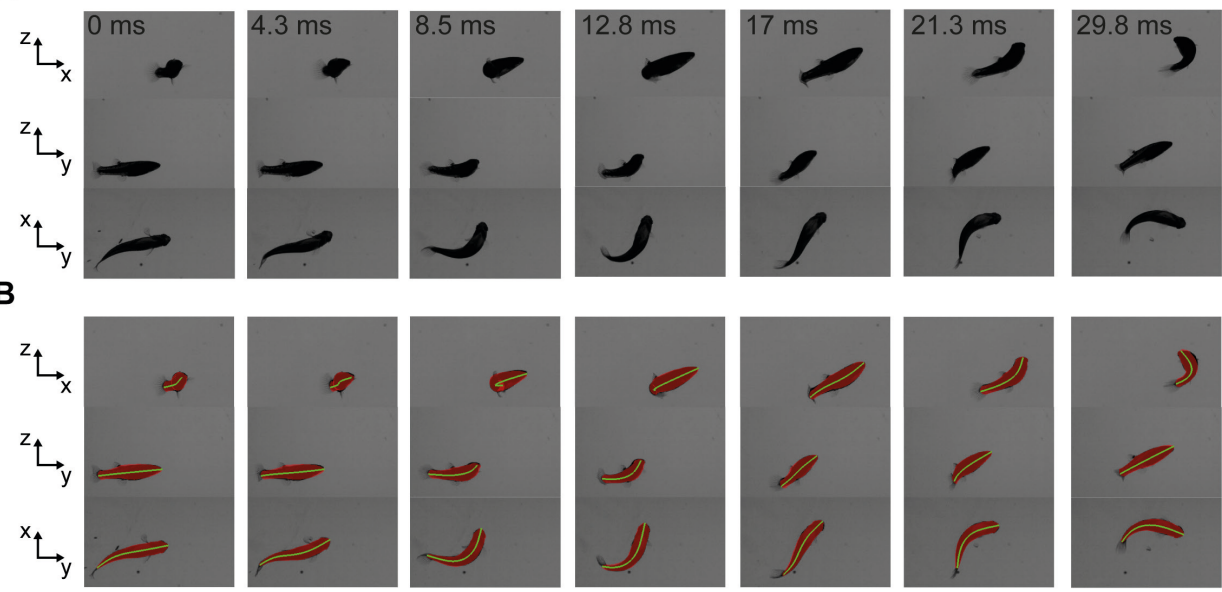

C
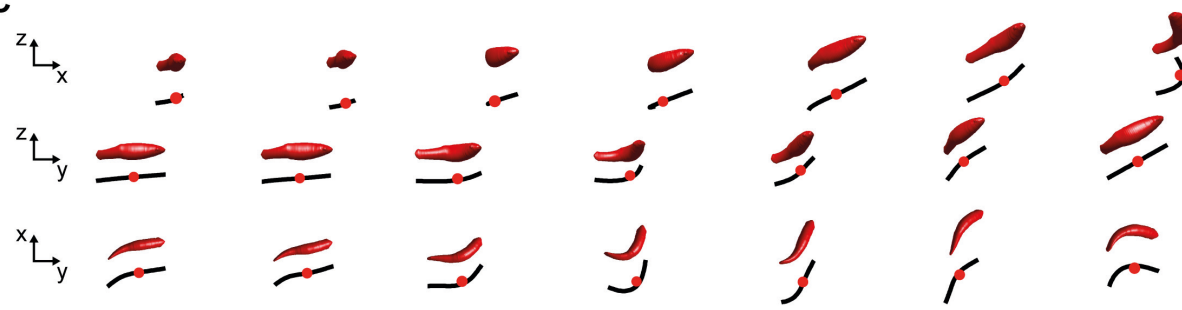

Figure 4-2. Overview of a typical three-dimensional fast-start manoeuvre with an upwards pitch. A: Raw movie images from the three orthogonally oriented cameras. The top two rows show horizontal views, the third row displays images from the bottom view. Images are cropped to capture only the region of motion. B: The same frames with an overlay of the body model fit (red) and centreline (green) for the respective cameras. C: Three-dimensional body representations for the above image frames; centrelines (black) and position of the centre of mass (red dot) are displaced vertically for visibility. 


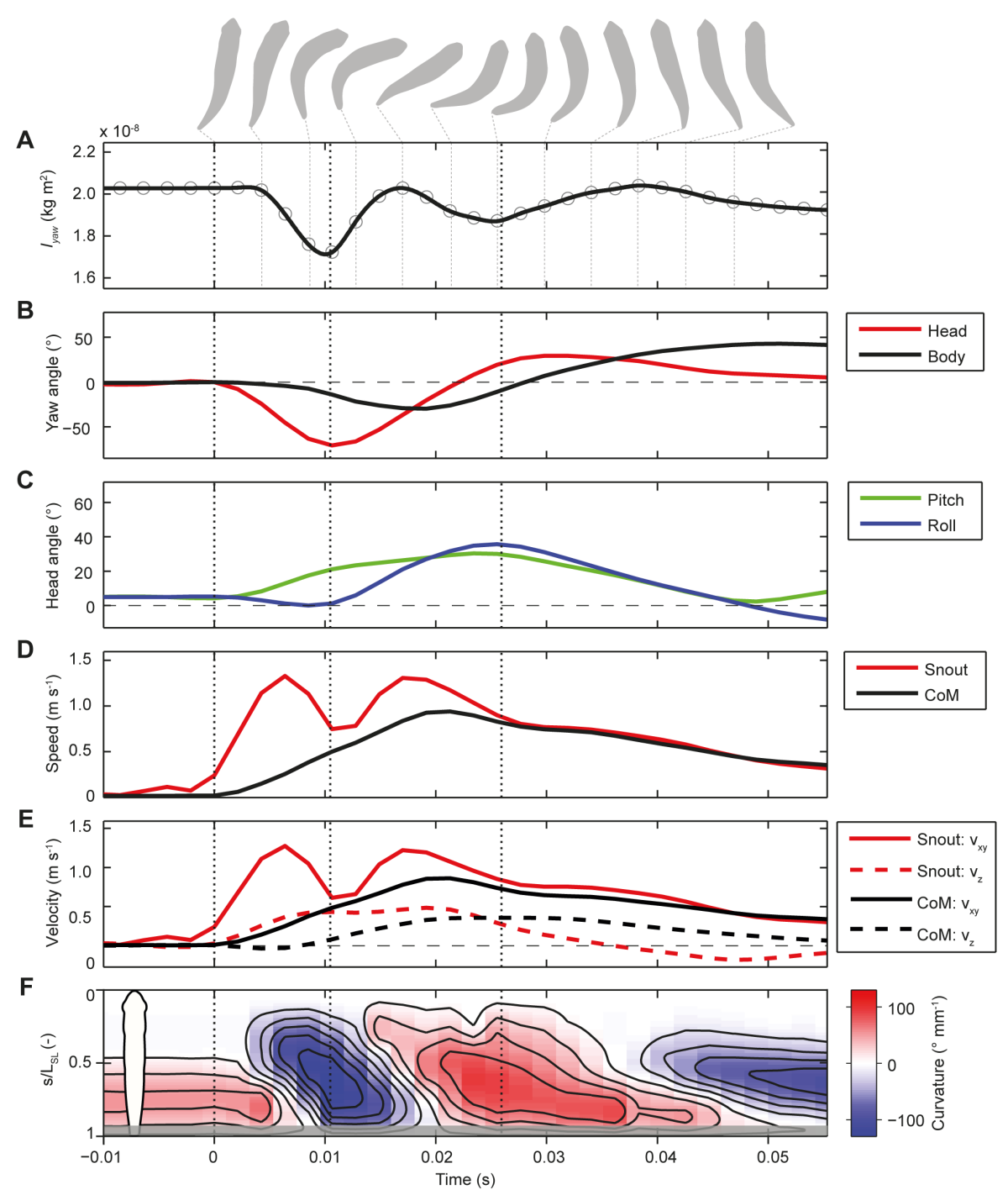

Figure 4-3. Kinematic variables from the fast-start manoeuvre displayed in Figure 4-2. A: the moment of inertia in the yaw plane $\left(I_{\text {yaw }}\right)$ during the manoeuvre. The negative peaks in $I_{\text {yaw }}$ are used to determine the end of stage 1 (second black dotted line) and the end of stage 2 (third black dotted line); hereafter the manoeuvre continues with a variable stage 3 , in this example a glide. The black line represents a cubic spline fit of the data (represented by the open circles). A bottom view of the body of every second frame is depicted at the top of the figure; displacement of the body is not shown. B: Change in yaw angle of the head and body over time. C: Change in pitch and roll angles of the head during the fast-start manoeuvre. D: Absolute speed measured at the snout and at the centre of mass. E: Velocity split up into horizontal and vertical components for the snout (red) and centre of mass (CoM, black) respectively. F: Curvature along the body over time. 
direction from stage 1 (Figure 4-6A). Neither azimuth nor elevation change correlate with changes of the roll angle of the head (Table 4-1, Figure 4-7). Elevation change is positively correlated with changes in pitch angle of the head during stage 2 and during the whole start (Table 4-1, Figure 4-7).

Escape heading is described in azimuth and elevation coordinates determined from the velocity vector at the end of stage 2 (Figure 4-8A). Initial orientation of the fish with respect to the stimulus does not limit the range of azimuth directions the fish escapes in (Figure 4-8B, non-parametric circular correlation coefficient $\rho$ : $0.00378, p=0.600,5000$ permutations). There is an effect of initial elevation with respect to the stimulus and elevation of final heading, indicating that fish that have a negative initial elevation towards the stimulus are more likely to aim their escape directions (further) downwards (Figure 4-8C, $\rho: 0.06121, p=<0.001,5000$ permutations).
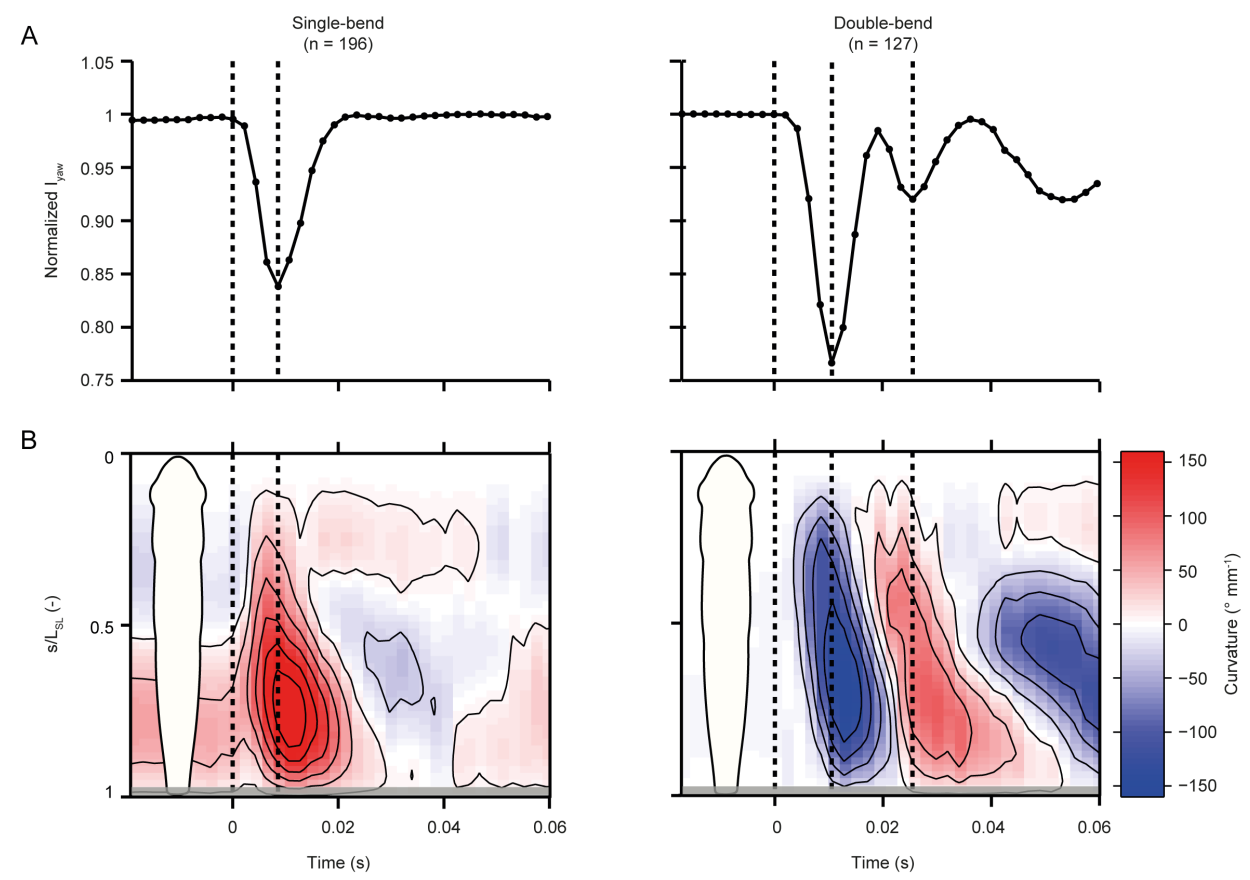

Figure 4-4. Example of the differences between single-bend (SB) and double-bend (DB) fast starts. A: Plots of the in-plane moment of inertia $\left(I_{\text {yaw }}\right)$ over time, normalized by maximum $I_{\text {yaw }}$ for comparison, for an example of a single-bend faststart (left) and a double-bend fast-start (right). B: Curvature plots of the sequences corresponding with A. A-B: Dashed vertical lines represent the beginning and end of the stages of the fast-start (onset at Time $=0 \mathrm{~ms}$ ). 
A

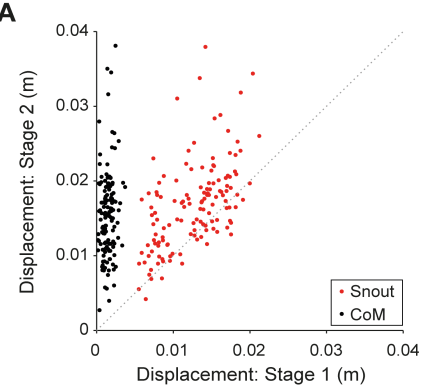

D

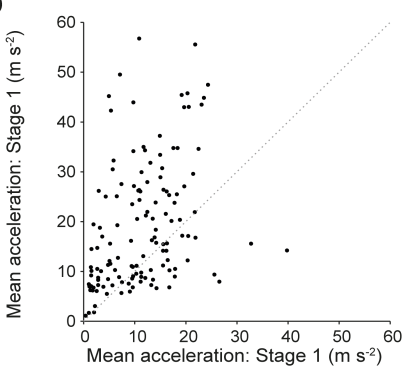

B

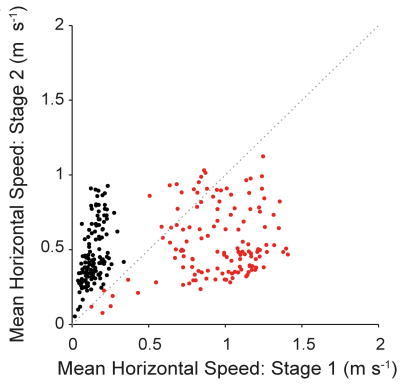

$\mathrm{E}$ 露

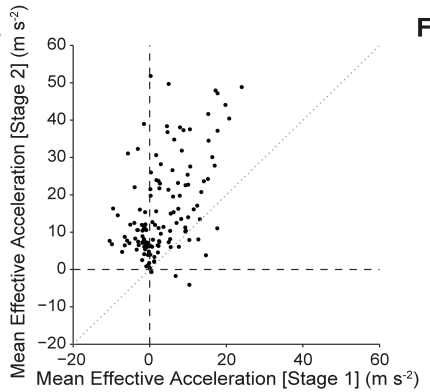

$\mathbf{C}_{\text {. }}$

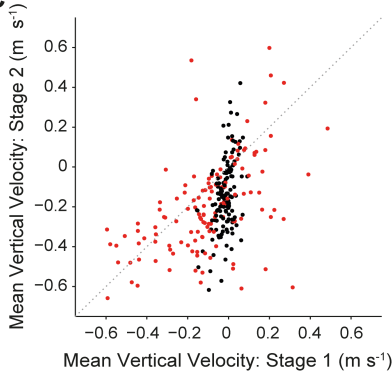

$\mathbf{F}$

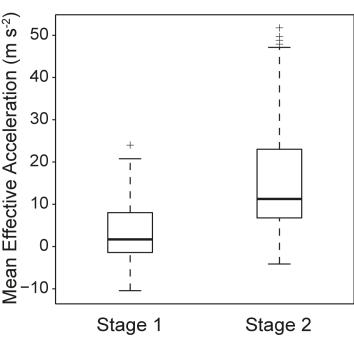

Figure 4-5. Displacement, mean speed, mean velocity, and mean acceleration during stage 1 and stage 2. A: Displacement of the snout (red) and centre of mass (CoM; black) during stage 1 and stage 2 of the fast-start. B: Mean horizontal speed of the snout (red) and CoM (black) during stage 1 and stage 2 of the fast-start. $\mathbf{C}$ : Mean vertical velocity of the snout (red) and centre of mass (black) during stage 1 and stage 2 of the fast-start. D: Mean acceleration of the CoM during stage 1 and stage 2 of the fast start. E: Mean effective acceleration of the CoM during stage 1 and stage 2 of the fast-start. F: Boxplot of the mean effective acceleration of the CoM during stage 1 and stage 2 of the fast-start. Bottom and top edges of the box indicate the 25th and 75th percentile of the data respectively; middle line indicates the median; whiskers indicate $\approx 99 \%$ of the data. Crosses mark individual outlier data points. A-E: dotted line represents $x=y$ isoline.

A

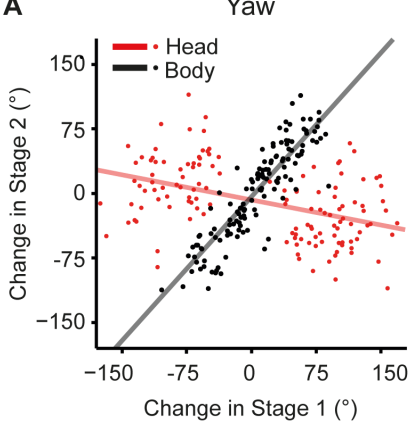

B

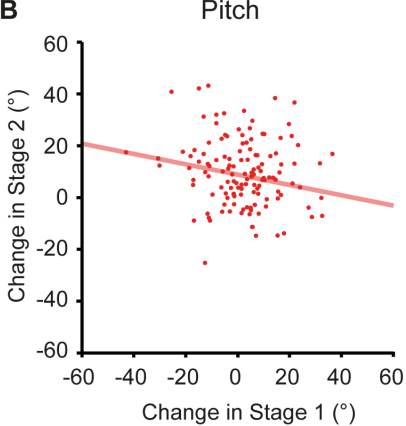

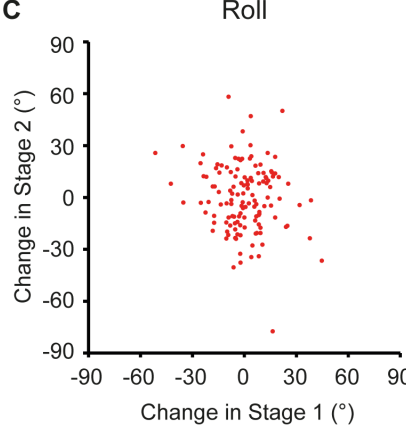

Figure 4-6.Tait-Bryan angle changes during the two stages of the fast-start. Mixed model estimates for the correlations are displayed in Table 4-1. A: Yaw-angle changes of the head (red) and body (black) show different correlations between stage 1 and stage 2. B: Pitch angle change of the head during stage 1 and stage 2. C: Roll angle change of the head during the two stages of the fast-start manoeuvre. 

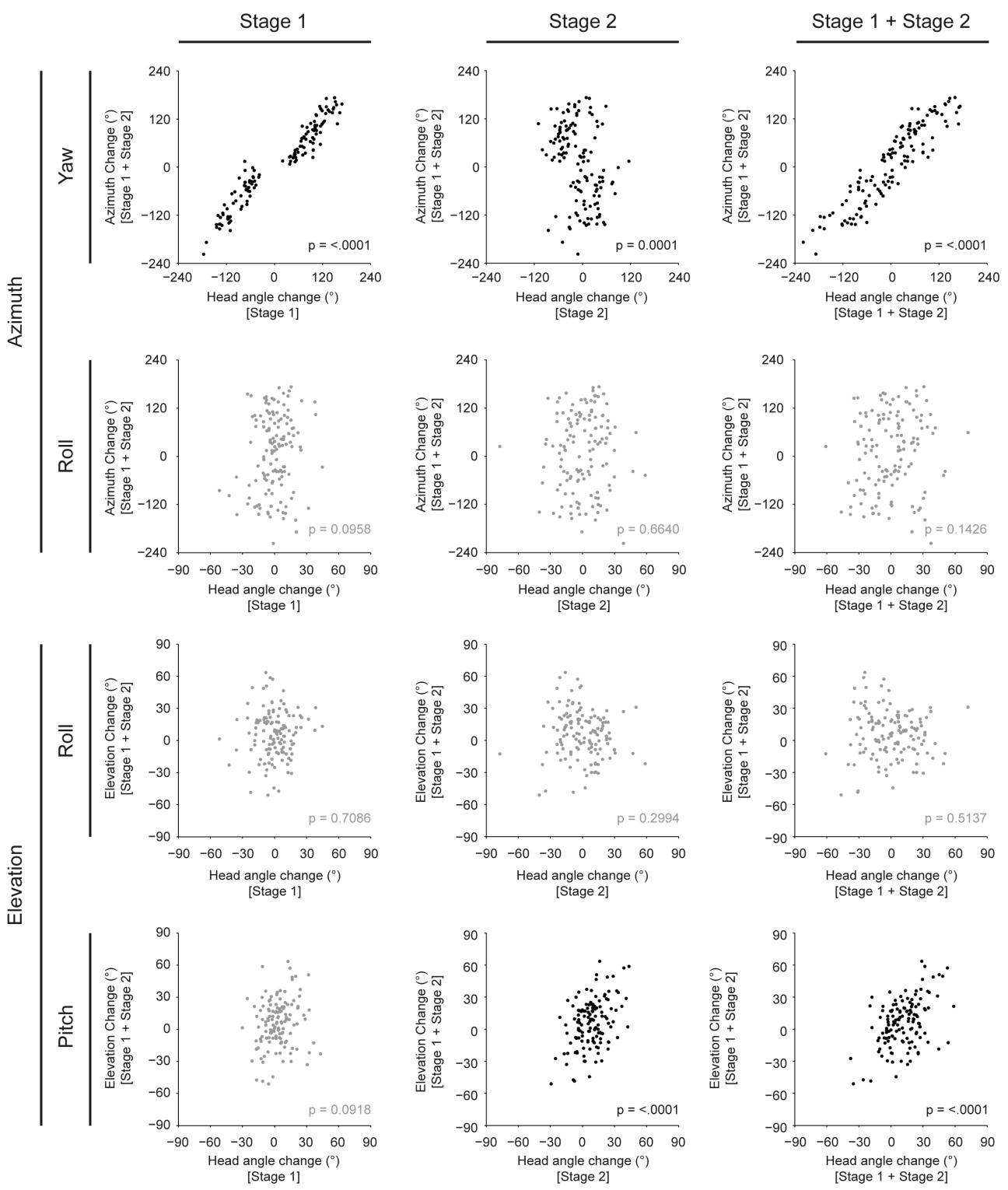

Figure 4-7. Relationship between head angle change during the different stages of the fast-start and change in orientation of the body between the onset of motion and the end of stage 2. Mixed model estimates for the correlations are displayed in Table 4-1; significant correlations are plotted in black, non-significant correlations are plotted in grey; $p$-values are displayed in the bottom-right corners. Top two rows: change in azimuth of the body is correlated with changes in yaw angle of the head during stage 1 , stage 2 and stage $1+2$. Change in azimuth is not correlated with changes in roll angle of the head. Bottom two rows: change in elevation of the body during the fast start is positively correlated with changes in pitch angle of the head during stage 2 and stage $1+2$, but not with stage 1. Changes in elevation are not correlated with changes in roll of the head. 
A

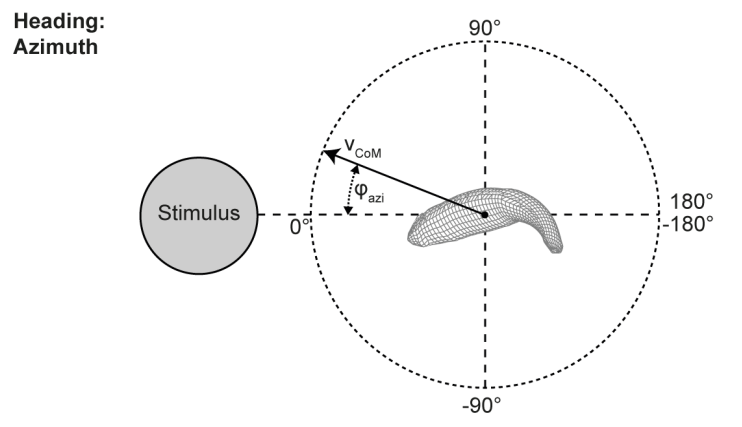

Heading: Elevation

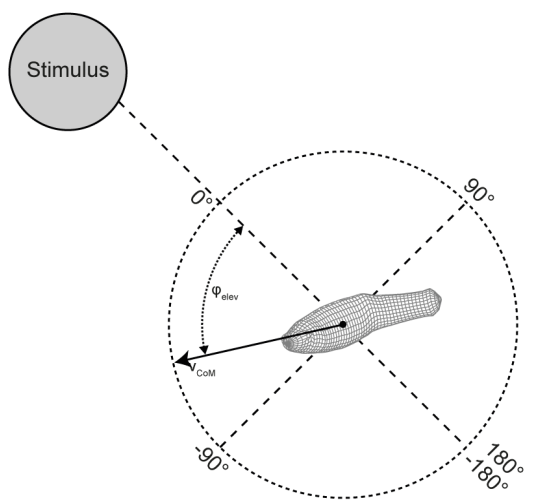

B

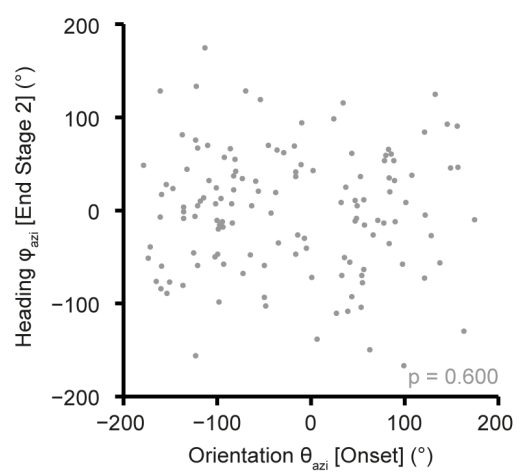

C

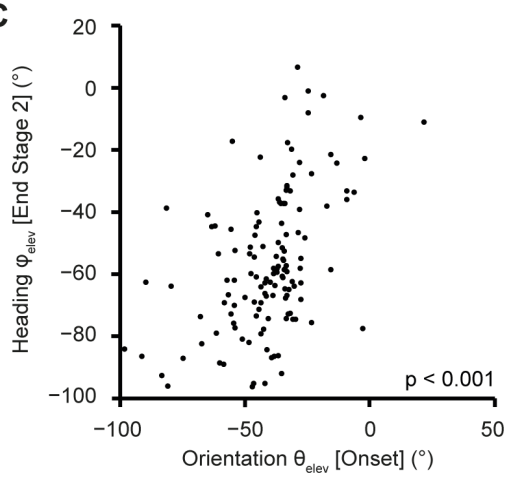

Figure 4-8. Correlation between initial orientation of the fish with respect to the stimulus, and escape heading at the end of stage 2. Significant correlations are plotted in black, non-significant correlations are plotted in grey; $p$-values are displayed in the bottom-right corners. A: Explanation of escape heading; azimuth and elevation are $0^{\circ}$ when the velocity vector of the centre of mass (CoM) faces the stimulus, and $(-) 180^{\circ}$ when it faces directly opposite. B: The azimuth heading at the end of the fast-start is not correlated with the orientation of the fish at the onset of motion. C: The elevation heading at the end of the fast-start is positively correlated with the orientation of the fish at the onset of motion.

\section{Discussion}

Adult Heterandria formosa vary the direction of their fast-start escape manoeuvre in three-dimensions, adding variety to their achieved escape directions. Our data show that the three-dimensional nature of fast-start responses is not exclusive to larval fish. The adult fish used in this study are one order of magnitude larger than the larval zebrafish used by Nair et al. [25], but the three-dimensional kinematics are similar. Extrapolating, it is likely that in natural predator-prey encounters, prey fish vary escape orientation in both horizontal and vertical planes. 
Chapter 4 I 3D analysis of the fast-start escape response of the least killifish

\section{Variation in 3D escape orientation and heading}

We used a statically positioned stimulus, always exciting the fish from above. The fish responded with a variety of escape angles, with azimuth angle changes of the body spanning from $-216-168^{\circ}$ and elevation changes of the body ranging from $-41^{\circ}-85^{\circ}$ (Figure $4-7$ ). For the changes in azimuth, this is likely due to natural variation in escape angle: the escape heading is unrelated to the initial orientation of the fish with respect to the stimulus (Figure 4-8B). The elevation of the heading of the fish at the end of stage 2 is correlated with elevation of the fish at the onset (Figure 4-8C): with the stimulus coming from the top, the fish are likely to escape (further) down. This result matches findings in larval zebrafish: they respond with a downwards oriented escape direction when positioned to the ventral side of an approaching predator [24]. Larvae that were positioned at the dorsal side respond with an escape in the horizontal plane; whether such a distinction holds for adult fish is still unconfirmed. Our dataset contains multiple upwards directed fast-start responses, indicating that there is no kinematic restriction for upwards directed escape responses.

In natural situations, predators can approach a prey from any orientation in three-dimensional space, with some predators generally attacking from above (e.g. birds) while others attack mostly from below (e.g. bottom-dwelling fish). How prey fish respond to different strike-orientations in 3D space is to our knowledge still unknown, despite its ecological relevance. Previous studies on the kinematics of fast-start responses in adult fish have largely neglected vertical escape directions, as the fast-start was considered a planar motion [1]. This was reflected in experimental designs, with the responses studied in shallow water in which vertical motion was restricted, and/ or with video recordings from a dorsoventral perspective that do not allow quantification of changes in elevation. However, our data show considerable variation in three-dimensional escape headings that could affect the outcome of predator-prey interactions.

\section{Is stage 1 a preparatory or a propulsive phase?}

Stage 1 of the fast-start manoeuvre plays an important role in the reorientation of the body, both in azimuth and elevation directions (Figure 4-7) and provides initial conditions of body curvature and tailfin orientation for stage 2 that favour propulsion in the subsequent tail beat. For this reason, this stage has often been described as preparatory [e.g. 1,13]. However, others have reported significant forces and accelerations of the centre of mass (CoM) during stage 1 (reviewed by Wakeling, [36]), or the generation of a 
jet that helps to propel the fish during stage 2 [15]. During the fast-start of adult $H$. formosa, the mean effective acceleration of the CoM during stage 1 is significantly larger than 0 : on average there is movement of the CoM in the final heading of the escape (Figure 4-5). This indicates that on average there is already a propulsive component of stage 1, albeit much smaller on average than the propulsive component of stage 2 (mean effective acceleration, stage 1: $3.47 \mathrm{~m} \mathrm{~s}^{-2}$, stage 2: $15.86 \mathrm{~m} \mathrm{~s}^{-2}$ ). Considerable differences occur within this overall pattern, as there is large variation among the analysed fast-starts: many have a negative effective acceleration (Figure 4-5). In the latter starts, stage 1 has an almost exclusively preparatory role. Overall, our results indicate that stage 1 is neither a purely preparatory nor a purely propulsive stage.

Fast-starts are three-dimensional manoeuvres; implications for related fields

Our observations on the three-dimensional nature of the fast-start could aid the understanding of other aspects of the fast-start response. The fast-start response has so far been studied from many different perspectives, including fluid mechanics [e.g. 37-39], neurobiology [e.g. 8,40], muscle physiology [e.g. 17,22], performance-related survival [41], and variability of the behaviour [e.g. 42,43]. However, three-dimensional motions of the body have rarely been considered.

To produce 3D motion, 3D forces and moments need to be produced. This is interesting from both a motor control and fluid mechanics point of view, as it requires breaking of dorsoventral symmetry. One mechanism to reach this, is by dorsoventrally asymmetric muscle excitation: Nair et al. [25] postulated that the pitching motion that drives a diving fast-start could be the result of inhibition of the motor neurons controlling the epaxial muscles, and excitation of those controlling the hypaxial muscles. This neural signal could span both stage 1 and stage 2, explaining the observed sustained pitching motion of the body during these stages [25]. In this study we however find a negative correlation between pitch angle change of the head in stage 1 and 2, indicating that, often, such a neuronal motor signal would not persist throughout both stages in adult fish.

A second mechanism to reach dorsoventral asymmetry in forces and moments could incur the use of either set of paired fins. Both pectoral and pelvic fins are known to play a role in changing pitch angles of the body and reducing pitch and yaw instabilities during slow swimming [44,45]. Their 
role, if any, in fast 3D turning is not yet understood, however. Abduction of the pectoral fin on the inside of the turn could help function as an 'anchor point', and a non-zero angle of attack could induce dorsoventral asymmetry.

Furthermore, the relative vertical displacement during the fast-start could change the fluid-dynamic effectiveness of the manoeuvre. Pitching motions, for instance, could change how zebrafish larvae interact with their own wake during sharp 'C-bends' [37]. A pitching motion of the head, either upwards or downwards, would alter the 'collision' of the head with the vortex, altering the attained final escape orientation. Simulations need to be performed for a range of naturally occurring body elevations to see if these fast-starts are equally effective as fast-starts performed in a horizontal plane.

In conclusion, the fast-start escape response is a complex three-dimensional manoeuvre in both larval and adult fish, indicating that the nature of this motion pattern might have been oversimplified in previous studies. This is especially relevant for studies focusing on ecological (survival) parameters of the fast-start, as they might be different for planar (horizontal) and three-dimensional motions.

\section{Author contributions}

M.F., J.L.V.L, E.M.Q. and B.J.A.P designed the experiment, M.F. E.M.Q. and R.P.M.P. designed and built the setup, M.F. conducted the experiments, M.F., J.L.V.L. and C.J.V. contributed to data analysis and data analysis methods, M.F. wrote the first draft of the manuscript with input from J.L.V.L. and C.J.V., all authors provided feedback on the manuscript. 


\section{References}

1. Domenici P, Blake RW. The kinematics and performance of fish faststart swimming. J Exp Biol. 1997;200: 1165-1178. Available: http://jeb. biologists.org/content/200/8/1165.short

2. Fernald RD. Fast body turns in a cichlid fish. Nature. 1975;258: 228-229. doi:10.1038/258228a0

3. Canfield JG, Rose GJ. Activation of Mauthner neurons during prey capture. J Comp Physiol A. 1993;172: 611-618. doi:10.1007/BF00213683

4. Wöhl S, Schuster S. The predictive start of hunting archer fish: a flexible and precise motor pattern performed with the kinematics of an escape C-start. J Exp Biol. 2007;210: 311-324. doi:10.1242/jeb.02646

5. Canfield JG. Some voluntary C-bends may be Mauthner neuron initiated. J Comp Physiol A Neuroethol Sensory, Neural, Behav Physiol. 2007;193: 1055-1064. doi:10.1007/s00359-007-0258-2

6. Krupczynski P, Schuster S. Fruit-catching fish tune their fast starts tocompensate for drift. Curr Biol. Elsevier Ltd; 2008;18: 1961-1965. doi:10.1016/j.cub.2008.10.066

7. Domenici P, Norin T, Bushnell PG, Johansen JL, Skov PV, Svendsen MBS, et al. Fast-starting after a breath: air-breathing motions are kinematically similar to escape responses in the catfish Hoplosternum littorale. Biol Open. 2014;4: 79-85. doi:10.1242/bio.20149332

8. Hale ME. S- and C-start escape responses of the muskellunge (Esox masquinongy) require alternative neuromotor mechanisms. J Exp Biol. 2002;205: 2005-2016. Available: http://www.ncbi.nlm.nih.gov/ pubmed/12089206

9. Spierts ILY, Van Leeuwen JL. Kinematics and muscle dynamics of Cand S-starts of carp (Cyprinus carpio L.). J Exp Biol. 1999;202: 393-406. Available: http://www.ncbi.nlm.nih.gov/pubmed/9914147\%5Cnhttp:// jeb.biologists.org/content/202/4/393.short\%0Ahttp://www.ncbi.nlm. nih.gov/pubmed/9914147

10. Webb PW. The effect of size on the fast-start performance of rainbow trout Salmo cairdneri, and a consideration of piscivorous predator-prey interactions. J Exp Biol. 1976;65: 157-177. doi:10.1016/S1546-5098(05)23009-1

11. Domenici $P$, Blake RW. The kinematics and performance of the escape response in the angelfish (Pterophyllum eimekei). J Exp Biol. 1991;156: 187-205. Available: http://jeb.biologists.org/content/156/1/187.short

12. Eaton RC, Bombardieri RA, Meyer DL. The Mauthner-initiated startle response in teleost fish. J Exp Biol. 1977;66: 65-81.

13. Weihs D. The mechanism of rapid starting of slender fish. Biorheology. 1973;10: 343-350.

14. Domenici P, Blake R. Escape trajectories in Angelfish (Pterophyllum eimekei). J Exp Biol. 1993;177: 253-272. 
Chapter 4 I 3D analysis of the fast-start escape response of the least killifish

15. Tytell ED, Lauder GV. Hydrodynamics of the escape response in bluegill sunfish, Lepomis macrochirus. J Exp Biol. 2008;211: 3359-3369. doi:10.1242/jeb.020917

16. Wakeling JM, Johnston IA. Muscle power output limits fast-start performance in fish. J Exp Biol. 1998;201: 1505-1526.

17. Jayne BC, Lauder GV. Red and white muscle activity and kinematics of the escape response of the bluegill sunfish during swimming. J Comp Physiol A. 1993;173: 495-508. doi:10.1007/BF00193522

18. Ellerby DJ, Altringham JD. Spatial variation in fast muscle function of the rainbow trout Oncorhynchus mykiss during fast-starts and sprinting. J Exp Biol. 2001;204: 2239-2250.

19. Foreman $\mathrm{MB}$, Eaton RC. The direction change concept for reticulospinal control of goldfish escape. J Neurosci. 1993;13: 4101-4113. Available: http://www.ncbi.nlm.nih.gov/pubmed/8410180

20. Domenici P, Blake RW. The effect of size on the kinematics and performance of angelfish (Pterophyllum eimekei) escape responses. Can J Zool. 1993;71: 2319-2326. doi:10.1139/z93-325

21. Kasapi MA, Domenici P, Blake RW, Harper D. The kinematics and performance of escape responses of the knifefish Xenomystus nigri. Can J Zool. 1993;71: 189-195. doi:10.1139/z93-026

22. Goldbogen JA, Shadwick RE, Fudge DS, Gosline JM. Fast-start muscle dynamics in the rainbow trout Oncorhynchus mykiss: phase relationship of white muscle shortening and body curvature. J Exp Biol. 2005;208: 929-938. doi:10.1242/jeb.01433

23. Kawabata Y, Yamada H, Sato T, Kobayashi M, Okuzawa K, Asami K. Pelvic fin removal modifies escape trajectory in a teleost fish. Fish Sci. Springer Japan; 2016;82: 85-93. doi:10.1007/s12562-015-0953-9

24. Stewart WJ, Cardenas GS, McHenry MJ. Zebrafish larvae evade predators by sensing water flow. J Exp Biol. 2013;216: 388-398. doi:10.1242/ jeb.072751

25. Nair A, Azatian G, McHenry MJ. The kinematics of directional control in the fast start of zebrafish larvae. J Exp Biol. 2015; 3996-4004. doi:10.1242/ jeb.126292

26. Voesenek CJ, Pieters RPM, Van Leeuwen JL. Automated reconstruction of three-dimensional fish motion, forces, and torques. PLoS One. 2016;11: e0146682. doi:10.1371/journal.pone.0146682

27. Müller UK, Van Leeuwen JL. Swimming of larval zebrafish: ontogeny of body waves and implications for locomotory development. J Exp Biol. 2004;207: 853-868. doi:10.1242/jeb.00821

28. Butail S, Paley DA. Three-dimensional reconstruction of the fast-start swimming kinematics of densely schooling fish. J R Soc Interface. 2011;9: 77-88. doi:10.1098/rsif.2011.0113 
29. Lefrançois C, Shingles A, Domenici P. The effect of hypoxia on locomotor performance and behaviour during escape in Liza aurata. J Fish Biol. 2005;67: 1711-1729. doi:10.1111/j.1095-8649.2005.00884.x

30. Van Leeuwen JL, Voesenek CJ, Müller UK. How body torque and Strouhal number change with swimming speed and developmental stage in larval zebrafish. J R Soc Interface. 2015;12: 20150479. doi:10.1098/ rsif.2015.0479

31. MacRae PSD, Travis J. The contribution of abiotic and biotic factors to spatial and temporal variation in population density of the least killifish, Heterandria formosa. Environ Biol Fishes. 2014;97: 1-12. doi:10.1007/ s10641-013-0117-7

32. Hedrick TL. Software techniques for two- and three-dimensional kinematic measurements of biological and biomimetic systems. Bioinspir Biomim. 2008;3: 34001. doi:10.1088/1748-3182/3/3/034001

33. Eilers PHC. A perfect smoother. Anal Chem. 2003;75: 3631-3636. doi:10.1021/ac034173t

34. Singer JD. Using SAS PROC MIXED to fit multilevel models, hierarchical models, and individual growth models. J Educ Behav Stat. 1998;23: 323-355. doi:10.3102/10769986023004323

35. Kölliker M, Richner $\mathrm{H}$. Navigation in a cup: Chick positioning in great tit, Parus major, nests. Anim Behav. 2004;68: 941-948. doi:10.1016/j.anbehav.2003.11.019

36. Wakeling JM. Fast-start mechanics. In: Shadwick RE, Lauder G V., editors. Fish Biomechanics. San Diego, CA: Elsevier Academic Press; 2006. pp. 333-368. doi:10.1016/S1546-5098(05)23012-1

37. Li G, Müller UK, Van Leeuwen JL, Liu H. Escape trajectories are deflected when fish larvae intercept their own C-start wake. J R Soc Interface. 2014;11: 20140848. doi:10.1098/rsif.2014.0848

38. Borazjani I, Sotiropoulos F, Tytell ED, Lauder GV. Hydrodynamics of the bluegill sunfish C-start escape response: three-dimensional simulations and comparison with experimental data. J Exp Biol. 2012;215: 671-684. doi:10.1242/jeb.063016

39. Borazjani I. The functional role of caudal and anal/dorsal fins during the C-start of a bluegill sunfish. J Exp Biol. 2013;216: 1658-1669. doi:10.1242/ jeb.079434

40. Canfield JG. Functional evidence for visuospatial coding in the Mauthner neuron. Brain Behav Evol. 2006;67: 188-202. doi:10.1159/000091652

41. Walker JA, Ghalambor CK, Griset OL, McKenney D, Reznick DN. Do faster starts increase the probability of evading predators? Funct Ecol. 2005;19: 808-815. doi:DOI 10.1111/j.1365-2435.2005.01033.x

42. Marras S, Killen S. Behavioural and kinematic components of the faststart escape response in fish: individual variation and temporal repeatability. J Exp Biol. 2011;214: 3102-3110. doi:10.1242/jeb.056648 
Chapter 4 I 3D analysis of the fast-start escape response of the least killifish

43. Jornod M, Roche DG. Inter- vs intra-individual variation and temporal repeatability of escape responses in the coral reef fish Amblyglyphidodon curacao. Biol Open. 2015;4: 1395-1399. doi:10.1242/bio.013508

44. Standen EM. Muscle activity and hydrodynamic function of pelvic fins in trout (Oncorhynchus mykiss). J Exp Biol. 2010;213: 831-841. doi:10.1242/ jeb.033084

45. Lauder GV, Madden PGA, Mittal R, Dong H, Bozkurttas M. Locomotion with flexible propulsors: I. Experimental analysis of pectoral fin swimming in sunfish. Bioinspir Biomim. 2006;1: S35-S41. doi:10.1088/1748$3182 / 1 / 4 /$ S05 
3D analysis of the fast-start escape response of the least killifish I Chapter 4 


\section{Chapter 5}

\section{How pregnancy affects body shape and 3D fast-start performance in live-bearing fish (Poeciliidae)}

Mike Fleuren, Johan L. van Leeuwen, Bart J.A. Pollux

Experimental Zoology Group, Department of Animal Sciences, Wageningen University \& Research, Wageningen, The Netherlands 
Chapter 5 I How pregnancy affects body shape and 3D fast-start performance

\begin{abstract}
The internal development of embryos unavoidably affects the morphology of pregnant live-bearing animals. Pregnancy-induced body-shape changes are thought to negatively affect swimming performance in live-bearing fish: pregnant fish cannot swim as fast as more slender non-pregnant individuals. Maintaining a relatively slender body shape during pregnancy could be advantageous, as it reduces the negative impact of reproduction on swimming performance and survival. Superfetation, the simultaneous presence of broods of different developmental stages, is a reproductive trait that is hypothesised to provide this benefit. Using a non-invasive method, we measured 3D morphological changes during pregnancy in three species of live-bearing fish (Poeciliidae) that differ in their degree of superfetation: Poeciliopsis turneri, Heterandria formosa and Phalloptychus januarius. We show that the amplitude of morphological changes during pregnancy is reduced with an increasing level of superfetation. Furthermore, we measured the effect of pregnancy on fast-start performance in a three-dimensional space. We show that pregnancy reduces swimming performance: maximum swimming speed and maximum rate of change of body curvature in the abdominal region are reduced in fish with a larger belly. Pregnancy negatively affects the curvature in the abdomen at the end of the initial 'C-bend' of the fast start, which leads to a smaller re-orientation in the yaw-plane. In general, the effects of pregnancy are largest in the horizontal plane. Whether superfetation leads to a better fast-start performance depends on the level of reproductive investment. Our results indicate that superfetation could provide an adaptive benefit to live-bearing fish in performance-demanding environments.
\end{abstract}




\section{Introduction}

A live-bearing mode of reproduction has evolved over 100 times independently in vertebrates [1]. However, the evolution of this reproductive mode concurs with large effects on the swimming abilities of live-bearing fish (Poeciliidae) during pregnancy. Pregnancy can alter locomotor performance in a number of different ways, e.g. through changes in metabolism due to aerobic and metabolic demands of the developing embryos [2], and through changes in morphology due to an increase in mass and volume of the embryos [3, Chapter 3]. A pregnancy-induced reduction in swimming performance is expected to lower female survival, and is therefore considered an important factor in life-history evolution in the Poeciliidae [4-7]. The effect of pregnancy on swimming performance has so far been quantified in two different types of swimming modes: sustained swimming and fast-start swimming. The former group of experiments focused on critical swimming speed, in which the speed is increased at fixed times intervals and with fixed speed increments until the fish is unable to maintain its position [8,9]. Critical swimming speed was reduced by $20 \%$ at the end of pregnancy in Gambusia affinis [3], but critical swimming speed tests on Poecilia reticulata revealed no effect of gestational stage on performance [10].

Other studies have focused on the effects of pregnancy on fast starts. Here, performance is generally determined from one or several parameters of the fast-start escape response, a manoeuvre that fish employ to quickly reorient themselves and propel away to escape predatory strikes [11-14]. Re-orientation can contain a strong three-dimensional component [15, Chapter 4]. The fast-start manoeuvre consists of two stages with a fixed kinematic pattern, and a variable third stage $[12,16]$. During stage 1 , the fish curves into a characteristic C-shape. During stage 2, a contralateral tail bend propels the fish away from its original position. During stage 3, the fish may continue swimming, coast, or brake using pectoral fins. Selection on fast-start performance occurs in populations with a high enough predation pressure. In the Trinidadian guppy (Poecilia reticulata), pregnant females from high-predation populations are faster at the beginning of an interbrood interval (the period between two parturition events), but the difference between the populations disappears when pregnancy progresses. Further evidence for selection on fast-start performance is found by comparing body shape of populations of fish from low- and high-predation populations: males from high-predation populations have evolved body shapes that are more beneficial for fast-start performance than those of the low-predation populations [17-19]. Arguably, females will have evolved similar changes to their body shape. 
Walker and colleagues [4] determined which specific parameters of the faststart performance (positively or negatively) affected the odds of surviving a predatory strike. Many of these parameters are linked to the swimming performance of the prey: higher peak performance is for instance characterized by higher velocities, accelerations and larger net distances travelled, and higher angular velocities of the fish during stage 1 . An increase in any or all of these parameters improves the odds of escaping a predatory strike. Arguably, these performance parameters will be affected by pregnancy.

So far, the effects of pregnancy on fast-start performance have been studied in a $2 \mathrm{D}$ framework, in which vertical motion of the fish was restricted by using shallow water levels [20,21]. However, the natural environment of fish is essentially $3 \mathrm{D}$, and both predator approaches and prey evasions may contain large vertical components [Chapter 4]. During fast-start manoeuvres, fish can change the body orientation in both yaw, pitch and roll angles [15, Chapter 4]. Only recently, biomechanicists have started to describe this behaviour in a three-dimensional context $[15,23$, Chapter 4$]$ and how pregnancy affects the vertical components of fast-start manoeuvres, and whether this affects the odds of survival are, to our knowledge, currently unknown.

Two (non-exclusive) reproductive modes have been hypothesised to provide an adaptive benefit to locomotor performance during pregnancy, as they could reduce the adverse effects of pregnancy on slenderness [23,24]. The first reproductive adaptation is matrotrophy, i.e. post-fertilization nutrient allocation, often through a placental structure [1,23,25-28]. Matrotrophy could be considered as a reproductive adaptation because the amount nutrients provisioned pre-fertilization (yolk) is reduced, resulting in smaller eggs and a smaller embryo mass throughout development [29-32] and a more slender body shape in pregnant females [Chapter 3]. The second hypothesised reproductive adaptation is superfetation, the simultaneous occurrence of broods of different developmental stages [23,24,33-36]. This trait exploits the difference in size between early- and late-stage embryos, leading to a reduction of the amplitude of the volume and slenderness changes during pregnancy (Figure 5-1). Perhaps because of the larger size differences between early- and late-stage embryos in matrotrophic species, there is a strong correlation between the evolution of matrotrophy and superfetation in Poeciliidae $[23,26]$.

Here, we aim to show how pregnancy-induced changes in morphology affect the fast-start escape response in livebearing fish. We adopt novel three-dimensional approaches to examine (i) changes in 3D morphology and (ii) locomotor performance in a 3D environment. We do this for three matro- 


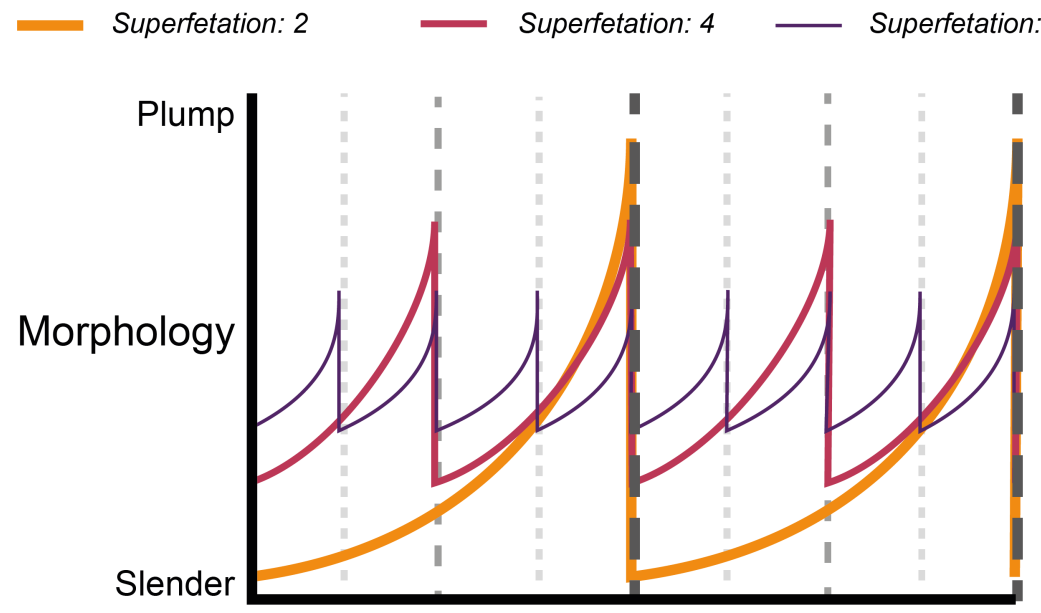

Time

Figure 5-1. The hypothesised effect of superfetation on morphological parameters. A superfetation of 2 ( 2 simultaneous broods of different developmental stages) corresponds roughly with Poeciliopsis turneri, a superfetation of 4 with Heterandria formosa and a superfetation of 8 with Phalloptychus januarius. This results in subsequently shorter interbrood intervals (the period between parturitions indicated by the dotted lines), and, theoretically, in a smaller amplitude of the morphological changes.

trophic species of live-bearing fish (Poeciliidae) that differ in their level of superfetation. We hypothesise that (i) pregnancy causes 3D changes in external body shape of fish, and expect the amplitude of these morphological changes in time to decrease with increasing levels of superfetation (Figure 5-1). Furthermore, we expect that (ii) fast-start performance is negatively affected by pregnancy in various aspects: kinematics, i.e. curvature in the abdomen and orientation change, and performance, i.e. curvature rate and maximum speed. Finally, we expect that increasing levels of superfetation lead to a better fast-start escape performance owing to a more slender and less variable morphology during pregnancy.

\section{Material and methods}

\section{Fish keeping \& husbandry}

We compared the morphology and fast-start performance during pregnancy of three different species of Poeciliidae: Poeciliopsis turneri Miller, 1975 (abbreviated Pt), Heterandria formosa Girard 1859 (Hf) and Phalloptychus januarius Hensel, 1868 (Pj). All species differ in their level of superfetation [23,37,38] and are all matrotrophic [26]. Laboratory stock populations of these fish are kept at the CARUS Aquatic Research Facilities of Wageningen University, The Netherlands. From these stock populations, new-borns were removed 
at $2-4$ week intervals and kept in age cohorts in $40 \mathrm{~L}$ tanks. Males were removed from these cohorts as soon as secondary sexual characteristics could be visually discerned. All procedures described were approved by the Animal Ethics Committee of Wageningen University \& Research (permit number 2013103).

After reaching sexual maturity (approximately $4-6$ months after birth), virgin females were moved to $9 \mathrm{~L}$ isolation tanks (Tecniplast, Bugugiatte, Italy), kept at a mean temperature of $24^{\circ} \mathrm{C}$, and enriched with a plastic plant. To reduce isolation stress, the bottom of the tanks of individually-housed $P$. turneri were covered with a layer of gravel. Virgin fish were randomly assigned to either a virgin control group ( $N=14$ per species), or a pregnant treatment group ( $N=14$ per species); females from the latter group were accompanied by $1-3$ males of the same species that were regularly switched around between females. The fish were supplied with fixed quantities of flake paste and liver paste during the morning and afternoon, as well as $5-10$ mature Artemia sp. (brine shrimp) during the afternoon. Before the start of the actual experiments, pregnant females were randomly assigned a virgin control, which together formed an experimental batch that performed experiments subsequently and on the same days. On measurement days, fish were only fed in the afternoons (post-measurement) to minimize the effect of food intake on swimming performance while providing sufficient food quantities for normal embryonic development (Pt: flake $0.25 \mathrm{ml}$, liver $0.30 \mathrm{ml}$; Hf: flake $0.04 \mathrm{ml}$, liver $0.06 \mathrm{ml}$; Pj: flake $0.08 \mathrm{ml}$, liver $0.12 \mathrm{ml}$; All: 5-10 Artemia sp. adult brine shrimp).

\section{Litter wet mass}

On a daily basis, all isolation tanks were checked for new-born fish in the mornings and the afternoons. Most new-borns were delivered in the morning. In rare occasions, neonates were born during experiments or in between fast start and morphological measurements. When caught, the new-borns were euthanized with a lethal dose of MS-222 (Tricaine-S; Western Chemical Inc., Ferndale, WA, United States), carefully paper dried with a gauze on a paper towel to remove excess water and weighed on a Mettler AE200 analytic balance (scale accuracy 0.0001 g; Mettler-Toledo B.V., Tiel, The Netherlands).

\section{Experimental procedure}

To measure fast-start performance, fish were placed in a cubic swimming arena $(0.23 \times 0.23 \times 0.30 \mathrm{~m}$; water level at $0.23 \mathrm{~m})$. Before introduction of the fish, water was refreshed $\left(23.9 \pm 0.5^{\circ} \mathrm{C}[\right.$ Mean $\left.\pm \mathrm{SD}]\right)$; after introduction the 
fish were allowed to acclimatize for 10 minutes in the dark and for 5 minutes with the top LED panel switched on. Fast-start sequences were recorded with three orthogonally-placed Mikroton EoSens CL MC1362 high-speed video cameras (Mikrotron GmbH, Unterschleissheim, Germany; resolution $1040 \times 1020$ pixels; $1 / 1000$ s shutter speed; 470 frames per second), calibrated with the direct linear transformation algorithm (DLT, method by [39]), synchronized with a Quantum Composers 9214 digital delay pulse generator (Quantum Composers Inc., Bozeman, MT, United States) and equipped with Epix PIXCI E8 frame grabbers (EPIX Inc., Buffalo Grove, IL, United States) and Nikkor $\mathrm{f}=28 \mathrm{~mm}, 1: 3.5$ lenses (Nikon, Tokyo, Japan) for P. turneri or Voigtländer Ultron $\mathrm{f}=40 \mathrm{~mm}, 1: 2$. Aspherical compact pancake lenses (RINGFOTO GmbH, Fürth, Germany) for H. formosa and P. januarius. The two types of lenses changed the dimensions of the field of view in the swimming arena: approximately $15 \times 15 \times 15 \mathrm{~cm}$ for $P$. turneri and $10 \times 10 \times 10 \mathrm{~cm}$ for the other two species. These sizes resulted in the required resolution to automatically track the location, orientation and shape of the fish with sufficient accuracy, while providing ample space for fish to escape in any desired direction.

Following the fast-start experiments, the fish were individually placed in a small tank (dimensions: $8 \times 8 \times 8 \mathrm{~cm}$ for $P$. turneri and $5 \times 5 \times 5 \mathrm{~cm}$ for $H$. formosa and $P$. januarius respectively) to record its morphology. Scale grids ( $1 \mathrm{~mm}$ resolution) were placed on all walls of the aquarium used for correct scaling at the location of the fish. Movement of the fish was limited by a displaceable wall and shallow water depth, but care was taken that the fish did not touch the walls. Simultaneous pictures were taken with three orthogonally-placed Nikon D3200 DSLR cameras (Nikon, Tokyo, Japan; sensor resolution 24 Mpix, equipped with Micro-Nikkor $\mathrm{f}=55 \mathrm{~mm}$ lenses), synchronized with a remote trigger (JinJiaCheng Photography Equipment Co., Ltd., Shenzhen, China). LED lights behind glass fibre cloths opposite to the cameras provided diffuse back lighting.

\section{Data analysis and statistical analysis}

In total, we recorded high-speed video sequences of 814 fast-start manoeuvres of $P$. turneri, 919 manoeuvres of $H$. formosa, and 428 manoeuvres of $P$. januarius. Fast-start movies were analysed with the Fishtracker program [22] for MATLAB 2013a (MathWorks, Natick, MA, United States). See Chapter 4 for an elaborate description of the analysis procedure. All performance parameters were normalized for standard length $\left(L_{\mathrm{SL}}\right)$. After analysis of these raw movies, we excluded movies for which the tracking algorithm failed to find a sufficiently accurate fit and those without a detectable onset of motion. 
We performed statistical analysis (see below) on the following number of movies: P. turneri pregnant - stage 1: 438 manoeuvres, stage 2: 219 manoeuvres; $P$. turneri virgin - stage 1: 316 manoeuvres, stage 2: 160 manoeuvres; $H$. formosa pregnant - stage 1: 392 manoeuvres, stage 2: 138 manoeuvres; $H$. formosa virgin - stage 1: 354 manoeuvres, stage 2: 153 manoeuvres; $P$. januarius pregnant - stage 1: 182 manoeuvres, stage 2: 91 manoeuvres; $P$. januarius virgin - stage 1: 161 manoeuvres, stage 2: 99 manoeuvres.

From the morphology images, one set of three pictures per female per day was selected for further analysis. Selection criteria consisted of minimal motion blur, minimal dorsoventral curvature of the caudal peduncle, and minimal rotation in pitch, yaw and roll directions. Six P. turneri measurements were omitted preceding analysis because these females were mistakenly fed shortly before imaging. These pictures were subsequently processed with an in-house developed MATLAB (version 2013a) program [23, Chapter 3], with which the pictures were converted into three-dimensional models.

From the 3D models, multiple morphological parameters were derived: width and height of the abdomen and caudal peduncle, maximum width and height in the abdominal region and from the fish as a whole, as well as frontal surface area, wetted surface area and total body volume. For measurements on the effects of width on performance, and correlates from the caudal peduncle, we consequently used the $20^{\text {th }}$ segment of the 51 ellipse body model (corresponding to $0.39 L_{\mathrm{SL}}$ ) as a fixed point on the abdomen, and the $40^{\text {th }}$ segment of the 51 ellipse body model (corresponding to $0.78 L_{\mathrm{SL}}$ ) as a fixed point on the caudal peduncle. To correct for differences is size within and between species, all longitudinal parameters were normalized by dividing by $L_{\mathrm{SL}}$ the two area parameters were normalized by dividing by $L_{\mathrm{SL}}{ }^{2}$ and volume was normalized by dividing by $L_{\mathrm{SL}}{ }^{3}$.

Relationships between fast-start parameters and morphology were tested for significance with linear mixed models using proc mixed [40] in SAS v9.3 (SAS Institute, Cary, NC, United States). All models correlated performance or kinematic variables with width in the abdomen and a curvature-related parameter of the tail (Table 5-1, Table 5-2). Two-levels of repeated measures were covered by the model: the repeated measures within individuals per day and between days. The yaw angle at the onset of motion (the orientation of the fish in the yaw plane) was included as a random effect in all models. The pitch angle at the onset of motion (the orientation of the fish in the pitch plane) was included as a random effect in the models for pitch change. Differences between litter wet mass and interbrood interval between spe- 
cies were calculated by two-sample $t$-tests using the $t t e s t 2$ function from the Statistics and Machine Learning Toolbox (v2013a) in MATLAB. Differences from all statistical tests were considered significant when $p<0.05$.

\section{Results}

\section{Pregnancy and 3D morphology}

The interbrood interval length, an indication of the level of superfetation $[23,37,38]$, differed between the three species. Poeciliopsis turneri had the longest interbrood interval (mean \pm SE: $9.0 \pm 0.8$ days), followed by Heterandria formosa (5.0 \pm 0.6 days) and Phalloptychus januarius ( $2.3 \pm 0.3$ days). Mean interval differed significantly between $P$. turneri and $H$. formosa (two-sample $t$-test, $\left.t_{32}: 4.1669, p=0.0002\right), P$. turneri and $P$. januarius $\left(t_{33}: 9.6468, p<0.0001\right)$, and between $H$. formosa and $P$. januarius $\left(t_{39}: 4.0229, p=0.0003\right)$.

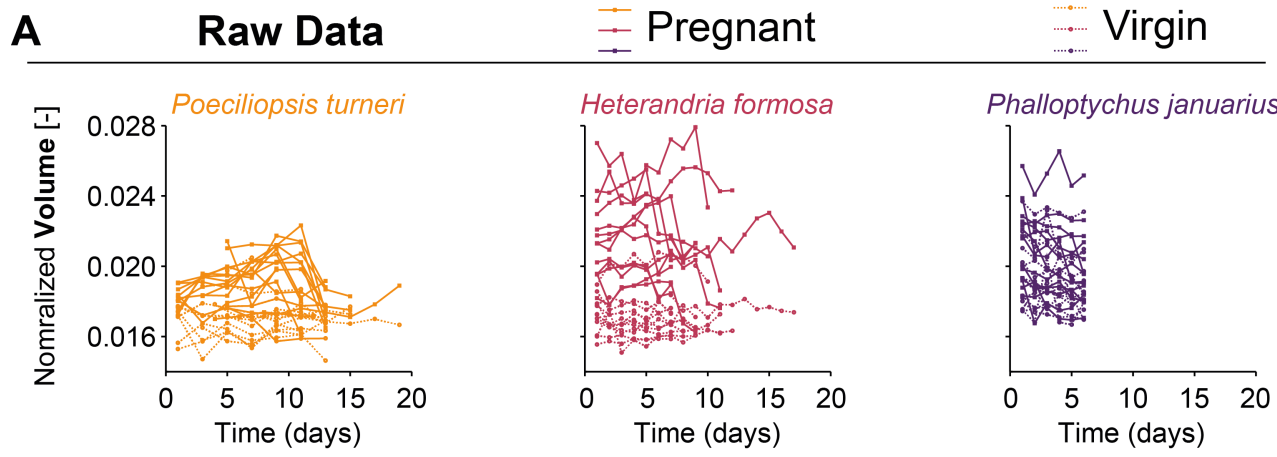

\section{B Fixed model estimates E Pregnant E Virgin}
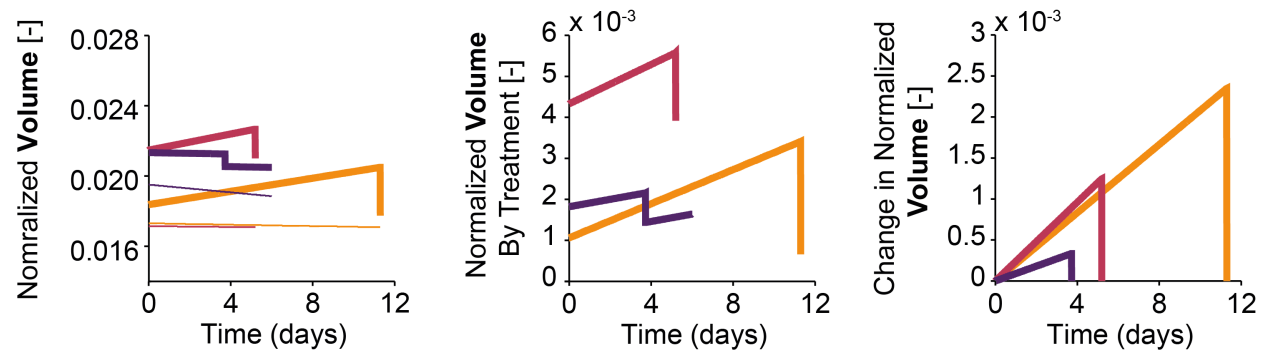

Figure 5-2. The effect of pregnancy on normalized volume. A: Raw data of normalized volume changes over time for Poeciliopsis turneri (orange), Heterandria formosa (red) and Phalloptychus januarius (purple). B: (left) Representation of mixed model estimates with fixed mean interbrood intervals for each species (colours consistent with A), pregnant (thick lines) and virgin (thin lines). (middle) Difference between pregnant and virgin fish of each species. (right) Normalized volume change estimates for each species. Exact values and statistical significance from the multi-level mixed modelling output can be found in Table 5-1 \& Table 5-2. 
A

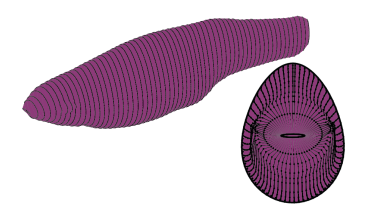

D

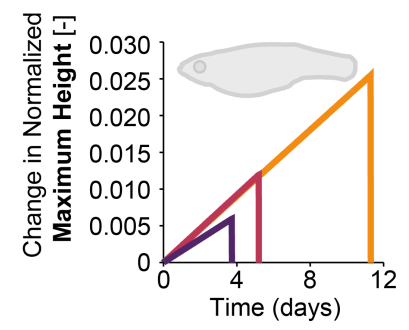

B

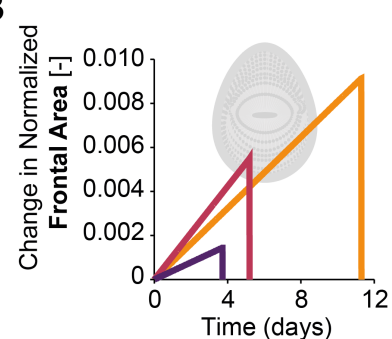

E

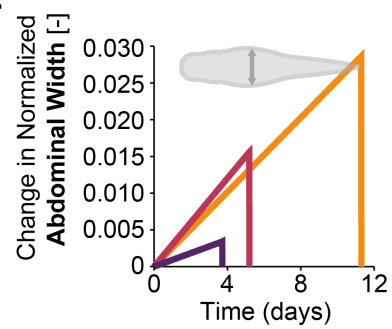

C

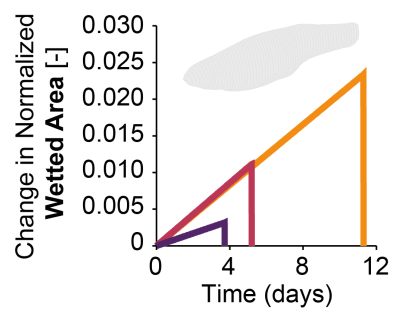

$\mathbf{F}$

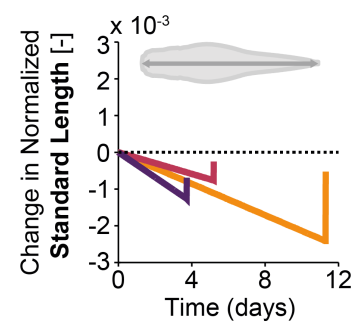

Figure 5-3. The effect of pregnancy on morphology. A: Three-dimensional body models, oblique view (top) and frontal projection (bottom). Normalized morphological change estimates for each species for wetted surface area (B), frontal surface area (C), maximum height (D), width in the abdomen $(E)$ and standard length $(F)$. Colours indicate Poeciliopsis turneri (orange), Heterandria formosa (red) and Phalloptychus januarius (purple). Exact values and statistical significance from the multi-level mixed modelling output can be found in Table 5-1 \& Table 5-2.

The differences in superfetation levels are reflected in the measured changes in volume (Table 5-1 \& Table 5-2; Figure 5-2). In a stepwise fashion, the raw morphological data (Figure 5-2A) are converted to volume change for one interbrood interval for each species (Figure 5-2B). All morphological parameters were calculated from three-dimensional body models (Figure 5-3A) and observed growth changes were similar for volume (Figure 5-2B), frontal surface area (Figure 5-3B), wetted surface area (Figure 5-3C), maximum height (Figure 5-3D), and abdominal width (Figure 5-3E). All parameters show almost no change in $P$. januarius, the species with the most superfetation. Growth rates are similar in $H$. formosa and P. turneri, but the morphological fluctuations are smaller in the former species due to the shorter interbrood interval (Table 5-1 \& Table 5-2). No significant morphological changes are observed in the width of the caudal peduncle (Table 5-1 \& Table 5-2) and standard length (Figure 5-3F).

Lastly, the species also differed in the mean wet mass of the litter: P. turneri has the largest mean wet mass per brood (total wet mass per brood: mean \pm SE: $0.136 \pm 0.015 \mathrm{~g})$, followed by $H$. formosa $(0.045 \pm 0.014 \mathrm{~g})$, and $P$. januarius $(0.009 \pm 0.001 \mathrm{~g})$. Differences in litter wet mass between species were significant ( $P$. turneri vs. H. formosa, two-sample $t$-test, $t_{32}: 4.2323, p=0.0002 ; P$. turn- 
eri vs. $P$. januarius, $t_{33}: 10.1258, p<0.0001 ; H$. formosa vs. $P$. januarius, $t_{3}: 2.5159$, $p=0.0161$ ), but standardization for $L_{\mathrm{SL}}$ (by dividing by $L_{\mathrm{SL}}{ }^{3}$ ) removed the differences between $P$. turneri and $H$. formosa (P. turneri: mean \pm SE: $1.387 \cdot 10^{-3}$ $\pm 1.747 \cdot 10^{-4} ;$ H. formosa: mean \pm SE: $2.520 \cdot 10^{-3} \pm 9.037 \cdot 10^{-4}$; $P$. januarius: mean \pm SE: $4.231 \cdot 10^{-4} \pm 5.056 \cdot 10^{-5}$; difference $P$. turneri vs. $H$. formosa, two-sample $t$-test, $t_{32}:-1.0349, p=0.3085$; difference $P$. turneri vs. $P$. januarius, $t_{33}: 6.2339, p$ $<0.0001$; difference $H$. formosa vs. $P$. januarius, $t_{39}: 2.3751, p=0.0226$ ).

\section{Pregnancy and 3D fast-start kinematics}

Pregnancy-induced morphological changes in the abdomen correlate with a decline in fast-start performance and the ability to curve in the abdominal region (Table 5-3-Table 5-5; Figure 5-4 \& Figure 5-5) and reorient to a novel escape direction (Table 5-3 \& Table 5-5; Figure 5-6). The abdominal curvature

A

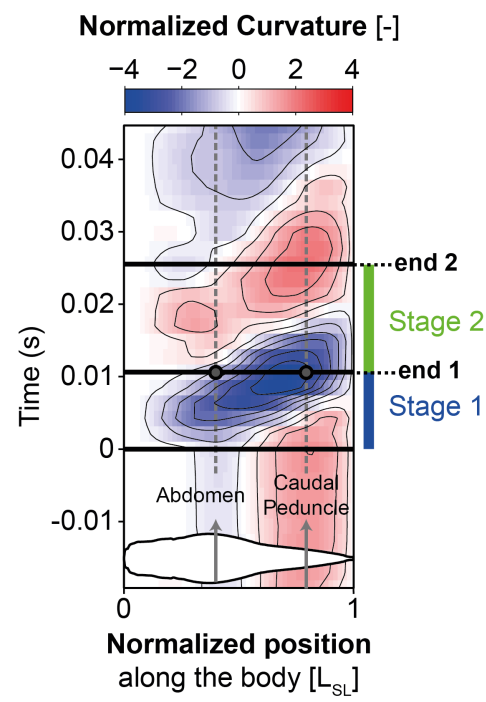

B

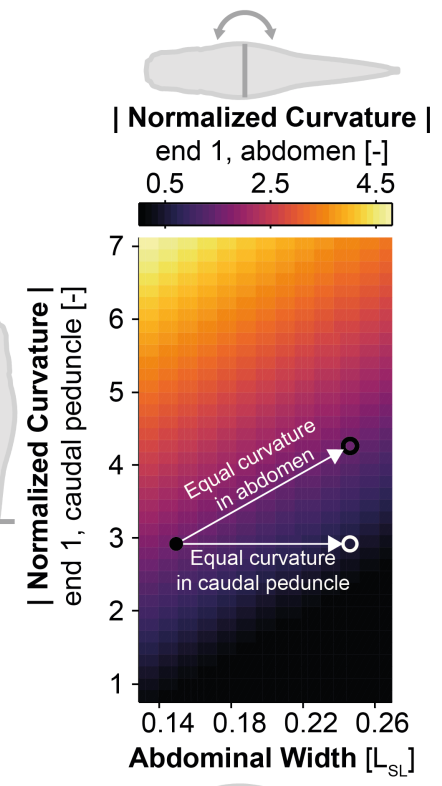

Figure 5-4. Explanatory figure showing how curvature changes during a faststart, and how curvature in the abdomen relates to the increase in abdominal width. A: Normalized curvature plot of the body of the fish over time, for a typical fast-start manoeuvre of fish. The beginning of motion (set at Time $=0$ ) and the ends of the two stages of the fast-start, named end 1 and end 2 respectively, are indicated by thick black lines. In the statistical models, curvature in the abdomen and caudal peduncle are measured at fixed points along the fish (grey arrows, dashed lines). B: Graphical representation of the fixed effect estimates of a mixed model. The surface plot indicates that for increasing abdominal width and equal curvature in the caudal peduncle, the curvature in the abdomen at the end of stage 1 decreases (black dot to white open circle); or that for increasing abdominal width and equal curvature in the abdomen, the curvature of the caudal peduncle at the end of stage 1 increases (black dot to black open circle). 
A
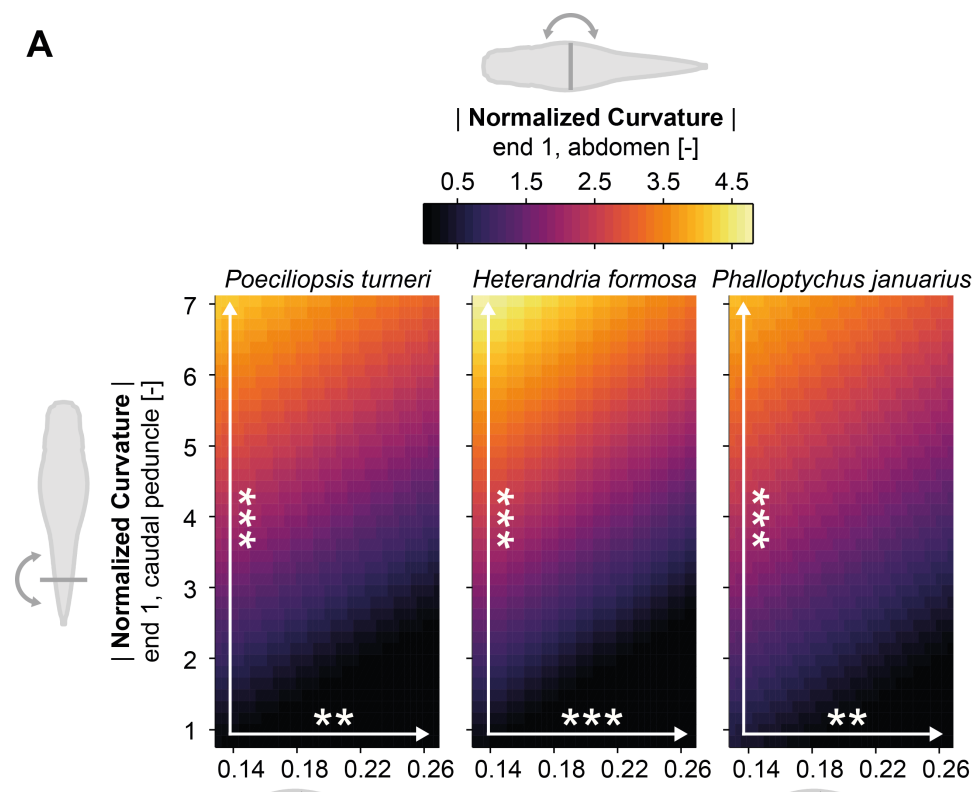

Abdominal Width $\left[\mathrm{L}_{\mathrm{SL}}\right]$

B

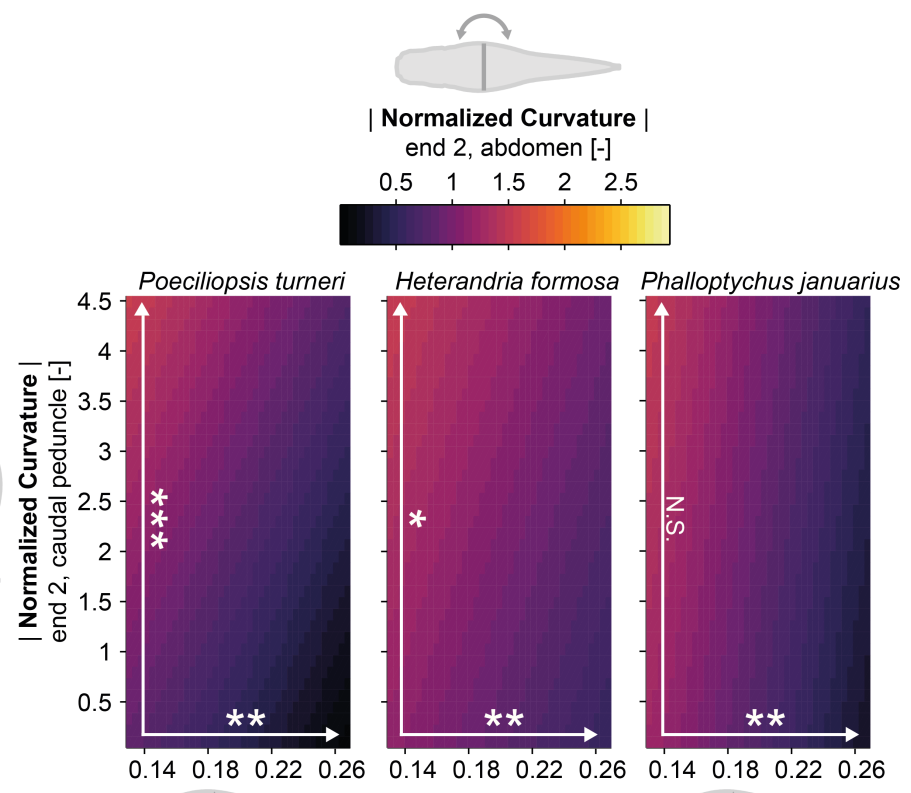

Abdominal Width $\left[\mathrm{L}_{\mathrm{SL}}\right]$

Figure 5-5.The effect of morphology on body curvature. A: The relationship between width of the abdomen, curvature in the caudal peduncle at the end of stage 1 , and curvature in the abdomen at the end of stage 1 for each species. B: The relationship between width of the abdomen, curvature in the caudal peduncle at the end of stage 2, and curvature in the abdomen at the end of stage 2 for each species. Exact values and statistical significance from the multi-level mixed modelling output can be found in Table 5-3 \& Table 5-4. N.S.: $p>0.05,{ }^{*}: 0.05>p>0.01,{ }^{\star *}: 0.01>p$ $>0.0001,{ }^{* * *}: p<0.0001$. 
A

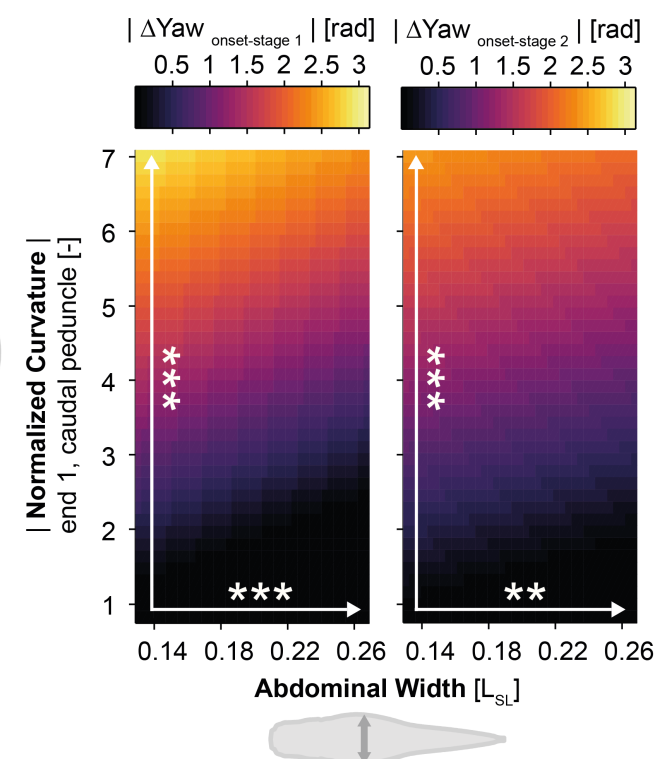

B

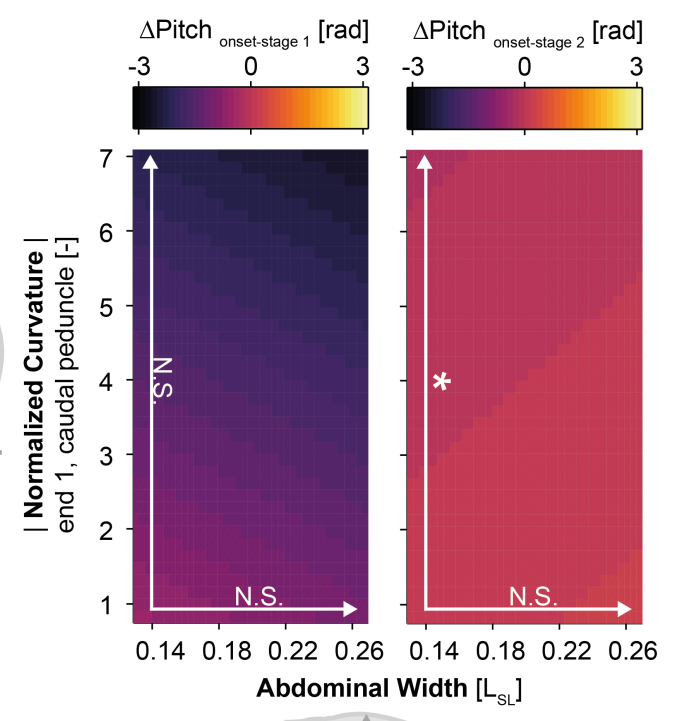

Figure 5-6. The effect of morphology on fast-start re-orientation. A: The relationship between width of the abdomen, curvature in the caudal peduncle at the end of stage 1 , and the change in yaw angle of the head between the onset of motion and the end of stage 1 (left) and between the onset of motion and the end of stage 2 (right), for all species pooled. B: The relationship between width of the abdomen, curvature in the caudal peduncle at the end of stage 1 , and the change in pitch angle of the head between the onset of motion and the end of stage 1 (left) and between the onset of motion and the end of stage 2 (right), for all species pooled. Exact values and statistical significance from the multi-level mixed modelling output can be found in Table 5-3 \& Table 5-5. N.S.: $p>0.05,{ }^{*}: 0.05>p>0.01,{ }^{* *}: 0.01>p>$ $0.0001,{ }^{* * *}: p<0.0001$. 
A

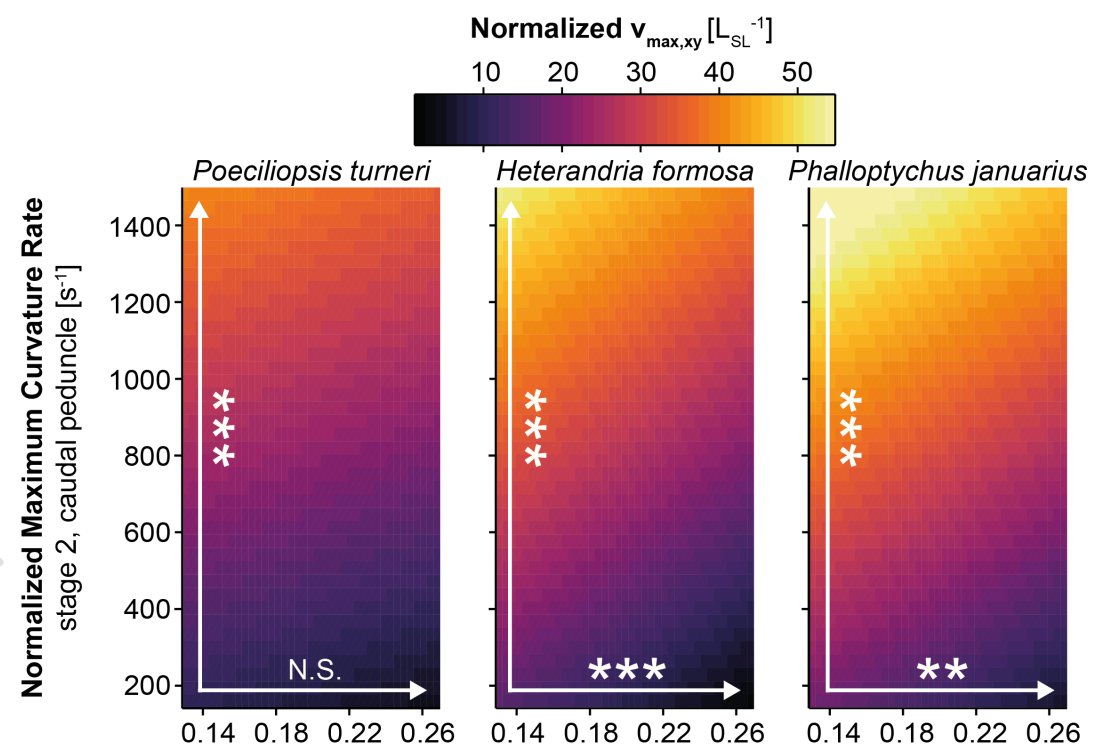

Abdominal Width $\left[\mathrm{L}_{\mathrm{SL}}\right]$

B

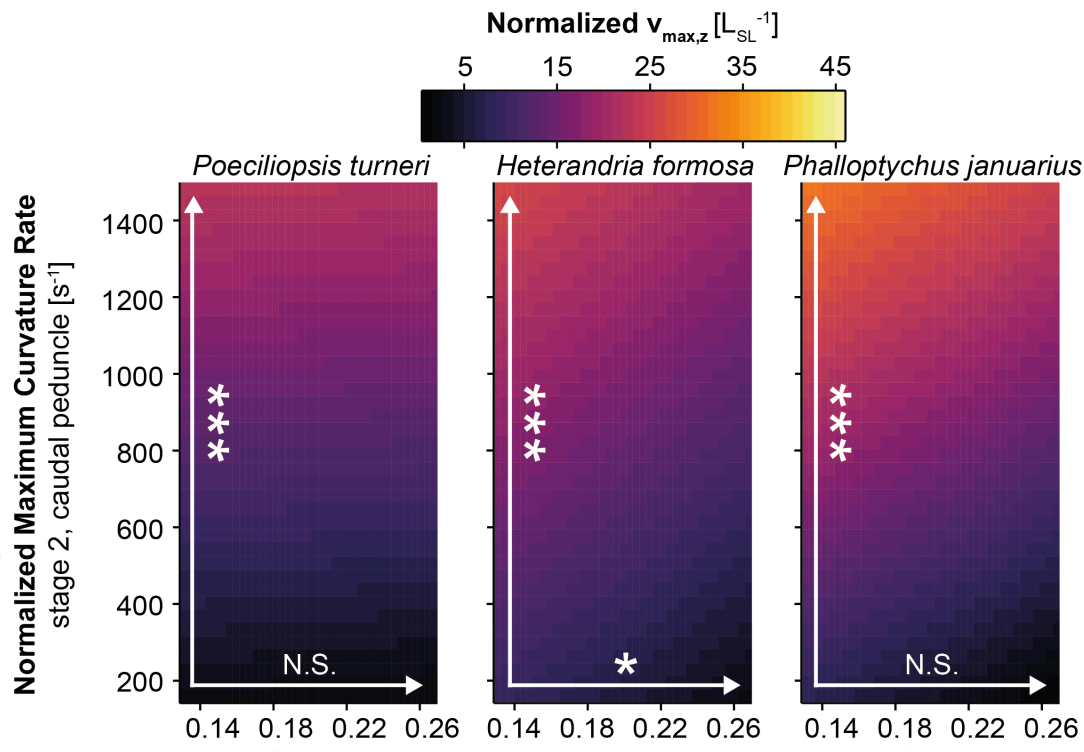

Abdominal Width $\left[L_{s L}\right]$

Figure 5-7. The effect of morphology on maximum speed for each of the three species. A: The relationship between width of the abdomen, maximum curvature rate in the caudal peduncle in stage 2, and maximum speed in the horizontal plane. B: The relationship between width of the abdomen, maximum curvature rate in the caudal peduncle in stage 2 , and maximum vertical velocity. Exact values and statistical significance from the multi-level mixed modelling output can be found in Table 5-3 \& Table 5-4. N.S.: $p>0.05,{ }^{*}: 0.05>p>0.01,{ }^{* *}: 0.01>p>0.0001,{ }^{* * *}: p<0.0001$. 
A

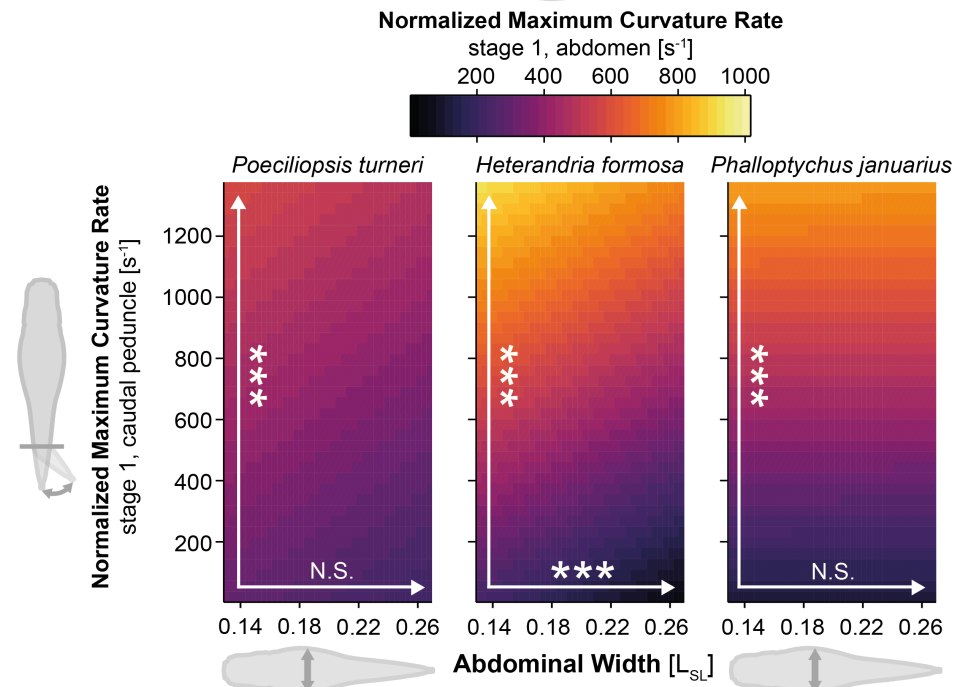

B

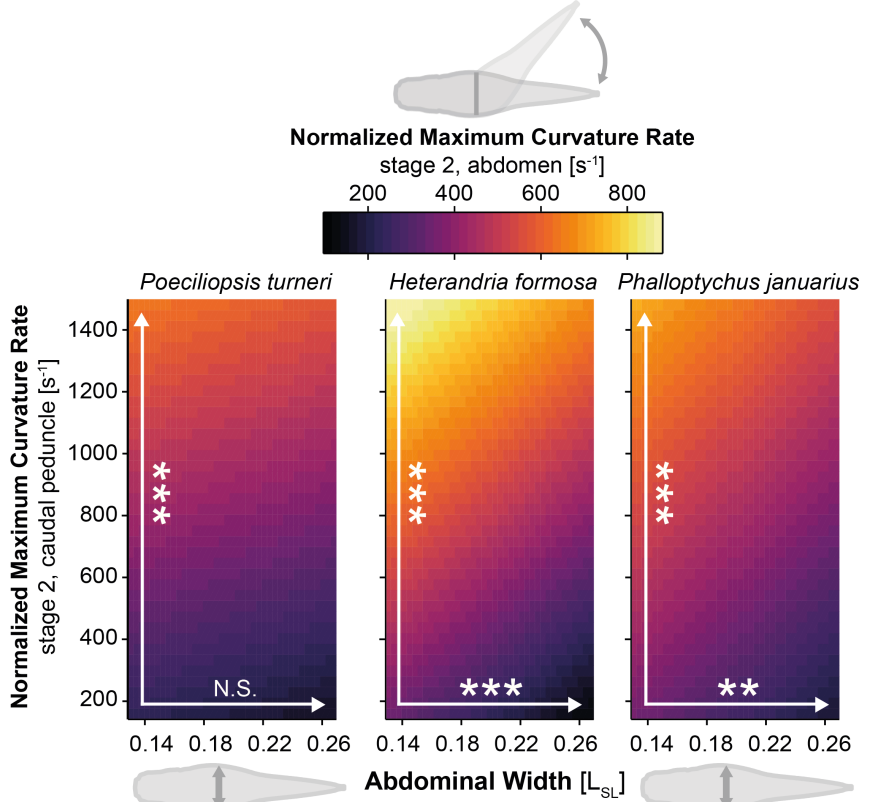

Figure 5-8. The effect of morphology on curvature rate for each of the three species. A: The relationship between width of the abdomen, maximum curvature rate in the caudal peduncle in stage 1 , and maximum curvature rate in the abdomen in stage 1. B: The relationship between width of the abdomen, maximum curvature rate in the caudal peduncle in stage 2 , and maximum curvature rate in the abdomen in stage 2. Exact values and statistical significance from the multi-level mixed modelling output can be found in Table 5-3 \& Table 5-4. N.S.: $p>0.05,{ }^{*}: 0.05>p>0.01$, ${ }^{* *}: 0.01>p>0.0001,{ }^{* * *}: p<0.0001$. 
during stage 1 of the fast start was negatively affected by the width increase in this part of the body: fish with thicker abdomens curved less in all three species (Table 5-4, Figure 5-5A). A similar trend was observed during stage 2 (Table 5-4, Figure 5-5B). The correlation between curvature in the abdomen and in the caudal peduncle was significant in both stages and for all species: higher abdominal curvatures corresponded to higher curvature in the caudal peduncle (Table 5-4, Figure 5-5).

The measured effect of abdominal width on local curvature is reflected in the yaw changes of the head: both the yaw change during stage 1 and the yaw change during stage 1 and 2 combined (the whole fast-start manoeuvre) were negatively correlated with an increase in abdominal width (Table 5-5, Figure 5-6A). The pitch-angle changes during these stages were not significantly correlated with an increase in abdominal width (Table 5-5, Figure 5-6B). These results indicate a link between pregnancy, morphology and a reduction in variation of preferred reorientation directions.

\section{Pregnancy and 3D fast-start performance}

The relationship between morphology and fast-start performance differed between species (Table 5-3 \& Table 5-4; Figure 5-7 \& Figure 5-8): in P. turneri, abdominal width did not correlate with any of the performance parameters (maximal speed in horizontal and vertical planes, maximum curvature rate in the abdomen), while in $H$. formosa there was a significant negative correlation between abdominal width and all performance parameters. In this species, plump fish performed worse at equal curvature rates of the tail. Phalloptychus januarius showed an intermediate of the other two species as horizontal speed and maximum abdominal curvature rate were negatively correlated with abdominal width, but vertical speed and maximum abdominal curvature rate in stage 1 were not. In all species, the tested curvature rates (maximum curvature rate in the caudal peduncle during stage 1 in Figure 5-8A, and stage 2 in Figure 5-7A, Figure 5-7B and Figure 5-8B respectively) were significantly correlated with both swimming speed and maximum abdominal curvature rate. 


\section{Discussion}

Here we discuss to what extent the results support the proposed hypotheses in the Introduction.

\section{Does superfetation reduce body shape variation during pregnancy?}

The difference in size between early- and late stage embryos forms the basis of the locomotor costs hypothesis: combining early- and late stage embryos should, assuming equal numbers, result in a less variable morphological pattern $[23,24]$. Because fewer embryos are in the fast growth phase (dry mass increases exponentially during development in matrotrophic fish; [32,41]), this should lead to smaller changes in maternal morphology over time. Our data clearly reflect this pattern (Figure 5-2 \& Figure 5-3): Poeciliopsis turneri and Heterandria formosa show significant size changes before and after parturition (i.e. significant increase in size during an interbrood interval) while Phalloptychus januarius does not.

Despite the reduced amplitude of morphological changes, superfetation does not by definition lead to a more slender body shape. Pregnant females of $H$. formosa are generally much less slender (e.g. bigger volume, frontal area) than virgin conspecifics (Figure 5-2), and also compared to late-stage pregnant $P$. turneri. This could be an effect of higher reproductive allocation: relative to body size, broods of $H$. formosa have equal relative wet litter mass to $P$. turneri, despite significantly shorter interbrood intervals (difference $p=$ 0.3085; see Results). Because $H$. formosa gives birth more often than $P$. turneri (difference $p=0.0003$; see Results), the long-term reproductive investment in the former species is higher. Instead of causing a more slender body shape, superfetation causes a less variable body shape; whether this body shape is more slender depends on the reproductive investment.

\section{Does pregnancy reduce three-dimensional fast-start performance?}

Pregnancy causes a decline in fast-start performance in live-bearing fish, but mainly affects this manoeuvre in the horizontal plane: in two out of three species the maximal horizontal speed decreases with increasing abdominal width (Figure 5-7A), while only H. formosa shows a significant negative relationship between increasing abdominal width and maximal vertical velocity (Figure 5-7B). Fast-start performance is further reduced by a significant negative relationship between abdominal width increase and changes in yaw angle, both in stage 1 and over the whole fast start (Figure 5-6A). This could make the motion of the fish more predictable for predators [42]. The relationship between abdominal width increase and pitch-angle change is not signif- 
icant (Figure 5-6B), but the relationship between abdominal width increase and pitch-angle change over the whole fast start does show a positive trend $(p=0.0817)$, however, indicating that there is a tendency for thicker females towards less downwards oriented, or more upwards oriented, responses. Further work, in which the orientation of the fish with respect to the stimulus and their escape headings are the subject of the research, could provide additional support for this hypothesis.

Because the 3D biomechanics of fast-start manoeuvres is a novel area, it is not yet known how the morphology of certain body regions affects changes in pitch and roll angles. A large part of steering for these angles could come from asymmetries in the caudal fin and from changes in the angle of attack of either or both of the pectoral fins. Due to limitations in lighting conditions, resolution and framerate in our setup, we were however not able to track changes in fin position from the present dataset. Fin-controlled steering makes it less likely that the ability to change orientation in pitch and roll is affected by pregnancy (compared to the ability to change orientation in the yaw direction, which is heavily affected by the ability to curve the abdomen). However, there are a few ways through which pregnancy could influence the orientation change in pitch (and perhaps also roll) during the fast-start manoeuvre. First, the ovary is placed on the ventral side of the dorsal column, leading to larger distention in the hypaxial muscles than in the epaxial muscles. As a result, the contraction of the epaxial muscles could be stronger, causing a bending in the dorsoventral plane and an upwards pitching moment of the cranial part of the body. This, however, is under the assumption that the number of sarcomeres within the hypaxial muscle fibres does not change during pregnancy. Experimental data on how pregnancy affects muscle strain in live-bearing fish could help to clarify the biomechanical effects of pregnancy on swimming performance, but, to our knowledge, such data are still unavailable.

The within-individual variation in fast-start performance was large, both between and within measurement days. To correct for this, we included curvature (rate) of the caudal peduncle into the statistical models. The curvature (rate) of the caudal peduncle is correlated with motivation to respond to the stimulus: large curvatures or high curvature rates in the caudal peduncle arguably indicate a stronger response of the subject to swim and/or turn away from the approaching danger. The morphology of the tail is not affected by pregnancy (Table 5-1 \& Table 5-2) and we assume that the non-linear feedback of the structure-fluid interactions have a relatively small effect on the mechanical behaviour of the caudal peduncle. Furthermore, it helps 
to discriminate between starts with a small re-orientation and starts with a large re-orientation component. Despite our measures to control this variation, it was still considerable. Especially in P. turneri, the variation was large and arguably one of the main causes of the absence of an effect of width on maximal attained speeds (Figure 5-7A,B). Previous reports arguing that (two-dimensional) fast-start performances are highly repeatable within individuals $[19,43]$, seem to be inapplicable to either our setup, or to fast-start performance measurements in a 3D compared to a 2D framework.

\section{Is superfetation an adaptation that improves fast-start performance?}

Our data reveals a strong negative effect of abdominal width increase on fast-start performance, at least in the horizontal plane. This indicates that traits that could reduce the increase in abdominal width during pregnancy, while maintaining equal levels of fecundity, provide an adaptive benefit. One of the traits to offer such a benefit, is superfetation [23,44]. Our study examined fast-start performance of species of fish that differed in their level of superfetation. Statements regarding the adaptive benefit of superfetation should however take into account three interactions: the relationship between morphology and performance, the relationship between superfetation and morphology (both described above) and the relationship between superfetation and reproductive allocation.

The measured changes in intra-species and interspecies morphology should be reflected in differences in locomotor performance, here measured as faststart escape performance. However, due to the differences in reproductive investment between species, i.e. specifically the higher reproductive allocation in H. formosa, the effects of level of superfetation and reproductive investment are heavily intertwined in our dataset. Therefore, a direct test of the hypothesis is not possible. Further testing on species that are more closely related, maybe even intra-species populations that differ in their level of superfetation, but not in their level of reproductive investment, could provide the answer.

Our data does, however, show how fast-start performance correlated with pregnancy-induced morphological changes in three dimensional space and that three species of live-bearing fish with different levels of superfetation experience varying morphological changes during pregnancy. This adds to a body of existing literature on the hypothesised morphological benefit of superfetation. In Poeciliopsis turrubarensis, the level of superfetation appears to be higher in populations that occupy faster-flowing streams and rivers than populations that live in standing or slow-flowing water [35]. The higher level 
of superfetation corresponded with a more slender body shape that likely reduced the energetic requirements of navigating in fast-flowing streams. However, this trend was not detected in populations of Poeciliopsis gracilis and Poeciliopsis infans that inhabited streams with different flow velocities [45]. Lastly, high-predation populations of Phalloceros harpagos displayed higher levels of superfetation than populations from regions with low predation pressure [46]. Work on natural populations is impeded by spatial and temporal differences in the level of superfetation, as the level of superfetation can differ unpredictably on a month-by-month basis [47]. We assumed that the superfetation level in our lab-reared animals were stable over time, due to a regular light regime, constant water flow rate, and fixed food quantities.

\section{Additional benefits of superfetation}

The locomotor cost hypothesis is only one of many hypotheses on the (adaptive) benefit of superfetation [44]. For instance, this trait could also function to increase the mean reproductive investment, through practically the same mechanism. Instead of a focus on minimizing the morphological effects of pregnancy, an animal could also focus on maximizing fecundity [48,49]. Such a strategy could be of interest when swimming performance is not a strong selective driver (i.e. in standing pools or in areas with low predation pressure), or to deal with intense or unpredictable adult mortality $[48,49]$.

Experimental work on superfetation levels in H. formosa under varying food conditions have found a positive relationship between food abundance and the level of superfetation: females from medium and high food abundance treatments had significantly more superfetation than food-deprived females [37]. Reznick and colleagues [29] report a decrease in interbrood interval length when $H$. formosa is subjected to high food abundance and an increase in interbrood interval length when they are subjected to low food quantities, likely a consequence of increasing and decreasing levels of superfetation respectively. A study on P. januarius in fluctuating food environments did not reveal an effect of food treatment on the level of superfetation, albeit that was not the purpose of the study [38]. When superfetation levels increase under high food conditions, this could be an indication of maximizing reproductive allocation.

\section{Concluding remarks}

The ability to escape predators, requiring a good fast-start performance, is an important parameter in the survival of an individual [4]. Reducing the adverse effects of pregnancy on swimming performance, while maintain- 
ing a high fecundity, therefore could provide a significant fitness advantage; something superfetation is hypothesised to bring [23,24]. Here, we have shown that superfetation indeed reduces the amplitude of morphological changes during pregnancy, but whether this indeed results in a more slender body shape (and an expected better fast-start performance) depends on the amount of reproductive investment.

Furthermore, we show that pregnancy negatively affects swimming performance as abdominal width increases. The biggest effects are observed in the horizontal plane: maximal horizontal velocity decreases with increasing abdominal width in two out of three examined species (Figure 5-7) and, for the three species combined, re-orientation in the yaw-plane is reduced (Figure 5-6). Performance in the vertical plane was reduced less, only in $H$. formosa did we find a negative effect of pregnancy, and also the pitch-angle change did not change significantly over pregnancy. The different effects in the horizontal and vertical plane merit further research on the mechanisms behind these differences, and whether pregnant live-bearing fish adjust their faststart manoeuvres to partly compensate the performance decline.

Our findings provide additional evidence for the locomotor costs hypothesis [23] and the adaptive benefit of superfetation in performance-demanding environments (e.g. high predator abundance or fast-flowing streams). This hypothesis however assumes equal reproductive investment, which the three species used here did not provide. Further research, with species or populations that differ less in their reproductive investment, could help to elucidate the possible locomotor performance benefit of superfetation. 
Chapter 5 I How pregnancy affects body shape and 3D fast-start performance

\section{Acknowledgements}

We would like to thank Elsa M. Quicazan-Rubio and Remco M.P. Pieters for their help with construction and testing of the experimental setup, Cees J. Voesenek for his help with the custom-made MATLAB program, Michael Kempkes for providing the breeding stocks of Heterandria formosa and David N. Reznick for providing stocks of Poeciliopsis turneri and Phalloptychus januarius. This study was supported by NWO-ALW Open Programme grant 821.02.024 to J.L.V.L. and VIDI grant 864.14.008 of the Netherlands Organisation for Scientific Research (NWO) to B.J.A.P.

\section{Author contributions}

M.F., J.L.V.L. and B.J.A.P. conceptualized the experiment, M.F. and J.L.V.L. designed the experimental methodology (hardware and software), M.F. performed the experiments and analysed the data, M.F. wrote a first draft of the manuscript and finalized the manuscript with comments from J.L.V.L. and B.J.A.P.

\section{Data storage and availability}

Data is stored on hard drives at three different locations. Upon publication of the manuscript, raw data (high-speed video movies and body model images) will be stored for a minimum of 10 years on an in-house managed server storage. Derived data will be made available on a Dryad database upon publication of the manuscript.

\section{Competing interests}

The authors declare no conflict of interest. 
Table 5-1. Multi-level modelling output of fixed effects of the mixed linear growth models for body morphology changes.

\begin{tabular}{llll}
\hline \hline $\begin{array}{l}\text { Type 3 Test of } \\
\text { Fixed Effects }\end{array}$ & Species & Species $\times$ Time & Species $\times$ Parturition \\
\hline & & & \\
Pregnant fish & & & \\
Volume & $F_{3,45}=1243.3, \quad p<.0001$ & $F_{3,262}=30.4, p<.0001$ & $F_{3,267}=69.4, p<.0001$ \\
Wetted Area & $F_{3,44.4}=7191.7, p<.0001$ & $F_{3,261}=29.3, p<.0001$ & $F_{3,266}=68.3, p<.0001$ \\
Frontal Area & $F_{3,45.3}=549.1, p<.0001$ & $F_{3,263}=47.6, p<.0001$ & $F_{3,269}=100.1, p<.0001$ \\
Maximum Height & $F_{3,45.3}=3653.8, p<.0001$ & $F_{3,263}=44.6, p<.0001$ & $F_{3,268}=106.8, p<.0001$ \\
Abdominal Width & $F_{3,46.5}=1583.2, p<.0001$ & $F_{3,265}=44.9, p<.0001$ & $F_{3,271}=95.2, p<.0001$ \\
Caudal Peduncle Width & $F_{3,56.6}=3448.2, p<.0001$ & $F_{3,275}=2.1, p=0.1075$ & $F_{3,281}=1.1, \quad p=0.3537$ \\
Standard Length $\left(L_{\mathrm{SL}}\right)$ & $F_{3,40.5}=2912.7, p<.0001$ & $F_{3,254}=0.6, p=0.5907$ & $F_{3,256}=1.5, \quad p=0.2050$ \\
& & & \\
Virgin fish & $F_{3,45.7}=2395.9, p<.0001$ & $F_{3,251}=4.2, p=0.0067$ & \\
Volume & $F_{3,44.5}=11437.3, p<.0001$ & $F_{3,225}=4.3, p=0.0057$ & \\
Wetted Area & $F_{3,44.4}=2143.1, p<.0001$ & $F_{3,251}=10.0, p<.0001$ & \\
Frontal Area & $F_{3,41.3}=8079.4, p<.0001$ & $F_{3,250}=27.0, p<.0001$ & \\
Maximum Height & $F_{3,45.9}=4608.8, p<.0001$ & $F_{3,251}=10.9, p<.0001$ & \\
Abdominal Width & $F_{3,62.7}=2634.0, p<.0001$ & $F_{3,257}=0.4, p=0.7744$ & \\
Caudal Peduncle Width & $F_{3,39.9}=1526.0, p<.0001$ & $F_{3,249}=0.5, p=0.6742$ & \\
Standard Length $\left(L_{\mathrm{SL}}\right)$ & & & \\
\hline \hline
\end{tabular}


Table 5-2. Multi-level modelling estimates of fixed effects of the mixed linear growth models for changes in body morphology. $\alpha$ : intercept, $\beta$ : slope of abdominal width, $y$ : slope of curvature correlate, Pt: Poeciliopsis turneri, Hf: Heterandria formosa, Pj: Phalloptychus januarius. Table continuous on the next page.

\begin{tabular}{|c|c|c|c|c|}
\hline $\begin{array}{l}\text { Type } 3 \text { Test of } \\
\text { Fixed Effects }\end{array}$ & & Species $\times$ Time & Species $\times$ Time & Species $\times$ Parturition \\
\hline \multicolumn{5}{|l|}{ Pregnant fish } \\
\hline \multirow{3}{*}{ Volume } & $\mathrm{Pt}$ & $\alpha: 0.018, t_{45.5}: 31.6, p<.0001$ & $\beta: 1.88 \mathrm{e}^{-4}, t_{252}: 7.2, p<.0001$ & $r:-2.75 \mathrm{e}^{-3}, t_{254}:-10.1, p<.0001$ \\
\hline & $\mathrm{Hf}$ & $\alpha: 0.021, t_{43.2}: 37.4, p<.0001$ & $\beta: 2.30 \mathrm{e}^{-4}, t_{260}: 6.3, p<.0001$ & $\gamma:-1.66 \mathrm{e}^{-3}, t_{263}:-9.8, p<.0001$ \\
\hline & $\mathrm{Pj}$ & $\alpha: 0.021, t_{46.5}: 36.5, p<.0001$ & $\beta:-2 \mathrm{e}^{-5}, t_{274}:-0.3, p=0.7762$ & $y:-7.2 \mathrm{e}^{-4}, t_{283}:-3.2, p=0.0017$ \\
\hline \multirow{3}{*}{ Wetted Area } & Pt & $\alpha: 0.485, t_{44.8}: 81.4, p<.0001$ & $\beta: 1.87 \mathrm{e}^{-3}, t_{252}: 7.4, p<.0001$ & $\gamma:-2.74 \mathrm{e}^{-2}, t_{254}:-10.5, p<.0001$ \\
\hline & $\mathrm{Hf}$ & $\alpha: 0.510, t_{42.8}: 86.5, p<.0001$ & $\beta: 2.03 \mathrm{e}^{-4}, t_{259}: 5.8, p<.0001$ & $y:-1.52 \mathrm{e}^{-2}, t_{263}:-9.3, p<.0001$ \\
\hline & $\mathrm{Pj}$ & $\alpha: 0.518, t_{45.6}: 86.4, p<.0001$ & $\beta:-3.6 \mathrm{e}^{-4}, t_{272}:-0.4, p=0.7762$ & $\gamma:-6.8 \mathrm{e}^{-3}, t_{283}:-3.1, p=0.0023$ \\
\hline \multirow{3}{*}{ Frontal Area } & $\mathrm{Pt}$ & $\alpha: 0.035, t_{45.8}: 19.0, p<.0001$ & $\beta: 7.49 \mathrm{e}^{-4}, t_{252}: 8.7, p<.0001$ & $y:-1.06 \mathrm{e}^{-2}, t_{254}:-12.0, p<.0001$ \\
\hline & $\mathrm{Hf}$ & $\alpha: 0.046, t_{43.2}: 25.7, p<.0001$ & $\beta: 9.78 \mathrm{e}^{-4}, t_{261}: 8.2, p<.0001$ & $\gamma:-6.58 \mathrm{e}^{-3}, t_{264}:-11.9, p<.0001$ \\
\hline & $\mathrm{Pj}$ & $\alpha: 0.046, t_{46.9}: 25.0, p<.0001$ & $\beta: 1.38 \mathrm{e}^{-4}, t_{276}: 0.5, p=0.6171$ & $y:-3.07 \mathrm{e}^{-3}, t_{285}:-4.1, p<.0001$ \\
\hline \multirow{3}{*}{$\begin{array}{l}\text { Maximum } \\
\text { Height }\end{array}$} & $\mathrm{Pt}$ & $\alpha: 0.253, t_{45.9}: 55.3, p<.0001$ & $\beta: 1.95 \mathrm{e}^{-3}, t_{252}: 9.1, p<.0001$ & $\gamma:-2.96 \mathrm{e}^{-2}, t_{254}:-13.5, p<.0001$ \\
\hline & $\mathrm{Hf}$ & $\alpha: 0.281, t_{43.4}: 62.5, p<.0001$ & $\beta: 2.01 \mathrm{e}^{-3}, t_{261}: 7.0, p<.0001$ & $y:-1.52 \mathrm{e}^{-2}, t_{264}:-11.1, p<.0001$ \\
\hline & $\mathrm{Pj}$ & $\alpha: 0.290, t_{46.9}: 63.2, p<.0001$ & $\beta: 5.65 \mathrm{e}^{-4}, t_{275}: 0.8, p=0.4066$ & $\gamma:-7.16 \mathrm{e}^{-3}, t_{284}:-3.9, p=0.0001$ \\
\hline \multirow{3}{*}{$\begin{array}{l}\text { Abdominal } \\
\text { Width }\end{array}$} & $\mathrm{Pt}$ & $\alpha: 0.178, t_{47.2}: 35.9, p<.0001$ & $\beta: 2.24 \mathrm{e}^{-3}, t_{252}: 8.7, p<.0001$ & $y:-3.26 \mathrm{e}^{-2}, t_{254}:-12.3, p<.0001$ \\
\hline & $\mathrm{Hf}$ & $\alpha: 0.212, t_{44}: 43.4, \quad p<.0001$ & $\beta: 2.75 \mathrm{e}^{-3}, t_{263}: 7.7, p<.0001$ & $\gamma:-1.81 \mathrm{e}^{-2}, t_{267}:-11.0, p<.0001$ \\
\hline & $\mathrm{Pj}$ & $\alpha: 0.199, t_{48.5}: 39.8, p<.0001$ & $\beta: 3.9 \mathrm{e}^{-6}, t_{279}:-0.0, p=0.9962$ & $y:-8.32 \mathrm{e}^{-3}, t_{288}:-3.8, p=0.0002$ \\
\hline \multirow{3}{*}{$\begin{array}{l}\text { Caudal Pedun- } \\
\text { cle Width }\end{array}$} & $\mathrm{Pt}$ & $\alpha: 0.085, t_{58.4}: 56.0, p<.0001$ & $\beta:-1.7 e^{-4}, t_{253}:-1.5, p=0.128$ & $\gamma: 1.89 \mathrm{e}^{-3}, t_{259}: 1.7, p=0.0928$ \\
\hline & $\mathrm{Hf}$ & $\alpha: 0.093, t_{50.7}: 63.2, p<.0001$ & $\beta:-1.3 \mathrm{e}^{-4}, t_{275}:-0.9, p=0.3721$ & $\gamma:-5.61 \mathrm{e}^{-7}, t_{281}:-0.0, p=0.9994$ \\
\hline & $\mathrm{Pj}$ & $\alpha: 0.087, t_{61.5}: 56.7, p<.0001$ & $\beta:-5.8 \mathrm{e}^{-4}, t_{290}:-1.7, p=0.0834$ & $\gamma: 5.76 \mathrm{e}^{-4}, t_{278}: 0.7, p=0.5148$ \\
\hline \multirow{3}{*}{$\begin{array}{l}\text { Standard } \\
\text { Length }\left(L_{\mathrm{SL}}\right)\end{array}$} & $\mathrm{Pt}$ & $\alpha: 0.046, t_{40.6}: 71.8, p<.0001$ & $\beta: 1.5 \mathrm{e}^{-5}, t_{251}: 1.0, p=0.3238$ & $y:-3.2 \mathrm{e}^{-4}, t_{252}:-2.1, p=0.0354$ \\
\hline & $\mathrm{Hf}$ & $\alpha: 0.026, t_{40.1}: 40.7, p<.0001$ & $\beta:-2 \mathrm{e}^{-5}, t_{253}:-0.9, p=0.3856$ & $\gamma: 3.0 \mathrm{e}^{-5}, t_{254}: 0.3, p=0.7562$ \\
\hline & $\mathrm{Pj}$ & $\alpha: 0.028, t_{40.8}: 43.8, p<.0001$ & $\beta: 2.1 \mathrm{e}^{-5}, t_{258}: 0.4, p=0.6687$ & $\gamma:-3 e^{-5}, t_{261}:-0.2, p=0.8303$ \\
\hline
\end{tabular}


Table 5-2. Table continues from previous page.

\begin{tabular}{|c|c|c|c|c|}
\hline $\begin{array}{l}\text { Type } 3 \text { Test of } \\
\text { Fixed Effects }\end{array}$ & & Species $\times$ Time & Species $\times$ Time & Species $\times$ Parturition \\
\hline \multicolumn{5}{|l|}{ Virgin fish } \\
\hline \multirow{3}{*}{ Volume } & $\mathrm{Pt}$ & $\alpha: 0.017, t_{46}: 47.0, \quad p<.0001$ & $\beta:-2 \mathrm{e}^{-5}, t_{251}:-1.4, p=0.1668$ & \\
\hline & $\mathrm{Hf}$ & $\alpha: 0.017, t_{43.6}: 47.2, p<.0001$ & $\beta:-1 \mathrm{e}^{-5}, t_{254}:-0.7, p=0.5047$ & \\
\hline & $\mathrm{Pj}$ & $\alpha: 0.020, t_{47.7}: 52.5, p<.0001$ & $\beta:-1 \mathrm{e}^{-4}, t_{249}:-3.2, p=0.0017$ & \\
\hline \multirow{3}{*}{ Wetted Area } & $\mathrm{Pt}$ & $\alpha: 0.475, t_{44.7}: 105, p<.0001$ & $\beta:-2 \mathrm{e}^{-4}, t_{250}:-1.3, p=0.1964$ & \\
\hline & $\mathrm{Hf}$ & $\alpha: 0.465, t_{42.7}: 104, p<.0001$ & $\beta:-1 \mathrm{e}^{-4}, t_{253}:-0.6, p=0.5712$ & \\
\hline & $\mathrm{Pj}$ & $\alpha: 0.504, t_{46.1}: 111, \quad p<.0001$ & $\beta:-1 \mathrm{e}^{-3}, t_{249}:-3.3, p=0.0011$ & \\
\hline \multirow{3}{*}{ Frontal Area } & $\mathrm{Pt}$ & $\alpha: 0.030, t_{44.6}: 41.6, p<.0001$ & $\beta:-6 \mathrm{e}^{-5}, t_{250}:-2.6, p=0.0112$ & \\
\hline & $\mathrm{Hf}$ & $\alpha: 0.032, t_{42.7}: 44.3, p<.0001$ & $\beta:-8 \mathrm{e}^{-5}, t_{253}:-2.6, p=0.0109$ & \\
\hline & $\mathrm{Pj}$ & $\alpha: 0.038, t_{46}: 52.2, p<.0001$ & $\beta:-3 \mathrm{e}^{-4}, t_{249}:-4.1, p<.0001$ & \\
\hline \multirow{3}{*}{$\begin{array}{l}\text { Maximum } \\
\text { Height }\end{array}$} & $\mathrm{Pt}$ & $\alpha: 0.238, t_{41.4}: 85.8, p<.0001$ & $\beta:-3 e^{-4}, t_{250}:-5.1, p<.0001$ & \\
\hline & $\mathrm{Hf}$ & $\alpha: 0.235, t_{40.6}: 85.5, p<.0001$ & $\beta:-2 \mathrm{e}^{-4}, t_{251}:-3.0, p=0.0031$ & \\
\hline & $\mathrm{Pj}$ & $\alpha: 0.272, t_{42}: 97.8, \quad p<.0001$ & $\beta:-1 \mathrm{e}^{-3}, t_{249}:-6.8, p<.0001$ & \\
\hline \multirow{3}{*}{$\begin{array}{l}\text { Abdominal } \\
\text { Width }\end{array}$} & $\mathrm{Pt}$ & $\alpha: 0.162, t_{46.2}: 65.9, p<.0001$ & $\beta:-3 \mathrm{e}^{-4}, t_{251}:-3.2, p=0.0014$ & \\
\hline & $\mathrm{Hf}$ & $\alpha: 0.171, t_{43.7}: 70.3, p<.0001$ & $\beta:-3 \mathrm{e}^{-4}, t_{254}:-2.3, p=0.0227$ & \\
\hline & $\mathrm{Pj}$ & $\alpha: 0.167, t_{47.9}: 67.4, p<.0001$ & $\beta:-9 e^{-4}, t_{249}:-4.1, p<.0001$ & \\
\hline \multirow{3}{*}{$\begin{array}{l}\text { Caudal Pedun- } \\
\text { cle Width }\end{array}$} & $\mathrm{Pt}$ & $\alpha: 0.086, t_{64}: 44.5, \quad p<.0001$ & $\beta: 4 \mathrm{e}^{-5}, t_{256}: 0.4, \quad p=0.6728$ & \\
\hline & $\mathrm{Hf}$ & $\alpha: 0.091, t_{55.2}: 54.2, p<.0001$ & $\beta: 2 \mathrm{e}^{-5}, t_{264}: 0.1, \quad p=0.8993$ & \\
\hline & $\mathrm{Pj}$ & $\alpha: 0.090, t_{70.6}: 50.2, p<.0001$ & $\beta:-2 \mathrm{e}^{-4}, t_{250}:-1.0, p=0.3394$ & \\
\hline \multirow{3}{*}{$\begin{array}{l}\text { Standard } \\
\text { Length }\left(\mathrm{L}_{\mathrm{SL}}\right)\end{array}$} & $\mathrm{Pt}$ & $\alpha: 0.048, t_{39.9}: 51.4, p<.0001$ & $\beta:-1 \mathrm{e}^{-5}, t_{249}:-1.2, p=0.2490$ & \\
\hline & $\mathrm{Hf}$ & $\alpha: 0.028, t_{39.6}: 29.7, p<.0001$ & $\beta:-7 \mathrm{e}^{-6}, t_{250}:-0.5, p=0.6554$ & \\
\hline & $\mathrm{Pj}$ & $\alpha: 0.030, t_{40.1}: 32.5, p<.0001$ & $\beta: 1 \mathrm{e}^{-6}, t_{249}: 0.05, p=0.9612$ & \\
\hline
\end{tabular}


Chapter 5 I How pregnancy affects body shape and 3D fast-start performance

Table 5-3.Multi-level modelling output of fixed effects of the mixed linear growth models for fast-start performance and kinematics. Abd: abdomen.

\begin{tabular}{|c|c|c|c|}
\hline $\begin{array}{l}\text { Type } 3 \text { Test } \\
\text { of Fixed Effects }\end{array}$ & Species & Species $\times$ Width $_{\text {abdomen }}$ & Species $\times$ Curvature correlate* \\
\hline$v_{\max , x y}$ & $F_{3,133}=24.40, p<.0001$ & $F_{3,126}=12.59, p<.0001$ & $F_{3,404}=149.41, p<.0001^{(1)}$ \\
\hline$v_{\max , z}$ & $F_{3,79.4}=4.74, p=0.0043$ & $F_{3,47.5}=2.73, p=0.0541$ & $F_{3,394}=48.18, \quad p<.0001^{(1)}$ \\
\hline Max curvature rate $_{\text {Stage 1, abd. }}$ & $F_{3,181}=30.14, p<.0001$ & $F_{3,103}=9.47, \quad p<.0001$ & $F_{3,549}=247.77, p<.0001^{(2)}$ \\
\hline Max curvature rate Stage 2, abd. $_{\text {. }}$ & $F_{3,152}=39.69, p<.0001$ & $F_{3,105}=13.41, p<.0001$ & $F_{3,358}=119.17, p<.0001^{(1)}$ \\
\hline Curvature $_{\text {Stage 1, abdomen }}$ & $F_{3,179}=5.97, p=0.0007$ & $F_{3,114}=19.99, p<.0001$ & $F_{3,815}=336.46, p<.0001^{(3)}$ \\
\hline Curvature $_{\text {Stage 2, abdomen }}$ & $F_{3,115}=29.40, p<.0001$ & $F_{3,86.3}=10.38, p<.0001$ & $F_{3,455}=7.79, \quad p<.0001^{(4)}$ \\
\hline Yaw change $_{\text {Stage } 1}$ & & $F_{1,285}=102.39, p<.0001$ & $F_{1,596}=746.44, p<.0001^{(3)}$ \\
\hline Yaw change $_{\text {Stage } 1+2}$ & & $F_{1,489}=8.44, \quad p=0.0038$ & $F_{1,349}=111.77, p<.0001^{(3)}$ \\
\hline Pitch change $_{\text {Stage } 1}$ & & $F_{1,355}=0.18, \quad p=0.6686$ & $F_{1,617}=0.60, p=0.4400$ \\
\hline Pitch change $\mathrm{e}_{\text {Stage } 1+2}$ & & $F_{1,399}=3.05, \quad p=0.081$ & $F_{1,272}=4.12, p=0.0435$ \\
\hline
\end{tabular}

* Curvature correlates: ${ }^{(1)}$ maximum curvature rate during stage 2 in the caudal peduncle; ${ }^{(2)}$ maximum curvature rate during stage 1 in the caudal peduncle; ${ }^{(3)}$ curvature at the end of stage 1 in the caudal peduncle; (4) curvature at the end of stage 2 in the caudal peduncle. 
Table 5-4. Multi-level modelling estimates of fixed effects of the mixed linear growth models for fast-start performance and kinematics. $\alpha$ : intercept, $\beta$ : slope of abdominal width, $y$ : slope of curvature correlate, Pt: Poeciliopsis turneri, Hf: Heterandria formosa, Pj: Phalloptychus januarius.

\begin{tabular}{|c|c|c|c|c|}
\hline $\begin{array}{l}\text { Type } 3 \text { Test of } \\
\text { Fixed Effects }\end{array}$ & & Species & Species $\times$ Width $_{\text {abdomen }}$ & $\begin{array}{l}\text { Species } \times \text { Curvature cor- } \\
\text { relate }^{*}\end{array}$ \\
\hline \multirow{3}{*}{$v_{\text {max }, x y}$} & $\mathrm{Pt}$ & $\alpha: 11.97, t_{124}: 3.0, p=0.0038$ & $\beta:-40.0, t_{139}:-1.7, p=0.0884$ & $y: 2.3 \mathrm{e}^{-2}, t_{325}: 11.8, p<.0001^{(1)}$ \\
\hline & $\mathrm{Hf}$ & $\alpha: 24.78, t_{106}: 6.1, p<.0001$ & $\beta:-98.7, t_{101}:-4.8, p<.0001$ & $\gamma: 2.7 \mathrm{e}^{-2}, t_{347}: 13.8, p<.0001^{(1)}$ \\
\hline & $\mathrm{Pj}$ & $\alpha: 26.31, t_{163}: 5.2, p<.0001$ & $\beta:-92.0, t_{128}:-3.4, p=0.0009$ & $\gamma: 3.0 \mathrm{e}^{-2}, t_{594}: 11.0, p<.0001^{(1)}$ \\
\hline \multirow{3}{*}{$v_{\max , z}$} & $\mathrm{Pt}$ & $\alpha: 1.15, t_{124}: 0.3, p=0.7904$ & $\beta:-6.44, t_{84.3}:-0.3, p=0.7967$ & $\gamma: 1.5 \mathrm{e}-2, t_{309}: 7.8, p<.0001^{(1)}$ \\
\hline & $\mathrm{Hf}$ & $\alpha: 12.94, t_{42.3}: 3.1, p=0.0037$ & $\beta:-46.58, t_{25 .}:-2.2, p=0.0382$ & $\gamma: 1.3 \mathrm{e}-2, t_{350}: 6.5, p<.0001^{(1)}$ \\
\hline & $\mathrm{Pj}$ & $\alpha: 11.32, t_{111}: 2.2, p=0.0313$ & $\beta:-50.11, t_{60.2}:-1.8, p=0.0708$ & $\gamma: 1.8 \mathrm{e}-2, t_{582}: 6.4, p<.0001^{(1)}$ \\
\hline \multirow{3}{*}{$\begin{array}{l}\text { Max curvature } \\
\text { rate } \\
\text { Stage 1, abdomen }\end{array}$} & $\mathrm{Pt}$ & $\alpha: 400.7, t_{339}: 5.8, p<.0001$ & $\beta:-729.5, t_{248}:-1.9, p=0.0541$ & $\gamma: 0.20, t_{810}: 6.0, p<.0001$ \\
\hline & $\mathrm{Hf}$ & $\alpha: 413.3, t_{84.9}: 7.4, p<.0001$ & $\beta:-1392.8, t_{45.7}:-5.0, p<.0001$ & $\gamma: 0.51, t_{363}: 24.0, p<.0001$ \\
\hline & $\mathrm{Pj}$ & $\alpha: 130.2, t_{254}: 1.6, p=0.1078$ & $\beta:-27.4, t_{142}:-0.1, p=0.9471$ & $\gamma: 0.49, t_{587}: 11.5, p<.0001$ \\
\hline \multirow{3}{*}{$\begin{array}{l}\text { Max curvature } \\
\text { rate } \\
\text { Stage 2, abdomen }\end{array}$} & $\mathrm{Pt}$ & $\alpha: 250.9, t_{176}: 3.9, p=0.0002$ & $\beta:-514.6, t_{150}:-1.4, p=0.1689$ & $\gamma: 0.31, t_{287}: 10.8, p<.0001$ \\
\hline & $\mathrm{Hf}$ & $\alpha: 497.4, t_{98.3}: 8.0, p<.0001$ & $\beta:-1653.1, t_{66.8}:-5.3, p<.0001$ & $\gamma: 0.42, t_{335}: 14.1, p<.0001$ \\
\hline & $\mathrm{Pj}$ & $\alpha: 482.0, t_{186}: 6.3, p<.0001$ & $\beta:-1289.0, t_{112}:-3.3, p=0.0014$ & $\gamma: 0.28, t_{488}: 6.5, p<.0001$ \\
\hline \multirow{3}{*}{$\begin{array}{l}\text { Curvature }_{\text {Stage 1, }} \\
\text { abdomen }\end{array}$} & $\mathrm{Pt}$ & $\alpha: 0.73, t_{507}: 1.8, p=0.0774$ & $\beta:-8.47, t_{283}:-3.8, p=0.0002$ & $\gamma: 0.66, t_{839}: 17.0, p<.0001$ \\
\hline & $\mathrm{Hf}$ & $\alpha: 1.06, t_{96.1}: 3.0, p=0.0034$ & $\beta:-10.76, t_{58.9}:-6.0, p<.0001$ & $\gamma: 0.73, t_{538}: 24.6, p<.0001$ \\
\hline & $\mathrm{Pj}$ & $\alpha: 1.18, t_{171}: 2.4, p=0.0173$ & $\beta:-8.36, t_{125}:-3.2, p=0.0017$ & $\gamma: 0.56, t_{1272}: 10.7, p<.0001^{(3)}$ \\
\hline \multirow{3}{*}{$\begin{array}{l}\text { Curvature }_{\text {Stage 2, }} \\
\text { abdomen }\end{array}$} & $\mathrm{Pt}$ & $\alpha: 1.61, t_{142}: 4.7, p<.0001$ & $\beta:-5.92, t_{132}:-3.0, p=0.0034$ & $\gamma: 0.16, t_{340}: 4.2, p<.0001^{(4)}$ \\
\hline & $\mathrm{Hf}$ & $\alpha: 1.71, t_{61.5}: 5.9, p<.0001$ & $\beta:-4.45, t_{44.9}:-3.0, p=0.0046$ & $\gamma: 0.09, t_{452}: 2.1, p=0.0359^{(4)}$ \\
\hline & $\mathrm{Pj}$ & $\alpha: 2.17, t_{187}: 5.6, p<.0001$ & $\beta:-7.27, t_{122}:-3.7, p=0.0004$ & $\gamma: 0.06, t_{625}: 1.1, p=0.2890^{(4)}$ \\
\hline
\end{tabular}

* Curvature correlates: ${ }^{(1)}$ maximum curvature rate during stage 2 in the caudal peduncle; ${ }^{(2)}$ maximum curvature rate during stage 1 in the caudal peduncle; ${ }^{(3)}$ curvature at the end of stage 1 in the caudal peduncle; (4) curvature at the end of stage 2 in the caudal peduncle. 
Chapter 5 I How pregnancy affects body shape and 3D fast-start performance

Table 5-5. Multi-level modelling estimates of fixed effects of the mixed linear growth models for changes in yaw and pitch during stage 1 and stage $1+2$. $\beta$ : slope of abdominal width, $\gamma$ : slope of curvature correlate.

\begin{tabular}{|c|c|c|}
\hline Type 3 Test of Fixed Effects & Width $_{\text {abdomen }}$ & Curvature $_{\text {Stage 1,peduncle }}$ \\
\hline Yaw change $_{\text {Stage } 1}$ & $\beta:-4.24, t_{285}:-10.1, p<.0001$ & $\gamma: 0.49, t_{596}: 27.3, p<.0001$ \\
\hline Yaw change $_{\text {Stage } 2}$ & $\beta:-2.47, t_{489}:-2.9, p=0.0038$ & $\gamma: 0.39, t_{349}: 10.6, p<.0001$ \\
\hline Pitch change ${ }_{\text {Stage } 1}$ & $\beta:-3.19, t_{355}:-0.4, p=0.6686$ & $\gamma:-0.26, t_{617}:-0.8, p=0.4400$ \\
\hline Pitch change ${ }_{\text {Stage } 2}$ & $\beta: 0.43, t_{399}: 1.8, p=0.0817$ & $\gamma:-0.02, t_{272}:-2.0, p=0.0435$ \\
\hline
\end{tabular}




\section{References}

1. Blackburn DG. Evolution of vertebrate viviparity and specializations for fetal nutrition: A quantitative and qualitative analysis. J Morphol. 2015;276: 961-990. doi:10.1002/jmor.20272

2. Timmerman CM, Chapman LJ. The effect of gestational state on oxygen consumption and response to hypoxia in the sailfin molly, Poecilia latipinna. Environ Biol Fishes. 2003;68: 293-299. doi:Doi 10.1023/A:1027300701599

3. Plaut I. Does pregnancy affect swimming performance of female Mosquitofish, Gambusia affinis? Funct Ecol. 2002;16: 290-295. doi:DOI 10.1046/j.1365-2435.2002.00638.x

4. Walker JA, Ghalambor CK, Griset OL, McKenney D, Reznick DN. Do faster starts increase the probability of evading predators? Funct Ecol. 2005;19: 808-815. doi:DOI 10.1111/j.1365-2435.2005.01033.x

5. Higham TM, Rogers SM, Langerhans RB, Jamniczky HA, Lauder GV, Stewart WJ, et al. Speciation through the lens of biomechanics: locomotion, prey capture and reproductive isolation. Proc R Soc London B Biol Sci. 2016;283: 20161294. doi:10.1098/rspb.2016.1294

6. Langerhans RB, Reznick DN. Ecology and Evolution of Swimming Performance in Fishes: Predicting Evolution with Biomechanics. In: Domenici P, Kapoor BG, editors. Fish Locomotion. Science Publishers; 2010. pp. 200-248. doi:10.1201/b10190-8

7. Arnold SJ. Morphology, performance and fitness. Am Zool. 1983;23: 347-361.

8. Brett RJ. The respiratory metabolism and swimming performance of young sockeye salmon. J Fish Res Board Canada. 1964;21: 1183-1226.

9. Plaut I. Critical swimming speed: its ecophysiological relevance. Comp Biochem Physiol Part A Mol Integr Physiol. 2001;131: 41-50. doi:10.1016/ S1095-6433(00)80239-1

10. Svendsen JC, Banet AI, Christensen RHB, Steffensen JF, Aarestrup K. Effects of intraspecific variation in reproductive traits, pectoral fin use and burst swimming on metabolic rates and swimming performance in the Trinidadian guppy (Poecilia reticulata). J Exp Biol. 2013;216: 3564-74. doi:10.1242/jeb.083089

11. Domenici P, Blake RW. The kinematics and performance of fish faststart swimming. J Exp Biol. 1997;200: 1165-1178. Available: http://jeb. biologists.org/content/200/8/1165.short

12. Weihs $\mathrm{D}$. The mechanism of rapid starting of slender fish. Biorheology. 1973;10: 343-350.

13. Wakeling JM. Fast-start mechanics. In: Shadwick RE, Lauder G V., editors. Fish Biomechanics. San Diego, CA: Elsevier Academic Press; 2006. pp. 333-368. doi:10.1016/S1546-5098(05)23012-1 
Chapter 5 I How pregnancy affects body shape and 3D fast-start performance

14. Spierts ILY, Van Leeuwen JL. Kinematics and muscle dynamics of Cand S-starts of carp (Cyprinus carpio L.). J Exp Biol. 1999;202: 393-406. Available: http://www.ncbi.nlm.nih.gov/pubmed/9914147\%5Cnhttp:// jeb.biologists.org/content/202/4/393.short\%0Ahttp://www.ncbi.nlm. nih.gov/pubmed/9914147

15. Nair A, Azatian G, McHenry MJ. The kinematics of directional control in the fast start of zebrafish larvae. J Exp Biol. 2015; 3996-4004. doi:10.1242/ jeb.126292

16. Eaton RC, Bombardieri RA, Meyer DL. The Mauthner-initiated startle response in teleost fish. J Exp Biol. 1977;66: 65-81.

17. Langerhans RB, Gifford ME, Joseph EO. Ecological speciation in Gambusia fishes. Evolution (NY). 2007;61: 2056-2074. doi:10.1111/j.15585646.2007.00171.x

18. Langerhans RB. Morphology, performance, fitness: functional insight into a post-Pleistocene radiation of mosquitofish. Biol Lett. 2009;5: 488491. doi:10.1098/rsbl.2009.0179

19. Langerhans RB, Layman C, Mona Shokrollahi A, DeWitt T. Predator-driven phenotypic diversification in Gambusia affinis. Evolution (N Y). 2004;58: 2305-2318. Available: http://onlinelibrary.wiley.com/ doi/10.1111/j.0014-3820.2004.tb01605.x/abstract

20. Ghalambor CK, Reznick DN, Walker JA. Constraints on adaptive evolution: the functional trade-off between reproduction and fast-start swimming performance in the Trinidadian guppy (Poecilia reticulata). Am Nat. 2004;164: 38-50. doi:10.1086/421412

21. Banet AI, Svendsen JC, Eng KJ, Reznick DN. Linking reproduction, locomotion, and habitat use in the Trinidadian guppy (Poecilia reticulata). Oecologia. 2016;181: 87-96.

22. Voesenek CJ, Pieters RPM, Van Leeuwen JL. Automated reconstruction of three-dimensional fish motion, forces, and torques. PLoS One. 2016;11: e0146682. doi:10.1371/journal.pone.0146682

23. Pollux BJA, Pires MN, Banet AI, Reznick DN. Evolution of placentas in the fish family Poeciliidae: an empirical study of macroevolution. Annu Rev Ecol Evol Syst. 2009;40: 271-289. doi:DOI 10.1146/annurev. ecolsys.110308.120209

24. Thibault RE, Schultz RJ. Reproductive adaptations among viviparous fishes (Cyprinodontiformes: Poeciliidae). Evolution (N Y). 1978;32: 320333. Available: http://www.jstor.org/stable/10.2307/2407600

25. Turner CL. Pseudoamnion, pseudochorion, and follicular pseudoplacenta in Poeciliid fishes. J Morphol. 1940;67: 59-89.

26. Pollux BJA, Meredith RW, Springer MS, Garland T, Reznick DN. The evolution of the placenta drives a shift in sexual selection in livebearing fish. Nature. 2014;513: 233-236. doi:10.1038/nature13451 
27. Grove B, Wourms J. The follicular placenta of the viviparous fish, Heterandria formosa. I. Ultrastructure and development of the embryonic absorptive surface. J Morphol. 1991;209: 265-284. Available: http://onlinelibrary.wiley.com/doi/10.1002/jmor.1052090304/abstract

28. Grove B, Wourms J. Follicular placenta of the viviparous fish, Heterandria formosa: II. Ultrastructure and development of the follicular epithelium. J Morphol. 1994;220: 167-184. Available: http://onlinelibrary.wiley.com/doi/10.1002/jmor.1052200206/abstract

29. Reznick DN, Callahan H, Llauredo R. Maternal effects on offspring quality in poeciliid fishes. Am Zool. 1996;36: 147. doi:10.1093/icb/36.2.147

30. Pires MN, Bassar RD, McBride KE, Regus JU, Garland T, Reznick DN. Why do placentas evolve? An evaluation of the life-history facilitation hypothesis in the fish genus Poeciliopsis. Funct Ecol. 2011;25: 757-768. doi:10.1111/j.1365-2435.2011.01842.x

31. Bassar RD, Auer SK, Reznick DN. Why do placentas evolve? A test of the life-history facilitation hypothesis in two clades in the genus Poeciliopsis representing two independent origins of placentas. Funct Ecol. 2014;28: 999-1010. doi:10.1111/1365-2435.12233

32. Reznick DN, Mateos M, Springer MS. Independent origins and rapid evolution of the placenta in the fish genus Poeciliopsis. Science (80). 2002;298: 1018-1020. doi:10.1126/science.1076018

33. Turner CL. Reproductive Cycles and Superfetation in Pœciliid Fishes. Biol Bull. 1937;72: 145-164.

34. Turner CL. Superfetation in Viviparous Cyprinodont Fishes. Copeia. $1940 ; 88-91$.

35. Zúñiga-Vega JJ, Reznick DN, Johnson JB. Habitat predicts reproductive superfetation and body shape in the livebearing fish Poeciliopsis turrubarensis. Oikos. 2007; 995-1005. doi:10.1111/j.2007.0030-1299.15763.x

36. Scrimshaw N. Superfetation in Poeciliid Fishes. Copeia. 1944;3: 180-183.

37. Downhower JF, Brown LP. Superfoetation in fishes and the cost of reproduction. Nature. 1975;256: 345-345. doi:10.1038/256345b0

38. Pollux BJA, Reznick DN. Matrotrophy limits a female's ability to adaptively adjust offspring size and fecundity in fluctuating environments. Funct Ecol. 2011;25: 747-756. doi:10.1111/j.1365-2435.2011.01831.x

39. Hedrick TL. Software techniques for two- and three-dimensional kinematic measurements of biological and biomimetic systems. Bioinspir Biomim. 2008;3: 34001. doi:10.1088/1748-3182/3/3/034001

40. Singer JD. Using SAS PROC MIXED to fit multilevel models, hierarchical models, and individual growth models. J Educ Behav Stat. 1998;23: 323-355. doi:10.3102/10769986023004323 
Chapter 5 I How pregnancy affects body shape and 3D fast-start performance

41. Pires MN, McBride K, Reznick DN. Interpopulation variation in life-history traits of Poeciliopsis prolifica: implications for the study of placental evolution. J Exp Zool. 2007;125: 113-125. doi:10.1002/jez.a

42. Domenici P, Blagburn JM, Bacon JP. Animal escapology II: escape trajectory case studies. J Exp Biol. 2011;214: 2474-2494. doi:10.1242/jeb.053801

43. Oufiero CE, Garland T. Repeatability and correlation of swimming performances and size over varying time-scales in the guppy (Poecilia reticulata). Funct Ecol. 2009;23: 969-978. doi:10.1111/j.1365-2435.2009.01571.x

44. Zúñiga-Vega JJ, Macías-Garcia C, Johnson JB. Hypotheses to explain the evolution of superfetation in viviparous fishes. In: Uribe M, Grier $\mathrm{H}$, editors. Viviparous fishes II. New Life Publications, Homestead, Florida; 2010. pp. 241-253.

45. Frías-Alvarez P, Zúñiga-Vega JJ. Superfetation in live-bearing fishes is not always the result of a morphological constraint. Oecologia. 2016;181: 645-658. doi:10.1007/s00442-015-3477-1

46. Gorini-Pacheco B, Zandonà E, Mazzoni R. Predation effects on matrotrophy, superfetation and other life history traits in Phalloceros harpagos. Ecol Freshw Fish. 2017; doi:10.1111/eff.12359

47. Frías-Alvarez P, Macías Garcia C, Vázquez-Vega L, Zúñiga-Vega J. Spatial and temporal variation in superfoetation and related life history traits of two viviparous fishes: Poeciliopsis gracilis and P. infans. Naturwissenschaften. 2014;101: 1085-1098. doi:10.1007/s00114-014-1247-2

48. Burley N. Clutch Overlap and Clutch Size: Alternative and Complementary Reproductive Tactics. Am Nat. 1980;115: 223-246. doi:Doi $10.1086 / 283556$

49. Travis J, Farr JA, Henrich S, Cheong RT. Testing Theories of Clutch Overlap with the Reproductive Ecology of Heterandria Formosa. Ecology. 1987;68: 611-623. 
$\underline{\text { How pregnancy affects body shape and 3D fast-start performance I Chapter } 5}$ 


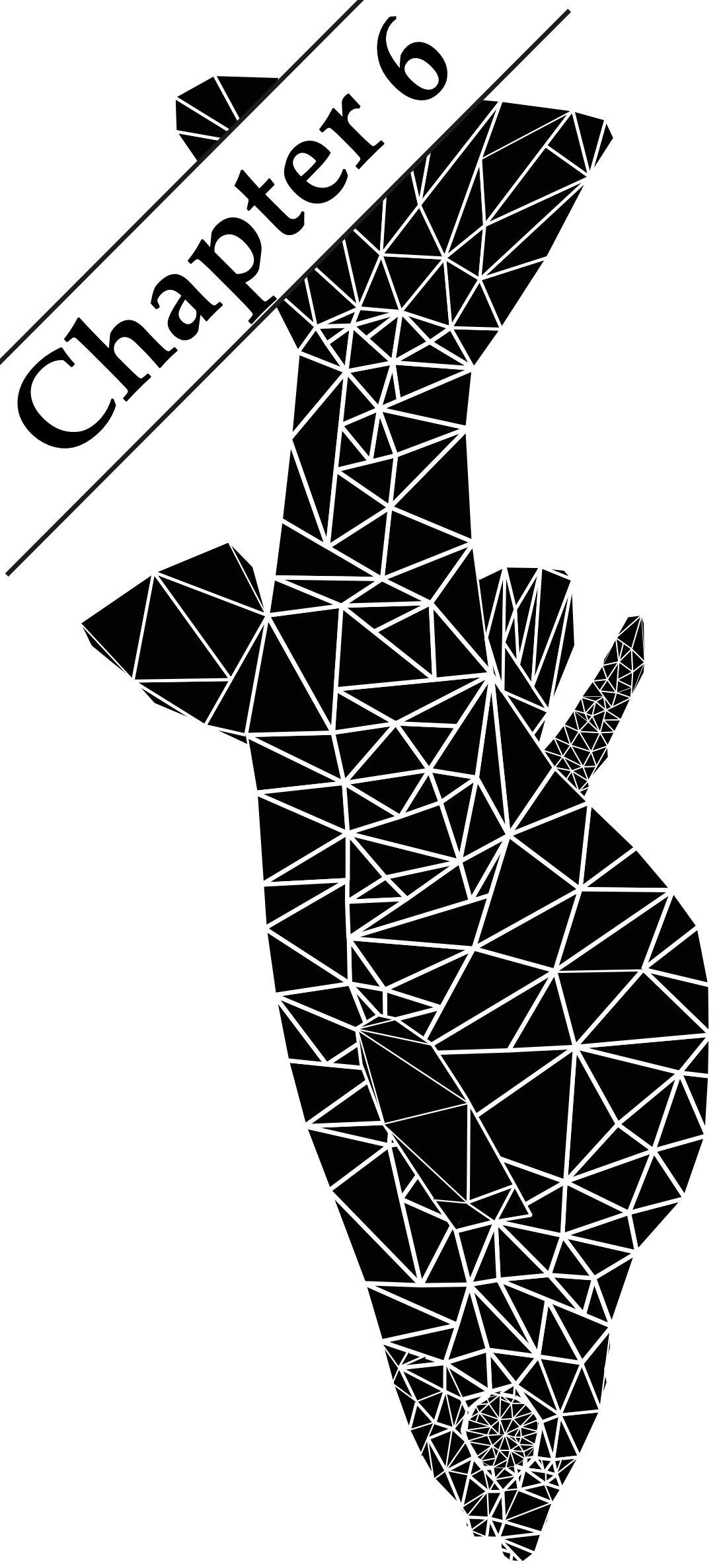




\section{Chapter 6}

\section{General Discussion}


Viviparity has evolved many times independently throughout the animal kingdom, in both vertebrate and invertebrate animals, in predators and in prey, and in sedentary, swimming, walking and flying animals $[1,2$, Chapter 2]. In Chapter 2, we outlined the biomechanical consequences of a live-bearing mode of reproduction, but for a more detailed description of these effects we focused on one particular family of livebearers for the remainder of this thesis: the Poeciliidae. Furthermore, we only focused on two of the (reproductive) adaptations that we described in Chapter 2: we reported the effects of matrotrophy on body shape in Chapter 3 and we examined the effects of superfetation on body shape and fast-start performance in Chapter 5. In this chapter, I will discuss the existing caveats: (i) do superfetation and matrotrophy provide the same benefit to non-Poeciliid live-bearing animals, (ii) could superfetation and matrotrophy provide other benefits to Poeciliidae than the locomotor benefits described in Chapter 3, 5, and (iii) do other (reproductive) adaptations exist within the Poeciliidae. Furthermore, I attempted to answer an evolutionary question using state-of-the-art techniques from biomechanics, including 3D high-speed video and automated tracking [Chapter 4,5$]$. These novel approaches caused some problems on their own: I will discuss (iv) the interaction between behaviour and performance in relation to our experimental setup, and (v) the difficulties of cross-disciplinary research. With the lessons learned from these latter two paragraphs, I will (vi) provide an outlook for future research.

The adaptive benefit of superfetation and matrotrophy in non-Poeciliid animals

In this thesis, we focus on one particular family of live-bearing animals, the Poeciliidae, and the possible adaptive benefit of superfetation and matrotrophy in these fishes. These traits have evolved independently in different lineages of animals, widely varying in locomotor mode, life history and ecology. Arguably, the adaptive benefit of superfetation and matrotrophy is different for many of these independent evolution events. Knowledge of these traits in the Poeciliidae might help identify knowledge gaps in other taxonomic groups.

Superfetation is a fairly unique strategy to two families of Teleost fishes: the Poeciliidae, Zenarchopteridae and Clinidae [3-5]. These are the only vertebrate families in which this trait occurs (in varying degrees) in a large percentage of the species [6-8]. The hypothesised adaptive benefit of superfetation may be similar between these families. Anecdotally, superfetation-like reproduction is documented in humans, livestock and rodents, and in the European brown hare (Lepus europaeus) the existence of superfetation is controversial (reviewed by Roellig et al. [3]). Within mammals, superfetation is 
a confirmed reproductive strategy in the American mink (Neovison (Mustela) vison) and in the European badger (Meles meles). In both these groups, superfetation is likely used as a method to disguise paternity and reduce infanticide [3], and thus unrelated to a locomotor performance decline during pregnancy.

Matrotrophy has evolved independently at least 33 times in vertebrate animal lineages; the majority of these origins (26) occurred in fishes and amphibians [1]. In invertebrate animals, matrotrophic viviparity has evolved in 20 different phyla, including Porifera, Cnidaria, Annelida, Mollusca, Arthropoda, Nematoda and Echinodermata [2]. This frequent evolution likely indicates an adaptive advantage of post-fertilization nutrient allocation, but comparative work on the effects of gestation in species with and without matrotrophy (like I present for Poeciliid fishes in Chapter 3) is, to my knowledge, currently non-existent.

For matrotrophy to provide an adaptive advantage to locomotor performance during pregnancy, there is one important prerequisite to the lifestyle of the animal: it should be fairly active [Chapter 2]. This criterion excludes all slow-moving and sedentary animals that have evolved matrotrophic nutrient provisioning: pregnancy has little effect on their locomotor performance and matrotrophy thus can have little adaptive benefit in improving this aspect. Matrotrophy could, however, provide an adaptive benefit in certain insects, for instance in viviparous Blattodea (cockroaches) [9] and Diptera (true flies) [10]. During the last few days of gestation, female cockroaches and tsetse flies are observed to be inactive [11-16]. If this inactivity is linked to the metabolic demands of the offspring (i.e. there are insufficient resources to explore/forage and provision offspring), or is linked to the weight of the clutch reducing locomotor performance, matrotrophy could provide an adaptive benefit: due to the lower oocyte mass at fertilization, the costs of pregnancy would be lower during initial development of a litter, reducing the need for inactivity.

Despite evolution of viviparity and matrotrophy in all three major clades of Amphibians (Salientia, frogs and toads; Caudata, salamanders and newts; Gymnophiona, limbless caecilians) [1], the effects of pregnancy on locomotion have, to my knowledge, not been studied in this class [Chapter 2]. As a result, no comparative data on the effects of the evolution of matrotrophy in these groups exist. From these groups, it is most likely that morphological constraints on locomotion were a factor in the evolution of matrotrophy in Caudata and Gymnophiona. The former group use a form of undulatory swimming [17] and as such are hindered by reduced flexibility in the ab- 
domen due to pregnancy (similar to fishes, Chapter 5). The latter group are fossorial amphibians for which abdominal distention would cause increased resistance while burrowing.

In reptiles, viviparity has evolved over 115 times independently [18], yet matrotrophy evolved independently only in six clades of Scincid lizards $[1,18,19]$. As a consequence, research in the Squamate clade (lizards and snakes) focused on the evolution of viviparity, and not on the evolution of viviparity-associated reproductive traits. Only four of the six evolutionary origins of matrotrophy in skinks involve a switch to high levels of matrotrophy, while in the other two evolutionary lineages the post-fertilization maternal provisioning is modest [1]. Evidence for incipient matrotrophy is found in phrynosomatid lizards [20] and thamnophine snakes [21]. Whether placentation in these species correlates with certain ecological traits, and whether it improves locomotor performance during pregnancy, is currently still unknown.

Mammals have only one evolutionary origin of viviparity and matrotrophy [1]. This makes direct comparative work on the adaptive evolution of this trait impossible in this family, as all extant Eutherian mammals possess these traits and there are no extant species with moderate levels of matrotrophy [1]. As such, only comparative work on other evolutionary events of the placenta could help reveal the adaptive benefit the placenta had for early mammals. Perhaps the closest to the early eutherian mammals in both size, reproductive physiology (both Amniota) and ecology (adapted to climbing, [22]) that have evolved a placenta, are the Scincid lizards. Comparative work on the effects of placentation on locomotion and habitat use during pregnancy might shed light on whether locomotor costs were a driver of the evolution of the placenta in the earliest known eutherian mammals. Although not directly applicable to the evolution of placentation in mammals, the evolution of the placenta in Poeciliidae can prove useful in studying the evolution of complex organs [7]. The independent evolution of placentas and the continuous scale of levels of matrotrophy [8] and associated intricacy of placental structures in this family [23] can act as a model system for the evolution of complexity.

\section{Other possible benefits of matrotrophy and superfetation in Poeciliidae}

In this thesis, I explored whether matrotrophy and superfetation reduce the locomotor performance decline during pregnancy in Poeciliid fishes. However, evolution can act on more levels than one and traits can have multiple 
(dis)advantages: what other benefits could matrotrophy and superfetation provide to Poeciliid fishes?

Gorini-Pacheco and colleagues [24] found that fecundity, matrotrophy and superfetation were increased in populations with higher predator density: the matrotrophy index (MI) was almost twice as high in the high-predation population (no predation MI: 2.5, low-predation MI: 3.5, and high-predation MI: 4.0) and the relative occurrence of superfetation, here the presence of two simultaneous broods, was significantly higher in high-predation populations (relative occurrence of superfetation under no predation: $7.5 \%$, low-predation: $8.1 \%$, and high-predation: $44.4 \%$ ). This indicates that there may be a role for matrotrophy and superfetation in increasing fecundity $[7,25-27]$. If so, matrotrophy and superfetation could facilitate the 'live fast - die young'-strategy often observed in high-predation populations of live-bearing fishes [28,29]. Because early-stage matrotrophic embryos are smaller than those of lecithotrophic species, and superfetation reduces the number of late-stage embryos present at any time, the maximum number of offspring that could possibly fit the abdominal cavity is higher with these traits. As a result, when resources are not limiting, levels of superfetation [30] and matrotrophy could be increased (through phenotypic plasticity or genetic selection) to increase fecundity. The level of superfetation is found to vary year-round in Poeciliopsis gracilis and Poeciliopsis infans [31], although the changes did not follow a conspicuous temporal pattern. These findings indicate that, at least for the level of superfetation, there is a certain degree of phenotypic plasticity that fish can utilize. To my knowledge, it is unknown whether matrotrophy can display similar plasticity.

Morphology is affected by pregnancy in a temporal manner: pregnant females have similar (abdominal) sizes as virgin conspecifics or are slightly larger depending on the levels of matrotrophy and superfetation, but the difference in morphology between pregnant and virgin fish increases when pregnancy progresses [Chapter 3,5]. A similar temporal pattern is to be expected for resource allocation and metabolism: early stage embryos require fairly little resources while close to parturition embryos are thought to require more oxygen (and metabolites in matrotrophic fish) to maintain metabolism and growth [32]. Currently, hardly any evidence exists for this hypothesis. Only Downhower and colleagues [33] provide data from field populations of Gambusia hubbsi that imply that superfetation reduces the cost of reproduction, but they did not directly measure this. 


\section{Other reproductive adaptations in Poeciliidae}

In Chapter 2, we discussed three different ways in which species could cope with the increased locomotor costs during pregnancy: adaptations that reduce the effects of pregnancy on locomotor performance, adaptations that avoid (maximum) locomotor performance during pregnancy, and adaptations to the life history of an animal. From the first category, 'adaptations to reduce the locomotor costs during gestation', we already discussed the effects of matrotrophy and superfetation in Chapter 3 and Chapter 5 respectively, and I added further remarks in this chapter. There is however a third adaptation from this category that was not yet covered for Poeciliid fishes: reduction or repositioning of the reproductive organs.

In the mosquitofish Gambusia affinis, the paired ovaries are fused after a few days of development to form one, centrally-located reproductive organ; a similar process occurs in males for the testes [34]. Similar fusion of the paired reproductive tracts appear to occur during development in other species of Poeciliidae [34], and in viviparous Goodeidae [35]. A larger scale morphological examination of Teleost fishes of Mexico revealed that in most fish species, the ovaries are either completely separated or fused at the most posterior end [36]. Extreme fusion of the ovaries was found in a large number of oviparous and viviparous species from the Cyprinodontiformes like the Poeciliidae and Goodeidae. This extreme fusion of these paired organs could be an exaptation to the evolution of viviparity [37-39]: the paired nature and central location allow for a bilaterally symmetrical increase in volume [Chapter 2]. However, in another evolutionary origin of viviparity in Teleost fishes, within the Scorpaeniformes, the ovaries are still a paired structure in which the two ovaries are divided by a central lamella [40-44]. The evolution of viviparity in this lineage indicates that, in Teleost fishes, fusion of the ovaries is no prerequisite for evolving a live-bearing mode of reproduction.

In the census of reproductive tract morphology of Mexican fishes [36], reduction of a single ovary is found in elongated fish species (the marbled swamp eel Synbranchus marmoratus and the Atlantic needlefish Strongylura marina), while strong asymmetry between left and right ovaries was observed in the common anchovy Anchoa mitchilli. These asymmetries are likely the effect of functional constraints, but are not related to the evolution of viviparity in fishes. These adaptations to the reproductive tract provide an example of convergent evolution with the functionally-driven adaptations to the reproductive tracts in squamate reptiles [Chapter 2]. 
The second category of adaptations, 'adaptations to avoid high-performance demanding situations', are mainly of a behavioural nature. In Poeciliidae, there are some indications of a habitat shift during pregnancy: pregnant Poecilia reticulata from high-predation populations were found to only dwell in shallow pools and slow-flowing margins of rivers [45]. They benefit from this in two different ways: these pools are not or less accessible to predators, and they spend less energy swimming against the flow. A similar effect was found in another study where "large" $P$. reticulata tended to avoid parts of pools where Hoplias, a piscine predator, was present [46]. In controlled tank experiments using lab-populations of Gambusia affinis as prey species and wild-caught small-mouth bass (Micropterus dolomieui) as predators, the presence of a refuge indeed increased survival rate [47]. However, the use of the refuge did not differ between female G. affinis of different stages of pregnan$\mathrm{cy}$, indicating that other factors (e.g. resource availability) could limit the use of shelters in certain situations. In wild populations, a shift in micro-habitat during late-pregnancy could coincide with a shift in diet. However, to my knowledge no studies have looked at this effect of pregnancy in Poeciliidae.

Behavioural responses could also include changes in the 'fight, flight or freeze' behaviour. Although it could be possible to measure the effects of pregnancy on fast-start latency, the time between when the stimulus hits the water and the first movement, our setup was not equipped to do this accurately. The duration between the moment of release and when the stimulus hit the water differed $\pm 10 \mathrm{~ms}$ each time, and it is difficult to discern the exact frame where the impact occurs from only a ventral view (the stimulus is not visible in the lateral views). Furthermore, there are complicating factors in that the stimulus is not falling through a tube (the fish can possibly see the movement before the impact), and the side-lights are turned on before the stimulus hits the water. These measures were taken to maximize responsiveness and the number of successful movie captures - a trade-off we had decide in favour of our main research question, we decided that the acquisition of a sufficient number of fast-start high-speed video sequences was more important.

For the last category of reproductive adaptations, 'life history adaptations', there is a larger body of Poeciliidae literature available. These have already been extensively discussed in Chapter 2: in response to a higher mortality rate in high-predation populations [48], $P$. reticulata evolve a life history that maximizes short-term offspring production. These fish reach reproductive age sooner, devote more resources per litter and produce litters more frequently than fish from low-predation populations [48-51]. At the same time, 
fish from high-predation populations evolve a noticeably better fast-start performance during the early stages of pregnancy [52], although the authors do not provide a morphological or physiological reason for this performance increase. At the late stages of pregnancy, this performance advantage disappears, likely due to increased resource allotment. High-predation populations of Phalloceros harpagos show a similar trend in reproductive allotment: greater reproductive allotment, a higher fecundity and a smaller size at maturity [24].

\section{Behaviour and performance, a complex relationship}

Arnold's morphology $\rightarrow$ performance $\rightarrow$ fitness paradigm [53], which links morphology of an individual to its performance and subsequently fitness, is a simplification of all the factors that influence an individual's fitness. Many studies have commented and expanded on Arnold's paradigm, highlighting the importance of, for instance, life history traits, behaviour and external selective agents [54-57]. In our review of the effect of pregnancy on performance and fitness [Chapter 2], these other factors are included in the reproductive adaptations as they either are adaptations themselves, or affect the evolution of adaptive traits. However, there is also a direct relationship between an individual's behaviour and its performance.

When measuring performance, as we did in Chapter 4,5, behaviour can obscure the effect of morphology on performance. In virgin Poeciliopsis turneri, for instance, there was a strong negative effect of time on performance: in subsequent days, the population of experimental animals performed less well. Because the morphology of these virgins hardly changes over time [Chapter 3,5], the basis for this performance decline must be behavioural: the fish got habituated to the stimulus. Habituation to the stimulus was one of the main reasons for taking the virgin control fish along in the experiments [Chapter 2]. However, when habituation in the virgin control group leads to a decline similar to, or sometimes even larger than, the decline in the pregnant treatment group, it becomes difficult to relate these time-dependent effects to the morphological changes of pregnancy or to habituation to the stimulus. We solved this by removing time as a fixed factor from our statistical models, replacing it with morphological variables (abdominal width in Chapter 5) while keeping the repeated measures as a random factor.

Previous reports of repeated fast-start performance studies in fishes show a high repeatability between fast starts at the within-day, between-day and between-week levels [58-62]. Our data, however, shows large variation in faststart performance within individuals, both within days and between days. 
The likely cause for this large variation is the complexity of our fast-start setup (three dimensional measurements against two-dimensional measurements and much simpler analysis in the aforementioned studies) and the minimal available space for a strong stimulus. Together with my colleague Elsa Quicazan-Rubio, I tested a range of different stimuli that elicit both a strong response and are repeatable in strength over time. Especially the first factor, stimulus strength, was difficult to achieve. The swimming arena was surrounded by three large LED screens, which were used to provide back-lighting to the cameras. This meant that the utilizable distance between the LED-panel at the top of the tank and the water surface was minimal: we only had $\pm 10 \mathrm{~cm}$ to drop the stimulus, while Oufiero and colleagues [62], for instance, dropped a stimulus from $85 \mathrm{~cm}$ above the water surface. Furthermore, the distance between the fish, which is located somewhere in the field of view at the centre of our swimming arena, and the stimulus in one of the corners, was fairly large in our setup: at least $10 \mathrm{~cm}$. In comparison, the work of Langerhans et al. [58] included a stimulus located at most $3 \mathrm{~cm}$ away from the fish. As a stronger (closer) stimulus is more likely to reach the threshold required to initiate the fast-start response through the Mauthner neurons [63-65], a stronger (closer) stimulus could also lead to higher repeatability.

A second behaviour that could have interfered with our performance measurements, is stress-related: when introduced to the swimming arena, fish are introduced to a novel environment or an environment in which they were startled in preceding days. Furthermore, the swimming arena is a fairly large open space without any cover or hiding places: an environment where these fish arguably do not feel comfortable. Despite a total acclimation period of 15 minutes, many fish frantically kept swimming along the edges of the aquarium; behaviour similar to that described for Gambusia affinis when introduced to an aquarium without any cover [47]. In our experiments, this stress-related behaviour resulted in fairly low passages of the field of view of the swimming arena. In extreme situations, fish completely freaked out and laid on the bottom of the swimming arena reluctant of going up, rendering the fish useless for further measurements that day and, often, also for subsequent days.

In this thesis, I have not focussed on direct effects of pregnancy on behavioural characteristics. It could for instance be that pregnancy affects the latency during fast-start response, or that pregnant fish are less likely to habituate to a stimulus. Equal habituation to a stimulus between virgin control fish and pregnant treatment fish is an assumption in our experimental setup with a virgin control group. To test the validity of the assumption, a 
large scale behavioural experiment should be performed. It could also be that pregnant fish are less likely to "give up" when swimming upstream. Behaviour and motivation play an important and often undervalued role in performance measurements, however, it is difficult to standardize these between treatment groups [66]. We attempted to standardize for behaviour by correlating performance with kinematic parameters, i.e. curvature and curvature rate in the analysis of fast-start performance [Chapter 5].

For our performance experiments, we have used laboratory-raised animals and measured these in a laboratory setting. By extrapolating our findings to a broader ecological and evolutionary context, we make an important assumptions: how animals perform in a laboratory context is similar to how animals perform in an ecological context, and this performance is related to their fitness $[67,68]$. This assumption might not always hold, as reviewed by Irschick [68]. Research in this field mainly focused on lizards; whether this assumption holds for our populations of live-bearing fishes requires future work comparing wild-caught individuals of the used species with the performance obtained in the laboratory [Chapter 5]. This work should not only focus on what animals can maximally achieve, but also compare values that animals actually operate at in nature: this might not always be maximal performance [69]. If animals generally do not use their maximum performance in a natural setting, the direct link between maximum performance and fitness fades.

\section{The drawbacks of the applied cross-disciplinary research}

With this thesis, I tried to answer evolutionary questions with state-of-theart biomechanical methods. Although I am convinced that in essence this is a good way to find answers in a scientifically solid way, the combination of two unrelated fields can create tensions. One example where these two fields encounter tension is the trade-off between quantity and quality. We wanted to describe fast-start manoeuvres in three-dimensional space, providing the first quantitative evidence for significant pitch and roll angles in this manoeuvre in adult fish [Chapter 4]. To do this in the best possible descriptive way (e.g. including tracking of fin motions), you would need a high resolution and a high frame-rate of the cameras: the first requires a small field of view which reduces the number of times fish will swim though that region of the aquarium, while the second requires very high light intensities (to minimize exposure times) that could induce unnatural and stress-related behaviour in the experimental animals. Both of these requirements, however, interfered with the quantitative objectives of the evolutionary question: comparing fast-start performance in three different species, over the course 
of pregnancy, and for both pregnant and virgin control fish. The initially desired level of biomechanical accuracy required a workload that was impossible to combine with the evolutionary questions. Because the evolutionary question was the main goal of this thesis, we compromised a little on the biomechanical details: although this partially reduced our ability to explain how fast starts work in three-dimensional space (and how pregnancy influences this), our work still is, both from a biomechanical and evolutionary perspective, novel and unprecedented in adult fish.

A second point that can be raised is whether it is absolutely necessary to use sophisticated biomechanical methods to answer our evolutionary questions regarding the adaptive benefit of matrotrophy and superfetation. Wouldn't it have sufficed to use a simple two-dimensional method to answer this question? I think that, in line with the results from Chapter 4,5, the answer to this question is no: we have shown that fast-start manoeuvres have a large three-dimensional component and restricting these manoeuvres to a horizontal plane would not be as informative. to accurately track whole-body deformations and measure body curvature and curvature rate (fast-start performance parameters that we found to be affected by pregnancy [Chapter $5])$, one needs information on the pitch and roll angles of the body. Without information on the pitch and roll changes of the body, curvature would be measured incorrectly in fast-start manoeuvres in which the fish exhibits pitch and/or roll. And although restricting our performance experiments to a two-dimensional space could have allowed us to test more individuals and/ or more species, but we would not have shown that pregnancy affects the horizontal and vertical components of the fast start differently [Chapter 5]. This finding could have implications for the escape tactics (e.g. more upwards or downwards oriented responses) pregnant fish employ to escape predators, an interesting question for follow-up research that could have ramifications for an individual's survival and fitness.

Lastly, there is some discrepancy between the fields in the used terms. In the field of evolutionary biology for instance, it is quite common to see terms as 'fusiform body shape' and 'streamlined phenotype' as descriptions of (often 2D) shape profiles of fish, and they are often used interchangeably [e.g. 69 uses both terms]. However, in biomechanics these terms are very strictly defined, e.g. fusiform corresponds to a three-dimensional shape and therefore could never be used to classify a two-dimensional body profile as information from the third dimension is missing. These mismatches in terminology and vocabulary may hinder cooperation between researchers of the different fields. 


\section{Perspectives for further work}

In this thesis we focused on the effects of pregnancy and reproductive adaptations on the fast-start performance. For the first time in adult fish, we presented quantitative evidence for strong pitching and rolling motions of which the first also correlates with changes in elevation [Chapter 4,5]. However, there are still a lot of questions remaining regarding the exact biomechanics underlying these three-dimensional fast-starts, and how these are affected by pregnancy. In their paper describing three-dimensional fast-start manoeuvres in larval zebrafish, Nair et al. [71] hypothesise that changes in elevation could be induced by differences in neural signal intensity between the motor neurons that innervate the epaxial (dorsal to the horizontal septum) and hypaxial (ventral to the horizontal septum) musculature. This in turn should then result in differences in strength of contraction between epaxial and hypaxial muscles, creating the dorsoventral excursion they observed. Due to limitations to the range of possible curvatures in our automated tracking software, we were not able to confirm whether dorsoventral excursion also precedes changes in elevation in fast-starts of adult Poeciliid fish. Whether dorsoventral excursion is indeed caused by differences in signal intensities between epaxial and hypaxial motor neurons still needs to be determined. Due to their translucency, zebrafish larvae are probably better suited for such experiments than (adult) Poeciliidae.

However, there are other ways to create up- or downwards oriented pitch torques that both Nair et al. [71] and we did not yet analyse: use of the fins. In larval zebrafish, the pectoral fins are thought to play no role during propulsion in slow swimming [72], but they are used to brake succeeding prey capture [73]; neonate and adult Poeciliidae, however, do use their fins during (slow) swimming and succeeding prey capture [74,75]. The role of the pectoral fins (but also the pelvic fins) in fast-start manoeuvres is not yet understood, but it is possible that the fin on the inner turn is extended to some extend and used as an 'anchor point'. Variations in the angle of attack of the pectoral fins could in turn result in upwards or downwards oriented pitch and roll torques. In my opinion, the next step in describing the three-dimensional fast-start manoeuvre, and how fish can create changes in elevation during this rapid manoeuvre, would be a qualitative analysis of pectoral (and pelvic) fin use. If these fins are indeed used to generate pitch torques, this raises new questions regarding the rapid neuronal activation of the fin motion.

In pregnant fish, pitch torques could also be the result of the increased dorsoventral asymmetry in the abdomen. The ventral location of the ovaries 
causes the distention to be directed laterally and ventrally; dorsal distention is largely inhibited by the presence of the stiff vertebral column. This could result in destabilizing differences in flow (and pressure) between the dorsal and ventral side of the body, resulting in a pitch torque. A similar effect could be caused by changes in local density, i.e. when the density of the ovaries is different from the rest of the body and this cannot be compensated for by the swim bladder [Chapter 2]. Furthermore, the distention of the abdomen could result in differences in the strain a muscle can exert: the muscles of the abdomen are stretched, and, at equal number of sarcomeres, they could generate less force [Chapter 5]. Whether the number of sarcomeres and other muscle properties change during pregnancy, is not known. Molecular muscle properties are known to change over relatively short intervals following exercise training [76-78]. Preliminary work on caudal peduncle muscles revealed no differences in gene expression between pregnant and virgin fish, further work should reveal whether this is also true for muscle from the abdominal region in which the actual distention occurs.

When the mechanisms of pitch torque generation are qualitatively described in 'normal' (slender) fish, it could be worth it to do further qualitative analyses of the effects of a thick abdomen on these pitch changes, and whether these would reinforce or weaken certain mechanisms for elevation change. For this end, experimental high-speed video imaging could be supplemented with particle image velocimetry (PIV) to measure water flow around pregnant fish and computational fluid dynamics (CFD).

In this thesis, I only examined the effects of pregnancy on fast-start swimming. However, when navigating streams and search for food, fish exhibit continuous swimming. Arguably, the morphological and physiological changes that occur during pregnancy also affect this type of locomotion [79]. We examined the effect of pregnancy (including whether superfetation provides an adaptive benefit) on continuous swimming by measuring critical swimming speed [80], and on basal metabolic rate by measuring respiration at rest. The total dataset comprises over 2000 high-speed video movies of swimming kinematics, and over 500 3D body models, but analysis of these data has not been finished yet. Our hypothesis are, however, similar to the hypotheses for fast-start performance: we expect pregnancy to increase basal metabolic rate and lower the critical swimming speed, while superfetation is expected to reduce these negative effects of pregnancy.

From an evolutionary biology perspective, it will be important to supplement the experiments performed in this thesis [Chapter 3-5] with data from wild-caught fish. Preferably, this includes the complete spectrum of 
Arnold's morphology $\rightarrow$ performance $\rightarrow$ fitness paradigm [53], but this is a lot of work. It might be worth it to focus on specific areas that still require attention or are necessary to validate our findings in a natural context. One focus should be to test whether wild fish perform in a similar way as our laboratory-kept fish $[67,68]$. Furthermore, it is important to test whether fish with better fast-start performance indeed have a higher survival; this could be tested with mark-recapture studies following fast-start performance measurements. Pedigree analyses on subsequent generations could be used to determine whether faster fish also have more (successful) offspring, and thus a higher fitness. These experiments require a lot of (manual) labour, but are important to validate some of the existing assumptions underlying the research presented in this thesis.

\section{Concluding remarks}

In this thesis, I have shown that pregnancy causes large changes in body morphology in live-bearing fishes (Poeciliidae). Matrotrophy and superfetation each are traits that reduce these effects of pregnancy, but each in different ways. Matrotrophy lowers the reproductive burden at the beginning of pregnancy, which causes a more slender body shape throughout [Chapter 3]. Superfetation reduces the amplitude of morphological changes during pregnancy, in principle leading to a more slender body shape. However, whether this actually results in a more slender body shape within a family-wide context will also depend on other confounding, species-specific or environmentally dependent variables (e.g. reproductive investment, Chapter 4). There is a negative correlation between the pregnancy-induced increase in body size and fast-start performance, which is a rapid three-dimensional manoeuvre [Chapter 4,5]. Matrotrophy, during the early stages of pregnancy, and superfetation thus have the potential to provide an adaptive benefit to swimming performance and survival of female viviparous fishes. 


\section{References}

1. Blackburn DG. Evolution of vertebrate viviparity and specializations for fetal nutrition: A quantitative and qualitative analysis. J Morphol. 2015;276: 961-990. doi:10.1002/jmor.20272

2. Ostrovsky AN, Lidgard S, Gordon DP, Schwaha T, Genikhovich G, Ereskovsky A V. Matrotrophy and placentation in invertebrates: a new paradigm. Biol Rev. 2016;91: 673-711. doi:10.1111/brv.12189

3. Roellig K, Menzies BR, Hildebrandt TB, Goeritz F. The concept of superfetation: a critical review on a "myth" in mammalian reproduction. Biol Rev. 2011;86: 77-95. doi:10.1111/j.1469-185X.2010.00135.x

4. Reznick DN, Meredith R, Collette BB. Independent Evolution of Complex Life History Adaptations in Two Families of Fishes, Live-bearing Halfbeaks (Zenarchopteridae, Beloniformes) and Poeciliidae (Cyprinodontiformes). Evolution (N Y). 2007;61: 2570-2583.

5. Gunn JS, Thresher RE. Viviparity and the reproductive ecology of clinid fishes (Clinidae) from temperate Australian waters. Environ Biol Fishes. 1991;31: 323-344. doi:10.1007/BF00002357

6. Meisner AD. Phylogenetic systematics of the viviparous halfbeak genera Dermogenys and Nomorhamphus (Teleostei : Hemiramphidae : Zenarchopterinae). Zool J Linn Soc. 2001;133: 199-283. doi:10.1006/ zjls.2000.0281

7. Pollux BJA, Pires MN, Banet AI, Reznick DN. Evolution of Placentas in the Fish Family Poeciliidae: An Empirical Study of Macroevolution. Annu Rev Ecol Evol Syst. 2009;40: 271-289. doi:DOI 10.1146/annurev. ecolsys.110308.120209

8. Pollux BJA, Meredith RW, Springer MS, Garland T, Reznick DN. The evolution of the placenta drives a shift in sexual selection in livebearing fish. Nature. 2014;513: 233-236. doi:10.1038/nature13451

9. Greven H, Flossdorf D, Köthe J, List F, Zwanzig N. Running speed and food intake of the matrotrophic viviparous cockroach Diploptera punctata (Blattodea : Blaberidae) during gestation. Entomol heute. 2014;26: $53-72$.

10. Meier R, Kotrba M, Ferrar P. Ovoviviparity and viviparity in the Diptera. Biol Rev. 1999;74: 199-258. doi:10.1111/j.1469-185X.1999.tb00186.x

11. Brady J, Gibson G. Activity patterns in pregnant tsetse flies, Glossina morsitans. Physiol Entomol. 1983;8: 359-369.

12. Lee $\mathrm{HJ}, \mathrm{Wu} \mathrm{YL}$. Mating effects on the feeding and locomotion of the German cockroach, Blattella germanica. Physiol Entomol. 1994;19: 39-45.

13. Tsai C-W, Lee H-J. Circadian locomotor rhythm masked by the female reproduction cycle in cockroaches. Physiol Entomol. 2000;25: 63-73. doi:10.1046/j.1365-3032.2000.00165.x 
14. Schultze-Motel P, Greven H. Metabolic heat flux in pregnant females of the viviparous cockroach Nauphoeta cinerea (Blaberoidea: Blaberidae). Entomol Gen. Schweizerbart; 1998;22: 199-204. Available: http://cat. inist.fr/?aModele=afficheN\&cpsidt $=2209252$

15. Rowclife C, Finlayson LH. Active and resting behaviour of virgin and pregnant females of Glossina morsitans morsitans Westwood (Diptera: Glossinidae) in the laboratory. Bull Entomol Res. 1982;72: 271-288. doi:10.1017/S0007485300010579

16. Abdelkarim EI, Brady J. Changing visual responsiveness in pregnant and larvipositing tsetse flies, Glossina morsitans. Physiol Entomol. 1984;9: 125-131. doi:10.1111/j.1365-3032.1984.tb00690.x

17. Ijspeert AJ, Crespi A, Ryczko D, Cabelguen J-M. From Swimming to Walking with a Salamander Robot Driven by a Spinal Cord Model. Science (80- ). 2007;315: 1416-1420. doi:10.1126/science.1138353

18. Stewart JR, Blackburn DG. Viviparity and Placentation in Lizards. In: Rheubert JL, Siegel DS, Trauth SE, editors. Reproductive Biology and Phylogeny of Lizards and Tuatara. CRC Press; 2014. pp. 448-563.

19. Metallinou M, Weinell JL, Karin BR, Conradie W, Wagner P, Schmitz A, et al. A single origin of extreme matrotrophy in African mabuyine skinks. Biol Lett. 2016;12: 20160430. doi:10.1098/rsbl.2016.0430

20. Blackburn DG, Gavelis GS, Anderson KE, Johnson AR, Dunlap KD. Placental specializations of the mountain spiny lizard Sceloporus jarrovi. J Morphol. 2010;271: 1153-1175. doi:10.1002/jmor.10860

21. Blackburn DG, Anderson KE, Johnson AR, Knight SR, Gavelis GS. Histology and ultrastructure of the placental membranes of the viviparous brown snake, Storeria dekayi (Colubridae: Natricinae). J Morphol. 2009;270: 1137-1154. doi:10.1002/jmor.10650

22. Ji Q, Luo Z-X, Yuan C-X, Wible JR, Zhang J-P, Georgi JA. The earliest known eutherian mammal. Nature. 2002;416: 816-822. doi:10.1038/416816a

23. Kwan L, Fris M, Rodd FH, Rowe L, Tuhela L, Panhuis TM. An examination of the variation in maternal placentae across the genus Poeciliopsis (Poeciliidae). J Morphol. 2015;276: 707-720. doi:10.1002/jmor.20381

24. Gorini-Pacheco B, Zandonà E, Mazzoni R. Predation effects on matrotrophy, superfetation and other life history traits in Phalloceros harpagos. Ecol Freshw Fish. 2017; doi:10.1111/eff.12359

25. Burley N. Clutch Overlap and Clutch Size: Alternative and Complementary Reproductive Tactics. Am Nat. 1980;115: 223-246. doi:Doi $10.1086 / 283556$

26. Travis J, Farr JA, Henrich S, Cheong RT. Testing Theories of Clutch Overlap with the Reproductive Ecology of Heterandria Formosa. Ecology. 1987;68: 611-623. 
27. Reznick DN, Miles DB. Review of life history patterns in Poeciliid fishes. In: Meffe GK, Snelson FF, editors. Ecology and Evolution of Livebearing Fishes (Poeciliidae). Prentice Hall, Englewood Cliffs, NJ; 1989. pp. 125-148.

28. Roff DA. The evolution of life histories: theories and analysis. London: Chapman \& Hall; 1992.

29. Stearns SC. The evolution of life histories. Oxford: Oxford University Press, Inc.; 1992.

30. Downhower JF, Brown LP. Superfoetation in fishes and the cost of reproduction. Nature. 1975;256: 345-345. doi:10.1038/256345b0

31. Frías-Alvarez P, Macías Garcia C, Vázquez-Vega L, Zúñiga-Vega J. Spatial and temporal variation in superfoetation and related life history traits of two viviparous fishes: Poeciliopsis gracilis and P. infans. Naturwissenschaften. 2014;101: 1085-1098. doi:10.1007/s00114-014-1247-2

32. Boehlert G, Kusakari M, Yamada J. Oxygen-consumption of gestating female Sebastes schlegeli - Estimating the reproductive costs of livebearing. Environ Biol Fishes. 1991;30: 81-89. doi:Doi 10.1007/Bf02296879

33. Downhower JF, Brown LP, Matsui ML. Litter overlap in Gambusia hubbsi: superfetation revisited. Environ Biol Fishes. 2002;65: 423-430. doi:10.1023/A:1021151428795

34. Koya Y, Fujita A, Niki F, Ishihara E, Miyama H. Sex Differentiation and Pubertal Development of Gonads in the Viviparous Mosquitofish, Gambusia affinis. Zoolog Sci. 2003;20: 1231-1242. doi:10.2108/zsj.20.1231

35. Guerrero-Estévez S, Moreno-Mendoza N. Gonadal morphogenesis and sex differentiation in the viviparous fish Chapalichthys encaustus (Teleostei, Cyprinodontiformes, Goodeidae). J Fish Biol. 2012;80: 572-594. doi:10.1111/j.1095-8649.2011.03196.x

36. Kobelkowsky A. Morphological Diversity of the Ovaries of the Mexican Teleost Fishes. Int J Morphol. 2012;30: 1353-1362.

37. Wourms JP, Grove BD, Lombardi J. The maternal-embryonic relationship in viviparous fishes. In: Hoar WS, Randal DJ, editors. Fish Physiology. New York: Academic Press; 1988. pp. 1-134.

38. Uribe MC, Aguilar-Morales M, De la Rosa-Cruz G, García-Alarcón A, Campuzano-Caballero JC, Guerrero-Estévez SM. Ovarian Structure and Embryonic Traits Associated with Viviparity in Poeciliids and Goodeids. In: Uribe MC, Grier HJ, editors. Viviparous fishes II. New Life Publications, Homestead, Florida; 2010. pp. 211-229.

39. Wourms JP. Viviparity: the maternal-fetal relationships in fishes. Am Zool. 1981;21: 473-515.

40. Pavlov DA, Emel'yanova NG. Transition to viviparity in the order Scorpaeniformes: Brief review. J Ichthyol. 2013;53: 52-69. doi:10.1134/ S0032945213010116 
41. Pavlov DA, Emel'yanova NG. Features of reproductive biology in two tropical fish species from the family Scorpaenidae. J Ichthyol. 2007;47: 353-365. doi:10.1134/S0032945207050049

42. Koya Y, Muñoz M. Comparative study on ovarian structures in scorpaenids: Possible evolutional process of reproductive mode. Ichthyol Res. 2007;54: 221-230. doi:10.1007/s10228-006-0394-7

43. Morris, Jr JA, Sullivan C V., Govoni JJ. Oogenesis and spawn formation in the invasive lionfish, Pterois miles and Pterois volitans. Sci Mar. 2011;75: 147-154. doi:10.3989/scimar.2011.75n1147

44. Erickson DL, Pikitch EK. A histological description of shortspine thornyhead, Sebastolobus alascanus, ovaries: structures associated with the production of gelatinous egg masses. Environ Biol Fishes. 1993;36: 273-282. doi:10.1007/BF00001723

45. Banet AI, Svendsen JC, Eng KJ, Reznick DN. Linking reproduction, locomotion, and habitat use in the Trinidadian guppy (Poecilia reticulata). Oecologia. 2016;181: 87-96.

46. Fraser DF, Gilliam JF. Nonlethal impacts of predator invasion: Facultative suppression of growth and reproduction. Ecology. 1992;73: 959970.

47. Laidlaw CT, Condon JM, Belk MC. Viability Costs of Reproduction and Behavioral Compensation in Western Mosquitofish (Gambusia). PLoS One. 2014;9: e110524. doi:10.1371/journal.pone.0110524

48. Reznick DN, Butler IV MJ, Rodd FH, Ross P. Life-History evolution in Guppies (Poecilia reticulata) VI. differential mortality as a mechanism for natural selection. Evolution (NY). 1996;50: 1651-1660.

49. Reznick DN, Endler JA. The Impact of Predation on Life History Evolution in Trinidadian Guppies (Poecilia reticulata). Evolution (NY). 1982;36: 160-177.

50. Reznick DN, Bryga HA. Life-history evolution in Guppies (Poecilia reticulata: Poeciliidae). V . Genetic basis of parallelism in life histories. Am Nat. 1996;147: 339-359.

51. Evans JP, Gasparini C, Pilastro A. Female guppies shorten brood retention in response to predator cues. Behav Ecol Sociobiol. 2007;61: 719727. doi:10.1007/s00265-006-0302-1

52. Ghalambor CK, Reznick DN, Walker JA. Constraints on adaptive evolution: the functional trade-off between reproduction and fast-start swimming performance in the Trinidadian guppy (Poecilia reticulata). Am Nat. 2004;164: 38-50. doi:10.1086/421412

53. Arnold SJ. Morphology, performance and fitness. Am Zool. 1983;23: 347-361.

54. Ghalambor CK. Multi-trait selection, adaptation, and constraints on the evolution of burst swimming performance. Integr Comp Biol. 2003;438: 431-438. Available: http://icb.oxfordjournals.org/content/43/3/431.short 
55. Langerhans RB, Reznick DN. Ecology and Evolution of Swimming Performance in Fishes: Predicting Evolution with Biomechanics. In: Domenici P, Kapoor BG, editors. Fish Locomotion. Science Publishers; 2010. pp. 200-248. doi:10.1201/b10190-8

56. Oufiero CE, Garland T. Evaluating performance costs of sexually selected traits. Funct Ecol. 2007;21: 676-689. doi:10.1111/j.1365-2435.2007.01259.x

57. Goodman BA, Hudson SC, Isaac JL, Schwarzkopf L. The evolution of body shape in response to habitat: Is reproductive output reduced in flat lizards? Evolution (NY). 2009;63: 1279-1291. doi:10.1111/j.15585646.2009.00621.x

58. Langerhans RB, Layman C, Mona Shokrollahi A, DeWitt T. Predator-driven phenotypic diversification in Gambusia affinis. Evolution (NY). 2004;58: 2305-2318. Available: http://onlinelibrary.wiley.com/ doi/10.1111/j.0014-3820.2004.tb01605.x/abstract

59. Royle NJ, Metcalfe NB, Lindstrom J. Sexual selection, growth compensation and fast-start swimming performance in Green Swordtails, Xiphophorus helleri. Funct Ecol. 2006;20: 662-669. doi:10.1111/j.13652435.2006.01147.x

60. Garenc C, Couture P, Laflamme MA, Guderley H. Metabolic correlates of burst swimming capacity of juvenile and adult threespine stickleback (Gasterosteus aculeatus). J Comp Physiol - B Biochem Syst Environ Physiol. 1999;169: 113-122. doi:10.1007/s003600050201

61. Chappell M, Odell J. Predation intensity does not cause microevolutionary change in maximum speed or aerobic capacity in Trinidadian guppies (Poecilia reticulata Peters). Physiol Biochem Zool Ecol Evol Approaches. 2004;77: 27-38. doi:10.1086/378920

62. Oufiero CE, Garland T. Repeatability and correlation of swimming performances and size over varying time-scales in the guppy (Poecilia reticulata). Funct Ecol. 2009;23: 969-978. doi:10.1111/j.1365-2435.2009.01571.x

63. Canfield JG. Functional evidence for visuospatial coding in the Mauthner neuron. Brain Behav Evol. 2006;67: 188-202. doi:10.1159/000091652

64. Canfield JG. Some voluntary C-bends may be Mauthner neuron initiated. J Comp Physiol A Neuroethol Sensory, Neural, Behav Physiol. 2007;193: 1055-1064. doi:10.1007/s00359-007-0258-2

65. Eaton RC, Bombardieri RA, Meyer DL. The Mauthner-initiated startle response in teleost fish. J Exp Biol. 1977;66: 65-81.

66. Losos J, Creer D, Schulte J. Cautionary comments on the measurement of maximum locomotor capabilities. J Zool. 2002;258: 57-61. doi:Doi $10.1017 /$ S0952836902001206

67. Irschick DJ, Losos JB. A comparative analysis of the ecological significance of maximal locomotor performance in Caribbean Anolis lizards. Evolution (NY). 1998;52: 219-226. 
68. Irschick DJ. Measuring performance in nature: implications for studies of fitness within populations. Integr Comp Biol. 2003;43: 396-407. doi:10.1093/icb/43.3.396

69. Irschick DJ, Herrel A, Vanhooydonck B, Huyghe K, Van Damme R. Locomotor compensation creates a mismatch between laboratory and field estimates of escape speed in lizards: A cautionary tale for performance-to-fitness studies. Evolution (NY). 2005;59: 1579-1587. doi:10.1111/j.0014-3820.2005.tb01807.x

70. Zúñiga-Vega JJ, Reznick DN, Johnson JB. Habitat predicts reproductive superfetation and body shape in the livebearing fish Poeciliopsis turrubarensis. Oikos. 2007; 995-1005. doi:10.1111/j.2007.0030-1299.15763.x

71. Nair A, Azatian G, McHenry MJ. The kinematics of directional control in the fast start of zebrafish larvae. J Exp Biol. 2015; 3996-4004. doi:10.1242/ jeb.126292

72. Green MH, Ho RK, Hale ME. Movement and function of the pectoral fins of the larval zebrafish (Danio rerio) during slow swimming. J Exp Biol. 2011;214: 3111-3123. doi:10.1242/jeb.057497

73. Budick SA, O'Malley DM. Locomotor repertoire of the larval zebrafish: swimming, turning and prey capture. J Exp Biol. 2000;203: 2565-2579. doi:10.1242/jeb.01529

74. Lankheet MJ, Stoffers T, Van Leeuwen JL, Pollux BJA. Aquired versus innate prey capturing skills in super-precocial live-bearing fish. Proc R Soc B Biol Sci. 2016;283. doi:10.1098/rspb.2016.0972

75. Svendsen JC, Banet AI, Christensen RHB, Steffensen JF, Aarestrup K. Effects of intraspecific variation in reproductive traits, pectoral fin use and burst swimming on metabolic rates and swimming performance in the Trinidadian guppy (Poecilia reticulata). J Exp Biol. 2013;216: 3564-74. doi:10.1242/jeb.083089

76. Van der Meulen T, Schipper H, Van den Boogaart JGM, Huising MO, Kranenbarg S, Van Leeuwen JL. Endurance exercise differentially stimulates heart and axial muscle development in zebrafish (Danio rerio). Am J Physiol Regul Integr Comp Physiol. 2006;291: R1040-8. doi:10.1152/ ajpregu.00116.2006

77. LeMoine CMR, Craig PM, Dhekney K, Kim JJ, McClelland GB. Temporal and spatial patterns of gene expression in skeletal muscles in response to swim training in adult zebrafish (Danio rerio). J Comp Physiol B Biochem Syst Environ Physiol. 2010;180: 151-160. doi:10.1007/s00360009-0398-5

78. Palstra AP, Beltran S, Burgerhout E, Brittijn S a, Magnoni LJ, Henkel C V, et al. Deep RNA sequencing of the skeletal muscle transcriptome in swimming fish. PLoS One. 2013;8: e53171. doi:10.1371/journal. pone. 0053171 
79. Plaut I. Does pregnancy affect swimming performance of female Mosquitofish, Gambusia affinis? Funct Ecol. 2002;16: 290-295. doi:DOI 10.1046/j.1365-2435.2002.00638.x

80. Plaut I. Critical swimming speed: its ecophysiological relevance. Comp Biochem Physiol Part A Mol Integr Physiol. 2001;131: 41-50. doi:10.1016/ S1095-6433(00)80239-1 


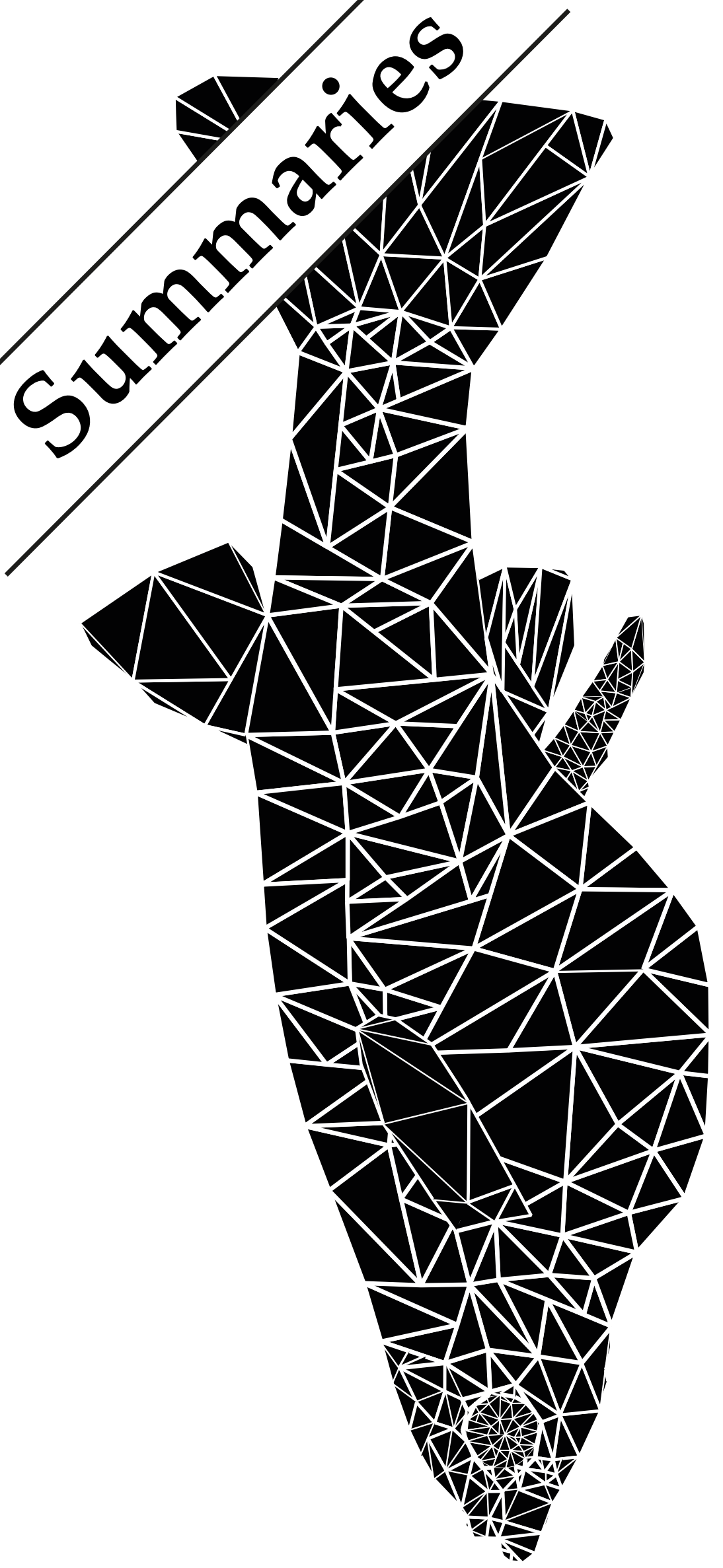




\section{Summaries}

Summaries in English and Dutch 


\section{Summary}

Viviparity, a live-bearing mode of reproduction, has evolved over 100 times independently in vertebrate animals. Despite its frequent evolution, viviparity has a number of hypothesised disadvantages compared to the ancestral mode of reproduction, oviparity (egg-laying). One of these disadvantages is a reduction in locomotor performance during pregnancy, the period of internal development of the embryos. Adaptations to a live-bearing reproductive mode could have evolved to reduce these locomotor costs. In this thesis, I aim to find whether matrotrophy, post-fertilization nutrient provisioning (e.g. through a placental structure), and superfetation, the presence of multiple broods of different developmental stages, reduce the locomotor performance decline during pregnancy in the Poeciliidae, live-bearing fishes.

In Chapter 2, we review the literature on the effects of pregnancy on morphology, performance and fitness. The biomechanics of each mode of locomotion (walking, swimming or flying) are distinct, and are affected differently by the added mass and volume of pregnancy. Furthermore, we list the possible adaptations that have evolved to reduce the locomotor costs of pregnancy, and divide them into three different categories: adaptations that reduce the locomotor costs of live-bearing, adaptations with which the locomotor costs of live-bearing are avoided, and adaptations to the life history of the animal. Lastly, we discuss hiatuses in the literature and experimental procedures to quantify the hypothesised benefit of adaptations.

In Chapter 3, we compare the morphological changes during pregnancy in two closely-related species of live-bearing fish: Poeciliopsis turneri and Poeciliopsis gracilis. These species mainly differ in their mode of nutrient provisioning: $P$. gracilis is lecithotrophic and $P$. turneri is an extensive matrotroph. We tracked the morphological changes in $3 \mathrm{D}$ using a non-invasive method that creates three-dimensional body models. We find that $P$. turneri is more slender during the early stages of pregnancy, but increase in size more rapidly. This is in line with the locomotor costs hypothesis, which predicts that matrotrophic fish are more slender during the early stages of pregnancy, but that the difference between the body shapes of lecithotrophic and matrotrophic fish diminishes as pregnancy progresses. Our results indicate that matrotrophy could indeed provide a morphological advantage during pregnancy.

Fast-start performance, a manoeuvre fish deploy to escape predatory strikes, is important for individual survival. In Chapter 4, we use state-of-the-art biomechanical methods to, for the first time, quantify this manoeuvre in 
three-dimensional space in adult fish (Heterandria formosa). We show that fish can orient their escapes in up- and downwards direction, and that this is correlated with a change in pitch angle of the body. Changes in roll angle of the body were not correlated with orientation of the fish. We furthermore demonstrate that stage 1 of the fast start, often described as a preparatory stage, can already contribute to propulsion. The results from Chapter 4 indicate that three-dimensional measurements of fast-start manoeuvres provide novel insights that were often overlooked.

Measuring fast starts in three-dimensional space is relevant in determining the adverse effects of pregnancy on locomotor performance. We did this by comparing three species of live-bearing fish: P. turneri, H. formosa and Phalloptychus januarius. In Chapter 5, we show that pregnancy-induced changes in abdominal width are correlated with a reduction in performance in the horizontal plane (maximal horizontal speed, change in yaw angle), but less so in the vertical plane (maximal vertical speed, change in pitch angle). Furthermore, we demonstrate that an increase in abdominal width is correlated with a decrease in abdominal curvature and, for some species, in a decrease in maximal curvature rate in the abdomen. Lastly, we show that the pregnancy-induced morphological changes depend on the level of superfetation: species with a high level of superfetation experience higher frequency, but smaller amplitude changes in the shape of the abdomen. Whether superfetation actually results in a more slender body shape, as predicted by the locomotor costs hypothesis, depends on the level of reproductive investment.

In this thesis, I show that pregnancy induces changes in morphology which comes with a cost in fast-start performance. Both matrotrophy and superfetation affect how body shape changes due to pregnancy, but whether the latter provides beneficial changes depends on the level of reproductive investment. Furthermore, I reveal that fast starts can have a substantial three-dimensional component which is relevant both to biomechanicists that aim to understand the physical and physiological mechanisms underlying this manoeuvre and to evolutionary biologists that strive to answer performance-related questions. 


\section{Samenvatting}

Levendbarende reproductie (vivipaar), is meer dan honderd keer onafhankelijk geëvolueerd in gewervelde dieren. Ondanks de frequente evolutie van deze reproductieve modus, heeft levendbarendheid verschillende veronderstelde nadelen vergeleken met de voorouderlijke wijze van voortplanten, het leggen van eieren (ovipaar). Een van deze veronderstelde nadelen is een vermindering van de prestaties in het (voort)bewegen tijdens de zwangerschap, de periode van interne ontwikkeling van de embryo's. Om de kosten van levendbarendheid voor het voortbewegen te verminderen, zouden verschillende aanpassingen aan de voortplanting geëvolueerd kunnen zijn. In deze thesis, streef ik uit te vinden of 'matrotrofie', de toevoer van voedingsstoffen naar de embryo na bevruchting van de eicel (bijvoorbeeld door een placenta), en 'superfoetatie', de gelijktijdige aanwezigheid van verschillende broedsels van verschillende ontwikkelingsstadia, de afname in voortbewegingsprestaties tijdens de zwangerschap verminderen in de Poeciliidae, de familie van de levendbarende tandkarpers.

In Hoofdstuk 2 geven wij een overzicht van de al bestaande wetenschappelijke literatuur op het effect van zwangerschap op morfologie, (voort)bewegingsprestaties en 'fitness'. De biomechanica van elk type beweging (lopen, zwemmen of vliegen) zijn zeer verschillend, en worden elk anders beïnvloed door de extra massa en volume van een zwangerschap. We vermelden verder de mogelijke aanpassingen die geëvolueerd zijn om de effecten van zwangerschap op overleving zo klein mogelijk te houden, en verdelen deze in drie categorieën: aanpassingen die de voortbewegingskosten van levendbarendheid verminderen, aanpassingen die de voortbewegingskosten van levendbarendheid vermijden, en aanpassingen aan de 'life history' van het dier. Tot slot bediscussiëren we bestaande hiaten in de literatuur en experimentele procedures om het veronderstelde voordeel van aanpassingen te kwantificeren.

In Hoofdstuk 3 vergelijken wij de morfologische veranderingen tijdens de zwangerschap van twee nauwverwante soorten van levendbarende vissen: Poeciliopsis gracilis en Poeciliosis turneri. Deze twee soorten verschillen met name in hoe zij hun embryo's van voedingsstoffen voorzien: $P$. gracilis is 'lecithotroof' en voorziet haar jongen via de dooier van voeding terwijl $P$. turneri 'matrotroof' is en haar jongen voornamelijk van voedingsstoffen voorziet via een placenta. Van beide soorten hebben we de morfologische (vorm) veranderingen in $3 \mathrm{D}$ gevolgd over tijd met een niet-invasieve methode die driedimensionale 'lichaamsmodellen' maakt. We vinden dat $P$. turneri slanker is tijdens de eerste stadia van de zwangerschap, maar sneller in grootte 
toeneemt. Deze resultaten zijn in liijn met de 'locomotor costs hypothesis', die veronderstelt dat matrotrofe vissen slanker zijn tijdens de eerste stadia van de zwangerschap, maar dat deze verschillen in lichaamsvorm tussen lecithotrofe en matrotrofe vissen verdwijnen als de zwangerschap voortschrijdt. Onze resultaten geven aan dat matrotrofie inderdaad een morfologisch voordeel kan zijn tijdens de zwangerschap.

De prestaties van individuele vis tijdens de 'fast start'(snelle start), een manoeuvre die vissen gebruiken om aan predatoren te ontsnappen, is belangrijk voor de overleving. In Hoofdstuk 4 gebruiken we de nieuwste technologie om, voor het eerst, deze manoeuvre in drie dimensies te kwantificeren in volwassen vissen. Hiervoor gebruiken we de dwergtandkarper, Heterandria formosa. We tonen aan dat vissen hun ontsnapping zowel opwaarts als neerwaarts kunnen uitvoeren, hetgeen gecorreleerd is aan veranderingen in de 'pitch'-hoek van het lichaam. Veranderingen in de 'roll'-hoek van het lichaam zijn niet gecorreleerd aan veranderingen in de oriëntatie van de vis. Bovendien laten we zien dat het eerste stadium van de 'fast start', die vaak beschreven wordt als een voorbereidend stadium, ook bij kan dragen aan de voortstuwing. De resultaten van Hoofdstuk 4 laten zien dat driedimensionale metingen aan 'fast-start' manoeuvres nieuwe inzichten geven die vaak over het hoofd zijn gezien.

Driedimensionale metingen aan 'fast starts' zijn ook relevant in het bepalen van de negatieve effecten van zwangerschap op de prestatie van vissen in deze manoeuvre. Wij hebben dit bepaald voor drie soorten levendbarende tandkarpers: Poeciliopsis turneri, Heterandria formosa en Phalloptychus januarius. In Hoofdstuk 5 laten we zien dat veranderingen in de breedte van de buik, veroorzaakt door zwangerschap, gecorreleerd zijn aan verminderde 'fast-start' prestatie in het horizontale vlak (maximale horizontale snelheid, verandering in 'yaw'-hoek), maar minder in het verticale vlak (maximale verticale snelheid, verandering in 'pitch'-hoek). We laten ook zien dat een toename in breedte van de buik is gecorreleerd met een afname van de bereikte kromming van de buik en, voor sommige soorten, de snelheid van kromming van de buik. Tot slot laten we zien dat de morfologische veranderingen tijdens de zwangerschap afhankelijk zijn van het niveau van superfoetatie: soorten met een hoge mate van superfoetatie hebben een lagere amplitude van veranderingen in de vorm van de buikregio, maar een hogere frequentie. Of superfoetatie inderdaad leidt to een slanker lichaam, zoals verondersteld door de 'locomotor costs hypothesis', hangt af van de (relatieve) investering in reproductie. 
In deze thesis laat ik zien dat zwangerschap veranderingen in de morfologie van vissen veroorzaakt, hetgeen leidt tot verminderde prestatie tijdens de 'fast start'. Zowel matrotrofie als superfoetatie beïnvloeden de veranderingen in lichaamsvorm tijdens de zwangerschap, maar of superfoetatie ook een daadwerkelijk voordeel brengt hangt af van de relatieve investering in reproductie. Ik laat ook zien dat 'fast starts' een substantiële driedimensionale component hebben die relevant is voor zowel biomechanici die de onderliggende fysische en fysiologische mechanismes van deze manoeuvre proberen te doorgronden, als voor evolutionair biologen die prestatie-gerelateerde vragen proberen te beantwoorden. 


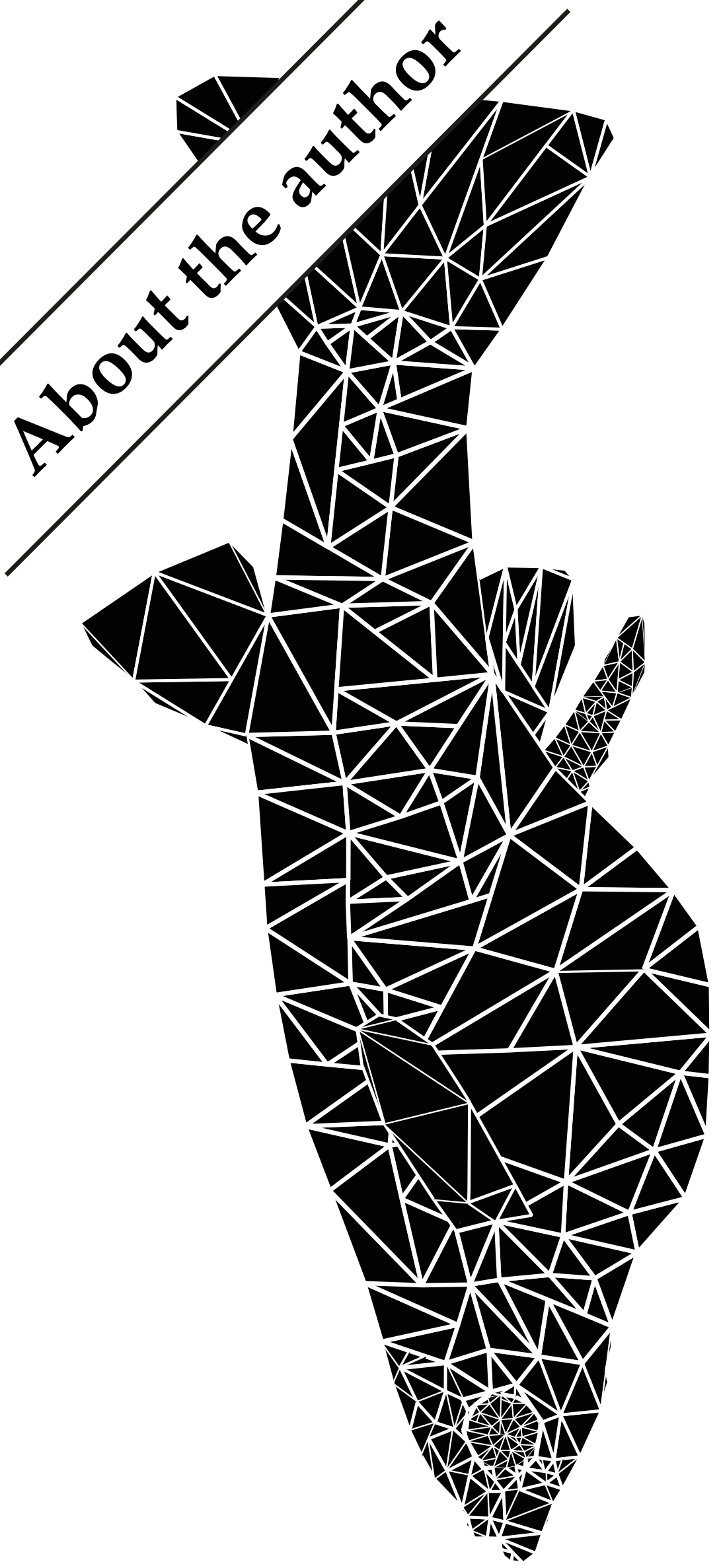




\section{About the author}

List of publications

Training activities

Curriculum vitae

Acknowledgements 


\section{List of publications}

M. Fleuren, J.L. van Leeuwen, D.N. Reznick and B.J.A. Pollux. The burden of viviparity: what do we know about the locomotor costs of live-bearing and the adaptations to reduce them?

Manuscript submitted for publication.

M. Fleuren, E.M. Quicazan-Rubio, J.L. van Leeuwen, B.J.A. Pollux. Why do placentas evolve? First evidence for a morphological advantage during pregnancy in live-bearing fish.

Manuscript submitted for publication.

M. Fleuren, J.L. van Leeuwen, E.M. Quicazan-Rubio, R.P.M. Pieters, B.J.A. Pollux, C.J. Voesenek. Three-dimensional analysis of the fast-start escape response of the least killifish, Heterandria formosa.

Manuscript submitted for publication.

\section{International conference abstracts}

M. Fleuren, J.L. van Leeuwen \& B.J.A. Pollux. Redefining the 'super' in superfetation: are pregnant live-bearing fishwith more superfetation better swimmers? European Society for Evolutionary Biology 2017, Groningen, the Netherlands

M. Fleuren, J.L. van Leeuwen \& B.J.A. Pollux. Morphology and 3D fast-start escape performance of pregnant and virgin live-bearing fish. Society of Experimental Biology (SEB) 2016, Brighton, United Kingdom

M. Fleuren, J.L. van Leeuwen \& B.J.A. Pollux. Pregnant as a prey: performance and kinematics of the 3D fast-start escape response of live-bearing fish. Zoology 2016, Antwerp, Belgium

M. Fleuren, E.M. Quicazan-Rubio, C.J. Voesenek, J.L. van Leeuwen \& B.J.A. Pollux. Reconstructing changes in 3D body shape during the pregnancy of three species of viviparous fish (Poeciliidae): effects of placentation and superfetation. Society for Integrative and Comparative Biology (SICB) 2014, Austin TX, United States 


\section{Overview of completed training activities}

The basic package

$\underline{3 \text { ECTS }}$

WIAS Introduction Course

2013

Ethics and Philosophy in Life Sciences

2013

Scientific exposure

9 ECTS

International conferences

Society for Integrative \& Comparative Biology (SICB),

Austin, TX, United States

2014

Society for Experimental Biology (SEB),

Brighton, United Kingdom

2016

$23^{\text {rd }}$ edition of the Zoology Congress,

Antwerp, Belgium

2016

Seminars and workshops

WIAS Seminar 'Regulatory mechanisms in Developmental Biology',

Wageningen, the Netherlands

WIAS Science Day,

Wageningen, the Netherlands

WIAS Science Day,

Wageningen, the Netherlands

2015

WIAS Science Day,

Wageningen, the Netherlands

2017

\section{Poster presentations}

Society for Integrative \& Comparative Biology (SICB),

Austin, TX, United States

WIAS Science Day,

Wageningen, the Netherlands

2015

Oral presentations

Society for Experimental Biology (SEB),

Brighton, United Kingdom

2016

$23^{\text {rd }}$ edition of the Zoology Congress,

Antwerp, Belgium

2016

WIAS Science Day,

Wageningen, the Netherlands

2017

In-depth studies

6 ECTS

MATLAB Academic Tour; Image Processing in MATLAB

2014

Introduction to Geometric Morphometrics $-6^{\text {th }}$ edition

Barcelona, Spain

2015

WIAS Advanced Statistics Course 'Design of Experiments'

2015

WIAS Course 'Statistics for the Life Sciences'

2016

$\underline{3 \text { ECTS }}$

2014

Use of Laboratory Animals

Project \& Time Management 
Professional skills support courses (continued)

$\begin{array}{ll}\text { Supervising MSc thesis students } & 2014\end{array}$

Data Management 2014

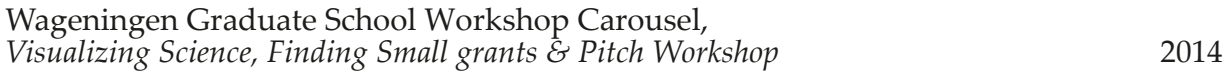

WIAS Course 'Survival Guide to Peer Review' 2017

WIAS Course 'Writing Scientific Proposals' 2017

Research skills training $\quad \underline{4 \text { ECTS }}$

PhD Research Proposal $\frac{\underline{4 E T S}}{2013}$

PE\&RC and SENSE Course 'Introduction to R for Statistical Analysis' 2016

\section{Didactic skills training}

$\underline{14 \text { ECTS }}$

Lecture on 'modes of reproduction and nutrient provisioning',

Developmental Biology of Animals, MSc course, Wageningen University 2014

Supervision of practicals and discussion lectures

Vertebrates: Structure and Function, BSc course, Wageningen University

2016

Supervision of two major MSc theses/internships

$2014-2017$

Supervision of one BSc thesis 2015

Tutoring of three 'Capita Selecta' projects $\quad$ 2015-2017

Total 44 ECTS

Completed of the training activities is in fulfilment of the requirements for the education certificate of the Graduate School of the Wageningen Institute of Animal Sciences (WIAS); One ECTS equals a study load of 28 hours. 


\section{Curriculum vitae}

Mike Fleuren was born in Heemskerk, Noord-Holland, The Netherlands, on the $18^{\text {th }}$ of September 1989. After completion of his high school study at the Gymnasium Felisenum in Velsen-Zuid, he started his career in biology with a Bachelor in said scientific field at Wageningen University in Wageningen, The Netherlands. He became an active member of the study association B.V.W. 'Biologica', where he held a year-long position in the board and orga-

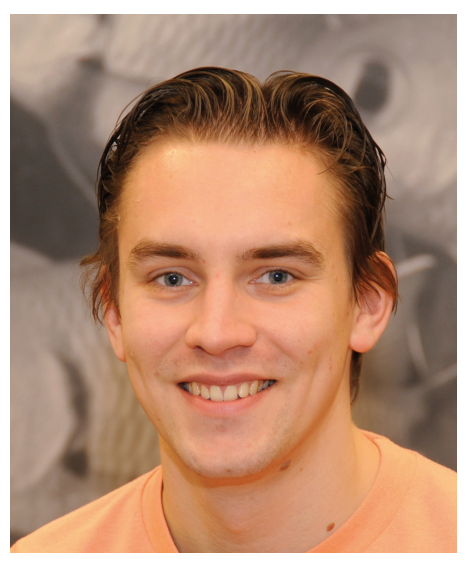
nized numerous activities as a member of different committees. Among the organized activities, a foreign excursion to Morocco stands out.

Mike stayed in Wageningen for the Biology Master. Following his interest in organismal and developmental biology, he started his Master thesis at the Experimental Zoology group under supervision of Dr Sander Kranenbarg, examining whether locomotion influences the development of the notochord in larval zebrafish (Danio rerio). During this thesis, he mastered histological and (electron) microscopical techniques that proved useful during his internship at the Wenner-Gren Institute, Stockholm University, Sweden. Under supervision of Prof. Dr Christos Samakovlis and Dr Dimitrios Papadopoulos, he developed a protocol for the use of a novel genetic marker, miniSOG, in Drosophila melanogaster. After his internship period, Mike graduated as a Master of Science on the 31 ${ }^{\text {st }}$ of August, 2012.

However, the Experimental Zoology group did not want to loose him and therefore offered Mike a temporary position as a research assistant. In this role, he could further use and expand his skills in electron microscopy during a project on sarcomere lengths in the arms and tentacles of the common cuttlefish (Sepia officinalis).

From March 2013 onwards, it was time for Mike to leave the ultramicrotomes and the dark microscopy rooms, to start his PhD endeavor. Little did he know he would spend one and a half years fenced-in at the fish facilities in another windowless room to conduct his swimming experiments. He conducted his work as a PhD candidate at the Experimental Zoology group (of course) of Wageningen University (of course), under the supervision of Prof. Dr Ir Johan L. van Leeuwen and Dr Bart J.A. Pollux. The findings of this research can be found in this thesis, titled 'Reproductive adaptations to reduce locomotor costs in viviparous fish (Poeciliidae)'. 


\section{Acknowledgements}

Although this $\mathrm{PhD}$ thesis is a single-author publication, the research that $\mathrm{I}$ describe was not possible without the help of many, many people. I would like to spend some words here to thank all of those who helped me with my work, to thank all of those who make Wageningen (and especially the Zodiac E1-Wing) such a magical place, and all of those who stood by me in the good and the bad times.

First of all, I want to express my deep gratitude to Johan and Bart for handing me the opportunity to perform this PhD project at the Experimental $\mathrm{Zo}$ ology group. The past years have been intense at times, but I believe we all have learned a lot about live-bearing reproduction, about swimming, but also about each other. You always believed in my qualities, and we worked on the things that I could improve - it was always a pleasure working with you. We started the cooperation between Bart's evolutionary group and the biomechanics of swimming group that was already established at EZO, and despite the usual quirks here and there, I think we managed well. I hope that many other cooperations between the three of us await.

All those experimental setups, it was a pain. Elsa and Remco, I could not have finished my PhD (within a decent time frame) without your help on the setups. Elsa, we are very different, but fortunately we worked out how we could use these differences to our advantage. You are the only one who truly understands how tough our experiments are, and I'm happy you were there when I needed to complain about it ;) I wish you all the best writing vibes and I hope to see your thesis reach completion soon! Remco, your knowledge on building setups is unsurpassed. Thank you for all your help building and tearing down my setups, your designs of calibration frames and light switches, and all the other things you supported me with.

What would EZO be without it's own software guru? Cees (alias de Kees), you have been invaluable for my project (or should I say EZO as a whole), as without the Fishtracker, I would not have been able to analyse all the data I gathered. You were always there to help debugging the code, either by doing it yourself or by pointing me in the right direction. I'm quite adept with MATLAB now, but nowhere near your level of skill. I'm honored that you agreed to be one of my paranymphs! Now don't forget to finish your own project ;) .

Minstens net zo belangrijk waren alle mensen die ervoor gezorgd hebben dat al mijn vissen een goed leven hadden. Menno, Wian, Sander, Emily, Truus, Jasper en al jullie stagair(e)s, ik weet dat jullie het soms zwaar hebben gehad 
met al onze liverpaste en flakepaste, en heel veel bakken die niet altijd even schoon waren. Het was ook fijn dat er eigenlijk altijd wel iemand was om even mee te praten bij een bakkie Senseo ${ }^{\circledR}$ (persoonlijk vond ik het praten beter dan de koffie ;) ). Stop ook nooit met die gezellige glühwijnparty's!

Also in the lab there were people there for me. Karen, you more or less carried the molecular work on the muscle tissues, and you were a wonderful daily supervisor for Marloes and Jeff, you taught them much more than I ever could. You three did the majority of our work to see if there are (molecular) changes in the muscle tissue of pregnant live-bearing fish, and I really enjoyed our discussions on the subject and I learned a lot from them. Henk, I could always count on you when I again needed to preserve my fish after the experiments. We worked out a protocol that, I think, worked swiftly and comfortably. Also thanks a lot for all the help with my photography attempts and the never-ending supply of hard drives! I'm really pleased that you agreed to be one of my paranymphs!

I'm happy to have been able to present my work in a group without any internal competition. Martin, Florian, Kees S., Arie, Sanderkloo and Sanderbarg, you were always available for questions or to provide advice, which often was very useful! Annemarie, you say you consider the EZO PhDs as your children, and you truly are the 'mother' that keeps the group together. Thank you for all the personal interest, and opening up your house for all the nice winter barbecues and New Year dinners!

Over the past four years, I've met so many wonderful people at EZO ('Little Princess' Cees, Kessels, Sebas, Ansa, Elsita, Myrthe, Andres, Wouter, Anton, Pulkit, Uroš, Julian, and Pimmie) but also at the neighbouring groups CBI (Carmen, Stiene, Annelieke, Marloes, Lieke, Olaf, Jules, Joeri, Mirelle, Sem, Esther, and Eva) and HMI (Linda \& Marcel, Sam, Edo, and Marcela). We shared the struggles of being PhD-candidate, but we also did so many things together: the unforgettable weekends, WE-days, an ice dive, Rhine barbecues, a Minion \& Strawberries stair case running night, (Good) Friday afternoon drinks, a 'Tokkie Thursday', the bouldering, the squash, and all the other things that I now forgot. Some of you became really good friends. \#Colleagueswithoutborders. No words can express my feelings better than the following words, a great Dutch musician once sang: 'Zijn het je ogen, is het je lach / Zijn het die dingen waarom ik jou niet kan missen, voor geen dag'.

Mam en pap, door jullie ben ik waar ik nu ben. Jullie hebben me altijd gesteund en stonden altijd klaar voor me als het nodig was. De laatste jaren was 
de afstand soms misschien wat groot, en mijn werktijden verre van ideaal, maar als ik thuis was, voelde het altijd goed, fijn en vertrouwd. Jullie waren ook niet te beroerd om de Move (in Wageningen beter bekend als de Pausmobiel) voor langere tijd uit te lenen om de ritjes op en neer nog enigszins dragelijk te maken. Bedankt voor alle steun en hulp tijdens de afgelopen jaren! Colin, ook jij bent de slimste en beste broer die ik ken ;) .

Suus, mijn liefste, waar was ik geweest zonder jou? De afgelopen jaren waren voor jou niet de makkelijkste, en dan moest ik vaak ook nog zeven dagen per week werken. Gelukkig was je er altijd voor me als ik weer eens vermoeid thuis kwam. Inmiddels kunnen we de schade aan gemiste weekendjes weg, baksels en Netflix-series weer inhalen, fijn! Zonder jou waren de afgelopen jaren waarschijnlijk veel moeizamer verlopen. Bedankt voor het expres niet zeuren als ik weer naar CARUS of Zodiac moest in het weekend, bedankt voor al je steun en bovenal voor al je liefde! $x$ 
The research described in this thesis was financially supported by the Netherlands Organization for Scientific Research (NWO).

Financial support from the Experimental Zoology group of Wageningen University for printing this thesis is gratefully acknowledged.

Design \& layout: Mike Fleuren

This thesis was printed by GVO drukkers \& vormgevers B.V. 
